UNIVERSIDADE DE BRASÍLIA

FACULDADE DE TECNOLOGIA

DEPARTAMENTO DE ENGENHARIA CIVIL E AMBIENTAL

\title{
APLICAÇÃO DA MODELAGEM ECOLÓGICA COM FOCO NA DINÂMICA DO FITOPLÂNCTON PARA AVALIAÇÃO DA QUALIDADE DA ÁGUA DO LAGO PARANOÁ - DF
}

CAROLINA CERQUEIRA BARBOSA

ORIENTADORA: LENORA NUNES LUDOLF GOMES CO-ORIENTADOR: RICARDO TEZINI MINOTI

DISSERTAÇÃO DE MESTRADO EM TECNOLOGIA AMBIENTAL E RECURSOS HÍDRICOS

PUBLICAÇÃO: PTARH.DM - 176/2015

BRASÍLIA/DF: OUTUBRO - 2015 
UNIVERSIDADE DE BRASÍLIA

FACULDADE DE TECNOLOGIA

DEPARTAMENTO DE ENGENHARIA CIVIL E AMBIENTAL

\section{APLICAÇÃO DA MODELAGEM ECOLÓGICA COM FOCO NA DINÂMICA DO FITOPLÂNCTON PARA AVALIAÇÃO DA QUALIDADE DA ÁGUA DO LAGO PARANOÁ - DF}

CAROLINA CERQUEIRA BARBOSA

DISSERTAÇÃO SUBMETIDA AO DEPARTAMENTO DE ENGENHARIA CIVIL E AMBIENTAL DA FACULDADE DE TECNOLOGIA DA UNIVERSIDADE DE BRASÍLIA COMO PARTE DOS REQUISISTOS NECESSÁRIOS PARA A OBTENÇÃO DO GRAU DE MESTRE EM TECNOLOGIA AMBIENTAL E RECURŞOS HÍDRICOS.

APROVADA POR:

Prof. Lenora Nunes Ludolf Gomes, PhD (ENC/FT/UnB)

(ORIENTADOR)

Prof. Ricardo Tezini Minoti, PhD (ENC/FT/UnB)

(CO-ORIENTADOR)

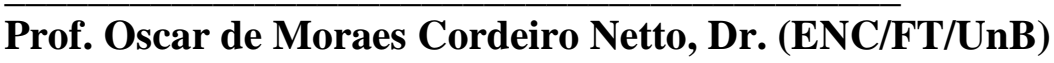

(EXAMINADOR INTERNO)

Prof. Talita Fernanda das Graças Silva, PhD (UFMG)

(EXAMINADOR EXTERNO)

BRASÍLIA/DF, OUTUBRO DE 2015 


\section{FICHA CATALOGRÁFICA}

BARBOSA, C.C.

APLICAÇÃO DA MODELAGEM ECOLÓGICA COM FOCO NA DINÂMICA DO FITOPLÂNCTON PARA AVALIAÇÃO DA QUALIDADE DA ÁGUA DO LAGO PARANOÁ - DF. xxiv, 146p., 210 x 297 mm (ENC/FT/UnB, Mestre, Tecnologia Ambiental e Recursos Hídricos, 2015). Dissertação de Mestrado - Universidade de Brasília. Faculdade de Tecnologia. Departamento de Engenharia Civil e Ambiental.

1. QUALIDADE DAS ÁGUAS 2. GLM-AED

3. MODELAGEM ECOLÓGICA 4. FITOPLÂNCTON

I. ENC/FT/UnB II. Título (série)

\section{REFERÊNCIA BIBLIOGRÁFICA}

BARBOSA, C.C. (2015). Aplicação da modelagem ecológica com foco na dinâmica do fitoplâncton para avaliação da qualidade da água do lago Paranoá - DF. Dissertação de Mestrado em Tecnologia Ambiental e Recursos Hídricos, Publicação PTARH.DM176/2015, Departamento de Engenharia Civil e Ambiental, Universidade de Brasília, Brasília, DF, 146p.

\section{CESSÃO DE DIREITOS}

NOME DA AUTORA: Carolina Cerqueira Barbosa

TÍTULO: Aplicação da modelagem ecológica com foco na dinâmica do fitoplâncton para avaliação da qualidade da água do lago Paranoá - DF.

GRAU: Mestre ANO: 2015

É concedida à Universidade de Brasília permissão para reproduzir cópias desta dissertação de mestrado e para emprestar ou vender tais cópias somente para propósitos acadêmicos e científicos. O autor reserva outros direitos de publicação e nenhuma parte dessa dissertação de mestrado pode ser reproduzida sem autorização por escrito do autor.

\section{Carolina Cerqueira Barbosa carollcbarbosa@gmail.com}


À minha família, em especial ao meus pais,

Luis Cláudio Barbosa e Maria da Conceição C. Barbosa, e aos meus avós, Antônio Barbosa, Eva Pereira Barbosa, Lindalva Cerqueira e Newton Cerqueira (in memoriam). 


\section{AGRADECIMENTOS}

Agradeço a Deus, que é Pai, Filho e Espírito Santo, pelo dom da vida e por sempre me guiar e conceder saúde para que eu possa lutar pelos meus sonhos e à Virgem Maria por passar a frente e proteger os meus passos nos caminhos da vida.

Aos meus pais, Luís Cláudio e Conceição, pelo exemplo e por nunca medirem esforços para proporcionarem a mim e aos meus irmãos a melhor educação, além do apoio incondicional. Aos meus avós, Antônio e Eva, por terem sido meus melhores ouvintes e por todo o apoio dado no tempo em que estive vivendo em Brasília. Sem vocês eu não teria conseguido. E ao restante da minha família amada que sempre me apoiou, meus irmãos, Mateus e Luís Cláudio Filho, tios e primos, especialmente a Maria Eduarda Barbosa.

Ao meu amor, Danilo, por muito mais do que escutar minhas angústias, por ter sido meu braço direito na execução deste trabalho.

Agradeço à minha orientadora, Lenora Gomes, pelos ensinamentos e pela paciência e confiança em desenvolver este trabalho. Apesar das dificuldades da distância, nunca duvidou que conseguiríamos. Ao meu co-orientador, Ricardo Minoti, pelas sugestões e participação nas etapas fundamentais deste trabalho. Aos Professores Marco Antônio Souza e Oscar Cordeiro, pelas pertinentes contribuições feitas durante o seminário, e a todos os Professores do PTARH, que também contribuíram para o meu crescimento intelectual: Yovanka Ginoris, Sérgio Koide, Conceição Alves, Dirceu Reis, Wagner, Cristina Brandão, Ariuska Amorim e Carlos Lima, por todo conhecimento transmitido, paciência e dedicação.

Aos colegas da sala 21 (enquanto ali estive), Tatiana, José Daniel e Olga Rubênia, pela amizade, aprendizagem e troca de experiências durante os difíceis seminários. Aos queridos colegas colombianos, Daniel, Jimena e Luís Carlos, por toda ajuda, paciência e amizade. À turma de mestrado do ano de 2013, Rodrigo, Érica, Carlos, Marlian, Juan, Cláudia, Rovena, pelos ótimos momentos dentro e fora da sala de aula. Aos demais colegas, técnicos e funcionários do PTARH que direta ou indiretamente colaboraram no meu crescimento profissional e pessoal, em especial ao Msc. Lucas Liporoni, que gentilmente disponibilizou a maior parte dos dados utilizados neste trabalho. Também ao 
Doutor Diego Pujoni, da UFMG, pela parceria e auxílio nas descobertas com o modelo GLM.

Aos amigos que fiz em Brasília, em especial à Priscila, e aos amigos de sempre, em especial Thayane, Juliette, Samilla, Millene, Lillian, Wilkier, Benildes, Erton, aos demais colegas de faculdade e aos amigos da Paróquia São Judas Tadeu, em Palmas. Agradeço também aos colegas de trabalho da SRFA-09 pela paciência e apoio na conclusão deste trabalho.

Agradeço à UnB e ao PTARH pela oportunidade, e ao CNPq pelo apoio financeiro concedido na forma de bolsa de estudo do mestrado. 


\title{
RESUMO \\ APLICAÇÃO DA MODELAGEM ECOLÓGICA COM FOCO NA DINÂMICA DO FITOPLÂNCTON PARA AVALIAÇÃO DA QUALIDADE DA ÁGUA DO LAGO PARANOÁ - DF
}

\author{
Autora: Carolina Cerqueira Barbosa \\ Orientadora: Lenora Nunes Ludolf Gomes \\ Co-orientador: Ricardo Tezini Minoti \\ Programa de Pós-Graduação em Tecnologia Ambiental e Recursos Hídricos \\ Brasília, 27 de outubro de 2015
}

Utilizou-se o modelo hidrodinâmico-ecológico GLM-AED para simular a dinâmica do fitoplâncton e a qualidade da água do lago Paranoá-DF. A escolha do modelo foi baseada em critérios pré-estabelecidos que levassem em conta a simplicidade da estrutura do modelo, a disponibilidade na rede (acesso livre) e tivesse a opção de modelar o fitoplâncton, visto a importância desses organismos nos ambientes aquáticos. O período selecionado para análise de sensibilidade e calibração foi de 01/03/2007 a 31/03/2009. A análise de sensibilidade e calibração hidrodinâmica foi realizada de maneira otimizada com o desenvolvimento de um script no software R, onde se identificaram três parâmetros sensíveis no lago Paranoá: coeficiente aerodinâmico de transferência de calor latente, coeficiente aerodinâmico de transferência de momento e coeficiente de atenuação vertical da luz. Após calibração, foram encontrados resultados satisfatórios para a simulação, com o erro padrão (RMSE) obtido para a temperatura ao longo da coluna d'água de $1,47^{\circ} \mathrm{C}$ e nas profundidades a $1,10,15$ e $20 \mathrm{~m}$ da superfície abaixo de $2^{\circ} \mathrm{C}$. Foi realizada, também, análise de sensibilidade e calibração ecológica voltada ao módulo de fitoplâncton, com foco nos dois grupos: clorofíceas e cianobactérias. Chegou-se a quatro parâmetros sensíveis: taxa de crescimento do fitoplâncton a $20^{\circ} \mathrm{C}$; temperatura ótima; constante de semi-saturação de luz para limitação de algas e taxa de respiração do fitoplâncton a $20^{\circ} \mathrm{C}$. O modelo GLM-AED obteve bom ajuste para simular a biomassa dos dois grupos do fitoplâncton, o RMSE médio foi de $0,036 \mathrm{mg} / \mathrm{L}$ nas quatro profundidades avaliadas para a simulação da biomassa de clorofíceas e de $0,012 \mathrm{mg} / \mathrm{L}$ para a biomassa de cianobactérias. Também, foi realizada simulação de cenário de eutrofização para o Lago, com situação de qualidade da água semelhante ao período mais crítico. O modelo obteve bons resultados e conseguiu responder ao cenário de piora da qualidade da água. Observaram-se melhores respostas do modelo ecológico em condições de maior trofia no Lago.

Palavras-chaves: modelagem ecológica, GLM-AED, fitoplâncton. 


\section{ABSTRACT \\ ECOLOGICAL MODELING APPLICATION FOCUSED IN THE PHYTOPLANKTON DYNAMICS TO ADDRESS WATER QUALITY AT PARANOA LAKE-DF}

Author: Carolina Cerqueira Barbosa

Supervisor: Lenora Nunes Ludolf Gomes

Co-Supervisor: Ricardo Tezini Minoti

Programa de Pós-Graduação em Tecnologia Ambiental e Recursos Hídricos.

Brasília, 27 October 2015.

The hydrodynamic-ecological model GLM-AED was used to simulate the phytoplankton dynamics and the water quality of the Paranoá lake-DF. The model selection was based in pre established criterions that consider model structure's simplicity, availability (open source) and the hability to simulate the phytoplankton dynamics, due to the importance of these organisms in the aquatic environment. The period used in the sensitivity analysis and calibration of the model started in 03/01/2007 and finished in 03/31/2009. The sensitivity and hydrodynamic calibration analysis was optimized using a script at $\mathrm{R}$ software, where it was identified three key parameters to the Paranoá Lake: bulk aerodynamic coefficient for latent heat transfer, bulk aerodynamic coefficient for transfer of momentum and extinction coefficient for PAR radiation. The calibration produced satisfactory results for the simulation with root mean square errors (RMSE) for the temperature in the surface of water column around $1,47^{\circ} \mathrm{C}$ and smaller than $2^{\circ} \mathrm{C}$ in the depths of $1,10,15$ and $20 \mathrm{~m}$. Also, it was performed a sensitivity and ecological calibration analysis focused in the phytoplankton module considering two main groups: green algae and blue-green algae. Four key parameters were observed during sensitivity analysis: phytoplankton growth rate at $20^{\circ} \mathrm{C}$, optimum temperature, light half saturation constant for algal limitation and phytoplankton respiration rate at $20^{\circ} \mathrm{C}$. The GLM-AED model managed to simulate the biomass of both phytoplankton's groups, the mean RMSE obtained for green algae group was $0,036 \mathrm{mg} / \mathrm{L}$ for the four evaluated depths in the simulation and the blue-green algae group was 0,012 $\mathrm{mg} / \mathrm{L}$. Likewise, an eutrophication scenario was simulated to the lake, with similar water quality to the most critical period. The model achieved good results similar to the water quality decrease. The ecological model results were as better as the eutrophic environment were present at the Lake.

Keywords: ecological modeling, GLM-EAD, phytoplankton 


\section{SUMÁRIO}

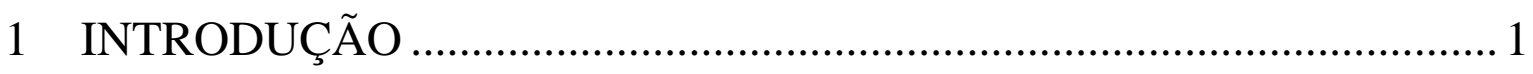

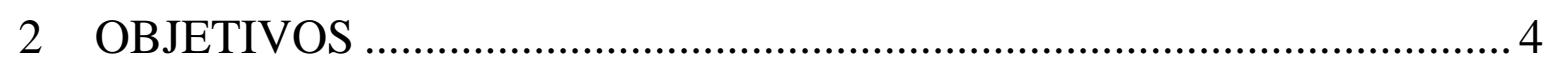

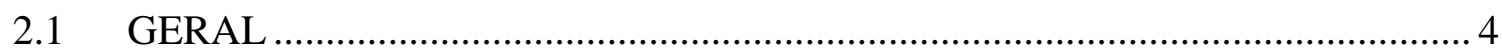

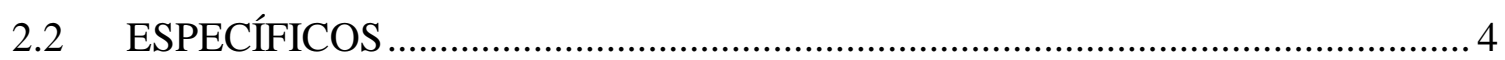

3 FUNDAMENTAÇÃO TEÓRICA E REVISÃO BIBLIOGRÁFICA......... 5

3.1 CONCEITOS DE QUALIDADE DA ÁGUA E DINÂMICA DA COMUNIDADE FITOPLANCTÔNICA EM AMBIENTES LÊNTICOS ......................... 5

3.2 TÉCNICAS PARA AVALIAÇÃO DA QUALIDADE DA ÁGUA EM LAGOS E

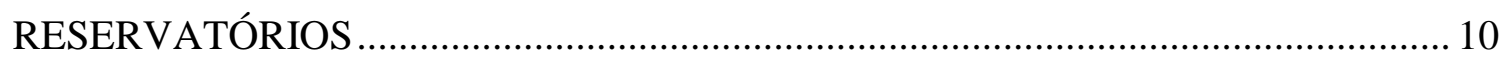

3.2.1 Modelagem Ecológica .................................................................................. 12

3.2.1.1 Modelagem ecológica em lagos e reservatórios........................................ 15

3.2.1.2 Fatores ambientais influentes e base de dados requerida na modelagem

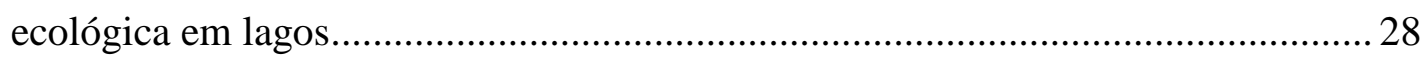

3.3 HISTÓRICO DE QUALIDADE AMBIENTAL DO LAGO PARANOÁ.............31

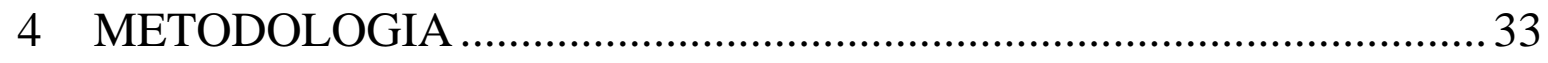

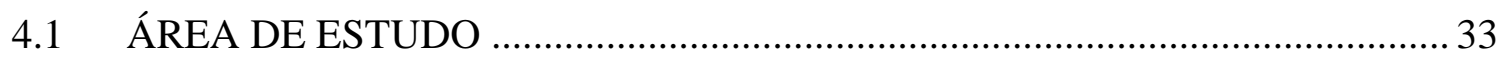

4.2 BASE DE DADOS PARA O DESENVOLVIMENTO DO ESTUDO .................38

4.3 SELEÇÃO DO MODELO ECOLÓGICO DE SIMULAÇÃO ………………….... 42

4.3.1 Descrição do modelo GLM-AED................................................................. 43

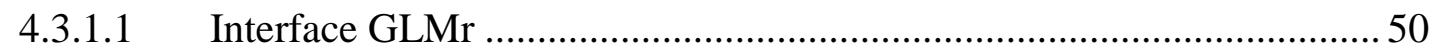

4.4 DEFINIÇÃO DAS CONDIÇÕES DE CONTORNO E UTILIZAÇÃO DA BASE

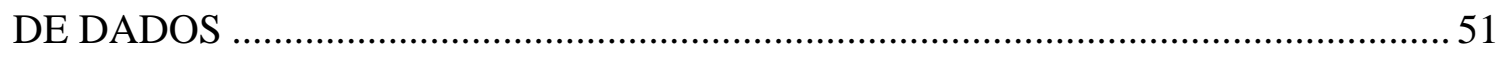

4.5 ANÁLISE DE SENSIBILIDADE e CALIBRAÇÃO DO GLM..............................54

4.6 ANÁLISE DE SENSIBILIDADE E CALIBRAÇÃO DO MÓDULO

ECOLÓGICO - AED (MÓDULO FITOPLÂNCTON) ……………………………….... 57

4.7 SIMULAÇÃO DAS VARIÁVEIS DE QUALIDADE DA ÁGUA ........................59 
4.8 SIMULAÇÃO DE CENÁRIO DE EUTROFIZAÇÃO.

5 RESULTADOS E DISCUSSÕES

5.1 ANÁLISE DA DISPONIBILIDADE E EXTENSÃO DA BASE DE DADOS CONSTRUÍDA.

5.2 AVALIAÇÃO DA CONSISTÊNCIA DOS DADOS METEOROLÓGICOS DE ENTRADA

5.3 ANÁLISE DE SENSIBILIDADE E OTIMIZAÇÃO DA CALIBRAÇÃO DO GLM 75

5.4 ANÁLISE DE SENSIBILIDADE E CALIBRAÇÃO DO MÓDULO ECOLÓGICO - AED (MÓDULO FITOPLÂNCTON) 81

5.5 SIMULAÇÃO DA QUALIDADE DA ÁGUA .86

5.6 SIMULAÇÃO DO CENÁRIO DE EUTROFIZAÇÃO .96

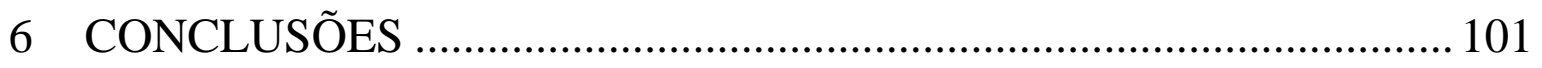

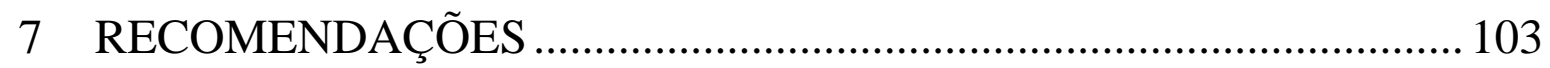

REFERÊNCIAS BIBLIOGRÁFICAS ................................................ 105

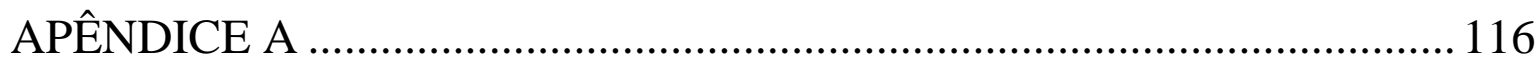

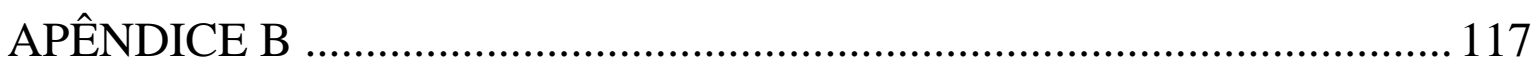

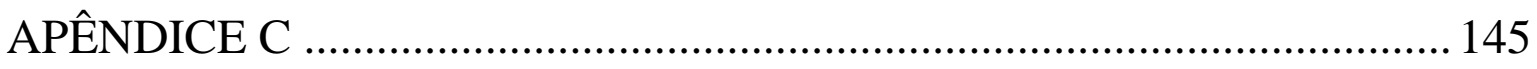




\section{LISTA DE FIGURAS}

Figura 3-1: Modelo simples da dinâmica do fitoplâncton. Adaptado de Whighan e

Recknagel (1999).

Figura 3-2- O desenvolvimento da modelagem ecológica dividido em seis estágios.

Adaptado de Jorgensen e Bendoricchio (2001).

Figura 3-3 - Citações científicas de modelos de ecossistema lacustre:

DYRESM(1D)/ELCOM(3D)/CAEDYM (1º publicação em 1991), PCLake (1º publicação em 1995), CE-QUAL-W2 (1 publicação em 1997) e PROTECH (1 publicação em 1999).

Adaptado de Trolle et al. (2012).

Figura 3-4: Esquema de controladores de temperatura e estratificação do modelo

hidrodinâmico GLM. Adaptado de Read et al. (2014b). 29

Figura 4-1-Normais de precipitação de 1961 a 1990, em mm, na estação Brasília (INMET, 2009)

Figura 4-2 - Normais de temperatura média do ar de 1961 a 1990 , em ${ }^{\circ} \mathrm{C}$, na estação

Brasília (INMET, 2009)

Figura 4-3: Unidades Hidrográficas da bacia do lago Paranoá. Adaptado de Souza (2014).

Figura 4-4: Divisão em segmentos do Lago Paranoá e respectivos tributários. Fonte:

Google Earth (2015)

Figura 4-5: Localização da Estação Meteorológica Brasília. Fonte: Google Earth (2015). 40

Figura 4-6: Representação do perfil batimétrico do lago Paranoá. Adaptado de CAESB

Figura 4-7: Exemplo das conexões entre os módulos AED e as variáveis dos módulos.

Adaptado de Hipsey et al. (2013).

Figura 4-8: Mapa de batimetria do braço Central do lago Paranoá. Adaptado de CAESB

Figura 5-1: Séries temporais dos dados de temperatura disponibilizados pela CAESB para os pontos de monitoramento nos braços e ponto $\mathrm{C}$.

Figura 5-2: Séries temporais dos dados de oxigênio disponibilizados pela CAESB para os pontos de monitoramento nos braços e ponto $\mathrm{C}$.

Figura 5-3: Séries temporais dos dados de amônia disponibilizados pela CAESB para os pontos de monitoramento nos braços e ponto $\mathrm{C}$ 
Figura 5-4: Séries temporais dos dados de nitrato disponibilizados pela CAESB para os pontos de monitoramento nos braços e ponto $\mathrm{C}$.

Figura 5-5: Séries temporais dos dados de fosfato disponibilizados pela CAESB para os pontos de monitoramento nos braços e ponto $\mathrm{C}$.

Figura 5-6: Séries temporais dos dados de velocidade do vento disponibilizados pelo INPE e INMET para a Estação Brasília.

Figura 5-7: Séries temporais dos dados de ondas curtas disponibilizados pelo INPE e

INMET para a Estação Brasília.

Figura 5-8: Séries temporais dos dados de precipitação disponibilizados pelo INPE e

INMET para a Estação Brasília.

Figura 5-9: Séries temporais dos dados de temperatura do ar disponibilizados pelo INPE e INMET para a Estação Brasília. 66

Figura 5-10: Séries temporais dos dados de umidade relativa disponibilizados pelo INPE e

INMET para a Estação Brasília.

Figura 5-11: Séries temporais dos dados de ondas longas disponibilizados pelo INPE e

INMET para a Estação Brasília.

Figura 5-12: Séries temporais dos dados de vazão dos afluentes ao lago Paranoá-DF disponibilizados pela CEB.

Figura 5-13: Séries temporais dos dados de vazão de saída na barragem do lago Paranoá-

DF disponibilizados pela CEB.

Figura 5-14: Séries temporais dos dados de fitoplâncton nos pontos de monitoramento da

CAESB.

Figura 5-15: a) Série de dados brutos de temperatura do ar b) Série de dados ajustados de temperatura do ar.

Figura 5-16: a) Série de dados brutos de UR b) Série de dados ajustados de UR. .72

Figura 5-17: a) Série de dados brutos de velocidade do vento b) Série de dados ajustados de velocidade do vento.

Figura 5-18: a) Série de dados brutos de radiação de ondas longas b) Série de dados ajustados de radiação de ondas longas.

Figura 5-19: Validação dos dados do INPE para o mês de agosto de 2008. Fonte: Site do INPE (2015)

Figura 5-20: Perfil térmico simulado pelo modelo GLM.

Figura 5-21: Gráficos de comparação da simulação de base com os dados observados nas 4 profundidades. 
Figura 5-22: Gráficos de comparação de temperaturas simuladas x observadas após calibração nas 4 profundidades.

Figura 5-23: Perfis de temperatura simulada (azul) e observada (vermelho) no lago Paranoá para os meses de março de 2007, fevereiro, agosto e setembro de 2008 e janeiro e fevereiro de 2009.

Figura 5-24:a)Biomassa de clorofíceas observadas vs simuladas a 1m; b)Biomassa de clorofíceas observadas vs simuladas a 10m; c)Biomassa de clorofíceas observadas vs simuladas a $15 \mathrm{~m}$ e d)Biomassa de clorofíceas observadas vs simuladas a $20 \mathrm{~m}$.

Figura 5-25:a)Biomassa de cianobactérias observadas vs simuladas a 1m; b)Biomassa de cianobactérias observadas vs simuladas a 10m; c)Biomassa de cianobactérias observadas vs simuladas a $15 \mathrm{~m}$ e d)Biomassa de cianobactérias observadas vs simuladas a $20 \mathrm{~m}$.

Figura 5-26: Gráficos de fosfato simulado e observado no período de 2007-2009 e simulado no cenário.

Figura 5-27: Biomassa de clorofíceas simuladas e observadas no período de 2007-2009 e simuladas no cenário. 98

Figura 5-28: Biomassa de cianobactérias simuladas e observadas no período de 2007-2009 e simuladas no cenário. 


\section{LISTA DE TABELAS}

Tabela 3-1: Componentes dos principais modelos de qualidade de água de lagos e reservatórios. Adaptado de Mooij et al. (2010).

Tabela 4-1: Descrição das estações de monitoramento da CAESB no lago Paranoá.

Adaptado de Souza (2013).

Tabela 4-2: Principais características do modelo GLM. Adaptado de Yao et al. (2014).... 43

Tabela 4-3: Sumário de parâmetros físicos do GLM com valores padrão. Adaptado de

Hipsey et al., 2014.

Tabela 4-4: Sumário descritivo dos parâmetros do fitoplâncton, unidades e valores típicos.

Fonte: Hipsey et al.(2013).

Tabela 5-1: Extensão do período de dados disponível para simulações com o modelo

GLM-AED no lago Paranoá. .70

Tabela 5-2: Otimização obtida para os parâmetros do GLM no lago Paranoá.

Tabela 5-3: Erros e coeficientes da simulação de temperatura com os parâmetros

otimizados para o Lago Paranoá - DF.

Tabela 5-4: Valores calibrados para os parâmetros do fitoplâncton no lago Paranoá-DF. . 85

Tabela 5-5: Biomassa dos grupos clorofíceas e cianobactérias no período de 1976-1998 e 1999-2011 no lago Paranoá. Adaptado de Souza (2013).

Tabela 5-6: Erro padrão encontrado nas 4 profundidades analisadas para biomassas de clorofíceas e cianofíceas.

Tabela 5-7: Biomassas médias observadas para clorofíceas e cianobactérias no ponto $\mathrm{C}$ de 1976 a 2010.

Tabela 5-8: Erros-padrão obtidos para as demais variáveis de qualidade da água pela calibração das clorofíceas.

Tabela 5-9: Erros-padrão obtidos para as demais variáveis de qualidade da água pela calibração das cianobactérias

Tabela 5-10: Média dos valores registrados para temperatura, OD, amônia, nitrato e fosfato, pela CAESB, entre 1976 a 2010. 


\section{LISTA DE NOMENCLATURA E ABREVIAÇÕES}

ADASA Agência Reguladora de Águas, Energia e Saneamento Básico do DF AED .Aquatic Ecodynamics Model Library ANA Agencia Nacional de Águas

CAESB Companhia de Saneamento Ambiental do Distrito Federal CEB. Companhia Energética de Brasília

CETESB Companhia Ambiental do Estado de São Paulo CONAMA Conselho Nacional de Meio Ambiente $\mathrm{DBO}$ Demanda bioquímica de oxigênio $\mathrm{DF}$ .Distrito Federal

DQA ..Diretiva Quadro das Águas EPA-NLA Environmental Protection Agency - National Lakes Assessment ETE Estação de Tratamento de Esgoto FABM The Framework for Aquatic Biogeochemical Models GLEON Global Lake Ecological Observatory Network GLM General Lake Model

IBI. Índices de Integridade Biótica IBGE Instituto Brasileiro de Geografia e Estatística

IQA Índice de Qualidade das Águas

INMET Instituto Nacional de Meteorologia

OD. ..Oxigênio dissolvido

PTotal. Fósforo Total

SIG Sistemas de Informação Geográficas

UGRHI Unidade de Gerenciamento de Recursos Hídricos UHE. Usina Hidrelétrica UNB .Universidade de Brasília 


\section{INTRODUÇÃO}

Lagos e reservatórios podem garantir o uso múltiplo das águas de acordo com as necessidades da população, sejam essas de usos consuntivos ou não. O gerenciamento desses corpos d'água é, por característica, um campo de ação multidisciplinar, onde existe um grande número de alternativas no planejamento e gestão, considerando seus usos, disponibilidades e preservação.

A importância de se avaliar a qualidade da água desses ambientes é assegurar a manutenção do ecossistema aquático, a saúde dos seres vivos que dela usufruem e os requisitos de qualidade da água, que são função de seus usos previstos.

Por meio dos programas de monitoramento da qualidade da água são obtidas informações para identificação de corpos hídricos impactados e conservação daqueles vulneráveis à poluição. A aplicação da ferramenta de modelagem tem como base o uso desses dados de monitoramento e tem sido largamente utilizada em análises ambientais. Os modelos são componentes essenciais dos sistemas de suporte à decisão. Dessa maneira, a modelagem tem se firmado como ferramenta para compreensão dos fenômenos que atuam sobre determinados sistemas, com possibilidade de entender como esses sistemas reagem e se comportam.

Os modelos ecológicos são focados nos diferentes ecossistemas existentes, onde cada modelo analisa determinado ecossistema quanto sua dinâmica e com base no comportamento dos organismos vivos presentes (Jorgensen e Bendoricchio, 2001). A aplicação desse tipo de modelagem para ambientes lacustres vêm sendo preferencialmente utilizada por conta da capacidade de retratar toda a dinâmica do ecossistema aquático, detalhando os processos que englobam os organismos vivos e as relações desses com a variação sazonal da qualidade da água. Os estudos têm aplicações diversas, principalmente, eutrofização em lagos, comportamento de uma determinada comunidade e interação entre nutrientes e fitoplâncton. Dessa maneira, é possível avaliar a qualidade do ambiente aquático para diferentes períodos e condições externas e internas e como essas afetam a produtividade primária. 
O lago Paranoá, localizado em Brasília, Distrito Federal - DF, foi criado em 1959 e dentre os múltiplos usos e funções do Lago, destacam-se o paisagismo, a recreação, o esporte náutico e a geração de energia elétrica. Logo após sua criação, no início dos anos 70, o Lago passou por um período de forte eutrofização, com episódios de florações de cianobactérias, o que levou à tomada de diferentes medidas para recuperação do ambiente como a implantação do tratamento terciário, com maior remoção de nutrientes, nas estações de tratamento de esgoto - ETEs Brasília Sul e Norte, nos anos de 1993 e 1994 . E ainda, no ano de 1998, a alteração da operação anual da Usina Hidrelétrica - UHE do Paranoá com vistas à renovação e circulação das águas do Lago.

Essas ações de modificação do tratamento dos efluentes e operação do reservatório levaram à melhoria da qualidade da água do lago Paranoá desde então. Atualmente, está sendo implantada pela Companhia de Saneamento Ambiental do Distrito Federal (CAESB) a utilização do Lago como fonte de abastecimento de água a usuários do seu entorno.

O presente estudo foi desenvolvido no lago Paranoá e como metodologia fez-se uso do modelo GLM-AED, um modelo hidrodinâmico-ecológico para representação da qualidade da água com enfoque no estudo da dinâmica do fitoplâncton. Procedeu-se, inicialmente, à análise da disponibilidade da base de dados obtida do monitoramento da CAESB, bem como a avaliação da consistência dos dados meteorológicos de entrada no modelo. Realizaram-se, então, a análise de sensibilidade e a calibração da hidrodinâmica e do módulo de fitoplâncton no Lago. E, ao final, foi realizada uma simulação de cenário de eutrofização para observar as respostas das variáveis de qualidade da água.

A motivação para realização desse estudo foi a importância de se avaliar a qualidade da água do lago Paranoá com ênfase na dinâmica do fitoplâncton, principalmente após o Lago estar em fase de implantação como manancial de abastecimento. Dessa forma, o controle constante do grau de trofia e compreensão do comportamento do fitoplâncton devido aos problemas de saúde pública que esses organismos podem ocasionar torna-se mais exigente para águas de abastecimento. Por isso, os modelos ecológicos são ferramentas adequadas que podem fornecer resultados rápidos que facilitam a tomada de decisão.

O texto está estruturado em capítulos divididos em: Objetivos Geral e Específicos; Revisão bibliográfica acerca de: Conceitos de qualidade da água e dinâmica da comunidade 
fitoplanctônica em ambientes lênticos, Técnicas para avaliação da qualidade da água em lagos e reservatórios e Histórico de qualidade ambiental do lago Paranoá; Metodologia; Resultados e discussões; Conclusões e Recomendações. 


\section{OBJETIVOS}

\subsection{GERAL}

Avaliar a aplicação da modelagem ecológica por meio do estudo da dinâmica da comunidade fitoplanctônica para avaliação da qualidade da água do lago Paranoá.

\subsection{ESPECÍFICOS}

- Selecionar um modelo ecológico adequado ao ambiente de estudo e à base de dados disponível;

- Aplicar e compreender as etapas do processo de modelagem para o modelo escolhido com a realização de análise de sensibilidade e calibração das variáveis hidrodinâmicas, bem como ao módulo de fitoplâncton para o lago Paranoá;

- Analisar a resposta do modelo por meio da simulação de cenário com base na mudança das variáveis de qualidade da água relacionadas ao histórico de ocorrência de floração de cianobactérias no Lago; 


\section{FUNDAMENTAÇÃO TEÓRICA E REVISÃO BIBLIOGRÁFICA}

Neste capítulo, será apresentada a revisão bibliográfica acerca de conceitos de qualidade da água e dinâmica da comunidade fitoplanctônica em ambientes lênticos; técnicas para avaliação da qualidade da água em lagos e reservatórios, com foco em modelagem ecológica; e um breve histórico de qualidade ambiental no lago Paranoá.

\subsection{CONCEITOS DE QUALIDADE DA ÁGUA E DINÂMICA DA COMUNIDADE FITOPLANCTÔNICA EM AMBIENTES LÊNTICOS}

Os recursos hídricos apresentam variadas aplicações e usos de acordo com a necessidade e demanda da população. Esses são conhecidos como usos múltiplos, advindos do progresso industrial, tecnológico e social da humanidade. Entre esses destacam-se: abastecimento para consumo humano, consumo industrial, irrigação, recreação, navegação, geração de energia elétrica e diluição de despejos.

No Brasil, o Conselho Nacional de Meio Ambiente - CONAMA estabeleceu as diretrizes e classificação das águas doces, salobras e salinas no território nacional quanto aos usos preponderantes por meio da Resolução ${ }^{\circ} 357 / 2005$, alterada quanto às condições e padrões de lançamento de efluentes pela Resolução nº430/2011. Nas bacias hidrográficas em que a condição de qualidade dos corpos de água esteja em desacordo com os usos preponderantes pretendidos, deverão ser estabelecidas metas de melhoria da qualidade da água para efetivação dos respectivos enquadramentos.

A condição do ambiente aquático é identificada por características físicas, químicas e biológicas, traduzidas por meio de parâmetros. A poluição é definida como a alteração nessas características decorrentes de atividades antrópicas tal que prejudique os usos legítimos estabelecidos para o corpo hídrico.

Quando cargas de nitrogênio são descarregadas nas águas naturais conjuntamente com o fósforo e outros nutrientes presentes nos despejos, provocam o aumento da produtividade do meio, podendo ocasionar as chamadas florações ou blooms de cianobactérias, caracterizando o processo de eutrofização. A resposta dos produtores primários ao 
enriquecimento por alta descarga de fósforo em um ambiente aquático pode também ser afetada por fatores locais, como uso do solo na respectiva bacia, características hidrológicas do sistema aquático e padrões de herbivoria e limitação por luz.

O fenômeno da eutrofização causa grandes impactos negativos: do ponto de vista ecológico, devido à floração de microalgas e cianobactérias e crescimento excessivo de plantas aquáticas; e do ponto de vista da saúde pública, pois as cianobactérias podem liberar toxinas na água; além do ponto de vista econômico, pela redução do estoque pesqueiro, perda do valor paisagístico do ambiente, entre outros.

A seguir, será apresentada a relação do fitoplâncton com a produtividade primária nos lagos e como a dinâmica desses organismos é influenciada pela qualidade da água nesses ambientes.

A produtividade primária corresponde à energia solar armazenada por atividade fotossintética ou quimiossintética de organismos produtores. Em um lago é representada pelo aumento de biomassa dos organismos fotossintetizantes, principalmente do fitoplâncton, observados em um dado intervalo de tempo, somadas todas as perdas ocorridas. Em geral, como perda considera-se somente a energia gasta na respiração (Esteves, 2011). É um processo no qual diferentes fatores bióticos e abióticos poderão exercer efeitos de estimulação ou inibição da reprodução desses organismos.

O fitoplâncton encontra-se como um grupo polifilético de microrganismos fotossintetizantes adaptados a viverem parcial ou continuamente em águas abertas e podem se apresentar sob forma de células isoladas, dotadas ou não de movimentos ou formando colônias.

Como a composição da comunidade fitoplanctônica se relaciona com o funcionamento dos ecossistemas aquáticos, é importante conhecer quais fatores governam sua dinâmica. A Figura 3-1 apresenta um modelo simples da dinâmica de processos que colaboram para o aumento ou diminuição da biomassa de fitoplâncton. Observa-se que as espécies apresentam um comportamento não-homogêneo na sua distribuição espacial tanto na coluna d'água (vertical) como ao longo da superfície (horizontal) que depende das 
condições climáticas e hidrodinâmicas, cargas de nutrientes e dinâmicas da cadeia alimentar aquática (Whighan e Recknagel, 1999).

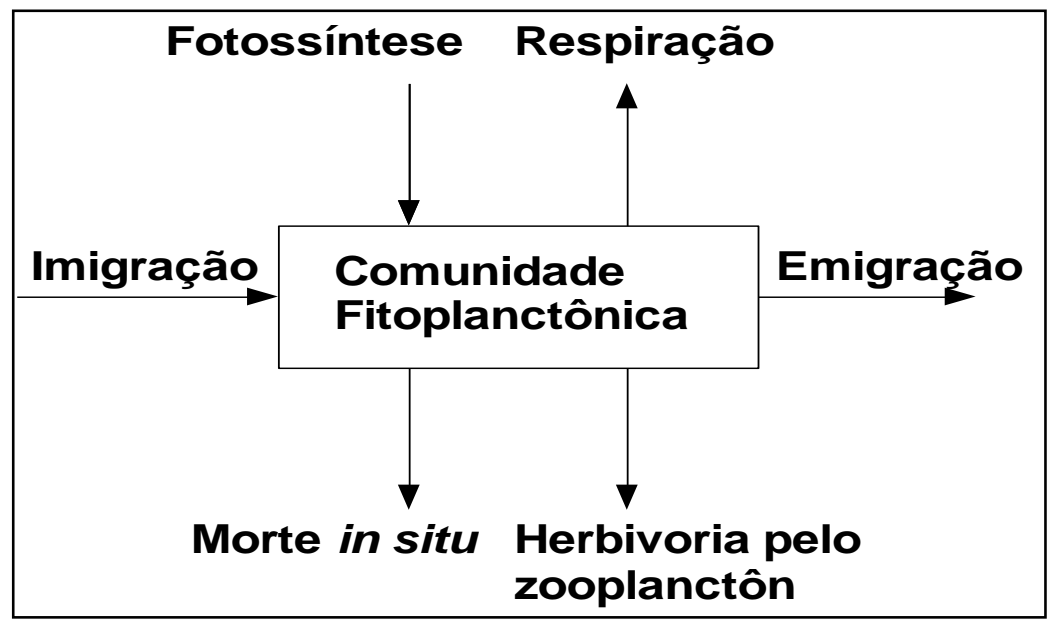

Figura 3-1: Modelo simples da dinâmica do fitoplâncton. Adaptado de Whighan e Recknagel (1999).

Por serem facilmente dispersos na coluna d'água, dado seu pequeno tamanho e elevada abundância, assume-se que as condições locais (estrutura física do sistema, disponibilidade de recursos, processos de escoamento hidráulico, sedimentação e herbivoria) determinarão quais espécies do fitoplâncton ocorrerão em um dado momento e lugar (Beisner et al., 2006). A dependência de luz para o crescimento e a dinâmica de circulação da coluna d'água produz um padrão sazonal para o fitoplâncton com variação da predominância de certas espécies de acordo com o aumento ou diminuição da intensidade de radiação solar e período de estratificação nos lagos. Embora esse padrão possa, ainda, ser alterado por mudanças em qualquer um dos fatores mencionados anteriormente.

A clorofila- $a$, por ser um pigmento fotossintetizante presente nos organismos fotoautótrofos, serve como indicador da biomassa do fitoplâncton no monitoramento de lagos. As concentrações de clorofila- $a$ são utilizadas para expressar quantitativamente a biomassa fitoplanctônica (densidade de algas e cianobactérias presentes).

O estudo do fitoplâncton é capaz de indicar possíveis alterações na qualidade da água e avaliar tendências sazonais, que se refletem em modificações do habitat ou no comportamento dos organismos aquáticos. Contudo, Salas (1983) afirma que a correlação 
entre clorofila- $a$ e biomassa pode ser muito variável, dependendo dos fatores ambientais e das espécies presentes no ambiente.

A disponibilidade de nutrientes é controlada por fatores externos, como ventos e precipitação, que podem carrear maiores taxas de sedimento para dentro do corpo hídrico, e fatores internos, como turbulência, estratificação e desestratificação da coluna d'água e taxa de decomposição. Em lagos profundos, estratificados a maior parte do ano, ocorrem grandes déficits de nutrientes na zona eufótica, e esse pode ser o principal fator controlador da flutuação sazonal do fitoplâncton (Esteves, 2011).

Muhid et al. (2013) determinaram os efeitos a curto prazo de adições de nitrogênio e fósforo, sobre o crescimento e composição de espécies de fitoplâncton usando experimentos em mesocosmos no lago Wivenhoe, Austrália. O estudo utilizou como fonte de enriquecimento os efluentes da estação de tratamento de águas residuárias operada por meio de tecnologia de tratamento de águas residuárias avançada $(A W W T)$, que combinam lodos ativados com microfiltração, oxidação avançada e osmose reversa, e mostrou que a entrada de concentrações consideradas baixas de fósforo inorgânico, correspondente a 5 $\mu \mathrm{g} / \mathrm{L}$, e de nitrogênio, $50 \mu \mathrm{g} / \mathrm{L}$, foram suficientes para aumentar a biomassa de fitoplâncton. Enquanto a biomassa foi afetada a curto prazo, a composição de espécies não apresentou o mesmo comportamento.

Pode-se distinguir cinco filos principais no fitoplâncton de água doce: Cyanophyta, Chlorophyta, Euglenophyta, Heterokontas (incluindo as classes Bacillariophycea e Chrysophyceae) e Dinophyta.

O presente trabalho destaca os seguintes filos: Cyanophyta, denominado de cianobactérias, e Chlorophyta, conhecido por clorofíceas.

As cianobactérias possuem grande capacidade adaptativa, como, por exemplo, manutenção do crescimento em condições limitantes de radiação. Por isso, estão sempre bem distribuídas em todos os biótopos do ecossistema lacustre. Do ponto de vista sanitário e de saúde pública, as cianobactérias assumem grande destaque por serem capazes de produzir toxinas que podem afetar a saúde das pessoas. 
Chlorophyta é o filo mais frequente do fitoplâncton de águas doces. Possuem pigmentação verde, pela alta concentração de clorofila- $a$ (que justifica serem denominadas "algas verdes"), são unicelulares ou filamentosas e habitam, preferencialmente, lagos mesotróficos ou eutróficos (Esteves, 2011).

Reynolds et al. (2002) buscaram elaborar um sistema de classificação de algas planctônicas que incorporasse a sensibilidade dessas as alterações do ambiente. Nesse estudo foram identificados 31 grupos funcionais de fitoplâncton. A terminologia 'grupos funcionais' procura diferenciar a comunidade fitoplanctônica baseada em suas capacidades de adaptação. Dado o momento em que é possível prever a presença individual de cada espécie em determinados locais, o esquema proposto parece oferecer a maneira mais clara para a compreensão e prever a distribuição e dinâmica de populações de fitoplâncton.

Da mesma maneira que o estudo de Reynolds et al. (2002) procurava analisar a relação do fitoplâncton com alterações ambientais, o estudo realizado por Philomeno (2007) buscou estabelecer relação "causa e consequência" existente entre as condições ambientais, por meio de variáveis físicas e químicas, e a biota, com foco na comunidade fitoplanctônica no lago Paranoá. Para isso, a autora analisou três períodos característicos do Lago: antes da mudança de operação do reservatório (1997/98), logo após esta (1999/2000) e seis anos após (2005).

Philomeno (2007) concluiu que o Lago estava em processo de oligotrofização, tendo passado por três fases distintas de qualidade da água, e o ambiente poderia estar em estado de transição entre diferentes estágios de trofia. E, ainda, que havia um padrão de melhoria da qualidade da água e substituição de dominância de cianobactérias por vários taxa com características diferentes.

O estudo de Rigosi et al. (2014) analisou as interações entre aquecimento global e o processo de eutrofização quanto ao aumento da frequência e magnitude de florações de cianobactérias e a expansão do alcance geográfico de algumas espécies e se isso seria dependente do estado trófico e variaria entre os taxa. Para isso, foi realizada uma avaliação do banco de dados de 1000 lagos norte-americanos da Agência Nacional de Proteção Ambiental dos lagos dos EUA (EPA NLA). 
Os autores concluíram que nutrientes e temperatura são igualmente importantes para explicar a variação das cianobactérias. Porém, em geral, os nutrientes foram significativamente mais importantes do que a temperatura em relação à clorofila- $a$, biovolume total de fitoplâncton e biovolume proporcional de cianobactérias. Descobriu-se, também, que, em todo o conjunto de dados da $E P A N L A$, os nutrientes e a temperatura não interagem sinergicamente para dominância de cianobactérias, e sim que seus efeitos foram predominantemente aditivos.

Como parâmetro de qualidade da água, a importância do fitoplâncton está sendo cada vez mais reconhecida e, dessa forma, sua utilização em ferramentas de avaliação da qualidade da água em lagos tem aumentado. Os grupos servem como bioindicadores e podem também ser aplicados em modelos que simulam a dinâmica do ambiente aquático.

\subsection{TÉCNICAS PARA AVALIAÇÃO DA QUALIDADE DA ÁGUA EM LAGOS E RESERVATÓRIOS}

O monitoramento de ambientes lênticos objetiva a coleta e análise de dados, acompanhamento de descargas pontuais de poluição e garantia ao atendimento dos usos múltiplos estabelecidos para o corpo hídrico e respectivas metas de melhoria da qualidade da água para os que se encontrarem em desacordo.

De posse dos dados de monitoramento, pode-se extrair informações relevantes para a tomada de decisão. Alguns instrumentos servem para avaliar esse conjunto de dados e indicar a qualidade ambiental do recurso hídrico.

De acordo com Whitfield e Elliott (2002), os indicadores ambientais são definidos como parâmetros químicos, físicos, biológicos ou socioeconômicos que melhor representam os principais elementos de um ecossistema complexo. Segundo Karr e Chu (2000), os organismos vivos representam a integração das condições ambientais do meio, e por essa razão, indicadores biológicos são melhores para detectar determinados distúrbios do que outros parâmetros físicos ou químicos, isoladamente.

A tentativa de agrupamento de variáveis físicas, químicas e biológicas que representem a qualidade do ambiente aquático resulta na formação de diferentes índices. Entre esses, 
destacam-se os índices de integridade biótica - IBIs baseados em organismos indicadores e os índices de qualidade das águas - IQAs.

Outro instrumento de grande aplicação para avaliação ambiental em lagos é a modelagem matemática. Para se permitir a discussão desse tema, existe a necessidade de conceituação de termos que são base ao entendimento da ferramenta em si. Entre esses conceitos, destacam-se: sistema, modelo e simulação.

Sistema pode ser definido como qualquer estrutura, esquema ou procedimento, real ou abstrato, que a um dado tempo de referência, inter-relaciona-se com uma entrada, causa ou estímulo de energia ou informação, e uma saída, efeito ou resposta de energia ou informação (Dooge, 1973 apud Tucci, 2005).

Modelo é uma representação simplificada de algum objeto ou sistema, em uma linguagem de fácil acesso e uso. Tem por objetivo o entendimento e a previsão as respostas do sistema em diferentes circunstâncias, a avaliação dos dados observados e fornecimento de entendimento das ligações entre os componentes que são parte do sistema (Tucci, 2005). Os modelos são classificados em: físicos, quando representam o sistema por meio de um protótipo que, na maioria das vezes, é em escala menor; analógicos, que se utilizam da analogia de equações que regem diferentes fenômenos para modelar, no sistema mais conveniente, o processo desejado; e matemáticos, são os que representam os sistemas a partir de equações matemáticas (Tucci, 1987; Tucci, 2005).

A simulação é o processo de utilização do modelo e, geralmente, é dividida em quatro fases (Tucci, 1987; Tucci, 2005):

i. Análise de sensibilidade: consiste na variação individual de cada parâmetro, valor que caracteriza o sistema, e verificação dos resultados de forma que é possível verificar qual(is) parâmetro(s) tem(têm) maior influência na simulação do sistema em estudo;

ii. Estimativas ou calibração: quando os parâmetros devem ser determinados, seja por calibração manual, alterando-os manualmente e observando o ajuste ou calibração automática, quando o próprio software possui em seu código a calibração otimizada, que é realizada automaticamente. 
iii. Verificação: onde é realizada a simulação do modelo com os parâmetros estimados e verifica-se a validade do ajuste realizado para outros dados.

iv. Previsão ou simulação de cenários: é feita a simulação do modelo com os parâmetros estimados para analisar a quantificação de suas respostas a entradas distintas, normalmente associadas à elaboração de cenários futuros.

Quanto à classificação dos modelos, esses podem ser diferenciados devido aos seguintes critérios: processos, uso da probabilidade na formulação do modelo, tempo, variabilidade espacial, função e solução de equações.

\subsubsection{Modelagem Ecológica}

Diferentemente dos modelos matemáticos simples, que propõem a representação matemática dos processos ambientais (físicos, químicos e biológicos) em sistemas hídricos, os modelos ecológicos incorporam a dinâmica dos organismos vivos na análise proposta.

Em Ecologia, quando se procura determinar o sistema a ser modelado, pode-se pensar em três níveis hierárquicos: população, comunidade e ecossistema. Os modelos ecológicos são modelos de ecossistemas, propriamente ditos, formados pela combinação de relações ecológicas conhecidas com os dados obtidos de observações de campo ou monitoramento. Esses modelos procuram fazer previsões sobre a dinâmica real do sistema. Muitas vezes, o estudo de imprecisões no modelo (quando comparado com observações empíricas) levará à geração de hipóteses sobre possíveis relações ecológicas que ainda não são conhecidas ou bem compreendidas (Jorgensen e Bendoricchio, 2001).

Jorgensen e Bendoricchio (2001) compararam os modelos ecológicos a mapas geográficos. Os autores afirmam que mapas servem para diferentes propósitos e todos diferem entre si, pois possuem focos distintos. Dessa forma, os modelos ecológicos se diferenciam pelo foco em cada ecossistema de acordo com os objetivos e problemas a serem solucionados.

A história da modelagem ecológica apresenta seis estágios distintos, caracterizados na publicação de Jorgensen et al.(2009). 
O primeiro estágio é iniciado pelos modelos de Lotka-Volterra e Streeter-Phelps nos anos 1920. O modelo de presa-predador foi formulado independentemente por Lotka em $1925 \mathrm{e}$ Volterra em 1926. As equações desse modelo descrevem mudanças oscilatórias em duas populações que interagem. Kingsland (1985) sugere ter sido o modelo presa-predador de Lotka o primeiro a mencionar a abordagem sistêmica. O modelo de Streeter e Phelps é conhecido como modelo clássico de OD e demanda bioquímica de oxigênio - DBO em rios para simular a qualidade da água. No segundo estágio, continuou-se o desenvolvimento desses modelos, ampliando seus conceitos.

A partir do terceiro estágio, verdadeiramente, a modelagem ecológica passou a emergir por meio da utilização de computadores que permitiram o desenvolvimento de modelos mais complexos e o uso desses na resolução de problemas de gerenciamento ambiental. A partir de meados dos anos 70, o desenvolvimento de modelos ecológicos com foco em diferentes tipos de ecossistemas e problemas ambientais finalmente estabeleceu a modelagem ecológica como disciplina.

O período de 1975-1980 corresponde ao quarto estágio, quando houve o amadurecimento da modelagem ecológica, por meio do ganho de experiência pela concepção de novos modelos, os quais, diferentemente dos sistemas físicos, tratavam-se de ecossistemas e conseguiam refletir suas características e comportamentos. No quinto estágio, surgiram diferentes modelos voltados para, principalmente: avaliar substâncias tóxicas no ambiente, outros tipos de ecossistema e problemas ambientais.

A partir de 1990, teve início o sexto estágio, o qual perdura até hoje, caracterizado por maiores estudos em modelos para sistemas terrestres. Caracteriza-se, também, pelo surgimento de novos modelos que aliam outras tecnologias e otimizações, como: lógicas fuzzy e Sistemas de Informação Geográficas - SIG. A Figura 3-2 resume os estágios de desenvolvimento da modelagem ecológica. 


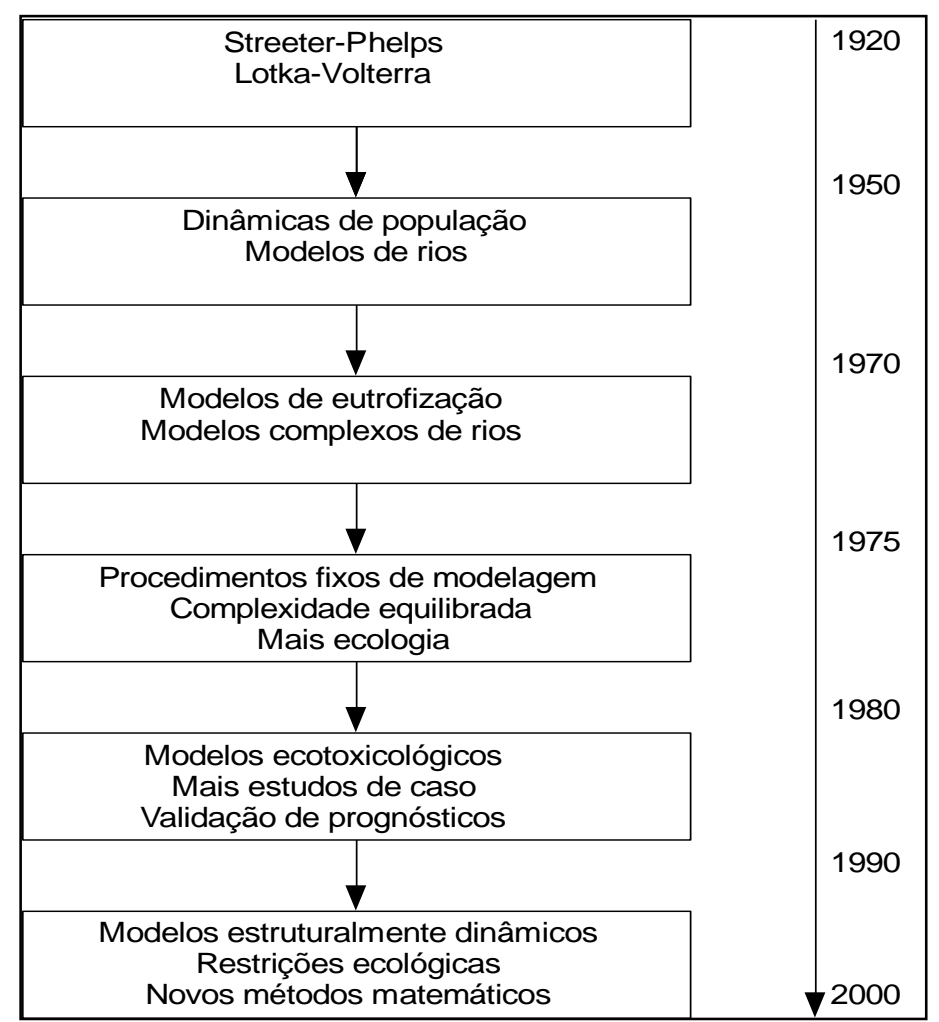

Figura 3-2- O desenvolvimento da modelagem ecológica dividido em seis estágios.

Adaptado de Jorgensen e Bendoricchio (2001).

Larocque et al. (2011) fizeram uma síntese das discussões ocorridas na Conferência da Sociedade Internacional de Modelagem Ecológica realizada em Quebec, no Canadá, no ano de 2009. Nos grupos de trabalho discutiram-se diversos temas, os quais foram então classificados em três grandes categorias: desenvolvimento teórico, população dinâmica e processos de ecossistemas, a fim de incentivar todos os participantes a proporem soluções e compartilhar ideias.

Ainda, no estudo de Larocque et al. (2011), o tema "Modelagem de ecossistema como apoio à decisão na gestão da água", inserido na categoria "Desenvolvimento teórico" foi debatido e dos pontos discutidos salientou-se a necessidade de pesquisa multidisciplinar para gerar e compartilhar novas ideias, mas também para integrar modelos ecológicos com hidrológicos, ambientais, e outros. E, ao final das discussões, trataram-se os desafios de lidar com as incertezas e validação dos modelos, e que a colaboração interdisciplinar é cada vez mais vista de maneira vital para o avanço da modelagem, bem como a matemática e as ciências computacionais para dar apoio. 
De acordo com Fragoso Jr (2008), o progresso recente na área de hidrologia, no sentido de avaliar e prognosticar com mais precisão os processos quantitativos, impulsionou a construção de modelos matemáticos eco-hidrológicos complexos, os quais integram a hidrodinâmica com os parâmetros de qualidade da água, melhorando, assim, a capacidade preditiva de constituintes químicos da água e de processos biológicos.

No âmbito dos modelos ecológicos, Benndorf e Recknagel (1982) propõem três principais categorias em relação a complexidade desses modelos. São elas:

1. Modelos que envolvem um grande número de variáveis de estado, que são valores que descrevem quantitativamente um fenômeno que varia no tempo e no espaço, nos quais os mecanismos de controle ecológico dentro de cada variável de estado são considerados de uma forma intermediária simples;

2. Modelos que envolvem um pequeno número de variáveis de estado, em que a prioridade é dada aos mecanismos internos de controle ecológicos;

3. Modelos que envolvem um grande número de variáveis de estado e investigação aprofundada dos mecanismos de controle ecológico internos.

Jorgensen (1997) realizou um levantamento sobre os trabalhos publicados em 100 volumes da revista "Ecological Modelling". Observou-se que pesquisadores brasileiros publicaram apenas 9 trabalhos nessa revista $(0,53 \%$ do total), no período de 1975 à 1996 . Com isso, o País conseguiu uma das piores médias de trabalhos publicados por habitante neste assunto (a $32^{\mathrm{a}}$ em 35 países).

De maneira geral, somente nos últimos anos, houve um avanço no entendimento da importância de modelos ecológicos, principalmente com foco em ambientes lacustres. Isso é devido a importância de associar os parâmetros de qualidade da água aos organismos vivos que indicam alterações de curto a longo prazo e permitem melhor compreensão da dinâmica do ecossistema.

\subsubsection{Modelagem ecológica em lagos e reservatórios}

Moss (2012) afirma que a importância de considerar os lagos e reservatórios em simulações, é, primeiro, por eles responderem rapidamente a mudanças no ciclo hidrológico por meio de alterações nos níveis da água e em sua composição química. 
Também, por manterem, em seus sedimentos, um registro de tais mudanças. Pelos lagos existirem em todas as partes do planeta e, apesar de suas individualidades, manterem muitos processos comuns que podem ser comparados entre latitudes. E por serem bem compreendidos como sistemas e, como todos os sistemas de água doce, eles têm grande importância para os seres humanos, como armazenamentos de água, fontes de alimentação, para recreação e diversos outros usos.

Com relação ao número de dimensões espaciais consideradas, Wrobel et al. (1989) classificam os modelos de simulação de escoamentos e qualidade da água em reservatórios da seguinte maneira:

i. Modelos Concentrados (Dimensão zero) - são modelos matemáticos que consideram o reservatório completamente misturado em todas as direções, ou seja, não simulam variações espaciais e não tem compromisso de representar os gradientes espaciais das variáveis hidrodinâmicas, químicas e biológicas. Aplica-se esse caso em estudos de balanço de massa simplificados que servem para dar uma avaliação preliminar das condições de armazenamento e concentração de poluentes no reservatório;

ii. Modelos unidimensionais - são modelos que consideram os gradientes espaciais em uma direção, geralmente na direção vertical ou longitudinal. Modelos longitudinais são aplicáveis para estudar variações do escoamento e concentrações ao longo do eixo do reservatório, desprezando a estratificação vertical que é marcante em reservatórios com grandes profundidades. Já os modelos verticais são apropriados para simular, justamente, temperatura e qualidade da água em reservatórios profundos;

iii. Modelos bidimensionais- simulam os fluxos e mudanças na qualidade da água nas direções verticais e longitudinais do reservatório, desprezando as variações na transversal. São geralmente aplicados para reservatórios maiores, profundos e estratificados, onde as variações laterais são negligenciáveis (Martin e McCutcheon, 1999);

iv. Modelos tridimensionais - são os modelos que representam todas as direções do espaço. Em geral, são utilizados conjuntamente para simulações de hidrodinâmica e qualidade da água. São mais complexos e eficientes, porém apresentam dificuldades práticas relacionadas ao número de parâmetros para controlar. 
Segundo Mooij et al. (2010), os métodos de modelagem de lagos classificam-se da seguinte maneira:

i. Modelos estáticos: Esse tipo de modelo é ainda útil, e está sendo usado para dar uma primeira estimativa dos efeitos de eutrofização de lagos. São simples e fáceis de usar, pois simulam condições estáticas. Porém, são limitados, justamente no sentido de requerer suposição dessas condições estáticas, enquanto a natureza das variáveis é instável e os processos ecológicos dinâmicos (Jorgensen et al., 2009);

ii. Modelos dinâmicos complexos: São especialmente úteis para atribuir às variáveis desenvolvimento no tempo e no espaço, por exemplo, impactos temporais e espaciais de alterações naturais/antropogênicas nos ecossistemas, dinâmicas em bioenergética e ciclos biogeoquímicos (Jorgensen et al., 2009);

iii. Modelos estruturalmente dinâmicos: Zhang et al. (2010) afirmam que, nesses tipos de modelo, os parâmetros são constantemente variados para representar adaptações e mudanças na composição das espécies. Essa abordagem tenta superar as fragilidades associadas aos modelos tradicionalmente utilizados: (1) conjuntos de parâmetros fixos e rígidos são usados nesses modelos que, dificilmente, podem refletir as mudanças de propriedades e composições das espécies de acordo com a condições prevalecentes do ecossistema e (2) a calibração muitas vezes é difícil, porque se tem de lidar com uma série de parâmetros incertos simultaneamente e testá-los dentro de uma ampla variedade de valores possíveis. Esse tipo de modelo permite mudanças adaptativas com a estrutura do modelo como convergência para chegar ao estado final (ou ótimo) no sistema (Jorgensen et al., 2009);

iv. Modelos com mínima dinâmica: São simples e descrevem as mudanças ao longo do tempo e consistem em algumas equações diferenciais ou diferenças finitas que se concentram em um único aspecto de um sistema, com base em pressupostos claros (van Nes e Scheffer, 2005). São mais populares em ciência fundamental do que em ciência aplicada, uma vez que visam ao desenvolvimento da teoria e da compreensão dos sistemas complexos do lago, em vez de fazer previsões realistas;

v. Uso de algoritmos evolucionários híbridos e redes neurais: Modelos híbridos são aqueles formados por qualquer combinação dos outros tipos de métodos apresentados anteriormente. Algoritmos evolucionários híbridos combinam algoritmos evolucionários com modelo orientado a objetos e busca descobrir regras de previsão de dados de séries temporais ecológicas. Combina programação genética para gerar e otimizar a estrutura das regras e algoritmos genéticos para 
otimizar os parâmetros dessas. Redes Neurais Artificiais são técnicas computacionais que apresentam um modelo matemático inspirado na estrutura neural de organismos inteligentes e que adquirem conhecimento por meio da experiência.

Mooij et al. (2010) ainda apresentam uma visão geral dos componentes de diferentes modelos de lagos em uma tentativa de classificá-los. A Tabela 3-1 foi adaptada de Mooij et al. (2010) com a inclusão do modelo de desenvolvimento recente GLM-FABM-AED. A categoria dos modelos foi atribuída conforme a classificação dos métodos de modelagem em lagos dada por Mooij et al. (2010), anteriormente. Alguns componentes ficaram sem preenchimento por falta de maiores informações acerca do referido modelo.

A cada ano, surgem novos modelos ecológicos com foco em lagos e reservatórios e os já existentes são utilizados em diversas aplicações e estudos de caso. Observa-se uma tendência em integrar diferentes modelos, com propósitos distintos, no alcance de um objetivo específico. Chapra (1997) afirma a existência de uma tendência na modelagem que busca a utilização conjunta de modelos que procuram retratar os mais importantes processos em distintos compartimentos ambientais, como a atmosfera, a bacia como um todo e os lagos. 
Tabela 3-1: Componentes dos principais modelos de qualidade de água de lagos e reservatórios. Adaptado de Mooij et al. (2010).

\begin{tabular}{|c|c|c|c|c|c|c|c|c|c|c|c|c|c|}
\hline $\begin{array}{ll}\begin{array}{l}\text { Nome } \\
\text { modelo }\end{array} & \text { do } \\
\end{array}$ & Vollenweider & $\begin{array}{l}\text { DYRESM- } \\
\text { ELCOM- } \\
\text { CAEDYM }\end{array}$ & $\begin{array}{l}\text { CE- } \\
\text { QUAL- } \\
\text { W2 }\end{array}$ & $\begin{array}{l}\text { DELFT3D- } \\
\text { ECO }\end{array}$ & MyLake & PCLake & $\begin{array}{l}\text { LakeShira } \\
\text { Modelo }\end{array}$ & $\begin{array}{l}\text { IPH- } \\
\text { TRIM3D- } \\
\text { PCLAKE }\end{array}$ & PROTECH & SALMO & Charisma & Piscator & $\begin{array}{l}\text { GLM- } \\
\text { FABM } \\
\text { AED }\end{array}$ \\
\hline Categoria & $\mathrm{i}$ & Ii & ii & ii & ii & ii & ii & ii & ii & ii & iv & iv & ii \\
\hline $\begin{array}{l}\text { Dimensão } \\
\text { espacial }\end{array}$ & $0-\mathrm{D}$ & $\begin{array}{l}1 \mathrm{DV} / \\
3-\mathrm{D}\end{array}$ & 2-DV & $3 \mathrm{D}$ & $1-\mathrm{DV}$ & $2-\mathrm{DV}^{*}$ & $1-\mathrm{DV}$ & $3-\mathrm{D}$ & $1-\mathrm{D}$ & 1-DV & 2-DH & 0 -D & $1-\mathrm{DV}$ \\
\hline Estratificação & - & + & + & + & + & - & + & + & - & + & - & - & \\
\hline Sedimentos & - & + & + & + & + & + & - & +- & - & + & + & - & + \\
\hline Zona Litorânea & - & + & - & - & - & + & - & - & - & - & - & + & - \\
\hline $\begin{array}{ll}\text { Grupos } & \text { de } \\
\text { fitoplâncton }\end{array}$ & 0 & 7 & $3+$ & $3-6$ & 1 & 3 & 2 & 3 & 10 & $2-10$ & 0 & 0 & 3 \\
\hline $\begin{array}{ll}\text { Grupos } & \mathrm{de} \\
\text { zooplâncton } & \end{array}$ & 0 & 5 & $3+$ & $1-3$ & 0 & 1 & 1 & 1 & 1 & 1 & 0 & 1 & \\
\hline $\begin{array}{ll}\text { Grupos } & \text { de } \\
\text { bentos } & \end{array}$ & 0 & 6 & $3+$ & 1 & 0 & 1 & 1 & 1 & 0 & 0 & 0 & 1 & 0 \\
\hline $\begin{array}{l}\text { Grupos de } \\
\text { peixes }\end{array}$ & 0 & 3 & 0 & 0 & 0 & 3 & 0 & 3 & 0 & 0 & 1 & +-8 & 0 \\
\hline $\begin{array}{ll}\text { Grupos } & \text { de } \\
\text { macrófitas } & \end{array}$ & 0 & 1 & $3+$ & 0 & 0 & 1 & 0 & 1 & 0 & 0 & +-5 & 0 & 0 \\
\hline $\begin{array}{ll}\text { Grupos } & \text { de } \\
\text { pássaros } & \end{array}$ & 0 & 0 & 0 & 0 & 0 & $0-1$ & 0 & $0-1$ & 0 & 0 & 1 & 3 & 0 \\
\hline Hidrodinâmica & - & + & + & + & + & +- & + & +- & +- & + & - & - & + \\
\hline Temperatura & - & + & + & + & - & - & - & - & & - & - & - & + \\
\hline Oxigênio & - & + & + & + & - & + & + & + & - & + & - & - & + \\
\hline $\begin{array}{l}\text { Carbono } \\
\text { inorgânico } \\
\text { dissolvido/CO2 }\end{array}$ & - & + & + & + & - & - & - & - & 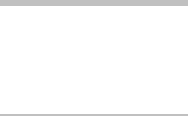 & - & - & - & + \\
\hline $\begin{array}{l}\text { Carbono } \\
\text { orgânico } \\
\text { dissolvido/CO2 }\end{array}$ & - & + & + & + & - & + & + & + & - & + & - & - & + \\
\hline $\begin{array}{l}\text { Dinâmica } \\
\text { microbiológica }\end{array}$ & - & + & + & + & - & +- & +- & +- & - & - & - & - & - \\
\hline $\begin{array}{l}\text { Aporte de } \\
\text { fósforo }\end{array}$ & + & + & + & + & + & + & + & + & +- & + & +- & +- & + \\
\hline $\begin{array}{ll}\begin{array}{l}\text { Aporte } \\
\text { nitrogênio }\end{array} & \text { de }\end{array}$ & + & + & + & + & - & + & + & + & +- & + & +- & +- & + \\
\hline
\end{tabular}


Tabela 3-1: Componentes dos principais modelos de qualidade de água de lagos e reservatórios. Adaptado de Mooij et al. (2010). (Continuação).

\begin{tabular}{|c|c|c|c|c|c|c|c|c|c|c|c|c|c|}
\hline Dinâmica interna de fósforo & - & + & + & + & + & + & + & + & + & + & - & - & + \\
\hline Dinâmica interna de nitrogênio & - & + & + & + & - & + & + & + & + & + & - & - & + \\
\hline Dinâmica interna de sílica & - & + & + & + & - & +- & - & +- & - & - & - & - & + \\
\hline $\begin{array}{l}\text { Sedimentação/ } \\
\text { Resuspensão }\end{array}$ & + & + & + & + & + & + & + & + & + & + & - & - & + \\
\hline Diagênese & - & + & +- & + & - & +- & - & - & - & - & - & - & \\
\hline
\end{tabular}

Resuspens

Diagênese

+: totalmente coberto, +-: parcialmente coberto, -: não coberto; 0-D: dimensão 0, 1-DV: unidimensional na vertical, 2-DH: bidimensional na horizontal, 2-DV: bidimensional na vertical, 2-DV*: bidimensional na vertical usando compartimentos, 3-D: tridimensional 
Jorgensen (2010) revisou os modelos de lagos publicados nos últimos cinco anos anteriores à sua publicação - compreendendo o período de 2005 a 2010, e suas aplicações em estudos de caso. O autor afirma que esses novos modelos têm-se centrado, principalmente, em três tendências, primeiro pela integração de modelos hidrodinâmicos e ecológicos; ainda, que os modelos estruturalmente dinâmicos publicados confirmam que esse tipo de modelo oferece uma boa solução para os casos em que a adaptação e as mudanças na composição de espécies são importantes. E por último, um interesse crescente em modelar o impacto das mudanças climáticas nos ecossistemas lacustres.

O estudo de Hongping e Jianyi (2002) é um exemplo dessa tendência em utilizar modelos dinâmicos para obter respostas mais próximas à realidade do ambiente natural. Os autores modelaram o ecossistema do lago Oeste, Hangzhou - China, como um exemplo de lagos rasos naturais, com base na mudança da dinâmica de quatro tipos principais de fitoplâncton para simular as mudanças do ecossistema depois de algumas manipulações com foco na redução da carga de fósforo advinda de outros tributários, utilizando um modelo dinâmico proposto no estudo.

O objetivo do modelo desenvolvido por Hongping e Jianyi (2002) era avaliar o benefício das manipulações na melhoria da qualidade da água sabendo que o excesso de algas é o grande motivo para a deterioração de sua qualidade por causa da eutrofização observada no Lago desde a década de 70. Em razão disso, o modelo buscou estudar a relação de fatores físico-químicos e o crescimento das algas, e explorar os efeitos de medidas sobre as comunidades de algas e sua biomassa.

O estudo de Hamidian e Hasanzadeh (2013) é outro exemplo da sequência no uso de modelos estruturalmente dinâmicos na busca de melhor representação do comportamento dos organismos vivos. Eles avaliaram se o PAMOLARE, modelo de gestão e controle da eutrofização em lagos, poderia prever a evolução do nível trófico. PAMOLARE é um modelo de bacia hidrográfica, que trabalha em conjunto com um modelo simples ou estruturalmente dinâmico de lago a fim de gerar resultados com base em diferentes medidas de restauração. 
O estudo de Zhang et al. (2008) segue a linha de tendência em aliar abordagem hidrodinâmica com ecologia. Os autores publicaram um modelo 2D, baseado no modelo CE-QUAL-W2, com foco em eutrofização para o lago Erie, na América do Norte, denominado EcoLE. O modelo conta com 18 variáveis de estado e é caracterizado por acoplar hidrodinâmica e processos ecológicos, detalhar submodelos do zooplâncton e incluir o impactos de mexilhões, que é uma problemática desde o final da década de 80 , quando o mexilhão zebra (Dreissena polymorpha) invadiu o lago Erie, seguido por outra espécie exótica, mexilhões quagga (D. bugensis), no início da década de 90, e que está substituindo o mexilhão zebra e tornando-se dominante nas bacias adjacentes. Apesar de serem espécies diferentes, elas promovem impactos ecológicos semelhantes no lago Erie.

Hense e Beckmann (2006) elaboraram um modelo numérico que contempla as fases de vida das cianobactérias considerando que essas possuem quatro fases distintas. $\mathrm{O}$ foco do estudo foi entender o comportamento das cianobactérias frente às mudanças ambientais. O conceito base do modelo é o EQN (energia-cota-nutriente) proposto por Beckmann e Hense (2004) para descrever processos de diferenciação que provavelmente dependem do estado de energia e nitrogênio presente nas células. $\mathrm{O}$ estudo indica que a previsão de florações de cianobactérias tem de ser baseada em um conhecimento detalhado de todas as fases de seu ciclo de vida.

Walter e Recknagel (2001) utilizaram o modelo SALMO, unidimensional dinâmico complexo, para simular o reservatório Burrinjuck, situado a cerca de $339 \mathrm{~km}$ a sudoeste de Sydney, na Austrália, por um período de 12 meses, de $1^{\circ}$ de julho a 30 de junho, por três anos consecutivos, 1979 a 1982.

A validação do SALMO foi realizada usando os dados de clorofila- $a$ e fósforo medidos em comparação com os valores previstos para aquele período. Após os resultados da validação serem considerados aceitáveis, em termos de precisão, o modelo foi usado para realizar análises de cenários como apoio à decisão para o controle estratégico da eutrofização no reservatório e revelou que as abordagens de controle por meio da redução de cargas de nutrientes externos em 50\% e combinação de mistura artificial com biomanipulação estabilizariam condições mesotróficas no Reservatório. 
O estudo de Walter e Recknagel (2001) também ressaltou a importância de análises de consistência e pré-processamento dos dados, visto que os dados iniciais foram coletados não equidistantes e exigiram média e interpolação para obter intervalos de 10 dias ao longo de todo o ano, que é o formato de dados requerido pelo modelo.

Recknagel et al. (2008) compararam o desempenho da biblioteca de simulação SALMO-OO, orientado a objetos e implementado em linguagem JAVA tendo por base o SALMO, com as regras do agente Microcystis descoberto por algoritmo evolucionário hibrido, que procura descobrir conjuntos de regras de previsão em dados de séries temporais ecológicas complexas, aplicando programação genética para a otimização das estruturas de regras e algoritmos genéticos para a otimização dos parâmetros. O estudo foi aplicado para quatro lagos monomíticos quentes hipereutróficos na África do Sul e provou ser uma ferramenta útil para a avaliação comparativa dos estados de três lagos: Rooteplaat, Klipvoor e Rooteplaat, entre julho de 2003 e junho de 2004, porém não proveu resposta específica para cenários de gerenciamento de controle de floração de algas.

O estudo de Zhang et al. (2013) segue o propósito de acoplar modelos com diferentes enfoques na busca do objetivo proposto. Os autores construíram e avaliaram uma abordagem multi-modelo e práticas de pesquisa simples, para serem usadas como ferramenta de gestão para prever a qualidade da água (níveis de nutrientes e fitoplâncton) e aplicabilidade para outros sistemas que fossem grandes, com pouca disponibilidade de dados e complexos, semelhantes ao lago dos Bosques, Canadá.

A abordagem multi-modelo de Zhang et al. (2013) acoplou em sequência um modelo físico, modelo de balanço de massa e modelos empíricos para incorporar a complexidade do lago (morfometria, processos hidrológicos e meteorológicos, química da água e aportes de nutrientes) e prever os níveis de nutrientes e biomassa de algas em vários segmentos do lago para o período compreendido entre 2000 e 2010 . O modelo hidrodinâmico foi usado para simular a circulação do lago, o modelo de balanço de massa foi usado para prever as concentrações de fósforo total, com base na carga de fósforo interno e externo e no ambiente hidrológico do lago. Por fim, esses valores de PTotal previstos foram usados para preencher os modelos empíricos para obtenção de medidas de biomassa total de fitoplâncton. 
Trolle et al. (2012) propõem uma estrutura de base comunitária para os modelos de ecossistema aquático, pois os autores afirmam que o grande empecilho nessa área é a forma limitada de comunicação e uma colaboração inadequada entre as esferas da comunidade científica. O levantamento de estudos na área identificou mais de 100 modelos aquáticos existentes nas duas últimas décadas, muitos dos quais têm níveis de complexidade ecológica e intenções, em termos de simulação de componentes selecionados dos ecossistemas aquáticos, semelhantes. Porém, apenas alguns desses modelos, exemplificados pela seleção de quatro dos modelos mais citados por ano, após suas primeiras publicações (as citações foram baseadas em pesquisa na base de dados doISI Web of Science usando acrônimos de modelo como palavras-chave, onde citações próprias também foram inclusas), têm demonstrado uso crescente. Além disso, esses modelos apresentam ora restrições de acesso aos códigos-fonte, ora flexibilidade e/ou complexidade limitada em seus módulos hidrodinâmicos e/ou ecológicos, o que dificulta a realização de melhorias.

O estudo de Trolle et al. (2012) identificou, então, os seguintes modelos: DYRESM/ELCOM/CAEDYM, onde o DYRESM é um modelo unidimensional capaz de simular a dinâmica de estratificação vertical e outros processos de mistura, acoplado ao ELCOM, modelo tridimensional que contempla hidrostática, equações de transporte escalar e turbulência horizontal e, por último, ao CAEDYM, modelo dinâmico unidimensional de ecossistema aquático; PCLake, modelo dinâmico bidimensional de ciclagem de nutrientes e biota (incluindo fitoplâncton, macrófitas e uma teia alimentar simplificada) em lagos rasos; CE-QUAL-W2, modelo bidimensional (longitudinal/vertical) de qualidade da água e hidrodinâmica e PROTECH, modelo unidimensional de simulação da dinâmica in situ do fitoplâncton em lagos e reservatórios, especializando-se na previsão da ocorrência de espécies do fitoplâncton, principalmente cianobactérias (Figura 3-3).

Em relação a esses modelos de uso crescente, vários estudos abordam suas aplicações em diferentes estudos de caso. No estudo de Janse et al. (2010), efetuam-se a calibração e a estimativa de incerteza nas previsões devido a variações de parâmetros do modelo PCLake, com base em um conjunto de dados multi-lago. A calibração foi baseada em dados de 43 lagos, onde eram conhecidos os fatores de entrada e havia banco de dados 
de observações. A abordagem proposta pelo modelo também representa busca por estratégias de gestão de lagos.

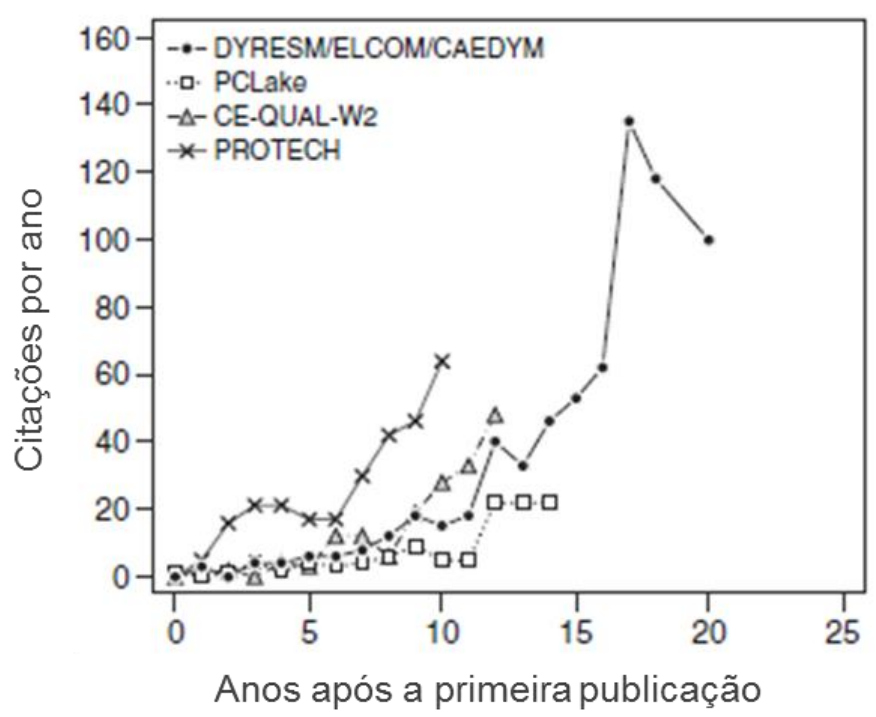

Figura 3-3 - Citações científicas de modelos de ecossistema lacustre:

DYRESM(1D)/ELCOM(3D)/CAEDYM (1 publicação em 1991), PCLake (1 publicação em 1995), CE-QUAL-W2 (1 publicação em 1997) e PROTECH (1º publicação em 1999). Adaptado de Trolle et al. (2012).

Fragoso et al. (2008) desenvolveram um modelo baseado no PCLake que acopla componente da hidrodinâmica com os processos ecológicos, chamado IPH-TRIM3DPCLake, que foi capaz de descrever a heterogeneidade espacial no lago Mangueira/RS, Brasil, um grande lago raso subtropical. O modelo representa as vantagens que são alcançadas por meio de uma melhor integração dos componentes hidrodinâmicos e ecológicos na modelagem de lagos e foi capaz de identificar as zonas com maior potencial de eutrofização.

Afshar et al. (2011) pretendiam desenvolver e apresentar uma abordagem computacionalmente viável para calibração de modelos de simulação complexos, como o CE-QUAL-W2. O modelo de calibração automática implementado baseia-se numa técnica de otimização de busca heurística global, o chamado modelo de otimização por enxame de partículas (Particle Swarm Optimization - PSO). Esse foi acoplado ao CEQUAL-W2 de maneira on-line pelas disponibilizações existentes que permitiram a parametrização do modelo hidrodinâmico do reservatório Karkheh, no Irã. O processo de calibração foi para um período de 7 meses com base diária para dois pontos de verificação, que é o exigido pelo modelo. 
Elliott et al.(2007) ampliaram o alcance mundial do modelo ecológico PROTECH aplicando-o pela primeira vez a um lago de alta latitude, o lago Erken, um corpo d'água mesotrófico no sudeste da Suécia. Várias características desse lago o tornavam um desafio para o PROTECH: seu longo tempo de retenção, a formação de gelo e a presença de uma distinta espécie de fitoplâncton regularmente dominante no final do verão.

Sabendo que o PROTECH não possui sub-rotinas para simular formação de gelo, acoplou-se a ele um modelo hidro-físico para lagos chamado PROBE que permitia que a formação de gelo e seus efeitos pudessem ser adequadamente capturados, e ainda, simular a dinâmica térmica diária para o PROTECH, a fim de que este conseguisse simular a dinâmica populacional do fitoplâncton. Ambos foram executados para 11 anos de dados e as saídas foram comparadas com os dados observados. Ao final, o PROTECH foi capaz de usar a estrutura de temperatura simulada do PROBE para simular corretamente a dinâmica populacional do fitoplâncton.

Gal et al. (2009) aplicaram e validaram o modelo DYRESM/CAEDYM para um conjunto de dados históricos do lago Kinneret, Israel, e em seguida estimaram o impacto de potenciais mudanças na carga de nutrientes sobre o ecossistema do Lago. A estimativa foi realizada por meio da variação das cargas de fósforo, nitrogênio e os dois em conjunto, por um período de 10 anos. Além disso, os resultados de cenários estavam ligados a índices de qualidade da água desenvolvidos para o lago Kinneret, os quais serviram como ferramenta para avaliar medidas de gestão.

Os modelos apresentados demonstram a eficiência no uso da modelagem ecológica para avaliação de qualidade da água e ferramenta para gerenciamento e controle de poluição, em observância que a maioria comprova as linhas de tendência atuais concluídas por Jorgensen (2010). Muitos estudos utilizaram ainda simulações de manipulações para previsão de respostas do ambiente e tomada de decisão em lagos eutrofizados.

Ainda no estudo de Trolle et al. (2012), os autores apontam como promissor o denominado The Framework for Aquatic Biogeochemical Models - FABM que mesmo estando em estágio inicial de desenvolvimento, já é capaz de armazenar e acoplar vários 
módulos biogeoquímicos e se conectar a modelos hidrodinâmicos 1D e 3D. E que módulos do ecossistema aquático, chamados AED, estão sendo desenvolvidos dentro do FABM. Dessa maneira, essa abordagem apresenta-se mais interessante para aplicações em estudo de caso devido a sua flexibilidade e disponibilidade em comparação aos quatro modelos de uso crescente.

Seguindo a linha de tendência dos modelos CE-QUAL-W2 e DYRESM/CAEDYM que acoplam uma abordagem hidrodinâmica inicial para embasar a modelagem ecológica de qualidade da água, tem-se então o modelo GLM-FABM-AED recentemente desenvolvido como uma iniciativa da Global Lake Ecological Observatory Network (GLEON; Kratz et al., 2006) e está atualmente sob contínuos testes, verificação e desenvolvimento (Yao et al., 2014).

A GLEON é uma rede formada por limnólogos, especialistas em tecnologia da informação e engenheiros que têm como objetivo comum construir uma rede científica internacional de observação da ecologia de lagos. Segundo Hipsey et al. (2012), The General Lake Model - GLM é um modelo hidrodinâmico de estratificação vertical capaz de simular balanço hídrico, aquecimento e resfriamento, e gelo e neve de um sistema de lagos e o FABM, como já citado anteriormente, é uma estrutura de modelagem desenvolvida para simular a dinâmica biogeoquímica e ecológica dos ecossistemas aquáticos, a qual comporta a biblioteca de módulos AED (Aquatic Ecodynamics Model Library). Ainda mais recente é a versão do modelo implementada no software $\mathrm{R}$, a qual não utiliza mais o FABM para agregar os módulos ecológicos. Por essa razão, os módulos AED já são default na versão denominada GLMr e o modelo simplifica-se como GLM-AED.

O estudo de Yao et al. (2014) selecionou quatro modelos ecológicos (Hostetler, Minlake, Simple Ice Model - SIM e GLM) para testar e comparar o desempenho na modelagem de temperatura da água, espessura do gelo, e ainda, previsões da dinâmica do gelo no lago sob um cenário de mudanças climáticas. Foram usados 16 anos de dados de monitoramento do lago Harp, Ontário- Canadá. O Lago tem uma superfície de $0,714 \mathrm{~km}^{2}$ e uma área da bacia hidrográfica de $4,7 \mathrm{~km}^{2}$. O período de simulação foi de 1978-1993. 
Yao et al. (2014) concentraram-se em modelos unidimensionais devido a esses fornecerem uma descrição essencial dos processos físicos nos lagos e requererem menos dados de entrada em comparação com os modelos de qualidade da água 2D ou 3D. Não foi realizada calibração dos modelos, pois foram utilizados os próprios valores padrão ou recomendados pelos desenvolvedores. Observou-se que os quatro modelos comportaram-se de maneira diferente na capacidade de simular os quatro conjuntos de observações. Foi, então, realizada uma classificação por meio de uma simples média dos quatro rankings de cada modelo onde o GLM ocupou a $3^{\circ}$ posição. Contudo, o GLM, em particular, mostrou-se eficiente à medida que está ainda em fase de desenvolvimento com novas versões sendo liberadas regularmente.

Já Read et al. (2014b) procuraram observar a diversidade de respostas ao clima que os lagos geram por meio de uma nova metodologia que utilizou um conjunto de dados de grande escala disponíveis na rede para executar simulações hidrodinâmicas. O modelo utilizado foi o GLM, porém somente seu módulo hidrodinâmico. Ao total, foram utilizados dados de 2368 lagos monitorados por um período de três décadas.

Pela observação dos estudos e aplicações de modelos ecológicos para lagos e reservatórios, pode-se inferir que essa ferramenta de avaliação ambiental vem sendo progressivamente aplicada devido aos bons resultados que consegue alcançar e a capacidade de acoplamento com outros tipos de modelos que permitem um melhor detalhamento das características e comportamento dos ambientes em geral. Esses resultados favorecem o gerenciamento ambiental e a tomada de decisão a médio e longo prazo.

3.2.1.2 Fatores ambientais influentes e base de dados requerida na modelagem ecológica em lagos

Em relação às condições climatológicas que exercem influência nos ambientes aquáticos continentais, Boehrer e Schultze (2008) afirmam que as condições meteorológicas configuram a estratificação e a ação dos ventos nos lagos e, dessa forma, direta ou indiretamente controlam seus processos biológicos. 
Quanto aos fatores climáticos que influenciam a dinâmica dos ecossistemas lacustres, a radiação solar é importante por ser responsável pela distribuição de calor na massa d'água e participar dos processos de evaporação e estratificação e desestratificação térmica. A precipitação total também exerce influência, pois ocasiona o aporte de nutrientes e material particulado, principalmente na estação chuvosa, que alteram as características físicas e químicas da água. Dessa maneira, pode provocar significativas alterações sazonais na qualidade da água.

Read et al. (2014b) ao utilizarem um modelo hidrodinâmico aplicado em lagos para avaliar o perfil térmico no ambiente, apresentam a relação dos dados hidrometeorológicos de entrada como componentes do fluxo de calor no modelo. Os autores propõem ainda que o fluxo de calor é considerado o principal controlador da temperatura em um lago e o apresentam na Figura 3-4.

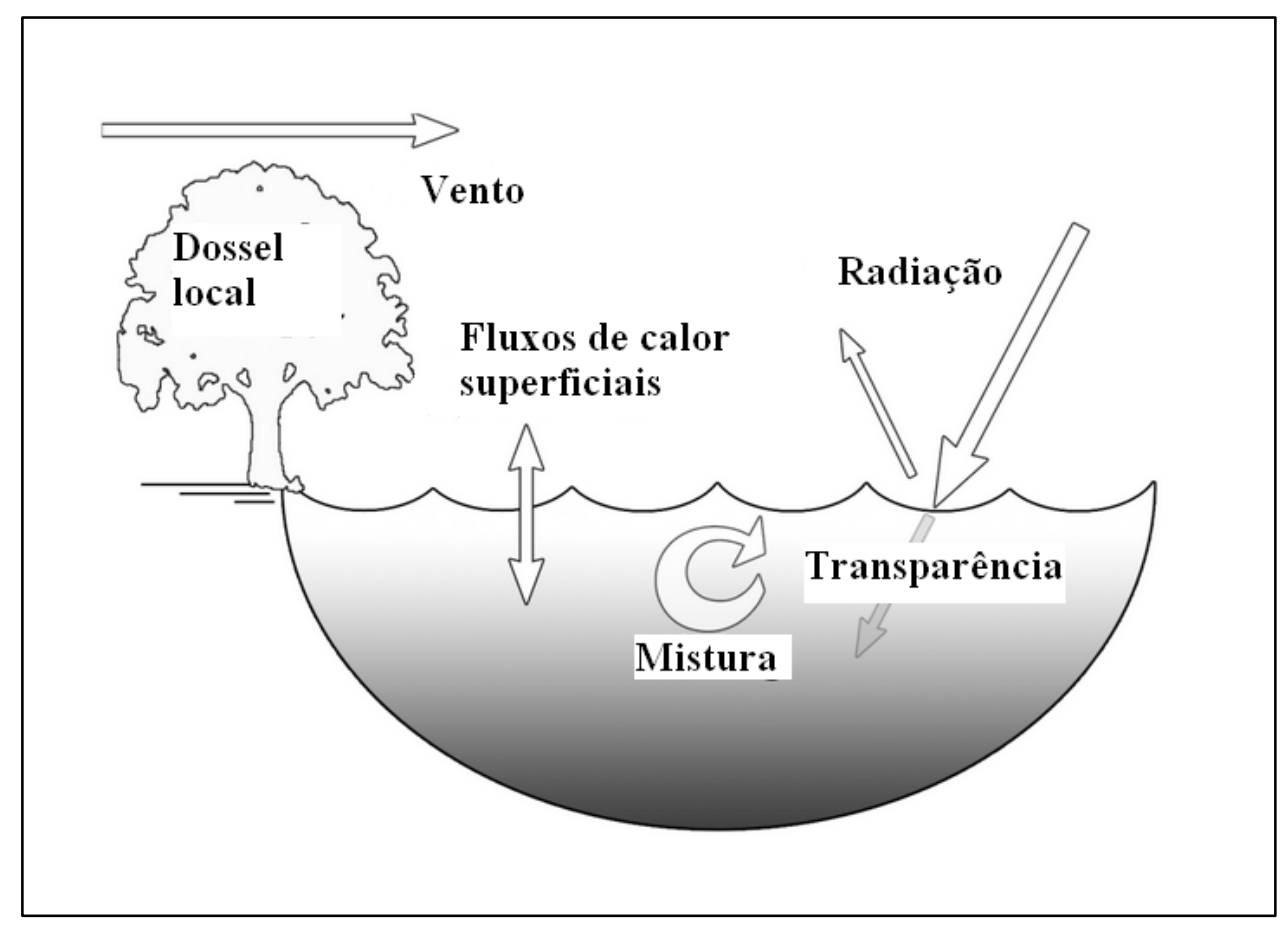

Figura 3-4: Esquema de controladores de temperatura e estratificação do modelo hidrodinâmico GLM. Adaptado de Read et al. (2014b).

Read et al. (2014b) também relacionam os componentes do fluxo de calor com a qualidade da água e apresentam os efeitos dos parâmetros no modelo hidrodinâmico, onde a hipsografia influencia os processos dependentes de tamanho e profundidade do lago dentro do modelo, incluindo o número de camadas verticais usadas; a transparência 
da água controla a taxa que a radiação solar no comprimento de ondas do visível é atenuada ao longo da coluna d'água e a cobertura de vento reduz a quantidade de energia advinda do vento, o qual provoca a mistura vertical.

Já os dados de monitoramento limnológico são utilizados como variáveis de avaliação da qualidade da água em lagos e reservatórios e podem ser empregados para a determinação do estado trófico dos corpos hídricos. Alguns deles são diretamente influenciados pelo uso do solo na bacia de drenagem, destacam-se nesse sentido: concentrações de fósforo, nitrogênio, oxigênio dissolvido - OD e clorofila- $a$. Tem-se ainda: transparência e temperatura da água, que são importantes para avaliação da produtividade primária e o entendimento da dinâmica de estratificação e desestratificação térmica.

Nos modelos hidrodinâmicos-ecológicos, os dados de monitoramento na bacia são a base para se proceder às simulações. Geralmente, os dados de entrada necessários para simulação de modelos ecológicos unidimensionais em lagos, acoplados a modelos físicos, dividem-se em:

- Dados de qualidade da água: que são as concentrações das variáveis de qualidade da água dos afluentes e do próprio lago;

- Dados limnológicos: medições da biomassa fitoplanctônica nos afluentes e ao longo da coluna d'água;

- Dados hidrológicos: vazões afluentes e efluentes ao lago;

- Dados meteorológicos: os quais podem contemplar medidas de radiação solar, precipitação, velocidade do vento e/ou direção do vento, umidade relativa e temperatura do ar;

- Dados morfométricos: batimetria do lago;

Dessa maneira, a base de dados a ser formada para utilização na modelagem ecológica torna-se vasta e complexa devido à variedade da tipologia das informações. Tem-se, ainda, a necessidade de análise da consistência dos dados brutos, que demanda mais tempo, contudo é fundamental para reduzir os erros e incertezas na utilização da modelagem. 


\subsection{HISTÓRICO DE QUALIDADE AMBIENTAL DO LAGO PARANOÁ}

Após dez anos de sua criação, no início da década de 1970, o lago Paranoá evidenciava degradação da qualidade da água, que se iniciou pela não retirada de cobertura vegetal antes do enchimento do reservatório (Burnett et al., 2001). Em 1975, constatou-se que a principal causa de poluição do Lago era o lançamento de esgotos brutos ou inadequadamente tratados.

O ambiente apresentou processo de eutrofização desde o início de 1970 até meados dos anos 90, tendo seu maior desastre ecológico caracterizado pela floração da espécie de cianobactéria Microcystis aeruginosa em 1978, o qual levou a anoxia de toda coluna d'água e mortandade de peixes. A caracterização dessa espécie como a mais problemática no Lago e a conclusão de uma série de estudos limnológicos apontou o fósforo como fator limitante ao seu crescimento e direcionaram-se para soluções que buscassem a redução de seu aporte ao lago (Burnett et al., 2001).

Segundo Pires (2004), dois marcos principais resultaram em melhorias significativas da qualidade da água do lago Paranoá. O primeiro deles foi a entrada em operação das ETEs Brasília Sul e Brasília Norte, ampliadas e modificadas para tratamento terciário, com vistas à remoção de nutrientes, em 1993 e 1994, respectivamente, juntamente com a interligação dos sistemas de esgotamento sanitário da bacia do Riacho Fundo que antes lançavam resíduos sem tratamento ou com tratamento insuficiente nos corpos d'água.

O segundo foi o deplecionamento do lago feito no fim de 1998, que se assemelhou a uma descarga do reservatório. A melhoria da qualidade da água do Lago com essa operação levou à modificação do esquema operacional anual da UHE do Paranoá a partir de então. O propósito de tal operação é reduzir o nível d'água do lago ao fim do período seco, formando-se um volume de espera para o recebimento das águas de chuvas e garantir o maior volume possível no fim do período chuvoso, assegurando-se uma defluência mínima na estiagem subsequente. Aumenta-se, assim, a renovação e circulação das águas do lago. 
Ainda no estudo de Pires (2004), uma análise da redução da concentração de fósforo na água permitiu concluir que a resposta do lago às medidas de controle do aporte de nutriente foi lenta. Para os braços do Riacho Fundo e do Bananal, os mais críticos, a maioria dos valores ficaram abaixo de $40 \mathrm{mg} / \mathrm{m}^{3}$ somente a partir de 2000. Já os braços do Gama e do Torto e a zona central, menos afetados pelos impactos da ocupação e das atividades urbanas, apresentam a maior parte dos valores abaixo do limite de acordo com a legislação desde 1995/1996, sendo os valores consistentemente inferiores a 25 $\mathrm{mg} / \mathrm{m}^{3}$ de 1999 em diante. A autora infere que o deplecionamento feito em 1998 e a posterior modificação da regra operativa do Lago, por sua vez, resultaram em drástica queda das densidades do fitoplâncton e concentração de clorofila- $a$ e na manutenção desses valores baixos.

Hoje, o lago apresenta-se, geralmente, como mesotrófico e com bons indicadores de qualidade da água. Mendonça-Galvão (2005) dá informações sobre o processo de oligotrofização do lago Paranoá e enfatiza as mudanças ocorridas nas comunidades aquáticas. Já Souza (2013) avaliou a aplicabilidade de índices de integridade biótica do fitoplanctôn para estimar a qualidade da água nos lagos Paranoá e Descoberto, Distrito Federal. A autora concluiu que os índices evidenciaram diferenças entre ambientes distintos, bem como a evolução na qualidade da água ao longo do tempo, contudo os índices não foram eficientes para comprovar alterações dentro do mesmo corpo d'água.

O estudo de Liporoni (2012) simulou a qualidade da água no lago Paranoá por meio do modelo CE-QUAL-W2, contudo sem calibrar os parâmetros relacionados a esse módulo. $\mathrm{O}$ autor conclui que se tratou de um primeiro exercício acadêmico utilizando o referido modelo no Lago e então analisou seu desempenho nas simulações realizadas. 


\section{METODOLOGIA}

Em consideração aos objetivos propostos e à revisão bibliográfica apresentada, o presente capítulo foi dividido nas seguintes seções que correspondem às etapas da metodologia: Área de estudo; Base de dados para o desenvolvimento do estudo; Seleção do modelo ecológico de simulação; Definição das condições de contorno e utilização da base de dados; Análise de sensibilidade e calibração do GLM; Análise de sensibilidade e calibração do módulo ecológico - AED (módulo de fitoplâncton), Simulação das variáveis de qualidade da água e Simulação do cenário de eutrofização.

\section{1 ÁREA DE ESTUDO}

O objeto de estudo do presente trabalho é o lago Paranoá, um reservatório localizado no DF com área superficial de $37,50 \mathrm{~km}^{2}$ e volume total de $498 \times 10^{6} \mathrm{~m}^{3}$, à cota 1000 metros (Ferrante et al., 2001).

Segundo a classificação climática de Köppen, o DF está localizado em área de predominância do clima tropical úmido (AW), coexistindo clima tropical (Aw) e temperado úmido (Cwb). O clima tropical úmido é caracterizado por uma estação chuvosa no verão e uma estação seca no inverno, com média de precipitação maior que $1.100 \mathrm{~mm}$ por ano.

Dessa forma, dois períodos distintos são bem caracterizados: uma estação seca bem definida no inverno, em geral de abril a setembro, e estação chuvosa no verão, de outubro a março (GDF, 2010; GDF, 2012). De acordo com o Instituto Nacional de Meteorologia - INMET (2009), as normais da estação climatológica Brasília, operada pelo INMET, no período de 1961 a 1990, mostram a distinção de períodos, estando os meses de maio a agosto com precipitações abaixo de $50 \mathrm{~mm}$, e de novembro a fevereiro acima de $200 \mathrm{~mm}$ (Figura 4-1).

Segundo a Figura 4-2, em relação à temperatura do ar, as normais de temperatura média indicam temperaturas mais baixas podendo chegar a $19^{\circ} \mathrm{C}$ nos meses de junho e julho, período de inverno, e altas temperaturas na primavera e no verão, com média máxima acima de $22^{\circ} \mathrm{C}$ em setembro. 


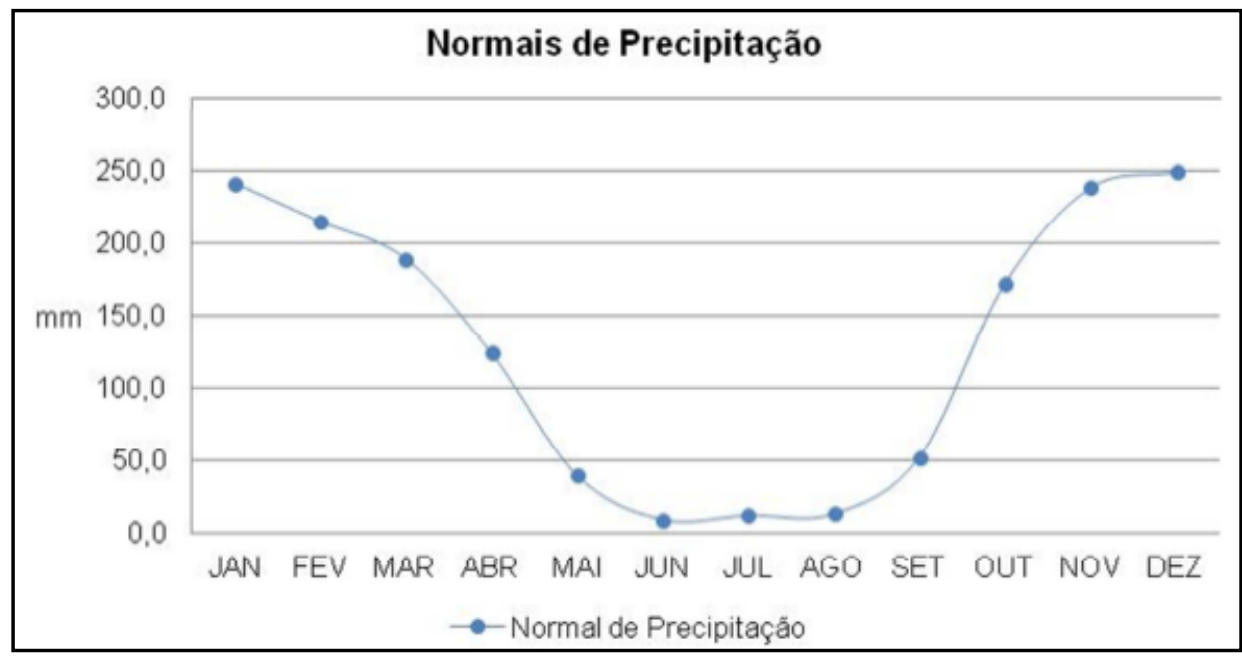

Figura 4-1-Normais de precipitação de 1961 a 1990, em mm, na estação Brasília (INMET, 2009).

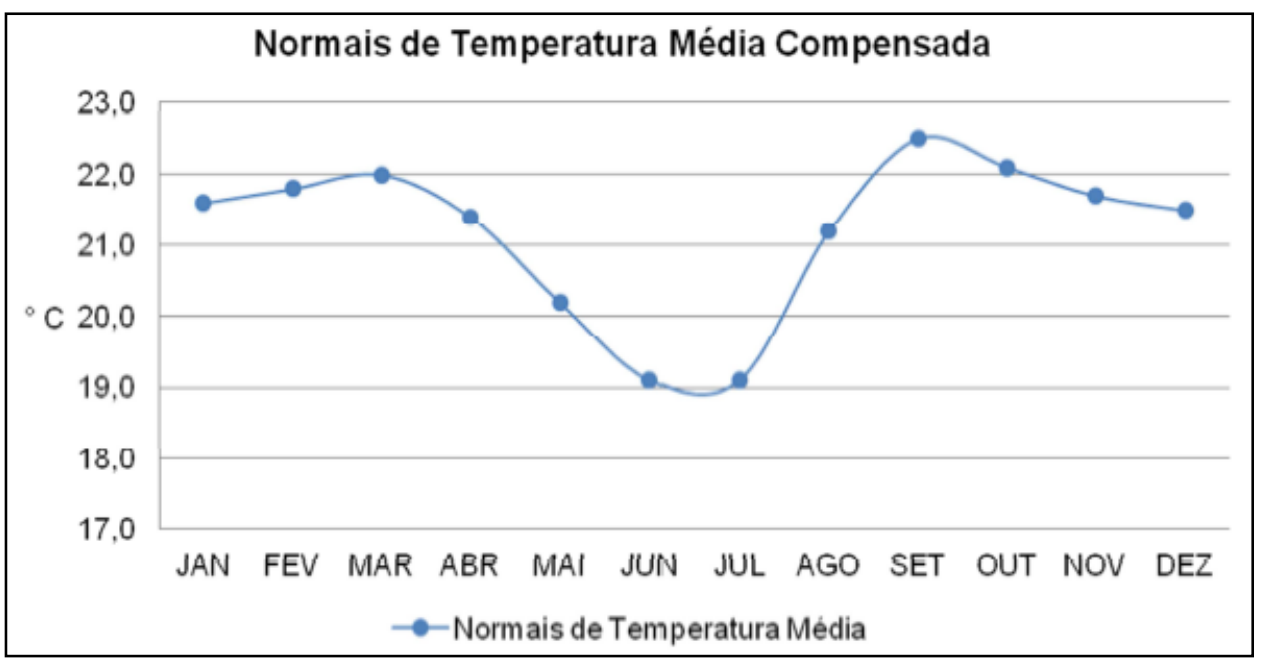

Figura 4-2 - Normais de temperatura média do ar de 1961 a 1990 , em ${ }^{\circ} \mathrm{C}$, na estação Brasília (INMET, 2009)

O Distrito Federal possui uma área de $5.789,16 \mathrm{~km}^{2}$ e sua região é drenada por cursos d'água pertencentes a três regiões hidrográficas, são elas: Tocantins/Araguaia, que, no DF, abrange a bacia do rio Maranhão, englobando praticamente toda a região norte do território; São Francisco, formada pela bacia do rio Preto, que delimita o território do DF a leste; e Paraná, responsável pela maior área drenada, constituída pelas bacias hidrográficas do rio São Bartolomeu, São Marcos, Corumbá, Descoberto (que delimita o território do DF a oeste) e lago Paranoá. Essas bacias abrangem 40 unidades hidrográficas de gerenciamento (Ferrante et al., 2001). 
A bacia do lago Paranoá está integralmente localizada no território do Distrito Federal. Isso possibilita uma gestão facilitada sobre os mananciais que abastecem o Lago. A bacia possui uma área total de 1.034,07 $\mathrm{km}^{2}$ (Pires, 2004) e é formada pelas unidades hidrográficas: córrego Bananal, Riacho Fundo, ribeirão do Gama, ribeirão do Torto e lago Paranoá (Figura 4-3).

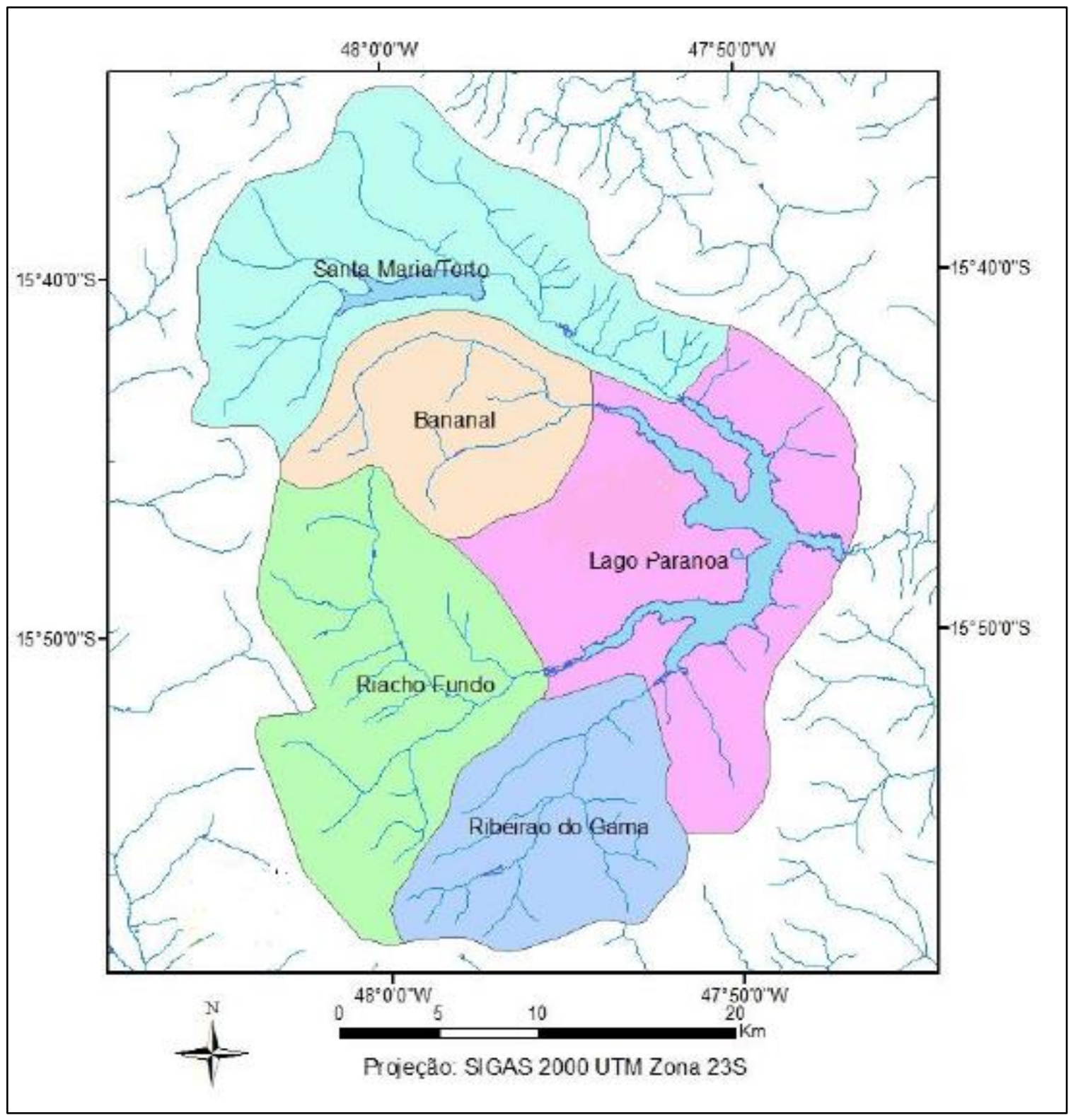

Figura 4-3: Unidades Hidrográficas da bacia do lago Paranoá. Adaptado de Souza (2014).

1. Unidade Hidrográfica do Bananal

Constituída pelo ribeirão Bananal, córrego Acampamento e outros pequenos córregos. É onde está localizada parte da unidade de conservação conhecida como Parque Nacional 
de Brasília, o que garante uma boa qualidade das águas do ribeirão Bananal. O Ribeirão possui uma extensão de 19,1 km e deságua diretamente no lago Paranoá, com uma vazão média de 2,4 m³/s (Ferrante et al., 2002; Pires, 2004; Souza, 2013).

\section{Unidade Hidrográfica do Riacho Fundo}

Os principais afluentes do ribeirão Riacho Fundo são: córrego Vicente Pires e Guará, pela margem esquerda, e córrego Coqueiros pela margem direita. Apresenta uma vazão média de 4,04 m³/s. Na sub-bacia do riacho Fundo ocorre degradação dos solos, movimentações de terra e forte urbanização, provocando um aporte substancial de sedimentos ao lago, comprovado pelo assoreamento observado no braço do lago Paranoá que recebe a contribuição dessa unidade (Ferrante et al., 2002; Pires, 2004; Souza, 2013).

\section{Unidade Hidrográfica do Gama}

O ribeirão Gama tem como principais afluentes os córregos Mato Seco e Cedro, na margem esquerda, e Capetinga e Taquara, na margem direita. Deságua diretamente no lago Paranoá, com uma vazão média de $2,9 \mathrm{~m} 3 / \mathrm{s}$. O Ribeirão apresenta áreas preservadas, com os seus tributários, os córregos Roncador, Taquara e Capetinga, atravessando o Jardim Botânico, a Reserva Ecológica do IBGE e a Fazenda Experimental da UnB, respectivamente (Ferrante et al., 2002; Pires, 2004; Souza, 2013).

4. Unidade Hidrográfica do Torto/Santa Maria

Essa unidade é formada pelos córregos Milho Cozido e Vargem Grande, afluentes do Santa Maria que, por sua vez, é afluente do córrego Três Barras e esse, após sua confluência com o ribeirão Tortinho, forma o ribeirão do Torto que desemboca diretamente no lago Paranoá com uma vazão média de $2,1 \mathrm{~m}^{3} / \mathrm{s}$. É onde se localiza a outra parte do Parque Nacional de Brasília.

\section{Unidade Hidrográfica do Lago Paranoá}

Essa funciona como bacia de captação dos principais cursos d'água que drenam a área urbana de Brasília. É constituída pelo lago Paranoá e por áreas de drenagens de córregos pequenos que afluem direto no lago: Taquari, Gerivá, Palha, Cabeça de Veado, Canjerana e Antas (Ferrante et al., 2002; Pires, 2004; Souza, 2013). 
Em relação à qualidade da água, como se trata da bacia com a maior ocupação humana, onde estão situadas, além da cidade de Brasília, as cidades do entorno do Núcleo Bandeirante, Riacho Fundo I e II, Guará I e II, Setor Habitacional Lúcio Costa, Águas Claras, Cruzeiro, Setor Sudoeste e Lagos Sul e Norte, os principais problemas são relacionados à disposição dos esgotos domésticos e à impermeabilização das superfícies de infiltração. Têm-se, ainda, problemas com a poluição difusa advinda da drenagem urbana lançada no lago (Costa, 2013; Souza, 2014).

Quanto à morfologia, o Lago apresenta formato dendrítico, bem compartimentado, recebendo seus afluentes em diferentes pontos. Nos braços, a profundidade pode variar de 5 a 20 metros e na região central apresenta profundidades maiores que 20 metros (Souza, 2013). O tempo de residência nos braços é maior que no centro do Lago e os tributários que chegam a cada braço apresentam características distintas em relação à qualidade da água, pelos diferentes graus de conservação das microbacias, da densidade populacional e usos do solo e dos recursos hídricos (Machado, 2004; Souza, 2013).

O uso e ocupação do solo predominantes na sub-bacia do lago Paranoá são: área urbana e solo exposto (Echeverria, 2007). As sub-bacias do Bananal, Santa Maria/Torto e Gama são as mais preservadas, pois encerram em seus limites áreas de proteção permanentes como o Parque Nacional, a Reserva do Instituto Brasileiro de Geografia e Estatística - IBGE e o Jardim Botânico, contudo a forte pressão imobiliária nas suas áreas tampões já inicia um processo de degradação ambiental (GDF, 2010).

Na Figura 4-4 são apresentadas as estações de monitoramento de qualidade da água da Companhia de Saneamento Ambiental do Distrito Federal (CAESB), escolhidas de acordo com suas características hidrológicas. O Lago pode ser assim dividido em cinco braços, os quais encerram em seus limites cinco estações de monitoramento, denominadas, respectivamente, A, B, C, D e E (CAESB, 2005). 


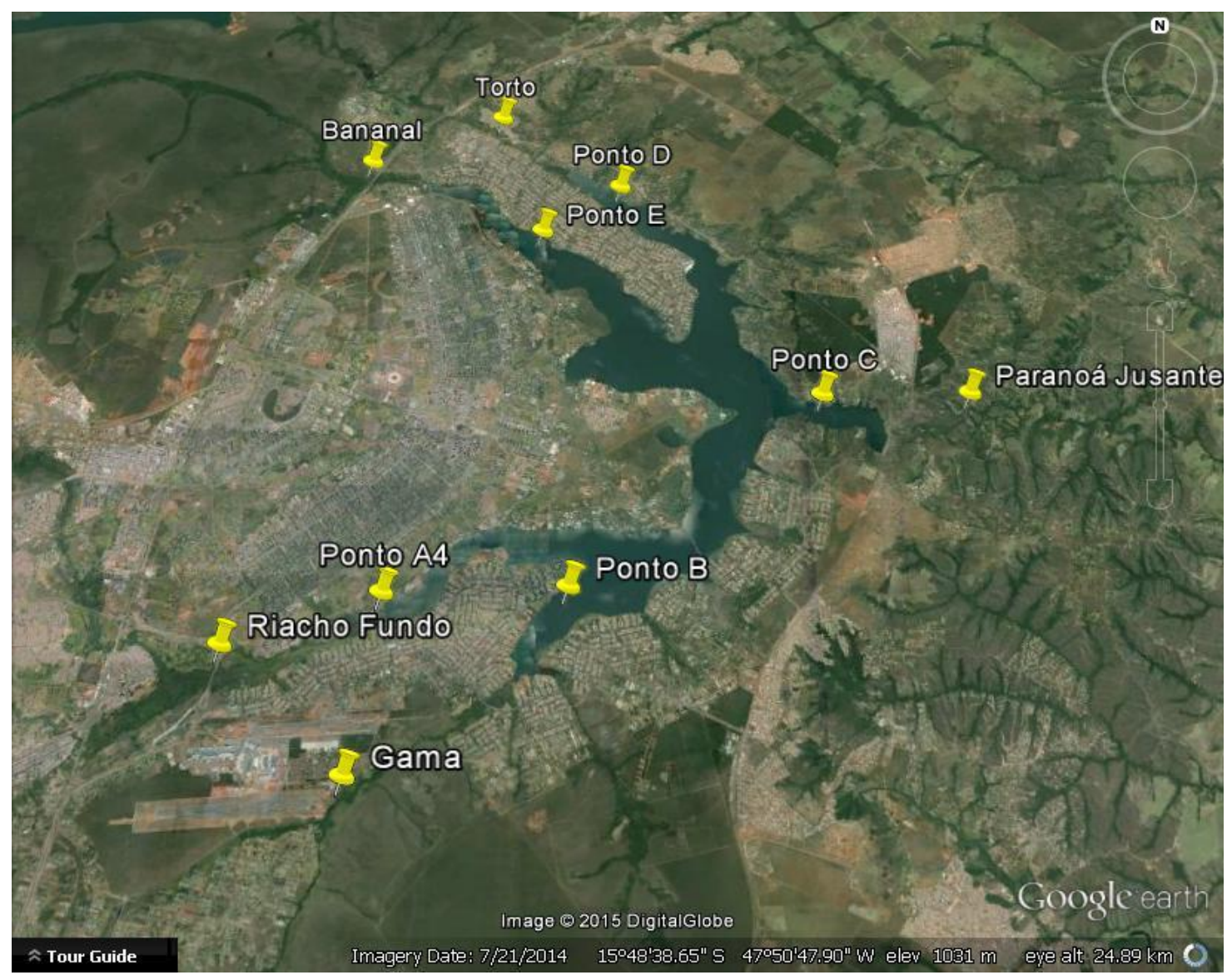

Figura 4-4: Divisão em segmentos do Lago Paranoá e respectivos tributários. Fonte:

Google Earth (2015).

\subsection{BASE DE DADOS PARA O DESENVOLVIMENTO DO ESTUDO}

A base de dados para o desenvolvimento do estudo foi formada pela aquisição de dados hidrológicos, meteorológicos, morfométricos, limnológicos e de qualidade da água provenientes de diferentes Órgãos, como CAESB, INMET, INPE - Instituto Nacional de Pesquisas Espaciais e CEB - Companhia Energética de Brasília.

Os dados de qualidade da água e vazão nos afluentes foram oriundos do programa de monitoramento da Companhia de Saneamento Ambiental do Distrito Federal - CAESB realizado desde 1976. A base de dados contemplou medições de temperatura da água, transparência, cor, turbidez, sólidos suspensos, sólidos dissolvidos totais, $\mathrm{pH}$, condutividade, alcalinidade, cloreto, ferro total, cobre, alumínio, OD, demanda bioquímica de oxigênio (DBO), demanda química de oxigênio (DQO), fosfato, fósforo total, nitrato, nitrito, nitrogênio total, clorofila-a, fitoplâncton, zooplâncton e $e$. Coli no período de 1976 a 2010. O monitoramento da qualidade de água é realizado com 
frequência mensal e as medidas de vazão nos tributários e na barragem com frequência diária.

Os dados de vazão na barragem, que corresponderam à vazão de saída no Lago, foram fornecidos pela CEB. O período disponibilizado foi de 1978 a 2011.

Em relação aos dados de fitoplâncton, os resultados das contagens fornecidos pela CAESB foram em indivíduos por litro (Ind/L) e biomassa $(\mathrm{mg} / \mathrm{L})$. A descrição das estações de amostragem de monitoramento realizado pela CAESB no lago Paranoá são dadas na Tabela 4-1.

Tabela 4-1: Descrição das estações de monitoramento da CAESB no lago Paranoá. Adaptado de Souza (2013).

\begin{tabular}{ccccc}
\hline Estações & Referência & $\begin{array}{c}\text { Coordenadas } \\
\text { Geográficas } \\
\text { Sul }\end{array}$ & $\begin{array}{c}\text { Coordenadas } \\
\text { Geográficas } \\
\text { Oeste }\end{array}$ & Profundidade de coleta \\
\hline A4 & $\begin{array}{c}\text { Ponte do Gilberto } \\
\text { Salomão }\end{array}$ & 155019.1 & 475357.2 & 1 metro da superfície \\
B & $\begin{array}{c}\text { Parque da QL 14 } \\
\text { (ultraleve) }\end{array}$ & 155014.6 & 475131.3 & 1 metro \\
& Área Central & 154730.9 & 474800.8 & Superfície*; 1, \\
C & & & & 10,15, \\
D & $\begin{array}{c}\text { Entrada do ribeirão } \\
\text { do Torto }\end{array}$ & 154402.8 & 475050.0 & metro do fundo \\
& $\begin{array}{c}\text { Clube Minas } \\
\text { Brasília }\end{array}$ & 154450.0 & 475159.6 & 1 metro \\
\hline
\end{tabular}

*Somente de 09/2009 a 08/2010

Os dados hidrometeorológicos foram obtidos junto ao INMET e INPE para a Estação Brasília que se localiza a $15^{\circ} 36^{\prime} 03^{\prime \prime S}$ e $47^{\circ} 42^{\prime} 47^{\prime \prime O}$ (Figura 4-5). Os dados do INMET corresponderam ás variáveis de precipitação e radiação de ondas curtas com medidas horárias de maio/2000 a dezembro/2011 e temperatura do ar e velocidade do vento com medidas diárias de agosto/1961 a dezembro/2011. Já o INPE, por meio da rede SONDA (Sistema de Organização Nacional de Dados Ambientais), disponibiliza o acesso aos 
dados na rede. Dessa forma, foram coletados os dados de ondas longas, ondas curtas, temperatura do ar, umidade relativa, velocidade do vento e precipitação com medições minuto a minuto disponíveis de junho/2004 a novembro/2014.

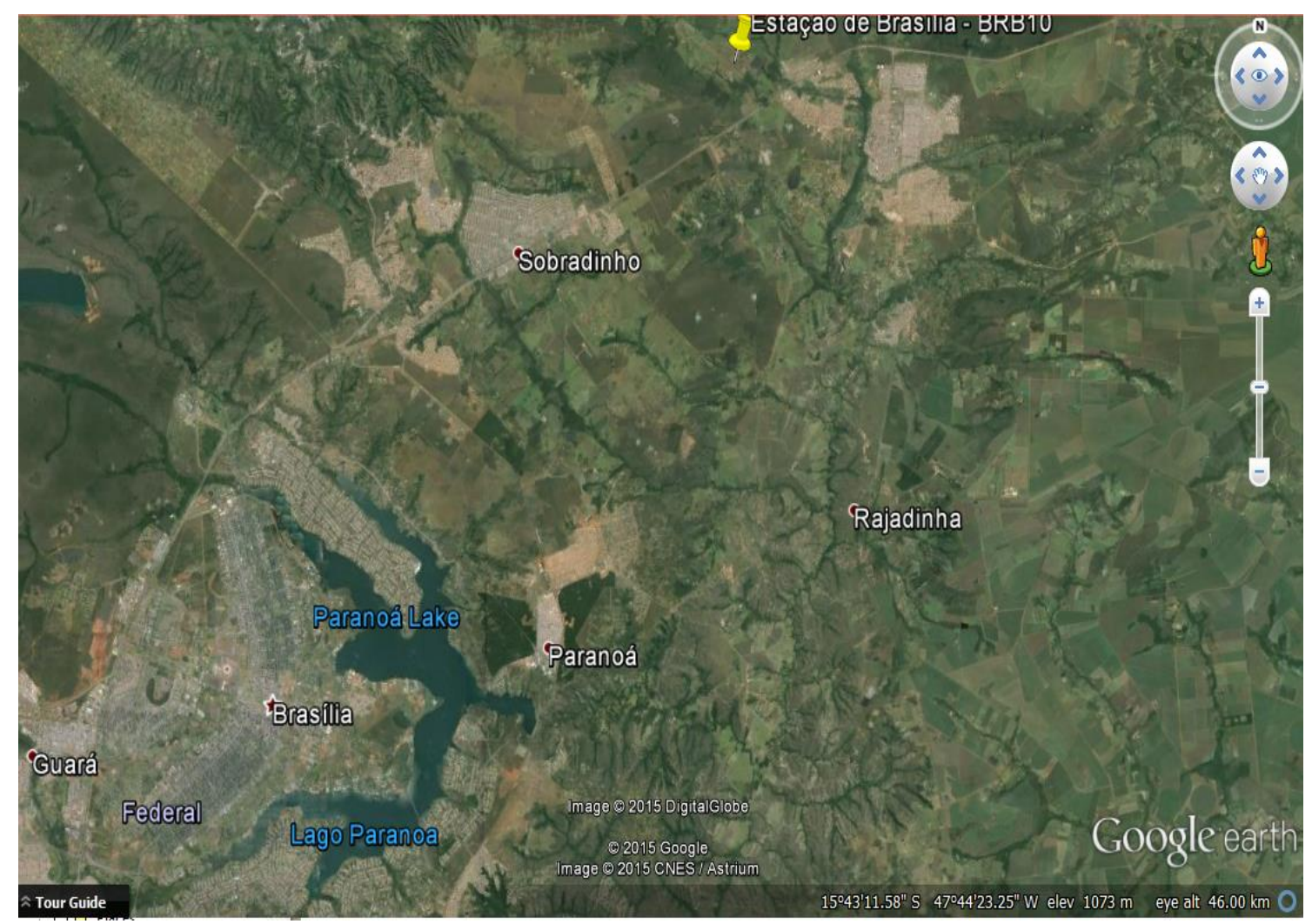

Figura 4-5: Localização da Estação Meteorológica Brasília. Fonte: Google Earth (2015).

Os dados de batimetria relativos à cota, área e volume do Lago foram provenientes do Relatório de Levantamentos Batimétricos e Sedimentométricos do lago Paranoá (CAESB, 2003) e arquivos em formato AutoCAD® disponibilizados pela CAESB. A Figura 4-6 apresenta o mapa do perfil batimétrico do lago Paranoá. 


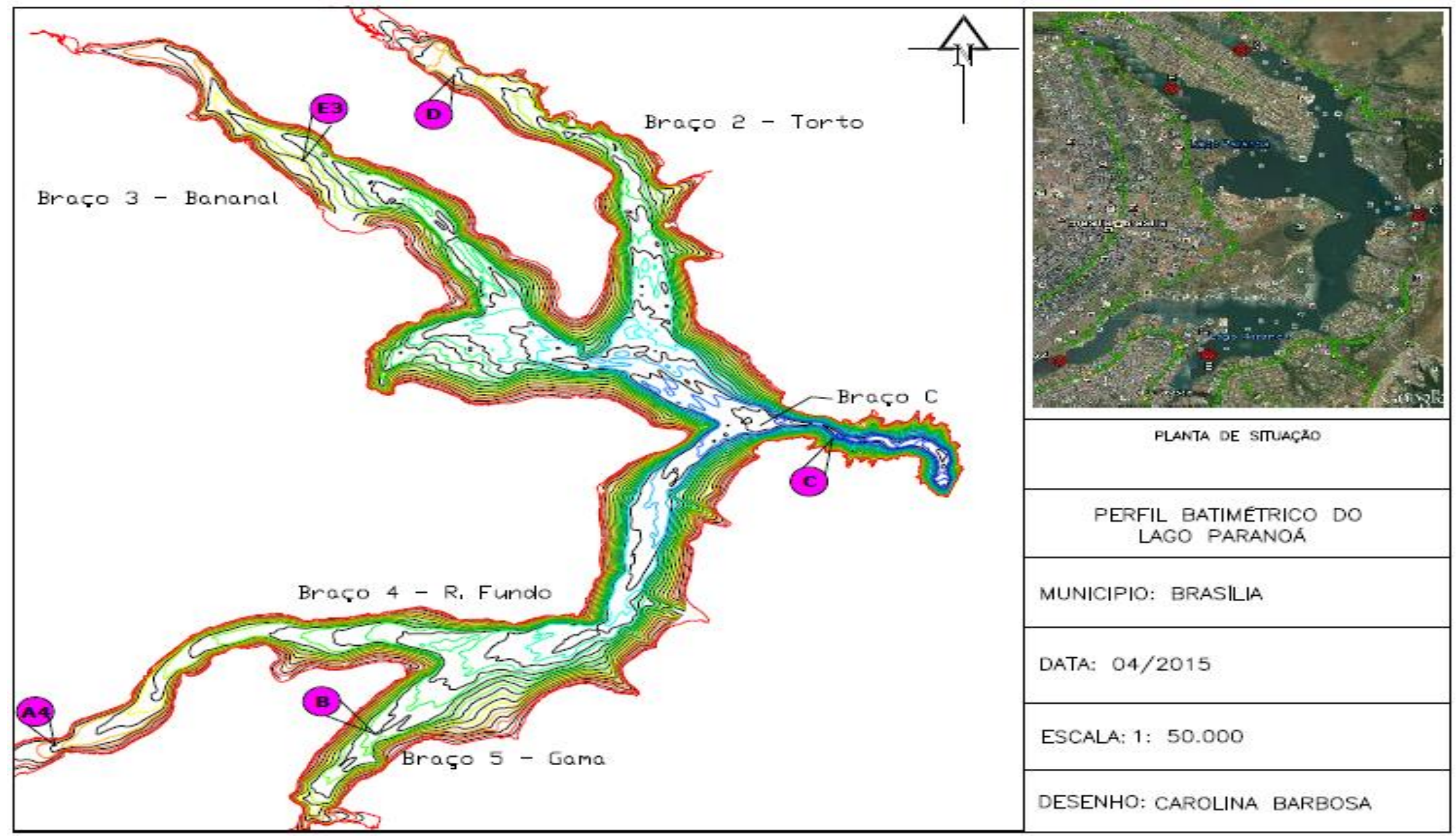

Figura 4-6: Representação do perfil batimétrico do lago Paranoá. Adaptado de CAESB (2003). 


\subsection{SELEÇÃO DO MODELO ECOLÓGICO DE SIMULAÇÃO}

Para a seleção do modelo ecológico, foi realizado levantamento bibliográfico no portal de periódicos CAPES e em periódicos indexados da área como Ecological Modelling e Hydrobiologia. As palavras-chave para a busca foram: ecological modelling, water quality, biological indicators, lakes/reservoirs, food webs, phytoplankton. A busca foi efetuada para os artigos publicados após o ano 2000 até o momento.

Para a análise dos modelos disponíveis, foram utilizados os seguintes critérios:

- Possibilitar a simulação da comunidade fitoplanctônica como variável principal;

- Modelo unidimensional na vertical, preferencialmente;

- Ferramenta de livre acesso (download acessível à comunidade);

- Dados de entrada requeridos minimamente compatíveis com os dados disponíveis para o lago Paranoá/DF.

Os quatro critérios para seleção levavam em conta os objetivos propostos no presente estudo, à base de dados formada e um maior detalhamento do Lago ao longo da coluna d'água.

Foram encontrados diversos artigos com aplicação de diferentes modelos ecológicos, sendo esses, muitas vezes, desenvolvidos unicamente para os estudos em questão e, dessa forma, não disponíveis na rede. Dentre os que mais evidenciavam aplicação em estudos de caso e atendiam a maior parte dos critérios estabelecidos, destacaram-se os modelos: SALMO-OO e DYRESM/CAEDYM. Contudo, os dois modelos não se encontravam disponíveis na rede.

Optou-se, então, pelo modelo GLM-AED, apesar de poucas publicações com sua utilização, em virtude de ser um modelo unidimensional, de livre acesso (software livre) e seguir a tendência em acoplar hidrodinâmica e ecologia. Trata-se de um modelo novo que foi desenvolvido pelo mesmo grupo que idealizou o modelo DYRESM/CAEDYM que tem sido aplicado na maioria dos estudos com simulações em lagos (Schladow e Hamilton, 1997; Gal et al., 2003; Trolle et al., 2008; Gal et al., 2009; Rigosi et al., 2011; Rigosi e Rueda, 2012b), tendo dessa maneira muitos fundamentos e equações em comum. 


\subsubsection{Descrição do modelo GLM-AED}

O modelo GLM-AED acopla um modelo hidrodinâmico (GLM) com a biblioteca de módulos ecológicos (AED). A descrição, a seguir, será realizada separadamente para os dois módulos.

O GLM é um modelo hidrodinâmico unidimensional que calcula perfis verticais de temperatura, salinidade e densidade pela representação dos efeitos dos fluxos de entrada e saída, mistura, aquecimento e resfriamento da superfície, e também inclui o efeito da cobertura de gelo no aquecimento e mistura do lago (Hipsey et al., 2014). As principais características são dadas na Tabela 4-2 e os parâmetros do modelo são dados na Tabela 4-3, que não inclui os parâmetros relacionados à neve e ao gelo, por não serem influentes na região em estudo. A descrição do GLM e do AED, que se segue, foi baseada na visão geral e documentação para o usuário de Hipsey et al. (2014) e Hipsey et al. (2013), respectivamente.

Tabela 4-2: Principais características do modelo GLM. Adaptado de Yao et al. (2014) Camadas flexíveis, variando com os fluxos

Divisão das camadas de água de água e fluxos de massa e mistura, por decisão do modelo.

Requerimento de dados

Sim

Temperatura do ar, umidade, cobertura de

Dados de entrada nuvens, vento, radiação solar, radiação de ondas longas, pluviosidade, queda de neve e vazões afluentes e efluentes.

O GLM incorpora uma estrutura de camadas de Lagrange flexível semelhante ao modelo DYRESM. Muitos dos algoritmos de aquecimento e de mistura do modelo foram baseados em equações apresentadas por Hamilton e Schladow (1997) para o DYRESM/CAEDYM, o que permite que as camadas possam alterar sua espessura por contração e expansão. 
Tabela 4-3: Sumário de parâmetros físicos do GLM com valores padrão. Adaptado de Hipsey et al., 2014.

\begin{tabular}{|c|c|c|c|}
\hline Símbolo & Descrição & Unidades & Valor padrão \\
\hline \multicolumn{4}{|c|}{ Estrutura do modelo } \\
\hline$h_{\min }$ & Espessura mínima da camada & M & 0.5 \\
\hline$h_{\max }$ & Espessura máxima da camada & M & 1.5 \\
\hline \multicolumn{4}{|c|}{ Propriedades do lago } \\
\hline$K_{W}$ & Coeficiente de extinção da radiação de ondas curtas & $m^{-1}$ & 0.2 \\
\hline$A_{c}$ & Área crítica & $\mathrm{m}^{2}$ & $10^{7}$ \\
\hline \multicolumn{4}{|c|}{ Parâmetros relacionados a termodinâmica superficial } \\
\hline$C_{D}$ & Coeficiente aerodinâmico para transferência de momento & - & 0.0013 \\
\hline$C_{W}$ & Coeficiente aerodinâmico de massa para transferência de calor sensível & - & 0.0013 \\
\hline$C_{E}$ & Coeficiente aerodinâmico de massa para transferência de calor latente & - & 0.0013 \\
\hline $\mathrm{E}$ & Emissividade da água superficial & - & 0.985 \\
\hline$\Sigma$ & Constante de Stefan-Boltzmann & $\mathrm{W} m^{-2} k^{-4}$ & $5.6697 e^{-8}$ \\
\hline \multicolumn{4}{|c|}{ Parâmetros relacionados à mistura vertical } \\
\hline$c_{K}$ & Eficiência da mistura- agitação & - & 0.2 \\
\hline$C_{S}$ & Eficiência da mistura - cisalhamento & - & 0.3 \\
\hline$C_{T}$ & Eficiência da mistura - exigência cinética & - & 0.51 \\
\hline$C_{w}$ & Eficiência de mistura - agitação do vento & - & 0.23 \\
\hline$C_{H Y P}$ & Eficiência de mistura da turbulência hipolimnética & -- & 0.5 \\
\hline$C_{K H}$ & Eficiência de mistura - ondas turbulentas de Kelvin-Helmholtz & - & 0.3 \\
\hline \multicolumn{4}{|c|}{ Parâmetros relacionados ao fluxo de entrada e saída } \\
\hline $\mathrm{C}$ & Nível de arrasto da afluência & & 0.016 \\
\hline G & Velocidade máxima de retirada & $\mathrm{m} d^{-1}$ & 0 \\
\hline
\end{tabular}


A formulação de camadas de Lagrange evita a necessidade de calcular velocidades verticais, diminuindo consideravelmente o tempo computacional e minimizando a difusão numérica. Cada camada é homogênea, as diferenças de propriedade entre as camadas representam a distribuição vertical e as espessuras das camadas são ajustadas dentro do modelo de acordo com a resolução necessária para representar o gradiente de densidade vertical.

Com relação aos fluxos superficiais, o modelo representa os fluxos de momento, calor sensível e calor latente. A radiação de ondas longas pode ser especificada como fluxo líquido ou fluxo de entrada.

O fluxo de entrada pode ser especificado diretamente ou calculado pelo modelo com base na fração de cobertura de nuvens e temperatura do ar. Além do fluxo superficial de energia, o modelo explicita os fluxos de massa de evaporação, chuva e queda de neve (novamente enfatiza-se que os algoritmos para gelo e neve não serão especificados nesse estudo visto que não são necessários em regiões tropicais).

Em relação à mistura vertical, tem-se a premissa de que o equilíbrio entre a energia disponível, $E_{T K E}$ e a energia necessária para submeter-se a mistura, $E_{P E}$, fornece uma equação para a taxa de aprofundamento da camada de mistura superficial: $\frac{d_{h m i x}}{d t}$. O modelo calcula a energia cinética disponível devido à agitação do vento, à produção de cisalhamento entre as camadas, à reviravolta convectiva e à constante ondulatória de Kelvin-Helmholtz. O modelo calcula, assim, o primeiro desses argumentos de energia e, em seguida, percorre as camadas da parte superior para a parte inferior até que haja energia suficiente disponível até a i-ésima camada.

Quanto aos fluxos de entrada e saída, esses são variáveis sub-diárias, ou seja, considerados mais de uma vez por dia. Todas as equações de fluxo superficial, mistura vertical e fluxos de afluentes e efluentes para o modelo GLM estão apresentadas no Apêndice A. 
O modelo gera como resultados um arquivo em formato NETCDF, o qual contém matrizes de todas as variáveis simuladas e um arquivo que estima o balanço hídrico no lago.

Os módulos AED permitem que os componentes individuais do modelo possam ser configurados para representar as configurações do ecossistema aquático. Cabe aos usuários selecionar os módulos que lhe interessam na simulação e então habilitá-los para personalizar conexões com outros módulos (Figura 4-7). Em geral, são considerados os componentes de ciclagem de carbono, nitrogênio, fósforo e outros componentes como oxigênio, matéria orgânica e organismos que incluem diferentes filos do fitoplâncton e do zooplâncton.

Como esse estudo considera o fitoplâncton como principal variável de interesse, foi dada maior importância ao módulo de dinâmica do fitoplâncton no AED.

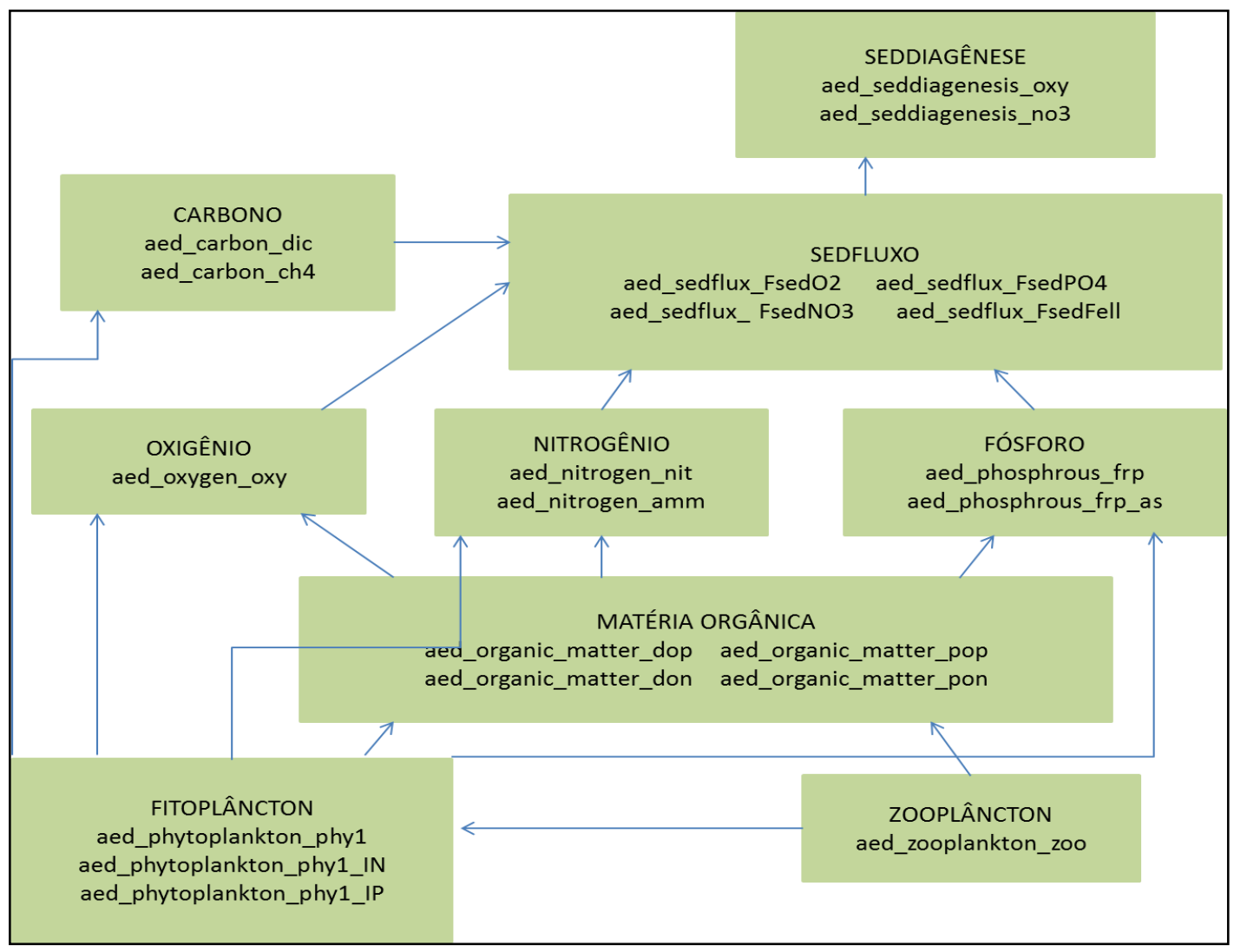

Figura 4-7: Exemplo das conexões entre os módulos AED e as variáveis dos módulos. Adaptado de Hipsey et al. (2013). 
A biomassa do fitoplâncton de um dado grupo é simulada em unidades de carbono (mmol $\mathrm{C} \mathrm{m}^{-3}$ ), e o grupo pode ser configurado para ter uma relação C:N:P constante, ou absorção dinâmica de $\mathrm{C}: \mathrm{N}: \mathrm{P}$ em resposta às mudanças da coluna de água e processos intracelulares. O módulo inclui até três taxa do fitoplâncton, são eles: Bacillariophycea, Chlorophyta e Cyanophyta. Nesse estudo, foram levados em conta apenas os dois últimos taxa, Chlorophyta e Cyanophyta. Para cada grupo do fitoplâncton, a taxa de crescimento potencial máximo, à $20{ }^{\circ} \mathrm{C}$, é multiplicada pelo valor mínimo das expressões de limitação pela luz, fósforo e nitrogênio.

Em termos de perda por respiração, mortalidade natural e excreção, essas são modeladas com um único coeficiente de taxa de 'respiração'. A dinâmica de fósforo e nitrogênio internos dentro dos grupos do fitoplâncton pode ser modelada usando armazenamentos intracelulares dinâmicos que são capazes de regular o crescimento.

A Tabela 4-4 apresenta um sumário descritivo dos parâmetros do fitoplâncton, unidades e valores típicos. Não são incluídos os parâmetros de salinidade e sílica na tabela: a salinidade por não exercer influência na área de estudo e a sílica por não ser medida no monitoramento de qualidade da água realizado pela CAESB e dessa maneira não estar presente na base de dados formada. 
Tabela 4-4: Sumário descritivo dos parâmetros do fitoplâncton, unidades e valores típicos. Fonte: Hipsey et al.(2013).

\begin{tabular}{|c|c|c|c|c|c|}
\hline Parâmetro & Descrição & Unidades & Diatomáceas & Cianofíceas & Cianobactérias \\
\hline$R_{\text {grouth }}^{P H Y}$ & Taxa de crescimento do fitoplâncton a $20^{\circ} \mathrm{C}$ & $/ \mathrm{d}$ & 3.0 & 0.9 & 1.0 \\
\hline $\bar{I}_{K}$ & Constante de semi-saturação de luz para limitação de algas & $\mu \mathrm{Em}^{-2} s^{-1}$ & 60 & 80 & 130 \\
\hline$I_{5}$ & Intensidade de saturação da luz & $\mu \mathrm{E} m^{-2} s^{-1}$ & 150 & 150 & 150 \\
\hline$\theta_{\text {growth }}^{P H Y}$ & Escala de temperatura de Arrenhius para crescimento & - & 1.06 & 1.06 & 1.06 \\
\hline$T_{\text {std }}$ & Temperatura padrão & ${ }^{\circ} \mathrm{C}$ & 20 & 20 & 20 \\
\hline$T_{\text {opt }}$ & Temperatura ótima & ${ }^{\circ} \mathrm{C}$ & 25 & 27 & 28 \\
\hline$T_{\max }$ & Temperatura máxima & ${ }^{\circ} \mathrm{C}$ & 32 & 33 & 35 \\
\hline$R_{\text {resp }}^{P H Y}$ & Taxa de respiração do fitoplâncton a $20^{\circ} \mathrm{C}$ & $/ \mathrm{d}$ & 0.085 & 0.085 & 0.085 \\
\hline$k_{f Y Y S}^{P H Y}$ & Fração de perda metabólica pela respiração & - & 0.25 & 0.25 & 0.25 \\
\hline$k_{f d o m}^{P H Y}$ & Fração de perda metabólica pelo DOM & - & 0.2 & 0.2 & 0.2 \\
\hline$\theta_{\text {TESP }}^{\text {PHY }}$ & Escala da temperatura de Arrenhius para respiração & - & 1.12 & 1.05 & 1.05 \\
\hline$K_{\mathrm{N}}$ & Concentração de semi-saturação de nitrogênio & $\mathrm{mmol} \mathrm{N} / \mathrm{m}^{3}$ & 3.5 & 2.7 & 1.0 \\
\hline
\end{tabular}


Tabela 4-4: Sumário descritivo dos parâmetros do fitoplâncton, unidades e valores típicos. Fonte: Hipsey et al.(2012). (Continuação)

\begin{tabular}{|c|c|c|c|c|c|}
\hline$R_{\text {NUptake }}^{P H Y}$ & Taxa máxima de absorção de nitrogênio & $\mathrm{mmol} \mathrm{N} / \mathrm{m}^{3} / \mathrm{d}$ & & & \\
\hline$R_{\text {WWY }}^{P A Y}$ & Concentração mínima de nitrogênio interno & $\mathrm{mmol} \mathrm{N} / \mathrm{mmol} \mathrm{C}$ & & & \\
\hline$R_{\text {WMAX }}^{P H Y}$ & Concentração máxima de nitrogênio interno & $\mathrm{mmol} \mathrm{N} / \mathrm{mmol} \mathrm{C}$ & & & \\
\hline$\frac{\overline{1}}{K_{p}}$ & Concentração de semi-saturação de fósforo & $\mathrm{mmol} \mathrm{P} / \mathrm{m}^{3}$ & 0.15 & 0.07 & 0.05 \\
\hline$R_{\text {PUptake }}^{P H Y}$ & Taxa máxima de absorção de fósforo & $\mathrm{mmol} \mathrm{P} / \mathrm{m}^{3} / \mathrm{d}$ & & & \\
\hline$R_{P M W}^{P H Y}$ & Concentração mínima de fósforo interno & $\mathrm{mmol} \mathrm{P} / \mathrm{mmol} \mathrm{C}$ & & & \\
\hline$R_{P M A X}^{P H Y}$ & Concentração máxima de fósforo interno & $\mathrm{mmol} \mathrm{P} / \mathrm{mmol} \mathrm{C}$ & & & \\
\hline$\omega_{P H Y}$ & Taxa de sedimentação do fitoplâncton & $\mathrm{m} / \mathrm{d}$ & -0.86 & -0.01 & -0.02 \\
\hline
\end{tabular}




\subsubsection{Interface GLMr}

Muito recentemente, a GLEON desenvolveu funções, chamadas 'ferramentas' ou tools, que interagem com o GLM e os módulos AED em interface com o software R. Essas ferramentas chamadas 'glmtools' fazem a interação do GLM com o R e o criado 'pacote' (package) de base do modelo se chama GLMr.

O software R é um sistema de computação estatística e geração de gráficos que fornece, entre outras coisas, uma linguagem de programação e interfaces com outras linguagens (R Core Team, 2015). Read et al. (2014a) justifica a escolha do R para integrar o modelo devido a alguns fatores, entre os quais:

- Estabilidade e rapidez do software;

- Suporte de documentação, comunidade envolvida e desenvolvedores;

- Altamente reprodutível e hábil a disseminação à comunidade científica;

- Versatilidade: solução para problemas numéricos;

- Capacidades gráficas;

As 'glmtools' são funções que retornam algumas informações do modelo, fazem as simulações e, ainda, possuem métricas que comparam os dados simulados com os observados. Nessa versão, os módulos ecológicos provenientes do AED estão inclusos no $\mathrm{R}$ e, dessa maneira, não existe mais interligação com o FABM. Assim, o códigofonte permite somente configurar o modelo de qualidade da água com os módulos AED, chamados de AED2.

O GLMr é projetado para manter a versão mais atualizada do modelo e roda em qualquer plataforma (Linux, Mac e Windows). Porém, essa versão disponibiliza apenas o executável e as funções para o modelo. Assim sendo, deve-se obter a parte o códigofonte que está disponível na rede.

Pela versão do modelo em $\mathrm{R}$ ser mais rápida e possuir uma interface bem melhor $\mathrm{e}$ usual do que as versões anteriores do GLM-AED (tratado anteriormente como GLMFABM-AED, pois nas primeiras versões os módulos AED eram acoplados na biblioteca de modelos biogeoquímicos e ecológicos e componentes dos modelos - FABM), no 
presente estudo foi utilizada a versão GLMr para rodar o modelo GLM, gerar os resultados e analisá-los no conjunto das profundidades. Após, rodar os módulos AED e gerar os resultados. Foi utilizado o GLMr versão $2.0 \beta$ disponibilizado por Winslow e Read (2014), o qual ainda está em fase experimental.

\subsection{DEFINIÇÃO DAS CONDIÇÕES DE CONTORNO E UTILIZAÇÃO DA BASE DE DADOS}

O braço central foi considerado como a parte representativa do lago Paranoá, por ser o único com monitoramento dos parâmetros de qualidade da água realizado em várias profundidades (ponto C do monitoramento, Figura 4-6) e, dessa forma, propiciar uma observação do perfil dessas variáveis ao longo da coluna d'água. Ainda, por ter sua localização na região mais profunda do Lago. As profundidades amostradas pela CAESB no ponto C são: superfície, 1, 5, 10, 15 e 20 metros da superfície e a 1 metro do fundo. Já os demais pontos de amostragem (pontos A, B, D e E, Figura 4-4) possuem monitoramento somente a 1 metro da superfície.

Desse modo, o volume de controle considerado foi o braço central e consideraram-se as estações dos quatro braços como afluentes ao lago Paranoá. A vazão de saída da barragem considerou-se como efluente do Lago. Por essa razão, os dados de qualidade da água dos pontos de monitoramento da CAESB foram utilizados como dados de entrada no modelo e considerou-se como vazões de entrada a dos tributários de cada braço (ponto D, Torto; ponto E, Bananal; ponto A, Riacho Fundo; ponto B, Gama).

Os dados de qualidade da água dos efluentes das duas ETEs, que descarregam no lago Paranoá, foram fornecidos pela CAESB apenas por um período de dez anos (2000 a 2010). Como ainda, nesse período, houve a indisponibilidade de medição da temperatura do efluente, a qual é fundamental como input no modelo, as ETEs não foram consideradas como entrada no presente trabalho.

Em termos quantitativos, a não consideração das vazões das duas ETEs como entrada no Lago, não teria significativa influencia no que tange o balanço hídrico simulado. A capacidade de projeto das vazões dos efluentes das ETEs Brasília Sul e Norte, respetivamente, são $1,5 \mathrm{~m}^{3} / \mathrm{s}$ e $0,92 \mathrm{~m}^{3} / \mathrm{s}$ (Pires, 2004). Contudo, o estudo de Pires 
(2004) ao simular o balanço hídrico de longo período entre os anos de 1992 e 2002 identificou uma vazão de descarga de $0,92 \mathrm{~m} 3 / \mathrm{s}$ para a ETE Brasília Sul e 0,40 m³ para a Norte, somando uma vazão média de $1,32 \mathrm{~m}^{3} / \mathrm{s}$. Então, considerando-se esses valores constantes para o período aqui simulado, onde as vazões de entrada em cada ponto de monitoramento, tiveram sua menor média no ponto $\mathrm{E}$, com um valor de $2,00 \mathrm{~m} / \mathrm{s} \mathrm{e} \mathrm{a}$ maior vazão média no ponto $\mathrm{A}$, com $4,53 \mathrm{~m} 3 / \mathrm{s}$, a soma das vazões das ETEs não se apresenta como representativa.

Como as medições de qualidade da água efetuadas pela CAESB são realizadas mensalmente e o modelo demanda valores diários, foi necessário interpolar os valores das mesmas. Para essa interpolação, utilizou-se o software MATLAB Versão 2011, o qual possui uma função chamada 'linspace' que gera um vetor linearmente espaçado entre dois pontos. Dessa forma, são declarados os pontos iniciais e finais para os quais se deseja fazer a interpolação e o número de pontos a serem criados foi contabilizado como o número de dias entre esses dois pontos.

No que se referem aos dados ecológicos e de qualidade da água, esses foram obtidos e inseridos por vazão, temperatura, oxigênio, nutrientes e biomassa de clorofíceas e cianofíceas. Foi necessário realizar conversão de unidades, visto que esses dados estavam em $\mathrm{mg} / \mathrm{L}$ (exceto temperatura) e devem ser inseridos no modelo em $\mathrm{mmol} / \mathrm{m}^{3}$ de C.

As vazões de cada tributário foram somadas às águas de drenagem, ou seja, foi calculado o escoamento superficial direto para cada braço. Essa estimativa teve por base o coeficiente de runoff adotado por Pires (2004) para o lago Paranoá e a área de drenagem de cada braço obtida por Liporoni (2012) com a utilização do software de geo-processamento Arc-Gis, versão 9.3.1, utilizando a base cartográfica do Sistema Cartográfica do DF (SICAD), em escala 1:10.000. A precipitação foi obtida da base de dados do INMET. Pires (2004) atribuiu diferentes coeficientes de escoamento variando conforme as áreas de drenagem e a época do ano. Os coeficientes encontrados pela autora foram utilizados para o cálculo do escoamento superficial em cada braço.

A base de dados coletada foi inserida nos arquivos de entrada '.csv'. Foram editados quatro afluentes relativos a cada braço: o 'inflow_a.csv' contendo as vazões do Riacho 
Fundo e variáveis de qualidade da água do ponto $\mathrm{A}$ de monitoramento. $\mathrm{O}$ arquivo 'inflow_b.csv' com as vazões do Gama e variáveis de qualidade da água do ponto B. E os 'inflow_d.csv' e 'inflow_e.csv' com as vazões do Torto e Bananal e variáveis do ponto D e E, respectivamente. Em suma, esses arquivos continham as medições de vazão, temperatura, OD, nitrato, amônia, fosfato e biomassa de clorofíceas e cianofíceas relativas às estações de monitoramento da CAESB dos quatro braços do lago Paranoá. Conforme mencionado anteriormente, as estações de cada braço foram considerados no presente trabalho como dados afluentes ao lago Paranoá.

Como vazão de saída, um arquivo em formato '.csv' foi editado com o somatório das vazões totais na barragem em passo diário. Ou seja, as vazões turbinadas mais as vazões vertidas.

Quanto aos dados meteorológicos, esses são inseridos também em formato '.csv', porém podem ser em passo diário ou sub-diário definidos conforme a disponibilidade de dados e declarados no script do modelo. Foram inseridos os dados de ondas curtas em $\mathrm{W} / \mathrm{m}^{2}$, ondas longas em $\mathrm{W} / \mathrm{m}^{2}$, temperatura do ar em ${ }^{\circ} \mathrm{C}$, umidade relativa em $\%$, velocidade do vento em $\mathrm{m} / \mathrm{s}$ e precipitação em $\mathrm{m} /$ dia em passo horário. O modelo também permite inserir os dados de cobertura de nuvens, contudo somente são fornecidos quando não se possui medições de radiação de ondas longas.

Quanto aos dados morfométricos, na Figura 4-8 é apresentada a batimetria identificada e utilizada, referente ao corte do braço central do lago Paranoá fornecida por CAESB (2003). Somente esse braço foi usado para gerar a curva hipsográfica. Observou-se uma profundidade máxima de $29 \mathrm{~m}$ no Lago.

Com os dados de entrada e a configuração do modelo preparada, uma análise da disponibilidade e extensão da base de dados construída foi realizada para selecionar o melhor período para calibração. 


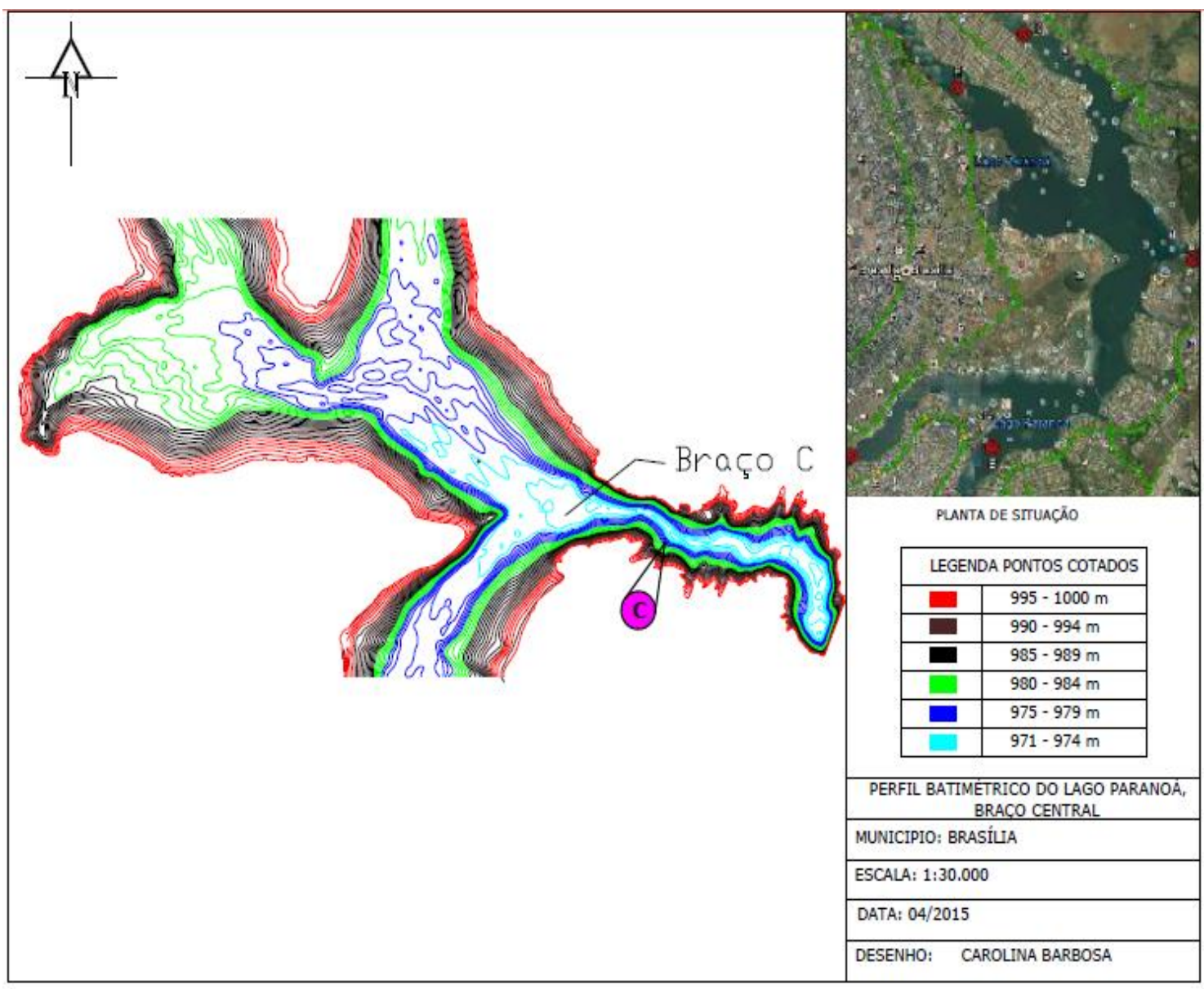

Figura 4-8: Mapa de batimetria do braço Central do lago Paranoá. Adaptado de CAESB (2003).

Após a escolha do período a ser simulado, procedeu-se a uma avaliação da consistência dos dados meteorológicos de entrada, visto a possibilidade de erros de medições ou por falta de calibração dos aparelhos de previsão. Para isso, foram plotados os gráficos dessas variáveis meteorológicas de entrada no software MATLAB e observados os dados que estivessem fora da linha de tendência ou do padrão esperado, chamados de suspeitos. Ao final, os dados suspeitos foram refeitos como a média das variáveis nos anos adjacentes.

\subsection{ANÁLISE DE SENSIBILIDADE E CALIBRAÇÃO DO GLM}

Temperatura é a variável de controle selecionada para calibração do GLM (módulo hidrodinâmico). O modelo gera o perfil vertical das variáveis no lago onde a matriz é formada pelo número de camadas pré-definidas no eixo x e o tempo dividido em 2 períodos no dia (11h e $23 \mathrm{~h})$ no eixo y. 
Inicialmente, uma simulação de base foi realizada, utilizando-se os parâmetros default do modelo hidrodinâmico. Após essa etapa, procedeu-se então a uma otimização da calibração do módulo hidrodinâmico com foco nos parâmetros relacionados a fluxo superficial e mistura vertical, além do parâmetro relacionado à propriedade do lago (Tabela 4-3). Não foram considerados os parâmetros acerca dos afluentes e efluentes.

Essa otimização consistiu em criar um algoritmo no software R para testar cada um desses parâmetros individualmente, $\pm 20 \%$ do valor padrão, e, após, gerar uma tabela com os valores do erro padrão ou também chamada raiz do erro médio quadrático (root mean squared error - RMSE) obtidos para a temperatura ao longo da coluna d'água.

O RMSE é uma medida do nível médio de erro de predição. Ele indica o quão perto os dados observados estão para os valores previstos do modelo (Malek et al., 2011). A unidade de medida do RMSE é a mesma da variável a que se refere e é a métrica mais utilizada em estudos com modelos ecológicos. O cálculo do RMSE é dado pela equação 2.

$$
R M S E=\sqrt{\frac{1}{N}} \sum_{n=1}^{N}\left(O_{n}-S_{n}\right)^{2}
$$

Onde, $O_{n}$ é o valor observado no n-ésimo dia, $S_{n}$ é o valor simulado no n-ésimo dia e $\mathrm{N}$ é o número de dias de simulação.

Ao final de todas as iterações, foram analisadas as tabelas geradas e selecionados os resultados que apresentaram menor RMSE para temperatura, bem como a diferença entre o melhor e o pior valor para determinar os parâmetros mais influentes. Dessa forma, pode-se dizer que essa metodologia realizada pode ser considerada uma análise de sensibilidade. Os menores valores de RMSE para cada parâmetro indicaram a melhor parametrização.

Após, os parâmetros default do GLM foram substituídos pelos valores parametrizados obtidos e então foi realizada a simulação. O RMSE continuou sendo a estatística para analisar o ajuste da temperatura simulada ao longo da coluna d'água por meio da função 
'compare_to_field', a qual está inserida no $\mathrm{R}$ e retorna o cálculo dessa métrica para o perfil de temperatura no lago.

Conforme o modelo gerava os resultados para temperatura em todas as profundidades ao longo da coluna d'água, outra função do GLMr gerava uma tabela com as temperaturas simuladas apenas nas profundidades de monitoramento no lago Paranoá $(1,10,15$ e $20 \mathrm{~m})$. De posse dessa tabela, os valores eram então inseridos em planilha eletrônica para os cálculos estatísticos e plotagens dos gráficos para avaliação dos ajustes. Além do RMSE, foram utilizadas outras duas ferramentas estatísticas para observar a qualidade das simulações, ou seja, avaliar o ajuste dos dados simulados com os dados observados. São elas:

- Cálculo do coeficiente de Nash-Sutcliffe (CN): A eficiência de Nash-Sutcliffe é uma estatística normalizada que determina a magnitude relativa da variância residual em comparação com a variância dos dados observados. O CN varia entre $-\infty$ e 1.0, com NSE = 1 sendo o valor ótimo (Nash e Sutcliffe, 1970). É um coeficiente adimensional (Equação 3).

$$
C N=1-\frac{\sum_{n=1}^{N}\left(O_{n}-S_{n}\right)^{2}}{\sum_{n=1}^{N}\left(O_{n}-\bar{O}\right)^{2}}
$$

- Cálculo do coeficiente de correlação (CC): expressa a relação entre os dados observados e simulados em termos quantitativos. É uma medida da intensidade de ajuste dos valores simulados aos dados de campo. Quanto mais próximo de 1, melhor (Ji, 2008). É um coeficiente adimensional (Equação 4).

$$
C C=\frac{\sum_{n=1}^{N}\left(O_{n}-\bar{O}\right)\left(S_{n}-\bar{S}\right)}{\sqrt{\sum_{n=1}^{N}\left(O_{n}-\bar{O}\right)^{2} \sqrt{\sum_{n=1}^{N}\left(S_{n}-\bar{S}\right)^{2}}}}
$$

Não foi realizada a etapa de verificação para o modelo hidrodinâmico pela indisponibilidade de outro período com dados completos para as simulações. 


\subsection{ANÁliSE DE SENSIBILIDAdE E CALIBRAÇÃo DO MÓDULO ECOLÓGICO - AED (MÓDULO FITOPLÂNCTON)}

Efetuada a análise de sensibilidade e calibração do módulo hidrodinâmico, partiu-se para a análise de sensibilidade e calibração do módulo ecológico - AED.

Como tratado anteriormente, o AED é uma biblioteca composta por módulos ecológicos interligados que na versão em R possui 11 módulos, porém somente 9 desses possuem conexões com o módulo de fitoplâncton (já o considerando), são eles:

- Módulo de fluxo no sedimento;

- Módulo de oxigênio;

- Módulo de carbono;

- Módulo de sílica;

- Módulo de nitrogênio;

- Módulo de fósforo;

- Módulo de matéria orgânica;

- Módulo de zooplâncton;

No presente trabalho, não se considerou o módulo de zooplâncton devido tanto à indisponibilidade de dados a respeito, quanto por uma preocupação em não se ampliar a complexidade do modelo e o módulo de sílica por esse elemento não ser representativo para o fitoplâncton da região de estudo.

O enfoque dado foi no módulo de fitoplâncton, especificamente nos dois grupos: clorofíceas e cianobactérias, devido os dois serem individualizados no referido módulo do GLM-AED. Por essa razão, a análise de sensibilidade e a calibração foram voltadas apenas para os parâmetros referentes a esse módulo. Todavia, para simular o módulo de fitoplâncton, chamado de 'aed2_phytoplankton', foi necessário inicializar os módulos ecológicos que se interligam a ele e, dessa forma, os demais módulos foram simulados, porém sem a análise de sensibilidade e calibração de seus parâmetros.

A análise de sensibilidade dos parâmetros do fitoplâncton consistiu em ajustar manualmente os parâmetros a um valor próximo ao intervalo sugerido por Hipsey et al. 
(2013) (vide Tabela 4-4) e que reproduzissem as condições observadas no lago Paranoá para os dois grupos de fitoplâncton escolhidos para simulação no presente estudo. Esses parâmetros são ainda divididos em 7 grupos dentro do módulo de fitoplâncton: parâmetros de crescimento, luz, respiração, salinidade, nitrogênio, fósforo e sílica.

Foram avaliados os efeitos sobre as clorofíceas e cianobactérias simulados devido a variações em torno dos valores padrão propostos por Hipsey et al. (2013). Essa análise de sensibilidade ocorreu manualmente com as variações dos parâmetros separadamente para os dois grupos de fitoplâncton e posterior geração da tabela com as biomassas simuladas apenas nas profundidades de monitoramento no Lago. Assim, a cada alteração de valor nos parâmetros foram observadas modificações ocorridas na biomassa dos dois grupos.

Dentro do módulo de fitoplâncton, o primeiro parâmetro modificado do grupo de crescimento foi a taxa máxima de crescimento do fitoplâncton a $20^{\circ} \mathrm{C}$ ( $R \_$growth) e após, a constante de semi-saturação para limitação de luz no crescimento do fitoplâncton $\left(I_{-} K\right)$. Em relação aos parâmetros de respiração, foi avaliada a taxa de perda metabólica por respiração do fitoplâncton a $20{ }^{\circ} \mathrm{C}\left(R_{-}\right.$resp $)$, taxa de perda metabólica devido à respiração pura do fitoplâncton ( $K_{-}$fres), taxa de sedimentação $\left(W \_p\right)$, temperatura padrão $\left(T \_s t d\right)$ e temperatura ótima $\left(T \_o p t\right)$. Para os parâmetros do grupo de nitrogênio e fósforo, avaliaram-se a fixação de nitrogênio e a absorção de fósforo pelo fitoplâncton (simNFixation e simDIPUptake)

Ao final da análise de sensibilidade, o processo de calibração ocorreu por meio de avaliação individual e posteriormente combinada dos parâmetros analisados. Em primeiro lugar, foi utilizado um valor de taxa de crescimento do fitoplâncton que aproximasse os valores simulados dos dados observados. Em seguida, foi testada a quantidade de luz que incide no lago para ajustar a distribuição de luz na superfície. $O$ passo seguinte foi calibrar a taxa de respiração do fitoplâncton de modo a melhorar a produção e perda do mesmo, o ajuste das temperaturas e o fator de Arrenhius.

Não foi realizada a etapa de verificação para o módulo ecológico pela indisponibilidade de outro período com dados completos para as simulações. 


\subsection{SIMULAÇÃO DAS VARIÁVEIS DE QUALIDADE DA ÁGUA}

Após análise de sensibilidade e calibração dos parâmetros hidrodinâmicos e ecológicos ligados à dinâmica do fitoplâncton, procedeu-se à simulação da qualidade da água para o lago Paranoá. As variáveis de qualidade da água foram então avaliadas. Primeiramente, a biomassa de clorofíceas e cianobactérias, por terem sido essas calibradas e, após, as demais variáveis: temperatura da água, OD, nitrato, amônia e fosfato.

Sabe-se que as variáveis de qualidade da água simuladas têm relação direta com a dinâmica do fitoplâncton e a produtividade primária do lago Paranoá. Dessa maneira, foi realizada análise das médias observadas durante os 30 anos de dados de monitoramento da CAESB para evidenciar o comportamento do ambiente ao longo dos anos.

As biomassas de clorofíceas e cianobactérias foram plotadas, confrontando-se os resultados simulados e os dados medidos em campo. E, ainda, para determinar o desempenho do modelo GLM-AED, foi utilizado o cálculo do RMSE (equação 2) para observar a eficiência dos resultados. O cálculo do RMSE também foi efetuado para as demais variáveis de qualidade da água no Lago.

\subsection{SIMULAÇÃO DE CENÁRIO DE EUTROFIZAÇÃo}

No intuito de observar a resposta do modelo a mudanças no comportamento das variáveis ecológicas: temperatura, oxigênio, nitrato, amônia, fosfato e biomassa de clorofíceas e cianofíceas em ambiente com alto nível de trofia, decidiu-se efetuar uma simulação do cenário de qualidade da água do período mais eutrofizado do lago Paranoá, com floração de Microcystis aeruginosa (ano de 1978), contudo, considerando o Lago com o volume, vazão e condições hidrometeorológicas observadas nos dias atuais.

As variáveis de qualidade da água inseridas no modelo foram provenientes do monitoramento da CAESB para o ano de 1978. Porém, os demais dados de entrada, 
como vazões, dados meteorológicos e morfométricos foram os mesmos utilizados para o período mais atual. No caso, o ano de 2008 foi o escolhido.

O monitoramento de qualidade da água da CAESB para 1978, ano crítico, apresentou uma lacuna nos dados que se prolongou de janeiro a março. Dessa maneira, tornou-se necessário estimar os três primeiros meses por meio de interpolação linear, com o mesmo procedimento adotado para o preenchimento diário dos dados de qualidade da água usados para análise de sensibilidade e calibração do GLM, por meio do software MATLAB Versão 2011.

Para observar os resultados nos valores das variáveis de qualidade da água e biomassa de clorofíceas e cianobactérias do cenário, ao final da simulação os resultados dessas variáveis foram plotados em gráficos para avaliação do ajuste obtido. Os gráficos foram compostos por 3 curvas: as variáveis simuladas e observadas no período escolhido para calibração do GLM-AED e as variáveis simuladas no cenário. 


\section{RESULTADOS E DISCUSSÕES}

No presente capítulo, são apresentados os resultados obtidos no desenvolvimento desse estudo. De início, é apresentada uma análise prévia dos dados coletados para a construção da base de dados do modelo e, na sequência, são apresentados os resultados provenientes da modelagem do Lago Paranoá - DF. Assim, o capítulo foi dividido da seguinte forma: Análise da disponibilidade e extensão da base de dados construída; Avaliação da consistência dos dados meteorológicos utilizados como dados de entrada no modelo; Análise de sensibilidade e otimização da calibração do GLM; Análise de sensibilidade e calibração do módulo ecológico - AED (módulo de fitoplâncton); Simulação da qualidade da água; Simulação do cenário.

\subsection{ANÁliSE DA DISPONIBILIDADE E EXTENSÃO DA BASE DE DADOS CONSTRUÍDA}

Procedeu-se a uma análise da extensão e disponibilidade dos dados de entrada dentro do banco de dados formado para definição do período que seria utilizado para análise de sensibilidade e calibração do GLM-AED. Essa escolha do período utilizado no estudo foi baseada na disponibilidade de todos os dados requeridos pelo modelo.

Em relação aos dados de qualidade da água, os pontos $\mathrm{A} 4, \mathrm{~B}, \mathrm{D}$ e $\mathrm{E}$ possuem monitoramento a 1 metro da superfície e o ponto $\mathrm{C}$ em 7 profundidades.

Porém, em duas das profundidades medidas no ponto $\mathrm{C}$, que seriam na superfície e a 5 metros da superfície, os dados disponíveis contemplavam apenas o período de setembro de 2009 a agosto de 2010. Dessa maneira, essas 2 profundidades de monitoramento não foram consideradas no presente trabalho.

Ainda, como será tratado nos itens seguintes, o modelo calcula os níveis d'água diários no resultado de balanço hídrico e esse balanço ao ser gerado pelo GLM nas simulações no lago Paranoá não conseguiu alcançar a cota máxima adotada de 29 m no Lago ao final da calibração hidrodinâmica. Não foram realizadas maiores análises a respeito desse fato, pois não era objetivo do presente trabalho aprofundar-se no balanço hídrico 
do Lago. Por essa razão, a profundidade a 1 metro do fundo não conseguiu ser simulada pelo modelo e, por conseguinte, no ponto $\mathrm{C}$ observaram-se apenas as medições a 1 metro, 10 metros, 15 metros e 20 metros da superfície.

As Figuras 5-1 a 5-5 apresentam a extensão dos períodos com dados disponíveis para as variáveis de qualidade da água em cada ponto de monitoramento localizado nos braços e no lago Paranoá de acordo com as medições realizadas pela CAESB.

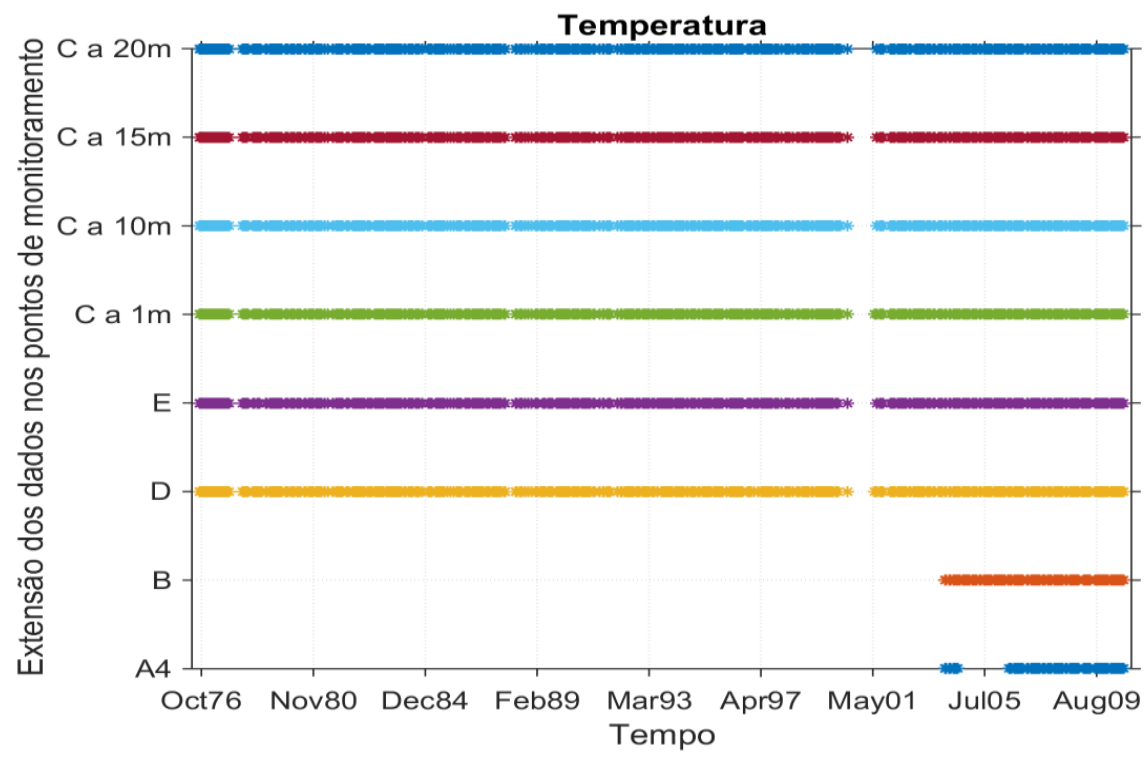

Figura 5-1: Séries temporais dos dados de temperatura disponibilizados pela CAESB para os pontos de monitoramento nos braços e ponto $\mathrm{C}$.

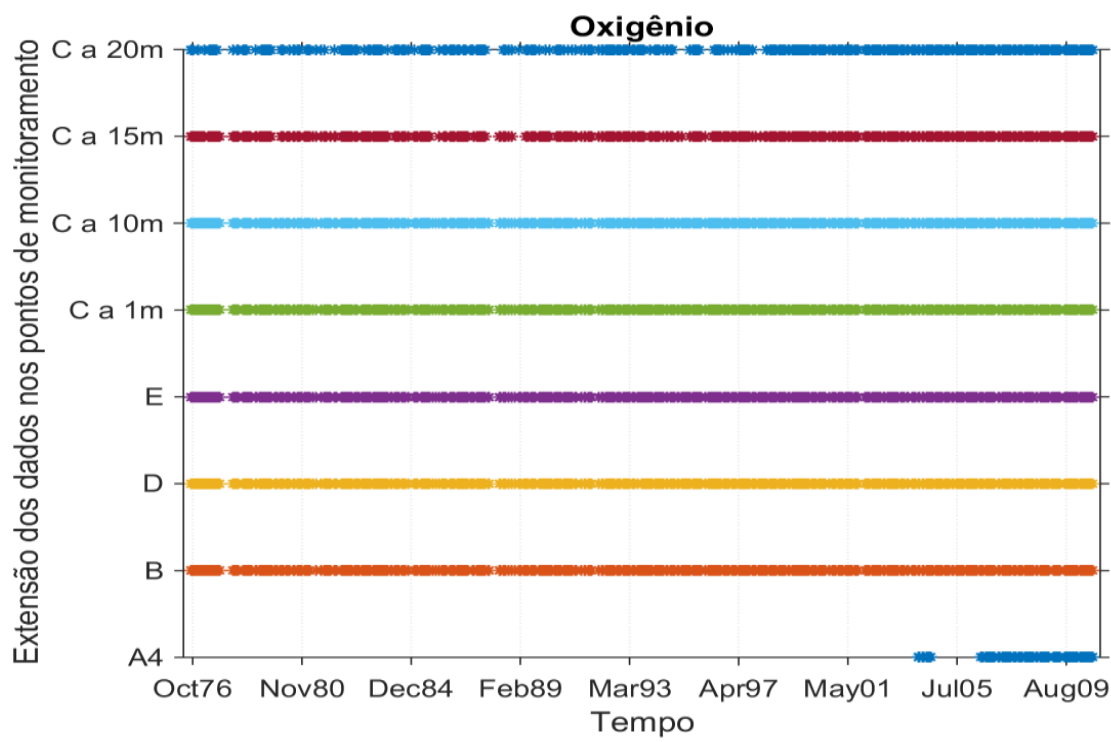

Figura 5-2: Séries temporais dos dados de oxigênio disponibilizados pela CAESB para os pontos de monitoramento nos braços e ponto $\mathrm{C}$ 


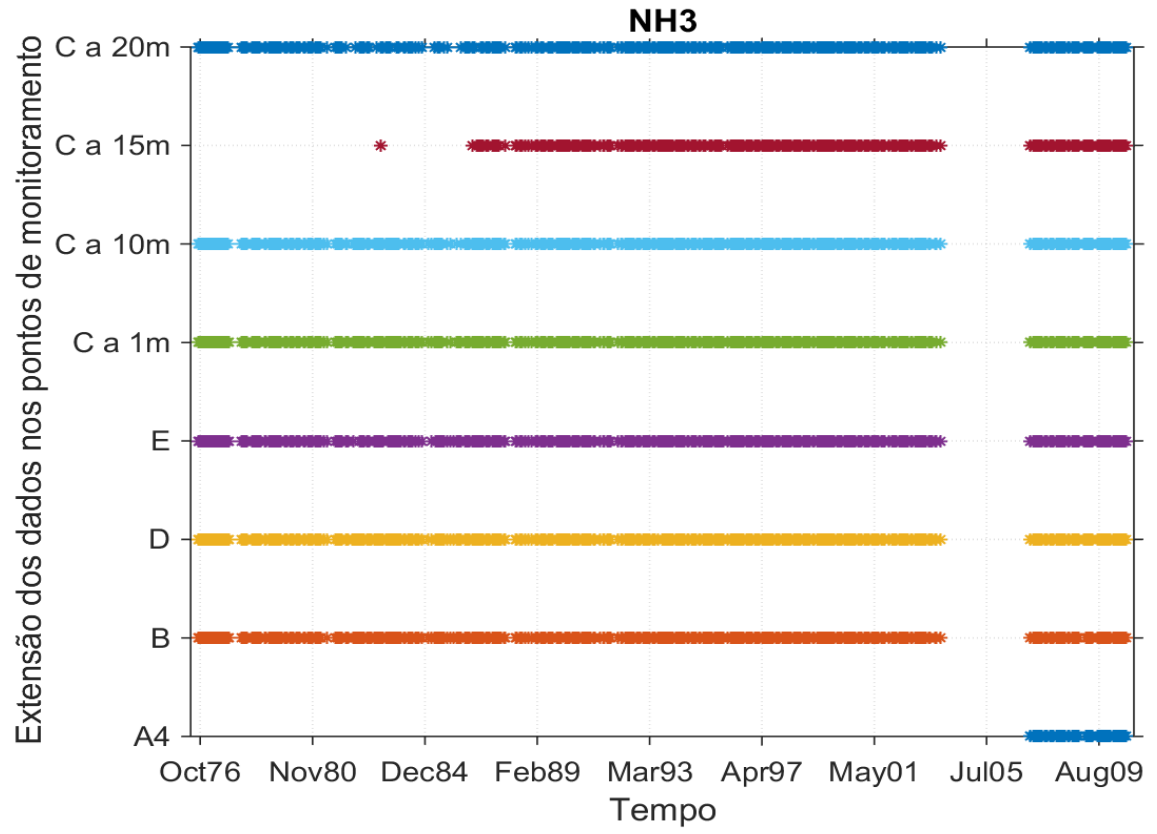

Figura 5-3: Séries temporais dos dados de amônia disponibilizados pela CAESB para os pontos de monitoramento nos braços e ponto $\mathrm{C}$

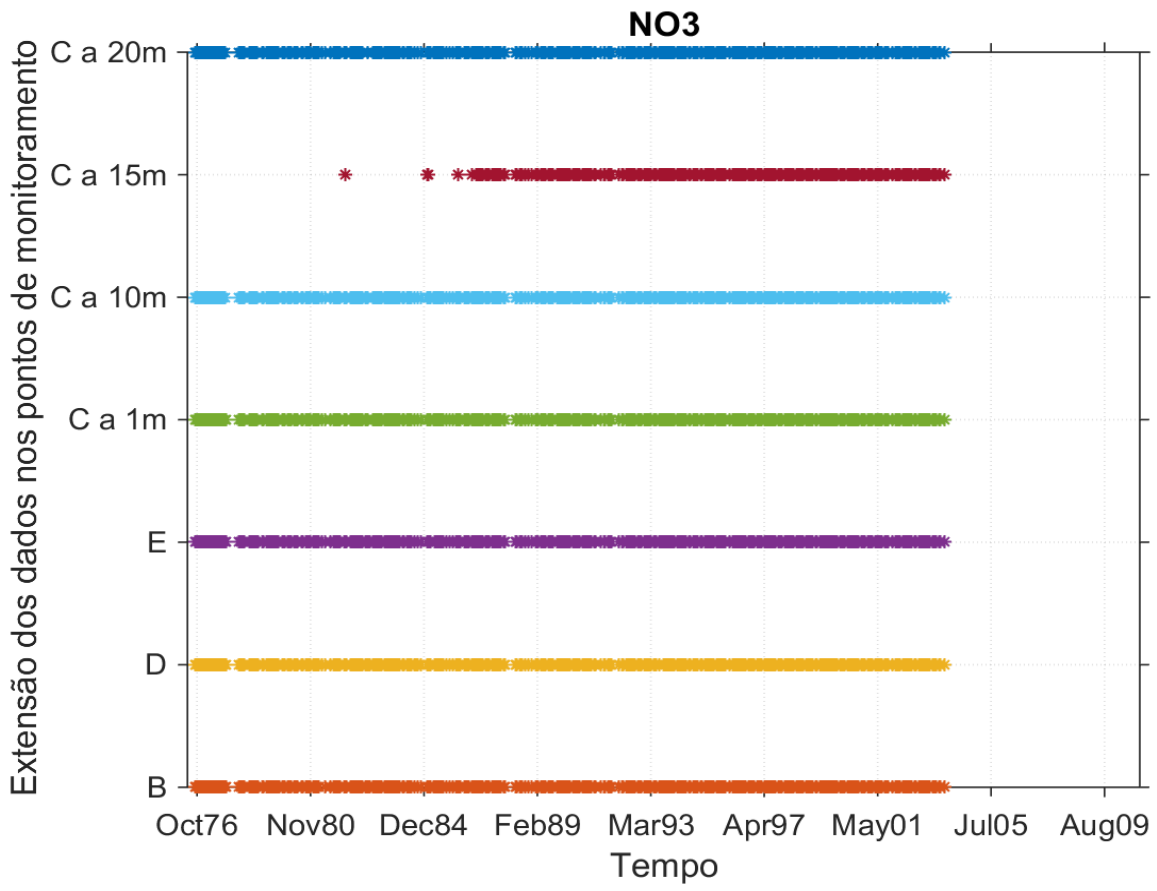

Figura 5-4: Séries temporais dos dados de nitrato disponibilizados pela CAESB para os pontos de monitoramento nos braços e ponto $\mathrm{C}$. 


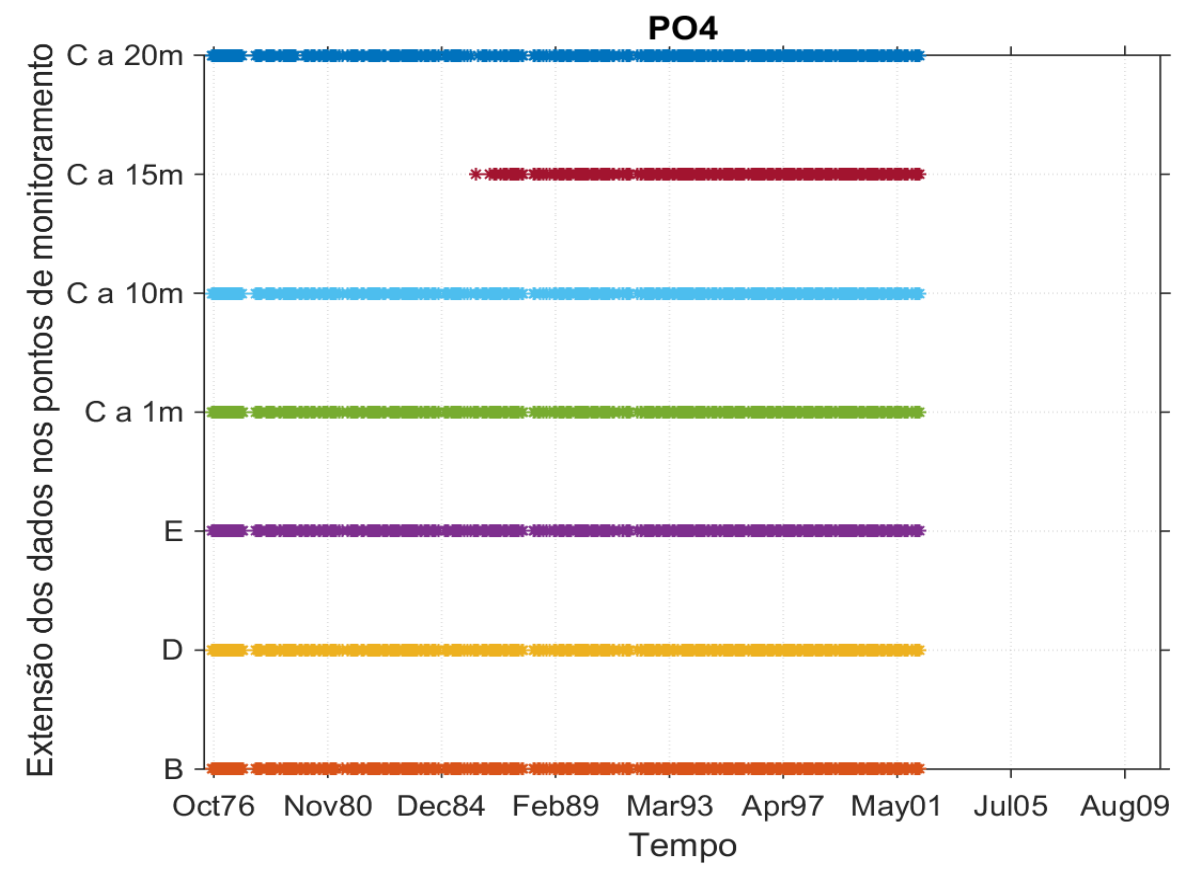

Figura 5-5: Séries temporais dos dados de fosfato disponibilizados pela CAESB para os pontos de monitoramento nos braços e ponto $\mathrm{C}$.

Observa-se nesses dados de qualidade da água que o período que vai de janeiro de 2004 a agosto de 2010 foi o que apresentou maior disponibilidade de variáveis nos braços. Contudo, os dados das concentrações dos nutrientes apresentaram grandes lacunas (Figura 5-3, Figura 5-4 e Figura 5-5), com o período de dados disponível para amônia limitado no ponto A4 de 12/02/2007 a 16/08/2010 e o período para as variáveis nitrato e fosfato diferindo das demais com disponibilidade no período de 19/09/1986 a 21/02/2002, com limitação no ponto C a 15 metros.

No que tange aos dados meteorológicos, como esses foram obtidos por duas fontes distintas: INMET e INPE, sendo que o INMET possui algumas variáveis com medição diária e outras de hora em hora, também foi necessário proceder à análise da extensão e disponibilidade desses dados (Figura 5-6 a Figura 5-11). Os dados de radiação de ondas longas e UR foram provenientes apenas do INPE. As variáveis radiométricas possuem unidades de medidas diferentes entre as duas bases de dados, sendo pelo INPE medidas em $\mathrm{W} / \mathrm{m}^{2}$ e pelo INMET a radiação global (ondas curtas) é dada em $\mathrm{KJ} / \mathrm{m}^{2}$. 


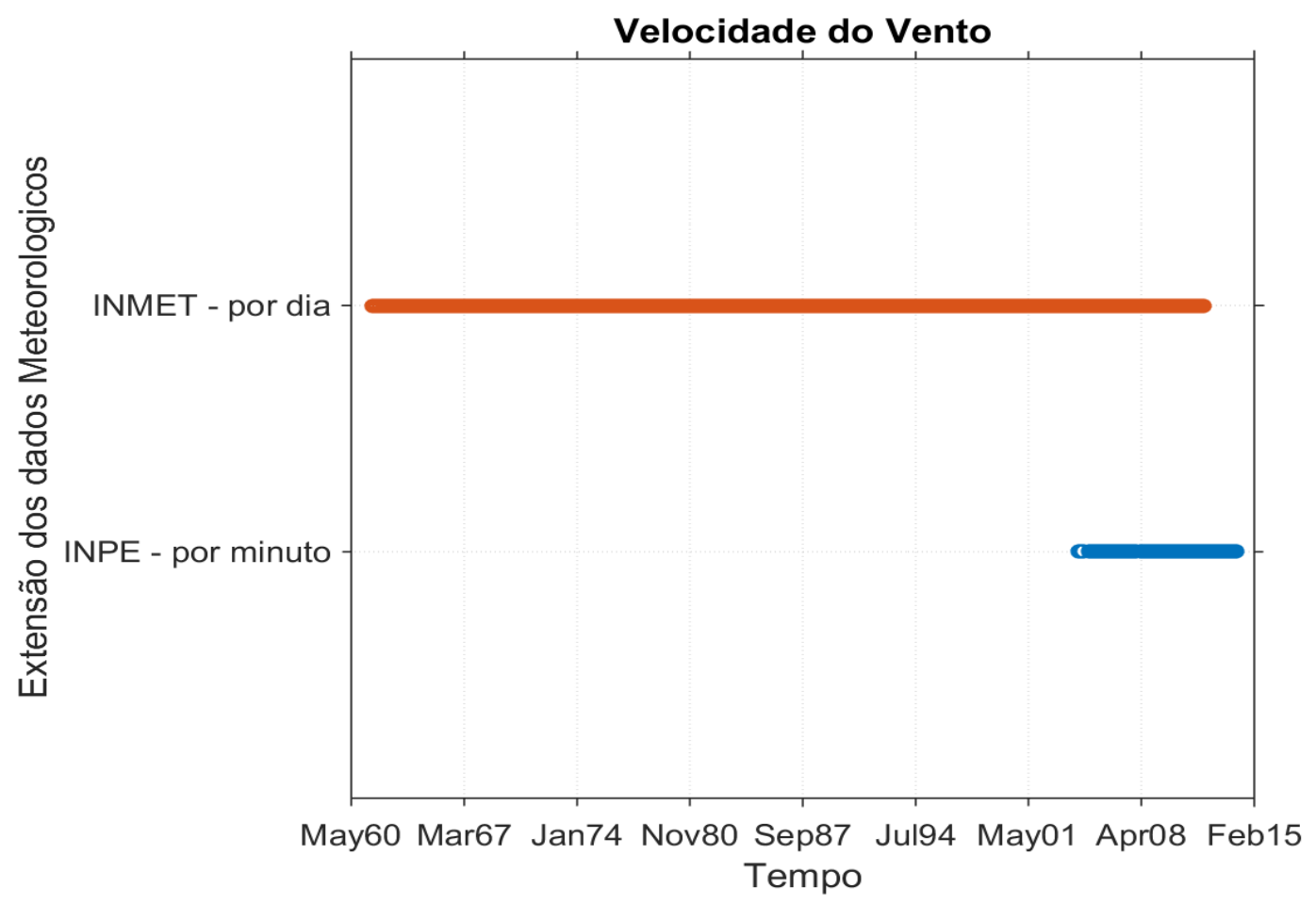

Figura 5-6: Séries temporais dos dados de velocidade do vento disponibilizados pelo INPE e INMET para a Estação Brasília.

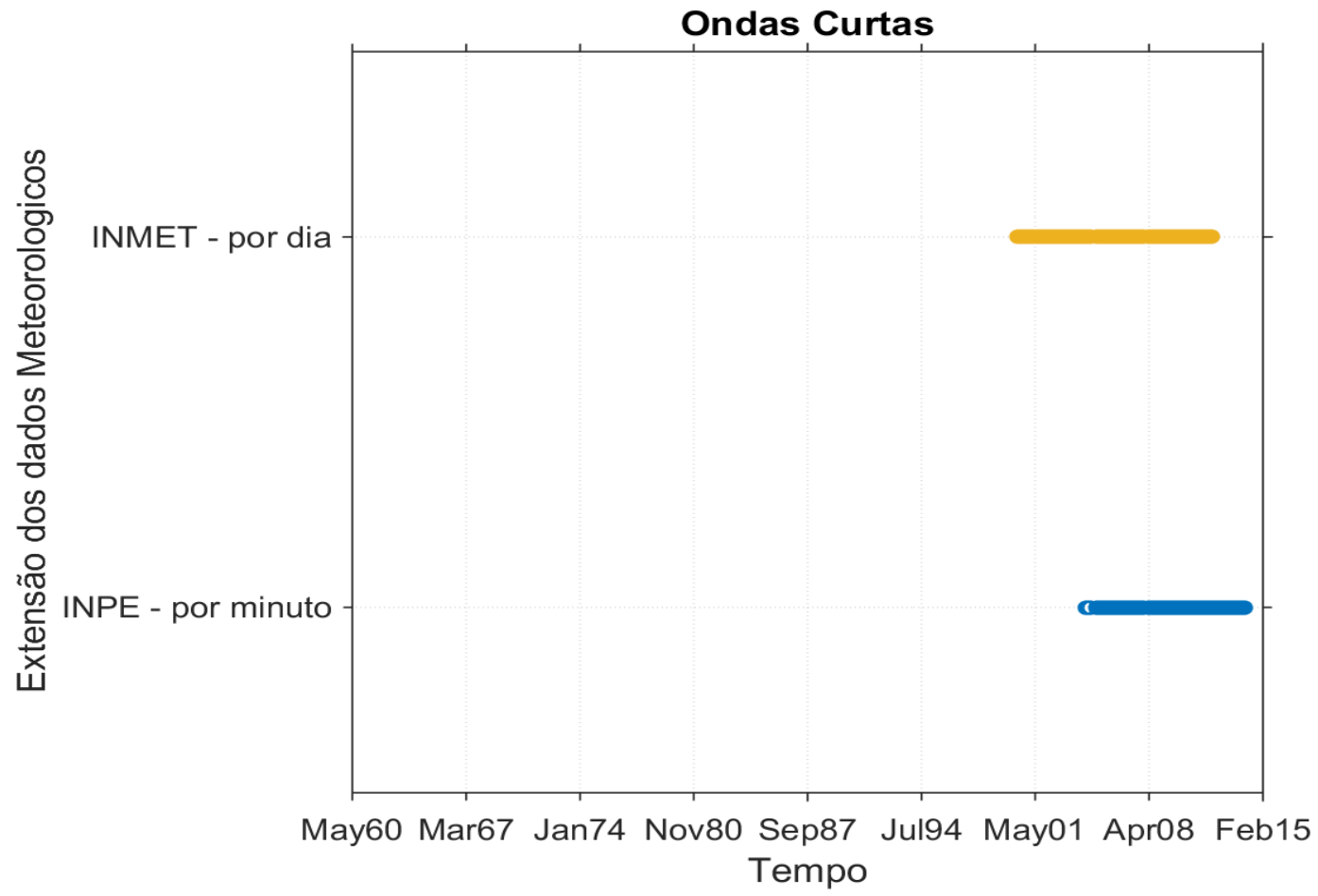

Figura 5-7: Séries temporais dos dados de ondas curtas disponibilizados pelo INPE e INMET para a Estação Brasília. 


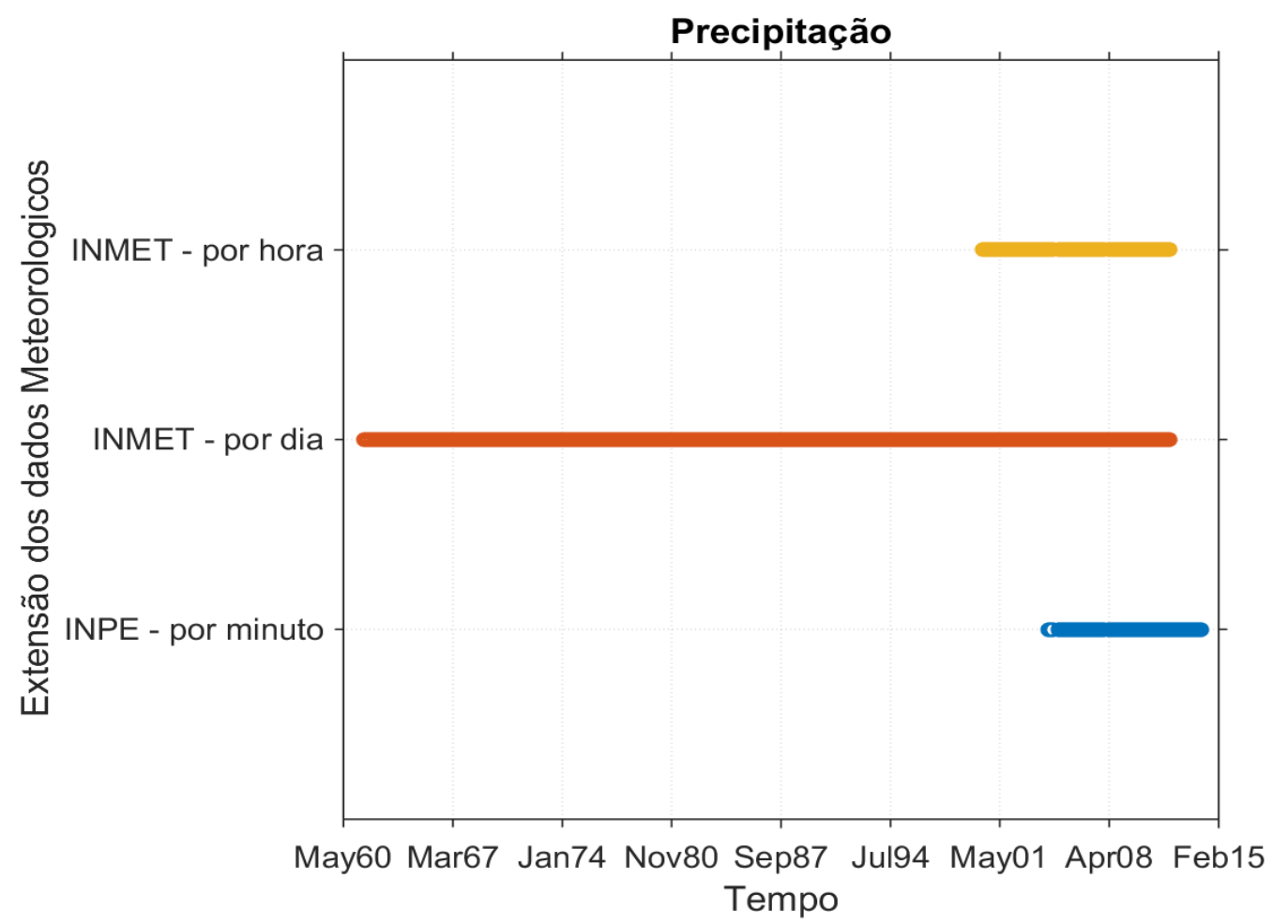

Figura 5-8: Séries temporais dos dados de precipitação disponibilizados pelo INPE e INMET para a Estação Brasília.

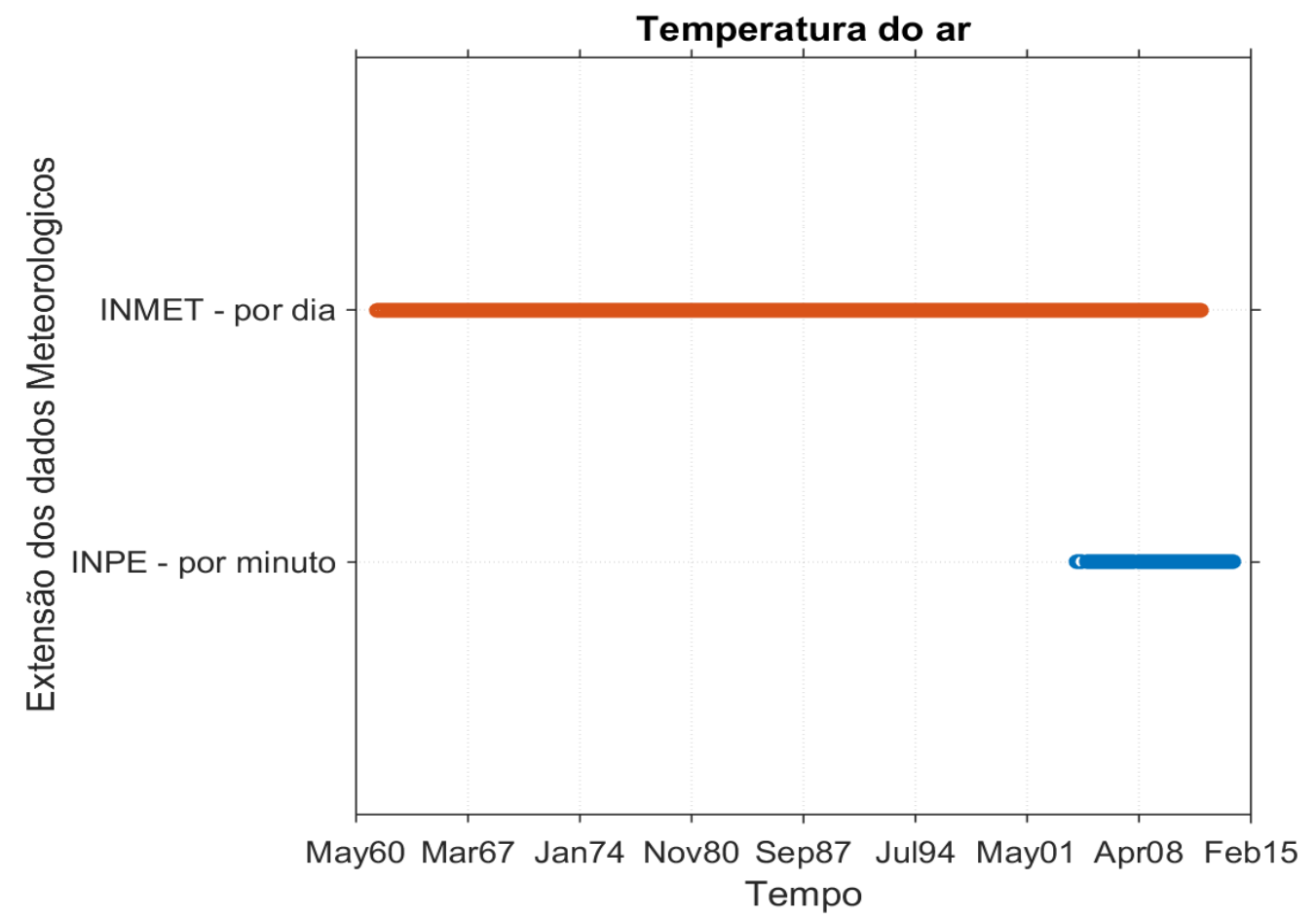

Figura 5-9: Séries temporais dos dados de temperatura do ar disponibilizados pelo INPE e INMET para a Estação Brasília. 


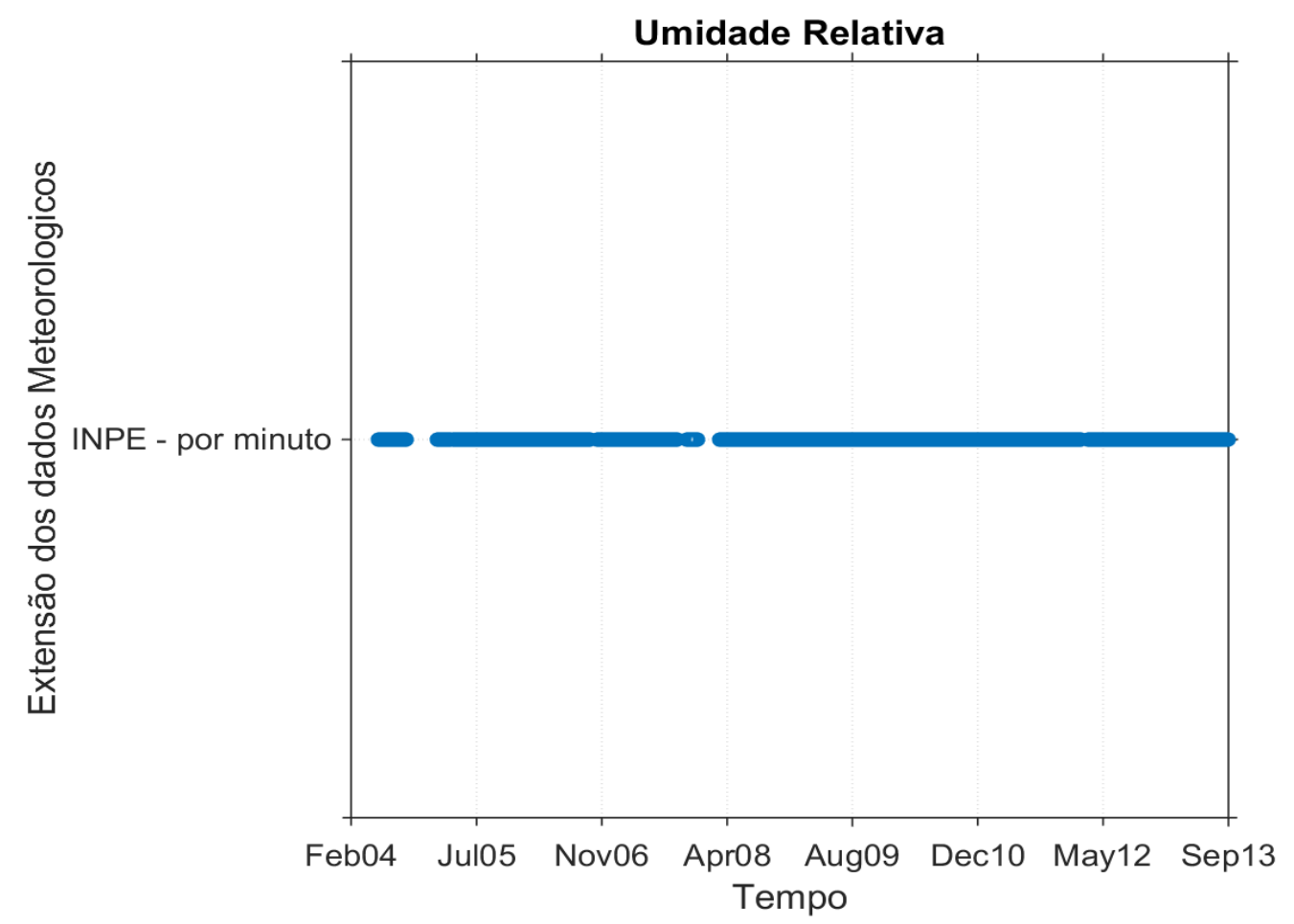

Figura 5-10: Séries temporais dos dados de umidade relativa disponibilizados pelo INPE e INMET para a Estação Brasília.

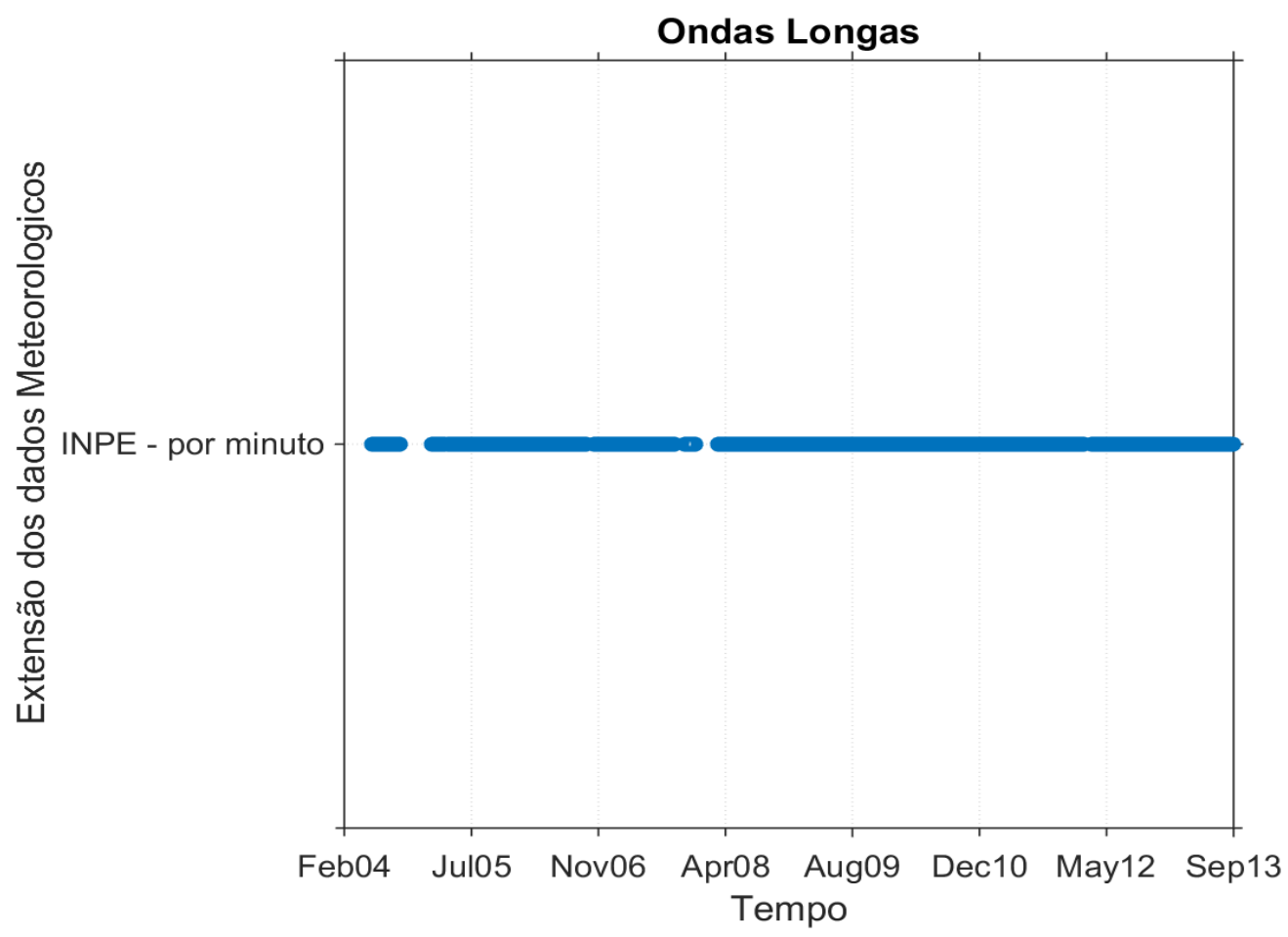

Figura 5-11: Séries temporais dos dados de ondas longas disponibilizados pelo INPE e INMET para a Estação Brasília. 
Observa-se que em se tratando da extensão dos dados hidrometeorológicos, o período disponível para esses foi limitado pelos dados de UR e ondas longas (Figura 5-10 e 511) provenientes do INPE. Esses dados estavam disponíveis apenas de 13/06/2004 a 31/12/2013 e com muitos períodos com lacunas de dados.

Para os dados de vazão dos afluentes, a Figura 5-12 apresenta o período de extensão desses. O Riacho Fundo é o limitante nesse período, iniciando em 01/03/1988 e finalizando em 31/12/2009.

Já para as vazões de saída, que correspondem à soma das vazões vertidas e turbinadas na barragem, os dados foram disponibilizados pela CEB. A Figura 5-13 apresenta a extensão de seu período que vai de janeiro de 1978 a dezembro de 2011.

Os dados limnológicos relativos a biomassa fitoplânctonica fornecidos pela CAESB foram disponibilizados de setembro de 1976 a agosto de 2012, conforme a Figura 5-14. Observa-se também muitas lacunas de dados nesse intervalo.

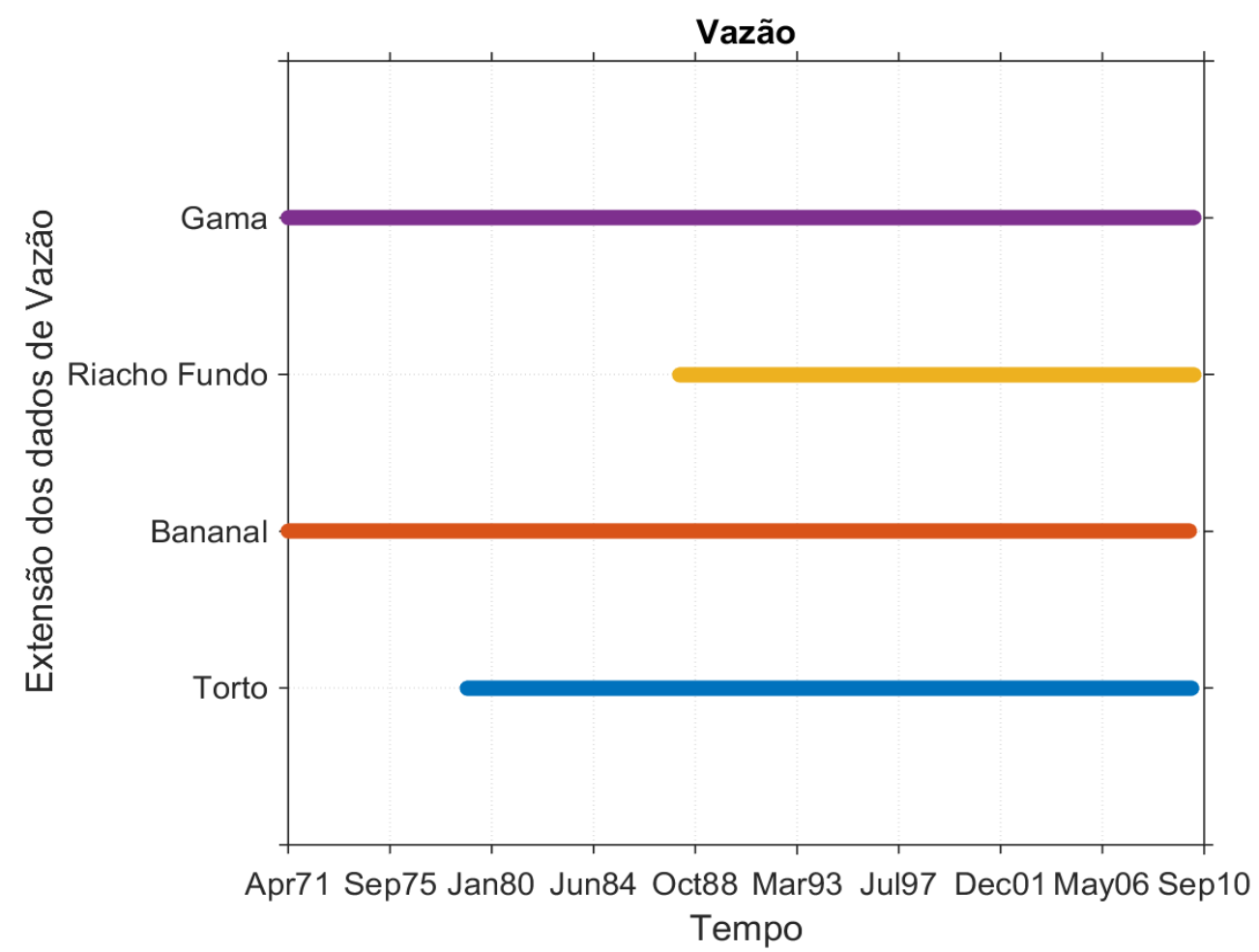

Figura 5-12: Séries temporais dos dados de vazão dos afluentes ao lago Paranoá-DF disponibilizados pela CEB. 


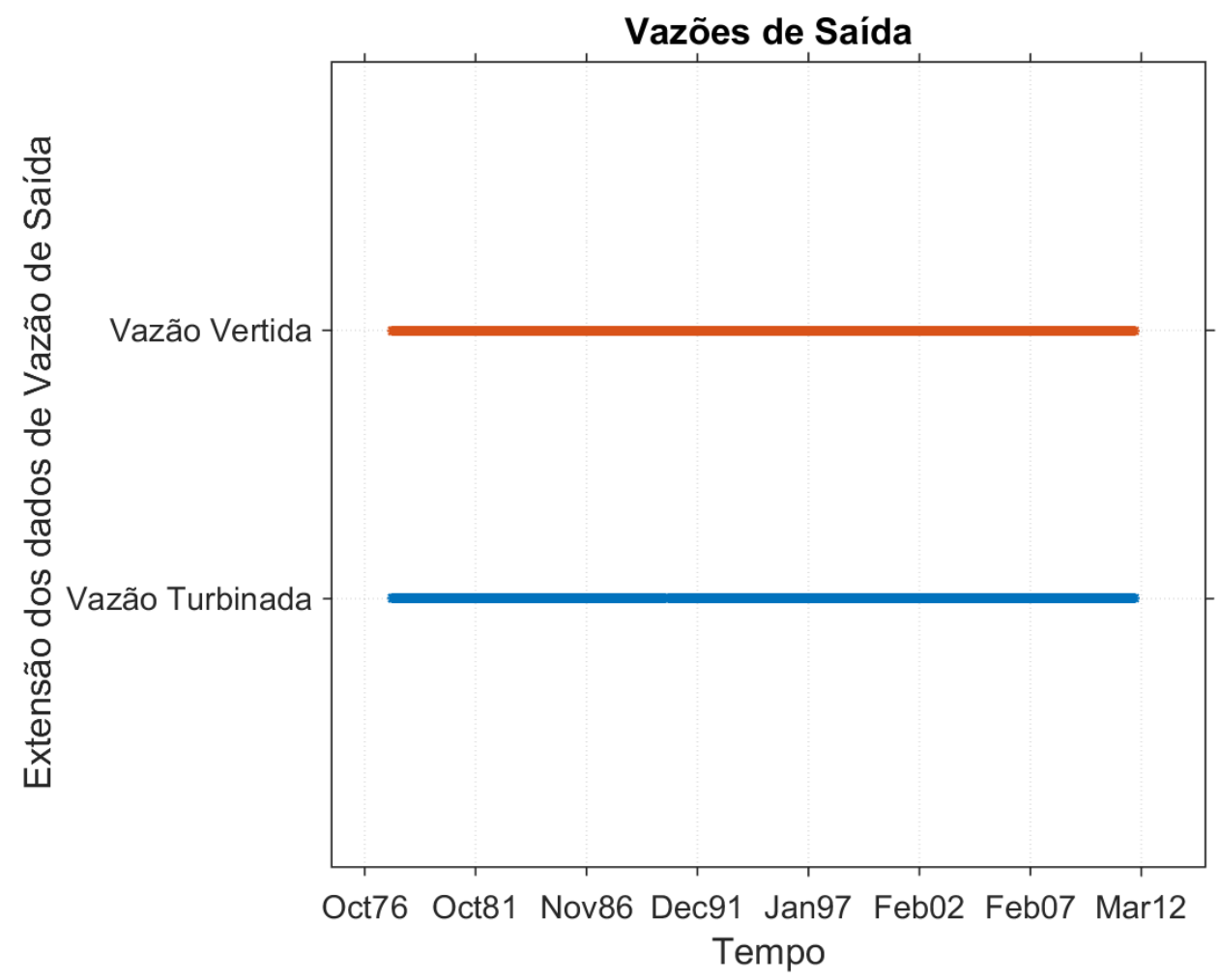

Figura 5-13: Séries temporais dos dados de vazão de saída na barragem do lago Paranoá-DF disponibilizados pela CEB.

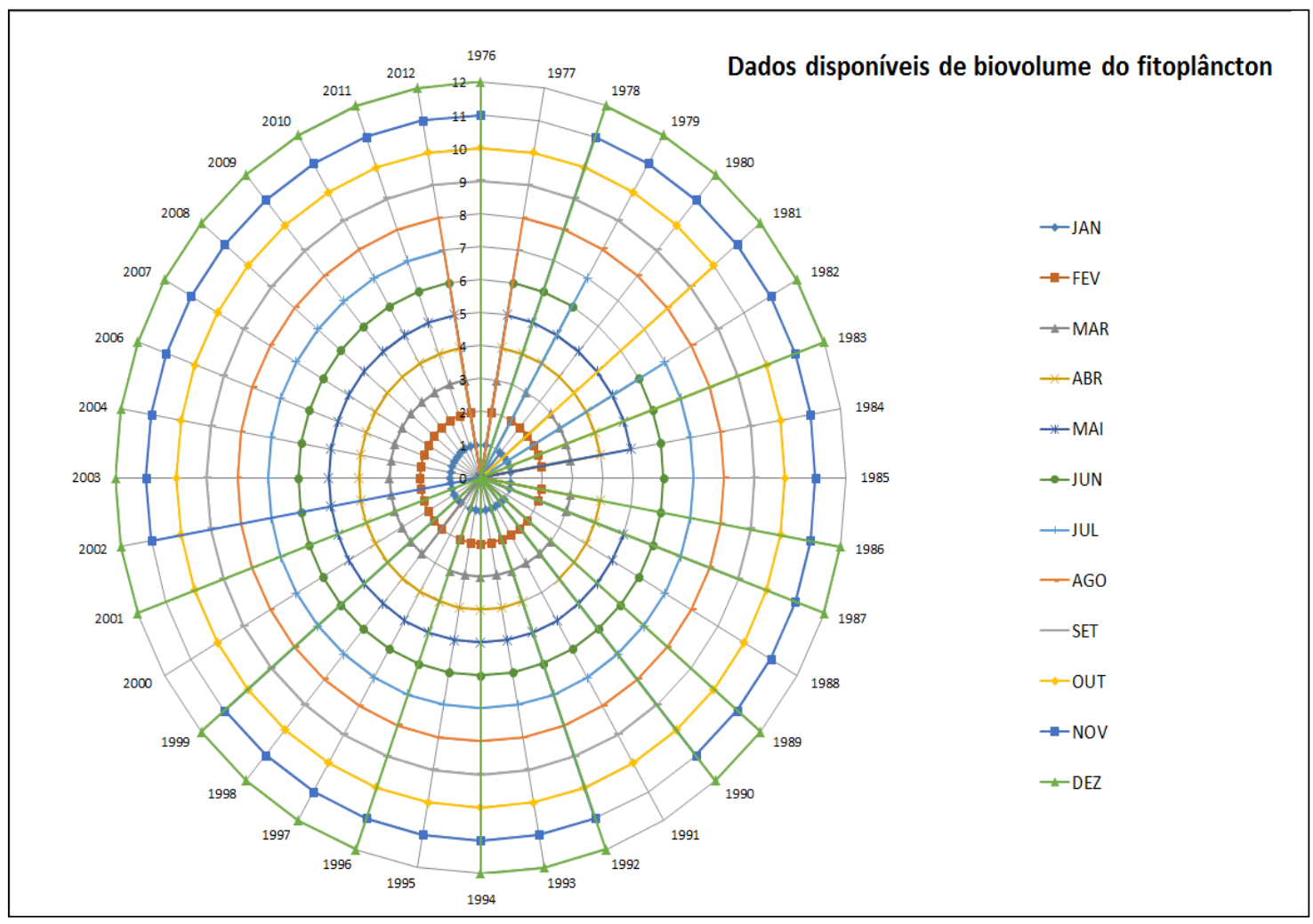

Figura 5-14: Séries temporais dos dados de fitoplâncton nos pontos de monitoramento da CAESB. 
A Tabela 5-1 apresenta o resumo da extensão do período de dados de qualidade da água, hidrológicos, meteorológicos e limnológicos disponíveis observados para o lago Paranoá-DF.

Tabela 5-1: Extensão do período de dados disponível para simulações com o modelo GLM-AED no lago Paranoá.

\begin{tabular}{cccc}
\hline Tipos de dados & $\begin{array}{c}\text { Período com maior } \\
\text { disponibilidade de } \\
\text { variáveis }\end{array}$ & Tipos de dados & $\begin{array}{c}\text { Período com maior } \\
\text { disponibilidade de } \\
\text { variáveis }\end{array}$ \\
\hline Dados de qualidade da & $12 / 02 / 2007$ & Dados & $13 / 06 / 2004$ \\
água & a & meteorológicos & a \\
& $16 / 08 / 2010$ & & $31 / 12 / 2013$ \\
Dados limnológicos & $09 / 1976$ & Dados de vazão & a \\
& a & & $31 / 12 / 203 / 1988$ \\
\hline
\end{tabular}

Pela análise da Tabela 5-1, observa-se que o período de 12/02/2007 a 31/12/2009 é a intersecção entre todos os tipos de dados. Porém, devido a pequenas lacunas nos dados meteorológicos, optou-se pelo período de 01/03/2007 a 31/03/2009, durante o qual os dados se apresentavam mais contínuos para se proceder às análises de sensibilidade e à calibração do modelo GLM-AED para o lago Paranoá.

Liporoni (2012) encontrou um período semelhante para proceder à simulação do módulo hidrodinâmico do modelo CE-QUAL-W2 para o lago Paranoá de acordo com a base de dados formada. O autor utilizou o período de 10/07/2007 a 31/07/2008 para calibração e 01/08/2008 a 06/08/2009 para a verificação. A base de dados formada nesse estudo foi muito semelhante a de Liporoni (2012) e assim sendo, confirmam-se os anos de 2007, 2008 e 2009 como os de melhor disponibilidade e consistência no monitoramento realizado pela CAESB.

Ainda, em relação aos dados do monitoramento da CAESB, as concentrações das variáveis nitrato e fosfato não foram medidas no período selecionado para calibração hidrodinâmica e do módulo de fitoplâncton e sabe-se que esses dois nutrientes são essenciais à dinâmica do fitoplâncton. 
Dessa forma, para preencher os dados faltantes de nitrato e fosfato do monitoramento histórico da Caesb, foram utilizados os dados obtidos do monitoramento de qualidade da água do lago Paranoá no âmbito do projeto de pesquisa “Avaliação do impacto do uso da terra sobre os sistemas aquáticos das Bacias Hidrográficas do Descoberto e do Paranoá para determinação de indicadores de integridade ambiental" (Edital 031/2010 MCT/CNPq/FNDCT/FAPs/MEC/CAPES/PRO-CENTRO-OESTE) desenvolvido no Programa de Pós-Graduação em Tecnologia Ambiental e Recursos Hídricos.

Os dados de nitrato e fosfato utilizados foram referentes ao período compreendido entre o mês de janeiro de 2012 até janeiro de 2013. Entende-se que o lago apresentou grau de trofia estável entre os anos de 2007 e 2013. Burnett et al. (2001), Mendonça-Galvão (2005) Andreoni-Batista (2007), Philomeno (2007), Liporoni (2012) e Souza (2013) apresentam informações sobre o processo de oligotrofização do Lago.

As séries temporais das concentrações das variáveis de qualidade da água e biomassa dos dois grupos de fitoplâncton medidas pela CAESB, nos períodos aqui utilizados, são dadas no Apêndice B.

Para os dados hidrológicos, a vazão de entrada para o braço do Gama apresentava uma lacuna com início em 02/06/2008 alcançando a data de 20/07/2008. Para preenchimento dessa falha, calculou-se a média de longo período para esse intervalo correspondendo a uma vazão de 3,0496 m³/s.

Em relação aos dados metereológicos, no que tange à base de dados do INPE, foi necessário estimar os dados de radiação de ondas longas e UR no período de $14 / 09 / 2007$ às 13:00 a 23/09/2007 às 17:00, 07/12/2007 às 20:00 a 06/03/2008 às 13:00 e 06/03/2008 às 14:00 a 10/03/2008 às 18:00 por serem dados inexistentes. Dessa forma, essas duas variáveis nos períodos em questão foram estimadas pela média horária desses meses nos anos adjacentes. 


\subsection{AVALIAÇÃO DA CONSISTÊNCIA DOS DADOS METEOROLÓGICOS DE ENTRADA}

Houve a necessidade de analisar a consistência dos dados meteorológicos de entrada e verificar se havia valores destoantes ou fora da tendência para o período analisado. Foram observados dados suspeitos para temperatura do ar, UR, velocidade do vento e radiação de ondas longas. Esses dados foram, então, refeitos como a média dos anos adjacentes. As Figuras 5-15 a 5-18 mostram os dados brutos (antes da correção numérica) e os dados ajustados (após a correção numérica).
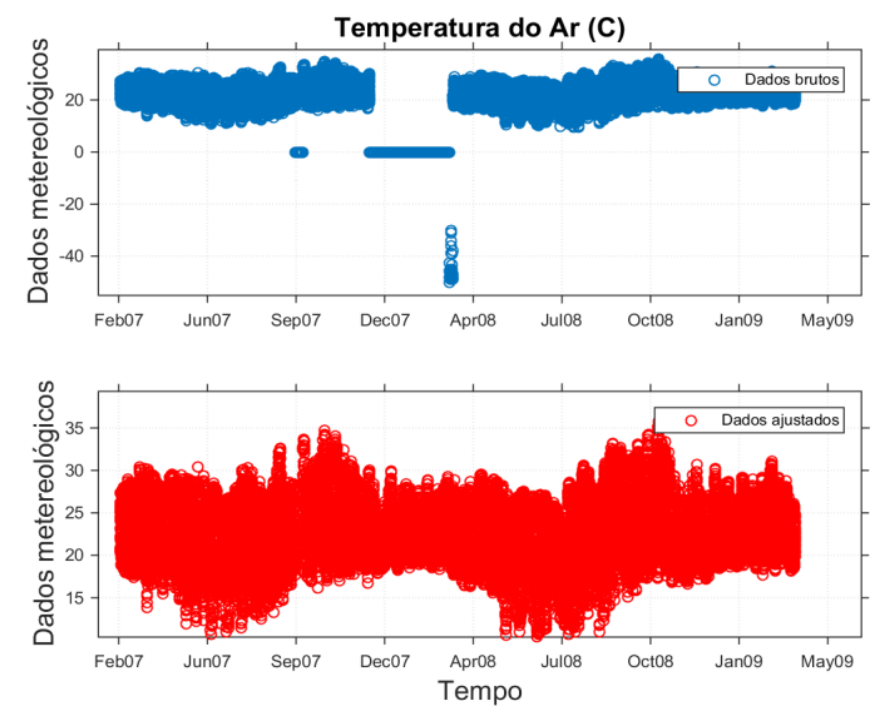

Figura 5-15: a) Série de dados brutos de temperatura do ar b) Série de dados ajustados de temperatura do ar.
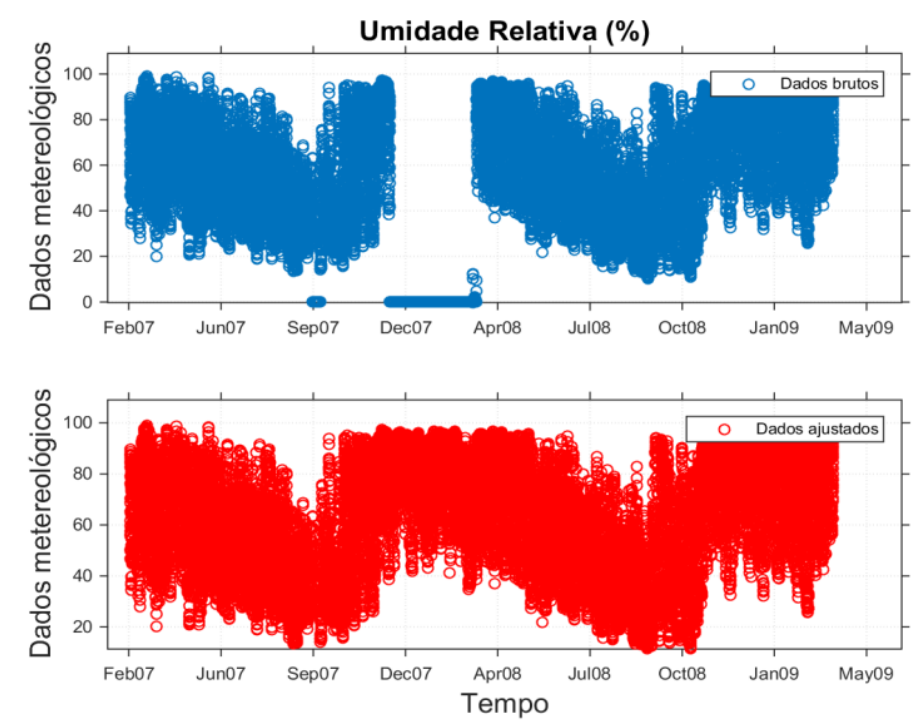

Figura 5-16: a) Série de dados brutos de UR b) Série de dados ajustados de UR. 

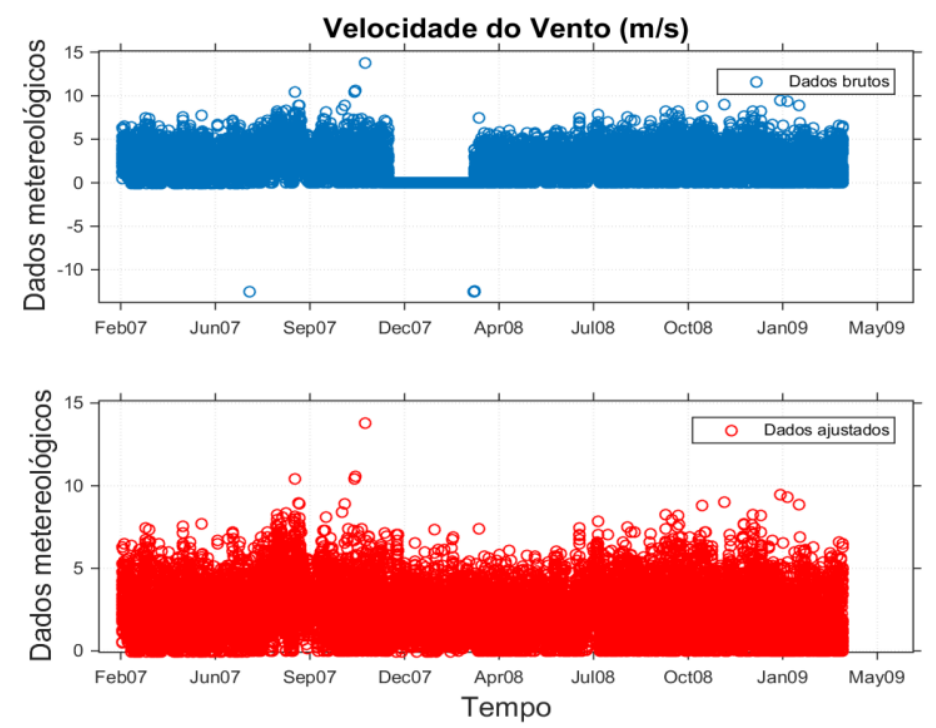

Figura 5-17: a) Série de dados brutos de velocidade do vento b) Série de dados ajustados de velocidade do vento.
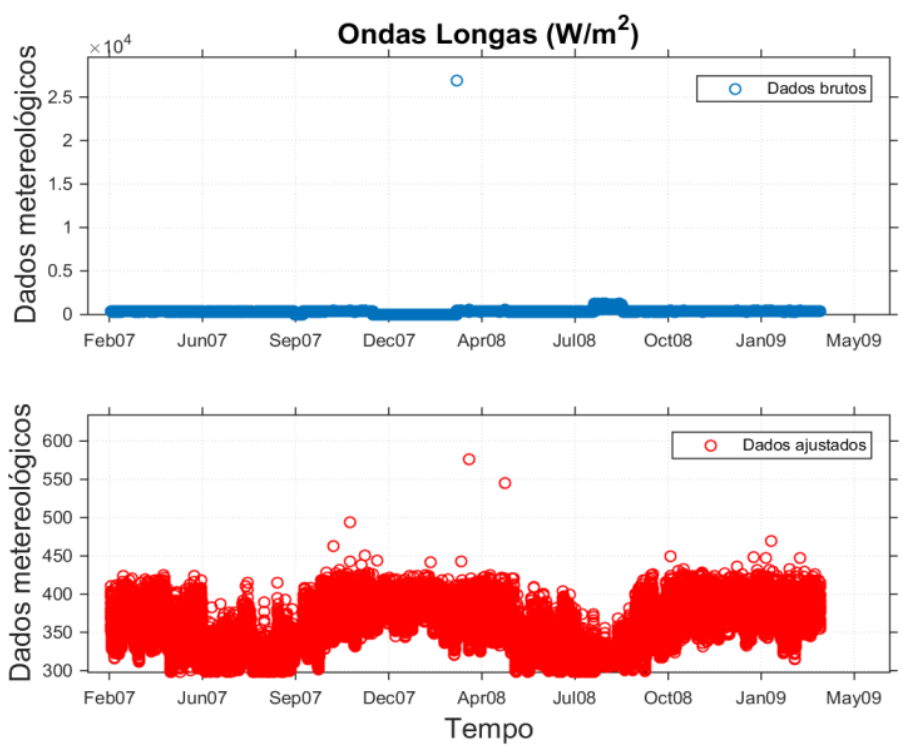

Figura 5-18: a) Série de dados brutos de radiação de ondas longas b) Série de dados ajustados de radiação de ondas longas.

Os dados suspeitos podem ser notados nos gráficos, pois atribuem valores nulos e até negativos para dados ambientais que não poderiam apresentar essas medições. Todavia, os dados de radiação de ondas longas foram os que mais chamaram a atenção, pois a média de ondas longas dos demais meses do período para calibração era de $360 \mathrm{~W} / \mathrm{m}^{2}$ e na Figura 5-18 nota-se um ponto isolado com a medida acima de $2500 \mathrm{~W} / \mathrm{m}^{2}$ e o mês de agosto de 2008 cujo nenhum valor era abaixo de $500 \mathrm{~W} / \mathrm{m}^{2}$. 
A Figura 5-19 mostra a validação dos dados de radiação solar, demais dados meteorológicos e vento divulgada no site do INPE (2015) para o mês de agosto de 2008. Percebe-se que a validação da radiação de ondas longas constata o referido mês como dados inteiramente suspeitos na $2^{\circ}$ etapa.

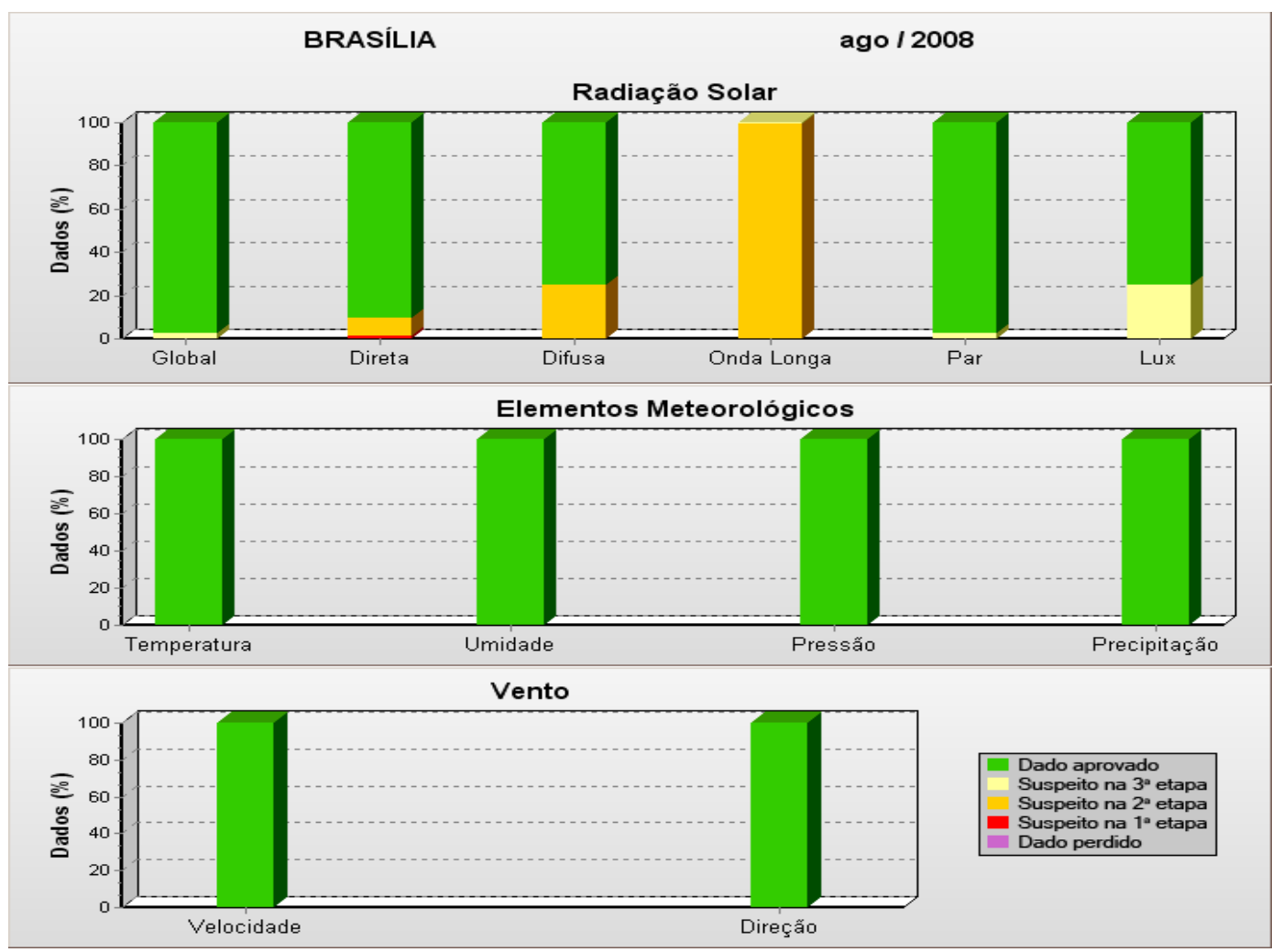

Figura 5-19: Validação dos dados do INPE para o mês de agosto de 2008. Fonte: Site do INPE (2015).

Rigosi e Rueda (2012b) buscaram analisar as fontes de incerteza na modelagem ecológica, com ênfase em modelos unidimensionais que acoplam um módulo físico para simular a estrutura física da coluna de água e módulos ecológicos. Se as incertezas no modelo físico propagam-se para os resultados do modelo ecológico. Para isso, foi avaliado o desempenho do modelo DYRESM-CAEDYM para o lago Béznar, localizada no sul da Espanha, durante um período de aproximadamente 2 meses no ano de 2005.

O estudo de Rigosi e Rueda (2012b) concluiu que a incerteza nas previsões físicas pode surgir a partir de uma variedade de fontes, entre elas as variáveis meteorológicas de entrada. Sabe-se que essas variáveis geralmente são medidas em pontos discretos no espaço, mas, na verdade estão sujeitas a grandes variações espaciais. Sabe-se que o 
fluxo de calor é considerado o mais importante controlador da temperatura em lagos e é composto pela dinâmica com os dados meteorológicos.

Já Gal et al. (2003) utilizaram o modelo DYRESM para simular as temperaturas observadas e o nível d'água no lago Kinneret, Israel, e realizou uma análise de sensibilidade para os parâmetros do modelo hidrodinâmico e para os dados de entrada para verificar os aspectos dos dados disponíveis que poderiam limitar a precisão das previsões do modelo. A análise de sensibilidade indicou que a saída do modelo foi mais sensível a alterações de dados meteorológicos, principalmente a radiação de ondas longas e velocidade do vento.

Dessa maneira, essa análise da consistência dos dados meteorológicos mostrou dados brutos suspeitos que possivelmente se não tivessem sido ajustados influenciariam no aumento da incerteza nos resultados do modelo GLM-AED para o lago Paranoá. Principalmente os dados de radiação de ondas longas.

\subsection{ANÁLISE DE SENSIBILIDADE E OTIMIZAÇÃO DA CALIBRAÇÃO DO GLM}

Os parâmetros relacionados à mistura, à termodinâmica e ao coeficiente de extinção de luz foram otimizados individualmente na busca do ótimo global que seriam os resultados parametrizados ou calibrados. Dois parâmetros ligados à termodinâmica não variam: a emissividade da água superficial (E) e a constante de Stefan-Boltzmann $(\Sigma)$, e dessa forma não foram considerados na análise de sensibilidade aqui proposta. Ao total, foram testados 10 parâmetros.

A Tabela 5-2 apresenta os valores ótimos encontrados para cada parâmetro, o menor e o maior valor de RMSE alcançado para o perfil em toda a coluna d'água e a variação entre esses dois valores.

Markfort et al. (2010) afirmam que o vento e os fluxos de calor são as causas mais importantes de circulação e turbulência em lagos pequenos e médios. Eles afetam fortemente a qualidade da água e os processos ecológicos e, por essa razão, estão 
sempre incluídos na dinâmica de qualidade da água de lagos e nos modelos de ecossistemas.

Tabela 5-2: Otimização obtida para os parâmetros do GLM no lago Paranoá.

\begin{tabular}{ccccc}
\hline Símbolo & $\begin{array}{c}\text { Valor } \\
\text { ótimo }\end{array}$ & $\begin{array}{c}\text { Menor valor } \\
\text { de } R \text { RSE }\end{array}$ & $\begin{array}{c}\text { Maior valor } \\
\text { de } \text { RMSE }\end{array}$ & Variação \\
\hline $\boldsymbol{C}_{\boldsymbol{T}}$ & 0.45 & 1.556 & 1.578 & 0.023 \\
$\boldsymbol{C}_{\boldsymbol{K}}$ & 0.1 & 1.549 & 1.593 & 0.044 \\
$\boldsymbol{C}_{\boldsymbol{S}}$ & 0.1 & 1.533 & 1.584 & 0.052 \\
$\boldsymbol{C}_{\boldsymbol{K} \boldsymbol{H}}$ & 0.375 & 1.546 & 1.595 & 0.049 \\
$\boldsymbol{C}_{\boldsymbol{H Y P}}$ & 0.575 & 1.555 & 1.577 & 0.022 \\
$\boldsymbol{C}_{\boldsymbol{W}}$ & 0.2 & 1.559 & 1.581 & 0.022 \\
$\boldsymbol{K}_{\boldsymbol{w}}$ & 0.11 & 1.492 & 1.652 & 0.160 \\
$\boldsymbol{C}_{\boldsymbol{h}}$ & 0.00137 & 1.532 & 1.621 & 0.090 \\
$\boldsymbol{C}_{\boldsymbol{e}}$ & 0.00147 & 1.448 & 2.017 & 0.569 \\
$\boldsymbol{C}_{\boldsymbol{d}}$ & 0.0011 & 1.552 & 1.793 & 0.241 \\
\hline
\end{tabular}

De acordo com a Tabela 5-2, três parâmetros se mostraram mais sensíveis no lago Paranoá: dois relacionados à termodinâmica, que foram o coeficiente aerodinâmico de transferência de calor latente $\left(C_{e}\right)$ e o coeficiente aerodinâmico de transferência de momento $\left(C_{d}\right)$; e um relacionado às propriedades do Lago, o coeficiente de atenuação vertical da luz $\left(K_{w}\right)$. Bem como a assertiva de Markfort et al. (2010), os parâmetros relacionados ao vento mostraram-se significativos no Lago. E ainda, os parâmetros com relação aos fluxos de calor confirmaram-se influentes nesse estudo.

Read et al. (2014b) examinaram a sensibilidade da temperatura modelada no GLM à transparência da água, ao tempo de residência e à altura da cobertura do vento, em 2368 lagos temperados. Os autores afirmam que a transparência da água controla a taxa de radiação solar no comprimento de ondas do visível, que é atenuada ao longo da coluna d'água, e que, dessa maneira, o parâmetro coeficiente de atenuação vertical da luz $\left(K_{w}\right)$ torna-se muito importante. Outro parâmetro que os autores identificaram como influente foi o coeficiente aerodinâmico de transferência de momento $\left(C_{d}\right)$, por controlar o fluxo de energia de mistura impulsionada pelo vento. E, por fim, os parâmetros relacionados aos coeficientes de cobertura do vento. 
Pujoni (2015) também se utilizou do modelo GLM para avaliar o efeito do coeficiente $K_{w}$ no padrão de circulação de lagos nas lagoas Carioca e Gambazinho, em Minas Gerais. Como a estação meteorológica que forneceu esses tipos de dados não tinha medições para radiação de ondas longas, o autor teve de estimá-los e, por essa razão, utilizou-se da estimativa de ondas longas no ajuste manual do modelo aos dados de campo. Dessa forma, ele obteve um bom ajuste do modelo em relação a temperaturas simuladas e observadas e encontrou um valor de 0,8 para o $K_{w}$ calibrado.

Dois dos três parâmetros ressaltados por Read et al. (2014b) e o parâmetro avaliado por Pujoni (2015), ao utilizar o GLM, foram também encontrados como sensíveis no lago Paranoá. Dessa maneira, o $K_{w}$ e o $C_{d}$ demonstraram-se como parâmetros influentes nos resultados da modelagem hidrodinâmica em lagos tanto temperados como tropicais.

Após a análise de sensibilidade e otimização da calibração, os valores ótimos encontrados para os parâmetros (Tabela 5-2, coluna 2) foram editados no GLM e o módulo hidrodinâmico foi então rodado para simular a temperatura no lago Paranoá.

A Figura 5-20 apresenta o perfil térmico gerado pelo modelo e a Tabela 5-3 apresenta as estatísticas obtidas nas quatro profundidades analisadas para a simulação com os parâmetros calibrados.

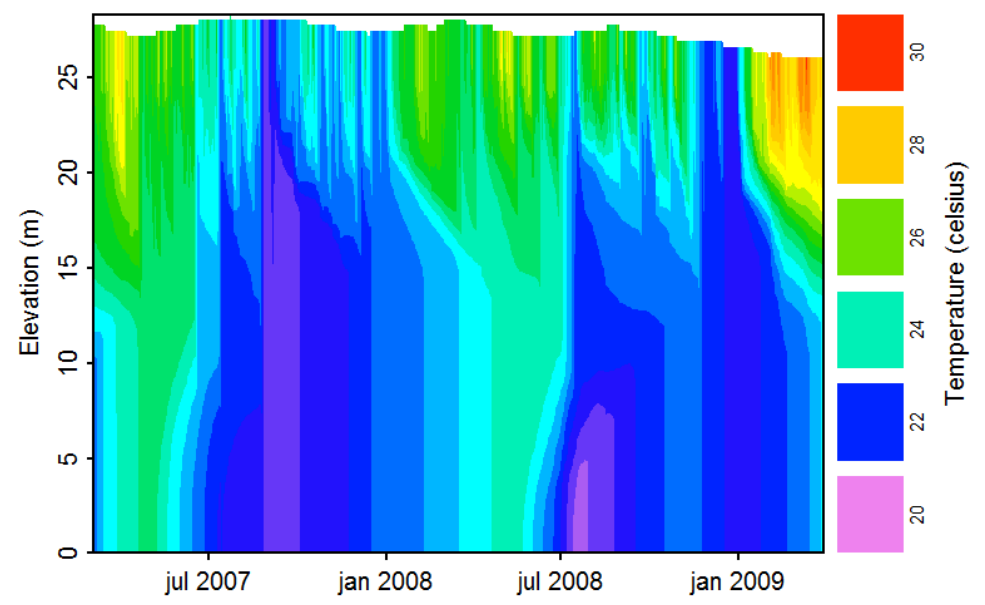

Figura 5-20: Perfil térmico simulado pelo modelo GLM. 
Tabela 5-3: Erros e coeficientes da simulação de temperatura com os parâmetros otimizados para o Lago Paranoá - DF

Estatísticas para os os resultados de temperatura após calibração

\begin{tabular}{lllll}
\hline Profundidades & $\mathbf{1 m}$ & $\mathbf{1 0 m}$ & $\mathbf{1 5 m}$ & $\mathbf{2 0 m}$ \\
RMSE $\left({ }^{\mathbf{0}} \mathbf{C}\right)$ & 1.90 & 1.52 & 1.07 & 1.25 \\
CC & 0.45 & 0.47 & 0.59 & 0.46 \\
CN & -0.41 & -0.30 & 0.14 & -0.81 \\
\hline
\end{tabular}

O modelo gerou como resultado um RMSE médio de $1,47^{\circ} \mathrm{C}$ para a temperatura ao longo da coluna d'água. Read et al. (2014b) encontraram valores de RMSE de 2,78 ${ }^{\circ} \mathrm{C}$ para as temperaturas ao longo da coluna d'água, $1,74^{\circ} \mathrm{C}$ para as temperaturas do eplímnio e 3,33 ${ }^{\circ} \mathrm{C}$ para as temperaturas do hipolímnio. Os autores atribuem, pela análise de sensibilidade preliminar, que, melhorando as estimativas da transparência da água, pode-se produzir ganhos significativos na qualidade das temperaturas simuladas nas profundidades maiores.

Como observado na Tabela 5-3, foram obtidos melhores ajustes quanto maiores as profundidades, o erro-padrão não chegou a $2^{\circ} \mathrm{C}$ de diferença e as correlações ficaram a uma média de 50\% entre dados observados e simulados. Liporoni (2012), utilizando o modelo bidimensional CE-QUAL-W2, encontrou um RMSE médio de $0.574^{\circ} \mathrm{C}$ para a temperatura em todas as profundidades analisadas no lago Paranoá e também encontrou melhores resultados nas maiores profundidades. $\mathrm{O}$ autor atribui isso à forte influência da radiação solar e do vento no ambiente de estudo.

A Figura 5-21 mostra as temperaturas obtidas pela simulação de base (com os parâmetros default) e a Figura 5-22 as temperaturas simuladas versus as observadas para as quatro profundidades avaliadas após calibração. 


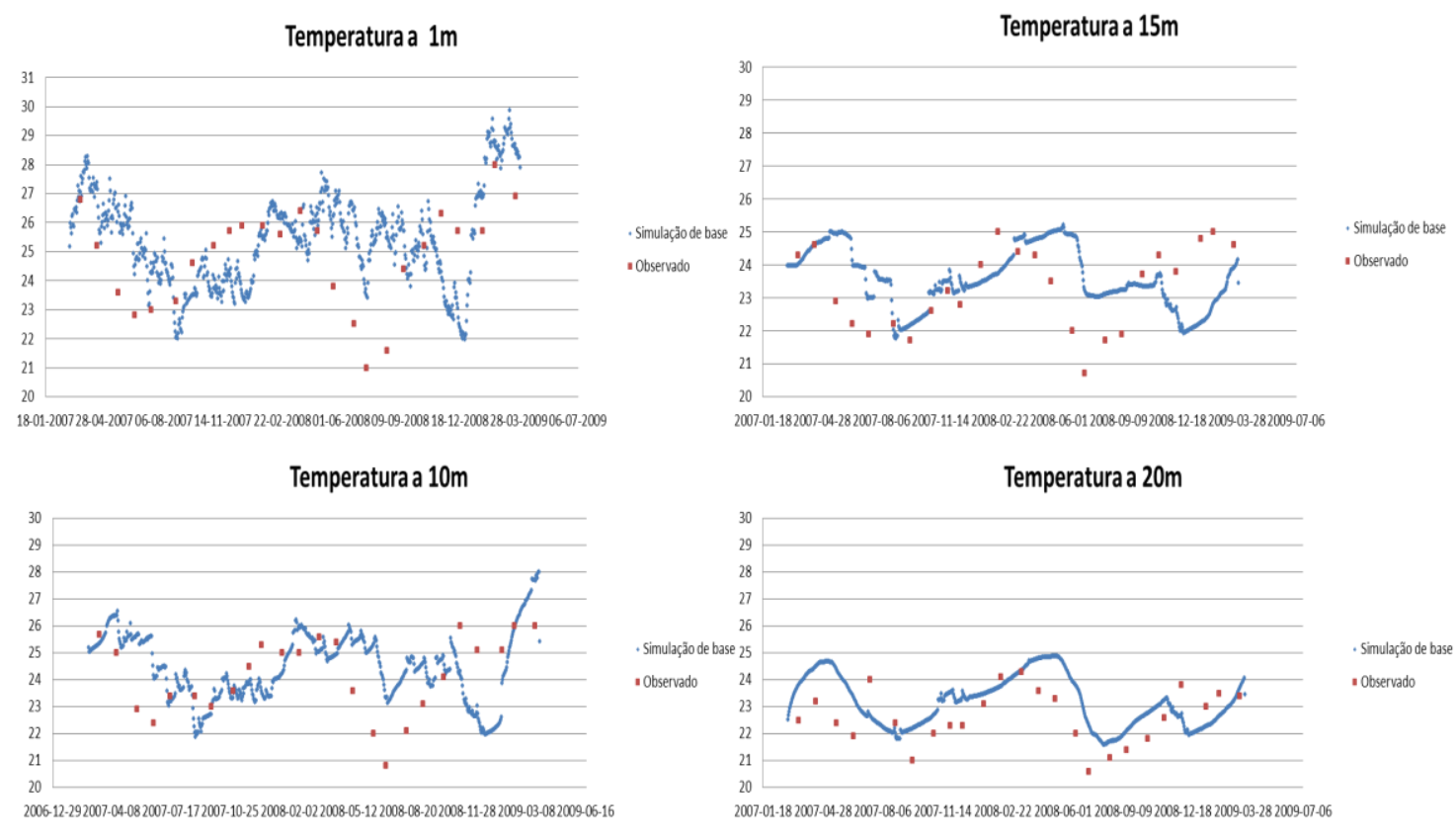

Figura 5-21: Gráficos de comparação da simulação de base com os dados observados nas 4 profundidades.

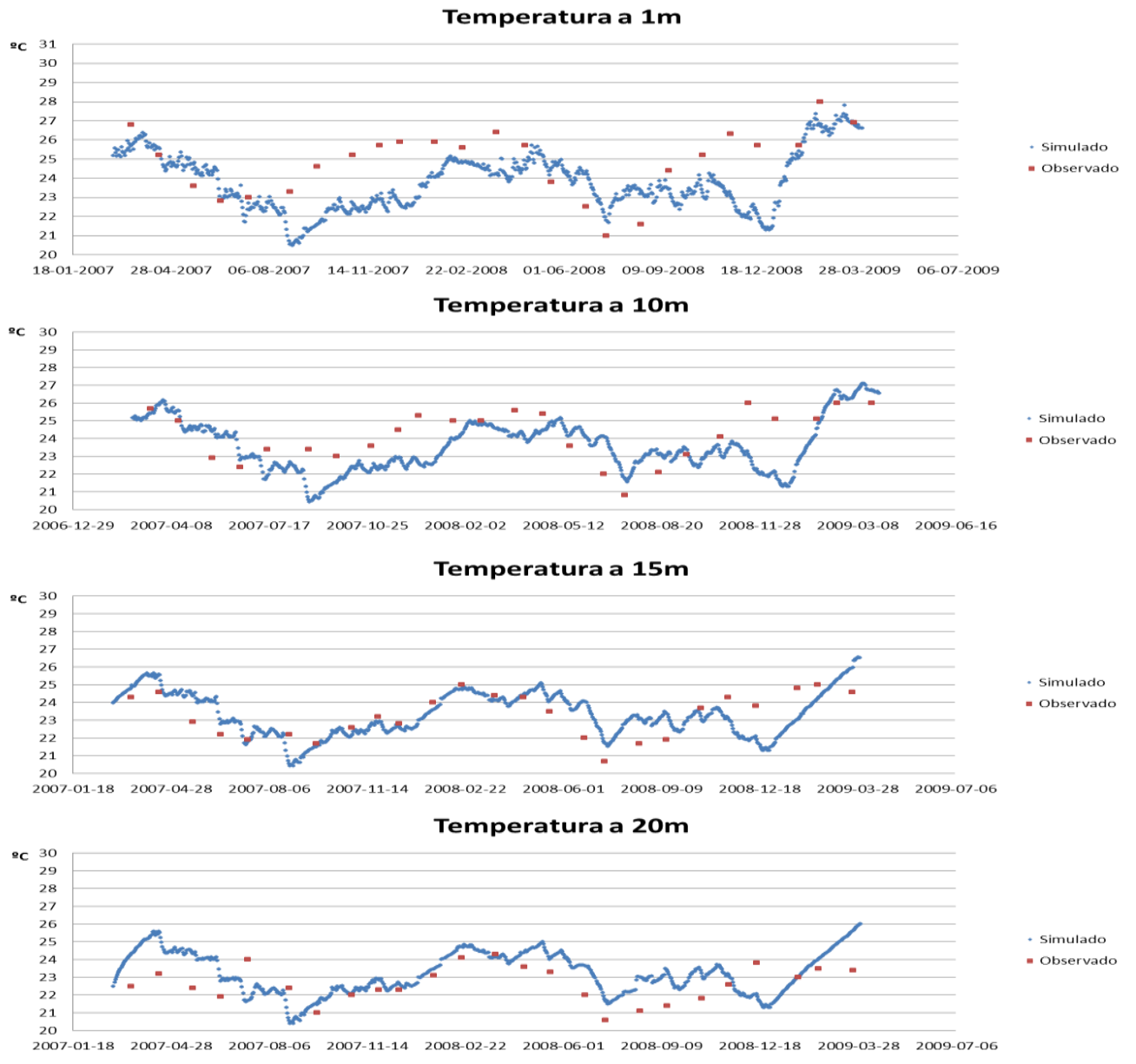

Figura 5-22: Gráficos de comparação de temperaturas simuladas x observadas após calibração nas 4 profundidades. 
Os dados do monitoramento da CAESB mostraram a temperatura nos meses de dezembro de 2008 e janeiro de 2009 com o mesmo valor de medição a 1 metro e 10 metros, correspondendo a $25,7^{\circ} \mathrm{C}$ e $25,1^{\circ} \mathrm{C}$, respectivamente. E, ainda, na profundidade de 10 metros, também os meses de fevereiro e março de 2009 apresentaram a mesma medida de temperatura: $26^{\circ} \mathrm{C}$. Com isso, pode-se observar a formação de um platô nesse período (Figura 5-21 e Figura 5-22).

Observando à Figura 5-22, no início do período calibrado (março a junho de 2007), as temperaturas simuladas a $1 \mathrm{~m}, 10 \mathrm{~m}$ e $15 \mathrm{~m}$ sugerem bom ajuste em relação aos dados observados nas 4 profundidades. Após isso, o modelo subestima as temperaturas no período até abril de 2008 e depois passa a superestimar até setembro de 2008, que seria o período seco. Após esse, as temperaturas simuladas voltam a subestimar a realidade. A $10 \mathrm{~m}, 15 \mathrm{~m}$ e $20 \mathrm{~m}$ o final do período simulado é superestimado.

No que tange ao ajuste do modelo relacionado aos perfis verticais de temperatura, a Figura 5-23 apresenta o perfil de temperaturas observadas e simuladas em alguns meses para o Lago.

Pode se observar o bom ajuste alcançado para os primeiros meses de simulação, representado por março de 2007 e também para os últimos meses do período considerado, representado por janeiro e fevereiro de 2009. Todavia, no primeiro mês de 2009 o modelo simulou o comportamento da temperatura com um erro fixo (viés).

Apesar de a Figura 5-23 evidenciar o mês de fevereiro de 2008 com temperaturas subestimadas, o perfil térmico simulado nesse mês apresentou bom ajuste. Em contrapartida, o mês de agosto do referido ano comprova a superestimação das temperaturas simuladas com um viés. Já para setembro de 2008, o modelo conseguiu se ajustar bem às temperaturas do epilímnio, contudo superestimou a temperatura nas maiores profundidades, e, também, apresentou dificuldade em simular a estratificação térmica no lago Paranoá. 

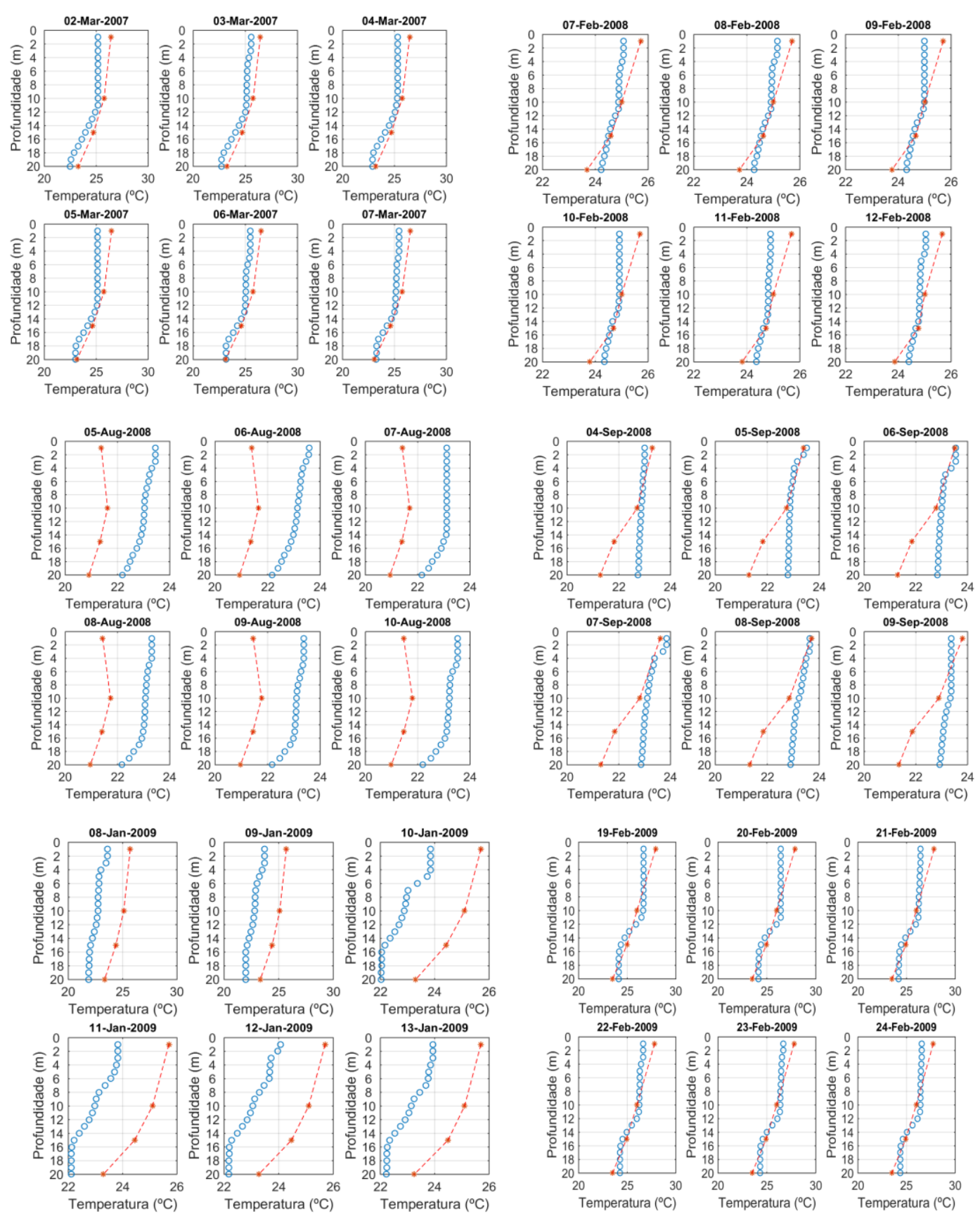

Figura 5-23: Perfis de temperatura simulada (azul) e observada (vermelho) no lago Paranoá para os meses de março de 2007, fevereiro, agosto e setembro de 2008 e janeiro e fevereiro de 2009.

\subsection{ANÁlise DE SENSIBILIDADE E CALIBRAÇÃO DO MÓdULO ECOLÓGICO - AED (MÓDULO FITOPLÂNCTON)}

Os parâmetros do fitoplâncton relacionados a crescimento, luz, respiração, nitrogênio e fósforo foram testados para observar a sensibilidade da biomassa de clorofíceas e cianobactérias a variações superiores e inferiores ao valor-padrão. A análise de 
sensibilidade foi realizada manualmente, alterando-se os valores dos parâmetros individualmente e observando os resultados da simulação da biomassa dos dois grupos de fitoplâncton, em comparação aos dados de biomassa de clorofíceas e cianobactérias observadas.

O primeiro parâmetro modificado do grupo de crescimento foi a taxa máxima de crescimento do fitoplâncton a $20^{\circ} \mathrm{C}$ ( $R \_$growth) e, como esperado, aumentando esse valor se observou um aumento da biomassa fitoplanctônica. As clorofíceas aumentaram de forma acentuada na superfície enquanto as cianobactérias predominaram no fundo do Lago. Esse aumento de ambas causou um aumento dos níveis de oxigênio na superfície. Ao diminuir o valor do parâmetro, também diminuiu a biomassa dos dois grupos.

O segundo parâmetro analisado foi a constante de semi-saturação para limitação de luz no crescimento do fitoplâncton $\left(I \_K\right)$ que, por sua vez, ao ser elevada, aumentou a quantidade do fitoplâncton na superfície. Quanto menor foi o valor desse parâmetro, maior a biomassa de fitoplâncton no fundo do Lago.

Em relação aos parâmetros de respiração, foi avaliada a taxa de perda metabólica por respiração do fitoplâncton a $20{ }^{\circ} \mathrm{C}\left(R \_r e s p\right)$. Esse parâmetro demonstrou relação direta com a biomassa de fitoplâncton e o consumo de oxigênio. Quanto maior o valor da taxa de respiração, menor a biomassa do fitoplâncton e, como consequência, menos oxigênio disponível no lago. Esse parâmetro foi o que se mostrou mais sensível para influenciar o fitoplâncton em todas as profundidades.

Outro parâmetro observado, ainda com relação ao grupo da respiração, foi a taxa de perda metabólica devido à respiração pura do fitoplâncton $\left(K_{-}\right.$fres $)$. Porém, esse apresentou pouca sensibilidade na biomassa do fitoplâncton. Com relação ao controle da população de fitoplâncton, um parâmetro que mostrou grande influência na redução dessa biomassa foi a taxa de sedimentação $\left(W_{-} p\right)$.

Com relação aos parâmetros relacionados ao nitrogênio e fósforo, o modelo permite considerar ou não a fixação de nitrogênio e a absorção de fósforo pelo fitoplâncton (simNFixation e simDIPUptake) nas simulações. Os resultados não mostraram grandes variações para o fitoplâncton. 
Após esse primeiro teste de sensibilidade, a análise foi voltada para os grupos que tiveram mais impacto nos resultados. Foram eles: crescimento, luz e respiração.

Para os parâmetros de crescimento do fitoplâncton, ajustando o parâmetro de temperatura padrão $\left(T \_s t d\right)$ para a média observada no período da simulação e aproximando a temperatura ótima (T_opt) desse ponto, garantiu-se uma melhor distribuição da biomassa durante todo o período simulado.

O ajuste da temperatura ótima para o crescimento do fitoplâncton melhorou o desempenho da simulação, tanto o grupo das clorofíceas quanto as cianobactérias, uma vez que todos os parâmetros mencionados podem ser alterados individualmente para cada um desses grupos. Com isso, como os dados observados mostravam mais clorofíceas nas menores profundidades do lago Paranoá, a temperatura ótima foi ajustada com um valor mais alto que a das maiores profundidades, onde existe uma maior concentração de cianobactérias. Ou seja, para clorofíceas, foi usada a média de temperatura até 10 metros e, para cianobactérias, a média de 15 a 20 metros.

Ao final da análise de sensibilidade, os parâmetros de crescimento, luz e respiração mostraram-se mais sensíveis no lago Paranoá. Essas observações foram levantadas com base nas diversas iterações realizadas manualmente e que refletiram nos resultados de biomassa dos dois grupos do fitoplâncton que estão sendo avaliados e nas demais variáveis de qualidade da água. Entre esses parâmetros, a taxa de crescimento do fitoplâncton a $20^{\circ} \mathrm{C}$, a temperatura ótima, a constante de semi-saturação para limitação de luz no crescimento do fitoplâncton, a taxa de perda metabólica por respiração do fitoplâncton a $20^{\circ} \mathrm{C}$ foram os parâmetros considerados mais sensíveis para os dois grupos de fitoplâncton.

Schladow e Hamilton (1997) ao fazer a análise de sensibilidade do modelo DYRESM para o reservatório Prospect, localizado na Austrália, avaliaram as mudanças na concentração média ao longo de toda a coluna de água, na distribuição vertical e na distribuição temporal de clorofila- $a$ e OD. Para isso, foram testados 29 parâmetros. Desses, apenas 10 se mostraram mais sensíveis aos aspectos analisados. Em semelhança ao encontrado no presente estudo, os parâmetros para os quais a concentração de 
clorofila- $a$ foi altamente sensível para os autores foram aqueles que alteram diretamente as taxas de crescimento ou indiretamente incidem sobre as taxas de crescimento por sua capacidade para assimilar fósforo.

Também, o estudo de Huang et al. (2012) confirmou a sensibilidade dos parâmetros ligados ao crescimento do fitoplâncton nos resultados das simulações do grupo ecológico. Os autores procederam a uma análise de sensibilidade dos parâmetros relacionados à cinética do fitoplâncton para um novo modelo hidrodinâmico-ecológico proposto a fim de simular a distribuição espacial e temporal de algas no lago Taihu, China. A concentração de clorofila- $a$ foi a única variável de estado utilizada para representar a biomassa de fitoplâncton. Os autores chegaram a 4 parâmetros mais sensíveis, sendo todos relacionados ao crescimento do fitoplâncton: taxa máxima de crescimento do fitoplâncton, constante de Michaelis para absorção de fósforo, taxa de perda de clorofila-a causada pela respiração e multiplicadores de temperatura.

Já Fragoso Jr. et al. (2008) evidenciaram a sensibilidade dos parâmetros ligados, também, à respiração do fitoplâncton e ao crescimento. Eles simularam a heterogeneidade espacial do fitoplâncton por meio de um modelo bidimensional horizontal que acopla hidrodinâmica e módulos de nutrientes e crescimento do fitoplâncton para o lago Mangueira, sul do Brasil. Para os parâmetros do fitoplâncton, os autores encontraram, como mais sensíveis à taxa de crescimento máximo, coeficiente de efeito de temperatura, coeficiente dos efeitos de respiração/excreção, taxa de respiração e taxa de herbivoria.

Dessa maneira, os autores citados identificaram os parâmetros que definem a taxa de crescimento e as perdas por respiração do fitoplâncton como influentes, bem como foi encontrado no presente estudo. Todavia, as análises dos autores levaram em conta somente as respostas da clorofila- $a$ como medida indireta do fitoplâncton e, por isso, obtiveram somente uma calibração geral para o fitoplâncton, não considerando grupos separadamente.

$\mathrm{Na}$ análise de sensibilidade aqui realizada, foram observadas diferentes respostas para cada um dos dois grupos fitoplanctônicos, muitas vezes antagônicas. Rigosi e Rueda (2012a) afirmam que as cianobactérias possuem elevada sensibilidade à luz e tolerância 
a altas temperaturas e as clorofíceas, por sua vez, possuem um comportamento tolerante a condições de baixa luminosidade, contudo são sensíveis ao aumento de temperatura no ambiente.

Dessa maneira, houve muita dificuldade em encontrar uma parametrização ótima para ambas ao mesmo tempo e optou-se por buscar duas calibrações. A primeira que satisfaria o grupo das clorofíceas e a segunda o grupo das cianobactérias. Após a análise de sensibilidade, os valores-ótimo encontrados foram considerados como a parametrização adequada para o lago Paranoá.

A Tabela 5-4 apresenta os valores do conjunto de parâmetros ótimos (calibrados) para cada um dos grupos, onde as siglas dos parâmetros no modelo correspondem a: $R \_$growth - taxa de crescimento do fitoplâncton a $20^{\circ} \mathrm{C} ; T \_o p t$ - temperatura ótima; $I \_K$ - constante de semi-saturação de luz para limitação de algas; e $R \_r e s p$ - taxa de respiração do fitoplâncton a $20^{\circ} \mathrm{C}$.

Tabela 5-4: Valores calibrados para os parâmetros do fitoplâncton no lago Paranoá-DF.

\section{Parâmetros calibrados do modulo de fitoplâncton}

\begin{tabular}{lllll}
\hline Grupos & R_growth (/d) & T_opt $\left({ }^{\circ} \mathrm{C}\right)$ & I_K $\left(\mu \mathrm{Em}^{-2} s^{-1}\right)$ & R_resp (/d) \\
Clorofíceas & $0.9 *$ & 23.5 & 90 & 0.04 \\
Cianobactérias & 1.4 & $28.0^{*}$ & 100 & 0.04 \\
\hline \multicolumn{2}{c}{ *valor padrão } & & &
\end{tabular}

Pela avaliação dos valores calibrados para os parâmetros, mostrado na Tabela 5-4, podese notar que a taxa de crescimento do grupo das clorofíceas encontrou seu ótimo no valor-padrão do modelo, que é de 0,9 /d. Bem como a temperatura-ótima para as cianofíceas que, depois de diversas iterações, estabeleceu seu valor final também como o padrão para seu grupo, correspondente a $28^{\circ} \mathrm{C}$.

Ainda, o parâmetro da taxa de crescimento das cianobactérias ficou acima do valor padrão do modelo, que é de 1.0 /d. Já para os parâmetros de meia saturação de luz para crescimento e taxa de respiração, os parâmetros encontraram valores ótimos abaixo do padrão de $130 \mu \mathrm{Em}^{-2} \mathrm{~s}^{-1}$ e 0.085 /d, respectivamente. Para as clorofíceas, a temperatura ótima e a taxa de respiração ficaram abaixo dos valores padrão de $27^{\circ} \mathrm{C}$ e 
0.085 /d e o parâmetro de meia saturação de luz para crescimento ficou acima dos 80 $\mu \mathrm{Em}^{-2} s^{-1}$, tidos como padrão.

Como tratado anteriormente, não se conseguiu essa parametrização conjuntamente, pois os grupos apresentam características próprias e apesar de todas as tentativas de realizar única calibração que favoreceria os dois grupos, essa não foi alcançada utilizando o modelo GLM-AED no lago Paranoá. Assim sendo, os valores de parâmetros da Tabela 5-4 foram alcançados, considerando sempre os parâmetros default para o outro grupo.

O modelo utilizado é de recente desenvolvimento e a escassez de publicações e constantes atualizações dificultaram maiores tentativas no seu manuseio. Ressalta-se que, a partir da escolha do modelo para utilização no lago Paranoá, iniciou-se utilizando a versão 1.4 e, até a finalização deste trabalho, a versão vigente já era a 2.0. Muitas mudanças foram sendo incorporadas a cada versão, desde a alteração no nome e nas unidades de algumas variáveis até na liberação da versão implementada no software R.

\subsection{SIMULAÇÃO DA QUALIDADE DA ÁGUA}

Ao se proceder às etapas de análise de sensibilidade e calibração do módulo do fitoplâncton no AED, foi necessário inicializar os módulos relacionados a oxigênio, carbono, nutrientes e matéria orgânica por serem esses ligados à dinâmica das comunidades fitoplanctônicas. Dessa maneira, neste tópico, são apresentados os resultados das simulações para os dois grupos do fitoplâncton (clorofíceas e cianobactérias) e para as demais variáveis de qualidade da água: temperatura, oxigênio, nitrato, amônia e fosfato.

Salienta-se, novamente, que somente o módulo de fitoplâncton foi calibrado devido ao objetivo aqui proposto, os demais módulos ecológicos foram apenas inicializados pelo modelo. Essa análise foi um primeiro teste na utilização dos módulos AED para o lago Paranoá.

Observam-se na Figura 5-24 e Figura 5-25 os resultados de biomassa de clorofíceas e cianobactérias simuladas versus as observadas, respectivamente, nas quatro profundidades analisadas. 


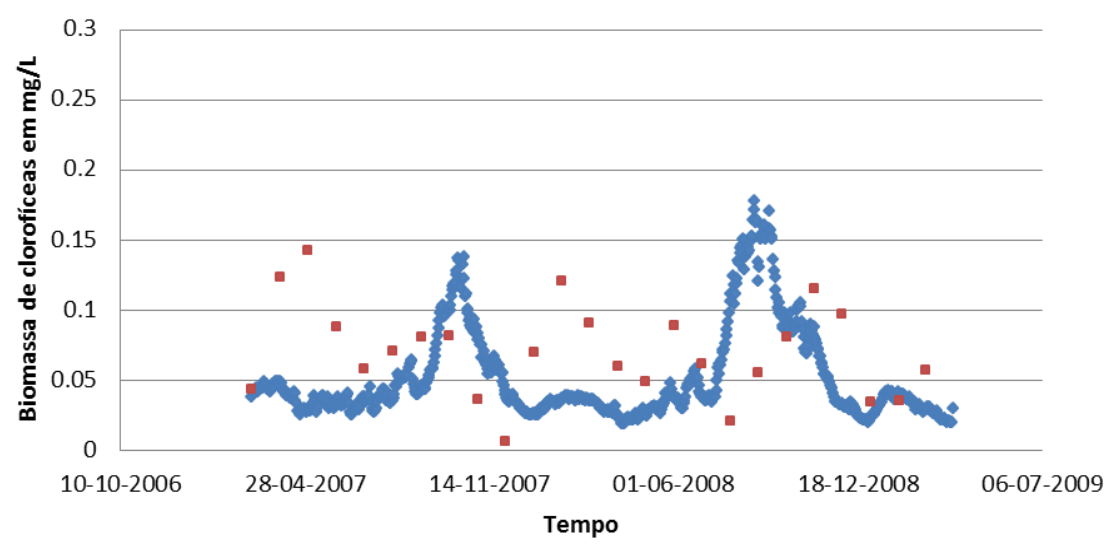

- Simuladas a $1 \mathrm{~m}$

- Observadas a $1 \mathrm{~m}$

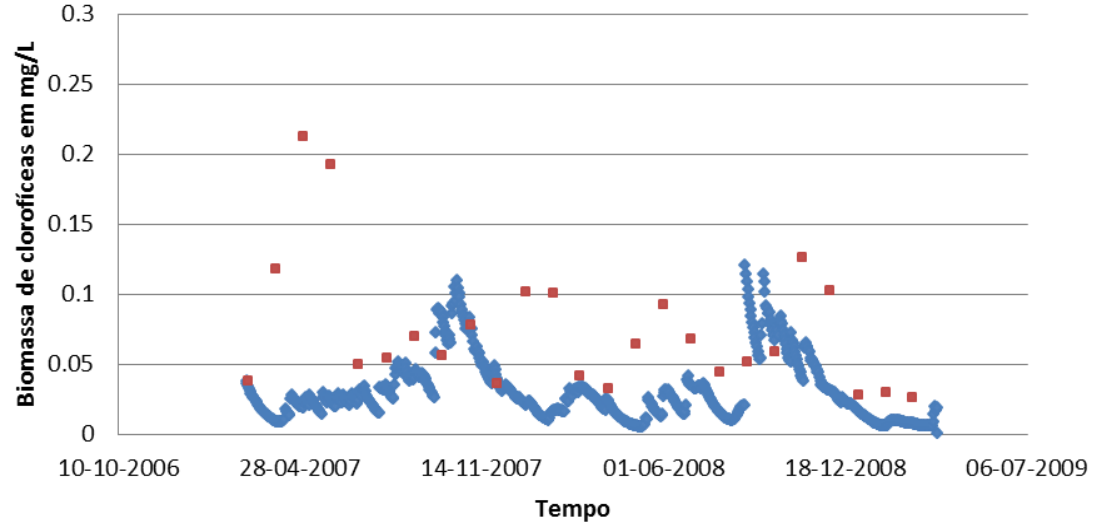

- Simuladas a $10 \mathrm{~m}$

- Observadas a $10 \mathrm{~m}$

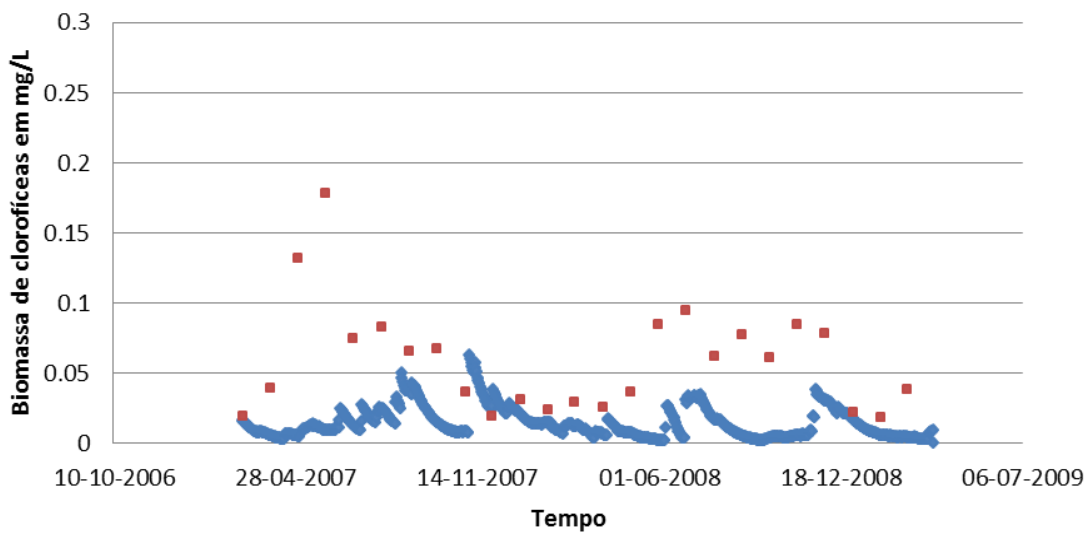

- Simuladas a $15 \mathrm{~m}$

- Observadas a 15m

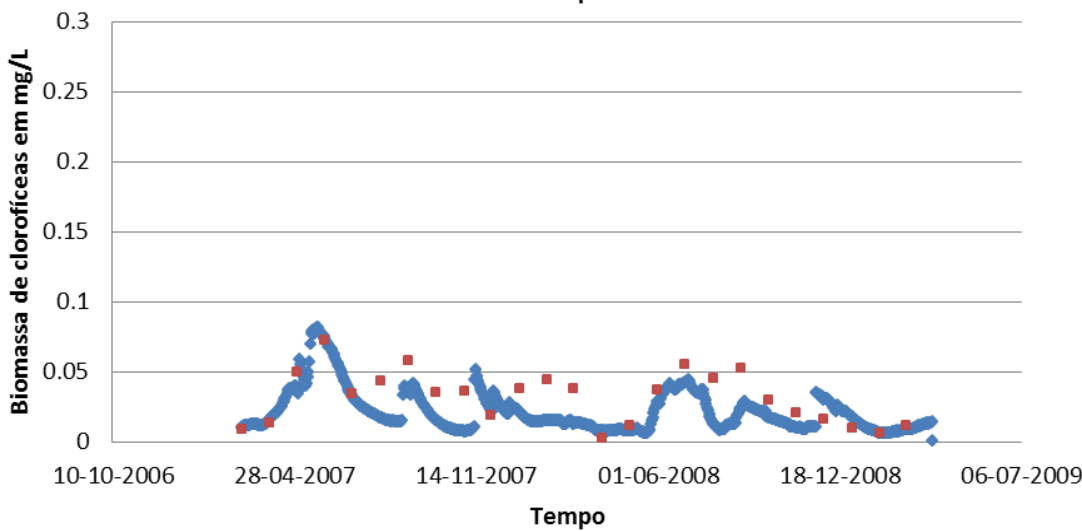

- Simuladas a 20m

- Observadas a 20m

Figura 5-24:a)Biomassa de clorofíceas observadas vs simuladas a 1m; b)Biomassa de clorofíceas observadas vs simuladas a 10m; c)Biomassa de clorofíceas observadas vs simuladas a $15 \mathrm{~m}$ e d)Biomassa de clorofíceas observadas vs simuladas a $20 \mathrm{~m}$. 


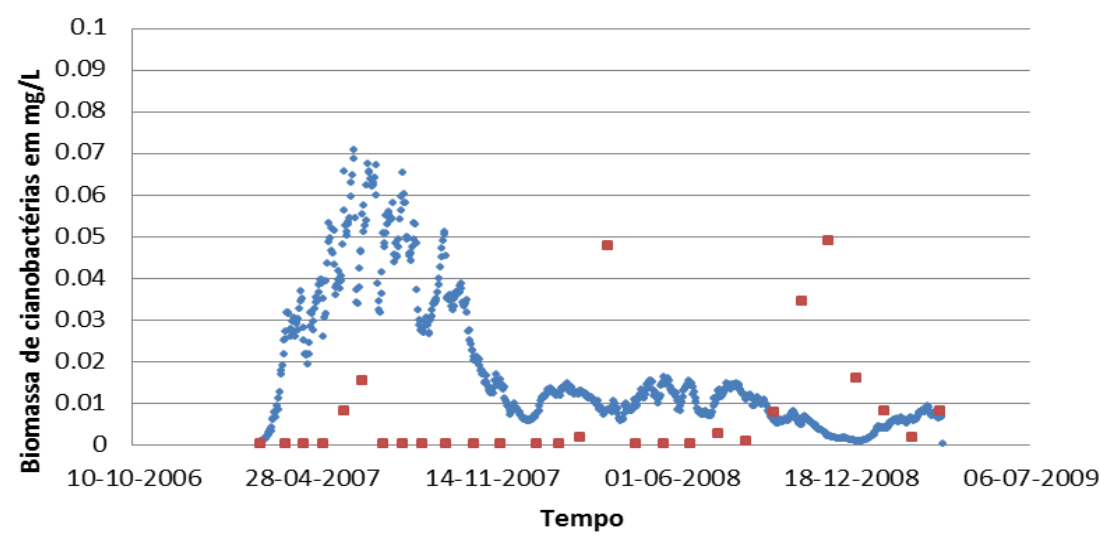

- Simulada a $1 \mathrm{~m}$

- Observada a $1 \mathrm{~m}$

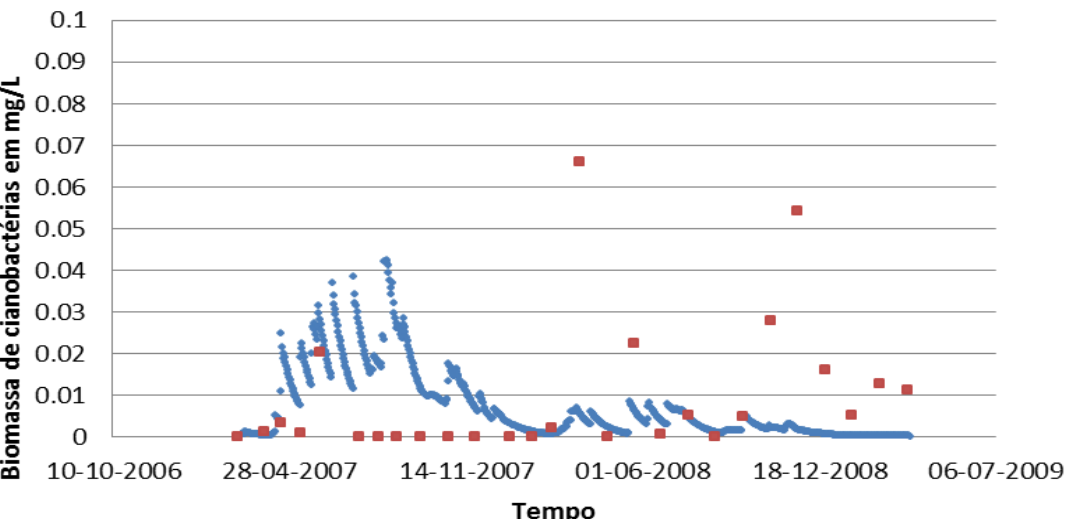

- Simulada a $10 \mathrm{~m}$

- Observada a $10 \mathrm{~m}$

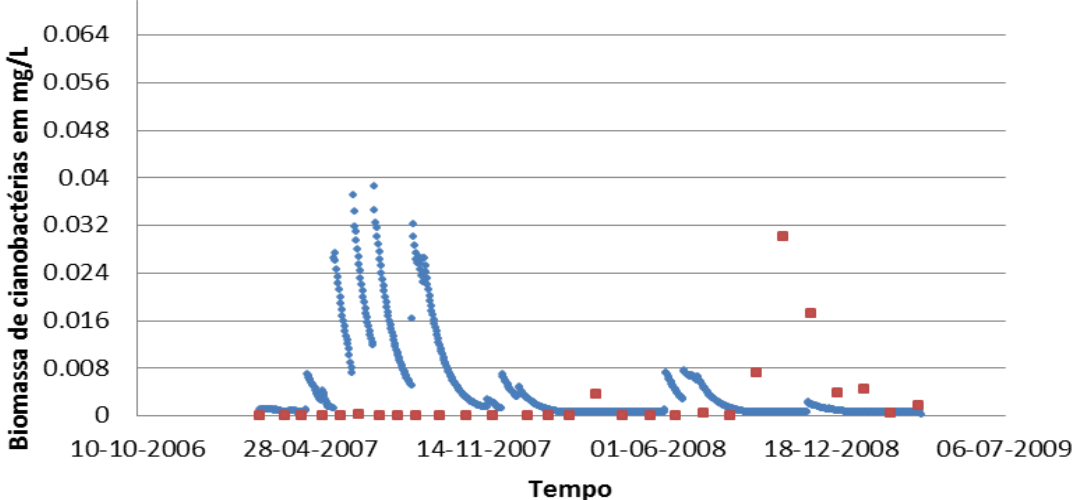

- Simulada a $15 \mathrm{~m}$

- Observada a $15 \mathrm{~m}$

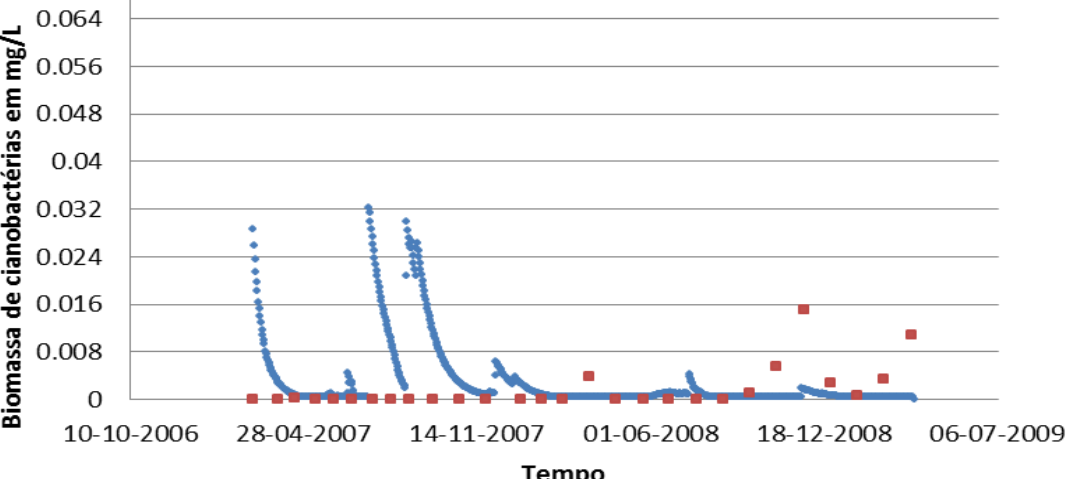

- Simulada a $20 \mathrm{~m}$

- Observada a 20m

Figura 5-25:a)Biomassa de cianobactérias observadas vs simuladas a 1m; b)Biomassa de cianobactérias observadas vs simuladas a 10m; c)Biomassa de cianobactérias observadas vs simuladas a $15 \mathrm{~m}$ e d)Biomassa de cianobactérias observadas vs simuladas a $20 \mathrm{~m}$. 
Na Figura 5-24, nos primeiros meses da simulação, correspondente ao período de março a julho de 2007, a profundidade de $20 \mathrm{~m}$ da superfície foi a única que alcançou um bom ajuste entre a biomassa observada e simulada de clorofíceas no lago Paranoá. Esse resultado pode ser atribuído à pouca representatividade do fitoplâncton, em termos quantitativos, nas maiores profundidades. Nas demais profundidades, o modelo subestimou a biomassa de clorofíceas nos meses iniciais do período de simulação.

É possível também notar, na Figura 5-24, dois viés na profundidade de $1 \mathrm{~m}$ da superfície nos meses de agosto a dezembro de 2007 e de junho a novembro de 2008, e a 10m da superfície, no período de dezembro de 2007 a março de 2008 e agosto de 2008 a janeiro de 2009, em que o modelo deslocou os picos para a esquerda. Não há como inferir a(s) razão(s) para esse comportamento do modelo, contudo, a falta de calibração dos demais parâmetros biogeoquímicos e/ou os próprios erros associados aos dados de entrada podem ter influenciado nos erros dos resultados simulados.

Ainda, em relação à Figura 5-24, na profundidade de $15 \mathrm{~m}$ da superfície, o modelo subestimou as clorofíceas a maior parte do tempo. Contudo, na profundidade de $20 \mathrm{~m}$ da superfície, observa-se bom ajuste dos dados simulados e observados durante todo o período analisado. Ressalta-se, mais uma vez, que esse comportamento é proveniente da menor representatividade do fitoplâncton nas regiões mais profundas do Lago.

Ao contrário das clorofíceas, as cianobactérias foram superestimadas nos primeiros meses de simulação em todas as profundidades, correspondente aos meses de março a outubro de 2007 (Figura 5-25). A média para esses meses foi de 0,01 mg/L de biomassa de cianobactérias e o modelo alcançou uma média de 0,045 mg/L.

Ainda, em relação à Figura 5-25, nota-se que o modelo não foi capaz de simular os picos observados a 1m,10m e 15m da superfície. Aparentemente, o AED se ateve aos mínimos observados para o grupo e não conseguiu acompanhar os poucos momentos de aumento na biomassa total. Assim como a biomassa de clorofíceas, que teve seu melhor ajuste nas maiores profundidades, a biomassa de cianobactérias também apresentou o mesmo comportamento. 
As clorofíceas apresentaram uma biomassa máxima observada de $0,21 \mathrm{mg} / \mathrm{L}$ no mês de maio de 2007 a 10m de profundidade. Já a biomassa de cianobactérias alcançou o seu valor máximo de medição em maio de 2008 com registro de $0,067 \mathrm{mg} / \mathrm{L}$ também a $10 \mathrm{~m}$ de profundidade. Esses valores da medição de campo não podem ser considerados como o padrão comportamental dos referidos grupos no lago Paranoá, pois são amostras de apenas 2 anos de um monitoramento de mais de 30 anos. Sabe-se que o padrão observado no Lago é o aumento da biomassa fitoplanctônica na estação chuvosa, que geralmente vai de outubro a março.

Branco e Senna (1996) investigaram as relações entre fitoplâncton, zooplâncton, clorofila- $a$, bactérias heterotróficas e as características físicas e químicas nas sete estações de monitoramento no lago Paranoá, durante o período de março de 1988 a março de 1989. Durante esse período estudado, o Lago era ainda classificado como eutrófico. Os autores identificaram que as concentrações do fitoplâncton diminuíram durante a estação seca na maioria dos pontos de monitoramento, principalmente em outubro (tido como o final da estação seca para esses anos). E, dessa maneira, eles concluíram que, na estação das chuvas, que ia de novembro a abril, a abundância do fitoplâncton era maior devido ao aporte de nutrientes ser diluído, a estratificação térmica e a alta temperatura da água intensificarem o metabolismo do fitoplâncton.

No estudo de Branco e Senna (1996), também se identificou predominância do grupo das cianobactérias no lago Paranoá no período de 1988-1989, onde 82\% das amostras analisadas foram identificadas como a espécie Cylindrosperinopsis raciborskii.

Souza (2013), ao identificar a biomassa para cada grupo funcional presente no lago Paranoá, encontrou os valores apresentados na Tabela 5-5.

Pode-se observar, na Tabela 5-5, o aumento da biomassa de clorofíceas no período de 1999 a 2011, caracterizado como de melhor qualidade da água no Lago. Contudo, a biomassa de cianobactérias diminuiu consideravelmente no mesmo período, sendo relativa apenas ao grupo funcional $S_{N}$ de acordo com a classificação de Reynolds et al. (2002) composta pelos gêneros Anabaena e Cylindrospermopsis. Os dois gêneros são tolerantes a condições com deficiência de luz e nitrogênio, sendo, dessa forma, presentes em todas as profundidades, com alta significância espacial no lago Paranoá. 
Tabela 5-5: Biomassa dos grupos clorofíceas e cianobactérias no período de 1976-1998 e 1999-2011 no lago Paranoá. Adaptado de Souza (2013).

\section{6-1998}

1999-2011

\begin{tabular}{ccccc}
\cline { 2 - 5 } Profundidade & $\begin{array}{c}\text { Clorofíceas } \\
(\mathrm{mg} / \mathrm{L})\end{array}$ & $\begin{array}{c}\text { Cianobactérias } \\
(\mathrm{mg} / \mathrm{L})\end{array}$ & $\begin{array}{c}\text { Clorofíceas } \\
(\mathrm{mg} / \mathrm{L})\end{array}$ & $\begin{array}{c}\text { Cianobactérias } \\
(\mathrm{mg} / \mathrm{L})\end{array}$ \\
$\mathrm{C} 1 \mathrm{~m}$ & 2 & 105,26 & 8,12 & 11,41 \\
$\mathrm{C} 10 \mathrm{~m}$ & 0,23 & 64,81 & 8,11 & 9,43 \\
$\mathrm{C} 15 \mathrm{~m}$ & 0,17 & 28,32 & 5,58 & 3,52 \\
$\mathrm{C} 20 \mathrm{~m}$ & 0,21 & 18,63 & 2,57 & 2,27 \\
\hline
\end{tabular}

Dessa maneira, o aumento da biomassa de clorofíceas e a diminuição da biomassa de cianobactérias representam a melhoria da qualidade da água do lago Paranoá de um período para outro. E, ainda, pela Tabela 5-5 pode-se notar que os dois grupos fitoplanctônicos diminuíram com o aumento da profundidade. Souza (2013) atribui a diminuição de valores ao longo do perfil vertical provavelmente devido às coletas já serem feitas fora da zona eufótica, que, de acordo com os dados de monitoramento obtidos pela autora, no período de 2004 a 2011, variou de 170 a $440 \mathrm{~cm}$ no ponto C.

De maneira semelhante, no presente estudo, em relação à biomassa de clorofíceas e cianobactérias, o modelo GLM-AED alcançou melhores ajustes nas maiores profundidades. Isso também pode ser atribuído ao fato de o modelo hidrodinâmico simular melhor a temperatura da água nas altas profundidades pela baixa ação dos ventos e da radiação solar e, com isso, conseguiu melhor desempenho na simulação da biomassa do fitoplâncton nas profundidades de 15 e 20 metros da superfície.

A Tabela 5-6 mostra os erros-padrão encontrados para os resultados simulados de fitoplâncton nas duas calibrações. A Tabela mostra um melhor ajuste para o grupo das cianobactérias, que tiveram um RMSE médio de 0,012 mg/L. Contudo, esse erro encontrado é significativo em comparação a própria biomassa média observada pelo referido grupo no lago Paranoá que é de $0,0016 \mathrm{mg} / \mathrm{L}$. 
Tabela 5-6: Erro padrão encontrado nas 4 profundidades analisadas para biomassas de clorofíceas e cianofíceas.

\begin{tabular}{|c|c|c|c|c|}
\hline \multicolumn{5}{|c|}{ Estatísticas para a biomassa simulada de cloroficeas } \\
\hline Profundidades & $1 \mathrm{~m}$ & $10 \mathrm{~m}$ & $15 \mathrm{~m}$ & 20m \\
\hline RMSE (mg/L) & 0.060 & 0.039 & 0.020 & 0.025 \\
\hline RMSE $\left(\mathbf{m m o l} / \mathbf{m}^{3}\right)$ & 5.05 & 3.28 & 1.72 & 2.14 \\
\hline \multicolumn{5}{|c|}{ Estatísticas para a biomassa simulada de cianobactérias } \\
\hline Profundidades & $1 \mathrm{~m}$ & $10 \mathrm{~m}$ & $15 \mathrm{~m}$ & $20 \mathrm{~m}$ \\
\hline RMSE (mg/L) & 0.023 & 0.011 & 0.008 & 0.006 \\
\hline RMSE $\left(\mathbf{m m o l} / \mathbf{m}^{3}\right)$ & 1.99 & 0.97 & 0.71 & 0.56 \\
\hline
\end{tabular}

Até o presente momento, não há trabalhos publicados utilizando o módulo ecológico para lagos FABM-AED ou somente AED. Há, apenas, uma descrição de resultados alcançados para o reservatório Mount Bold, Austrália, pela Prof. Ana Rigosi, da Universidade de Adelaide - AU, que os tornou público no fórum de discussão da AEMON (Aquatic Ecosystem MOdelling Network - AEMON - discussion forum). Esse estudo foi, então, a base comparativa para os resultados alcançados no presente trabalho.

A pesquisadora trabalhou com 5 grupos de fitoplâncton e calibrou o modelo por um período de 1 ano, de 2003 a 2004. Não foram fornecidos maiores detalhes sobre a metodologia adotada para a análise de sensibilidade e calibração, somente a disponibilização dos resultados alcançados. Dos grupos funcionais fitoplanctônicos simulados no presente estudo, somente as clorofíceas foram simuladas pela autora.

Rigosi (2015) encontrou um RMSE de 5.24 ug/L para clorofíceas na superfície. Observa-se que o erro encontrado pela pesquisadora foi menor que o encontrado para o lago Paranoá em uma fração de $10^{-1}$ de diferença. Contudo, não se pode inferir que os resultados aqui encontrados para concentração de clorofíceas foram superiores ou semelhantes aos da autora, pois não se sabe qual a biomassa média do grupo no reservatório Mount Bold.

A Tabela 5-7 apresenta as biomassas médias de longo período observadas para clorofíceas e cianobactérias entre 1976 e 2010, registradas pela CAESB. 
Tabela 5-7: Biomassas médias observadas para clorofíceas e cianobactérias no ponto C de 1976 a 2010.

\begin{tabular}{ccc}
\hline Profundidade & $\begin{array}{c}\text { Biomassa media de } \\
\text { clorofíceas }(\mathbf{m g} / \mathbf{L})\end{array}$ & $\begin{array}{c}\text { Biomassa media de } \\
\text { cianobactérias }(\mathbf{m g} / \mathbf{L})\end{array}$ \\
\hline $\mathbf{1 m}$ & 0,09 & 0,027 \\
$\mathbf{1 0 m}$ & 0,11 & 0,032 \\
$\mathbf{1 5 m}$ & 0,12 & 0,101 \\
$\mathbf{2 0 m}$ & 0,048 & 0,09 \\
\hline
\end{tabular}

Comparando-se os resultados de RMSE encontrados para os dois grupos de fitoplâncton (Tabela 5-6) com os valores médios de biomassa da Tabela 5-7, nota-se que, para as clorofíceas, os erros foram significativos nas profundidades de $1 \mathrm{~m}$ e $20 \mathrm{~m}$, pois foram coincidentes com o próprio valor médio de longo período. Em relação as biomassas de cianobactérias, os erros também foram significantes, principalmente nas menores profundidades, a $1 \mathrm{~m}$ e $10 \mathrm{~m}$ da superfície.

Em relação às simulações das demais variáveis de qualidade da água, como foram necessárias duas calibrações levando-se em conta as clorofíceas e cianobactérias separadamente, as variáveis responderam de maneira distinta nas duas calibrações. As Tabelas 5-8 e 5-9 apresentam os resultados de temperatura da água, OD, amônia, nitrato e fosfato gerados por ambas as calibrações.

Tabela 5-8: Erros-padrão obtidos para as demais variáveis de qualidade da água pela calibração das clorofíceas.

\begin{tabular}{llllll}
\hline Variáveis & \multicolumn{7}{c}{$\boldsymbol{d e}$} & \multicolumn{5}{c}{$\boldsymbol{R M S E}$} \\
\cline { 3 - 7 } $\begin{array}{l}\text { qualidade } \\
\text { água }\end{array}$ & $\boldsymbol{d} \boldsymbol{1 \mathrm { m }}$ & $10 \mathrm{~m}$ & $15 \mathrm{~m}$ & $20 \mathrm{~m}$ & $\begin{array}{l}\text { Média nas } \\
\text { profundidades }\end{array}$ \\
Temperatura $\left({ }^{\circ} \mathrm{C}\right)$ & 2,09 & 1,59 & 1,39 & 1,04 & 1,527 \\
OD $(\mathrm{mg} / \mathrm{L})$ & 5,63 & 4,64 & 3,51 & 2,10 & 3,97 \\
Amônia $(\mathrm{mg} / \mathrm{L})$ & 0,39 & 0,45 & 0,52 & 0,58 & 0,485 \\
Nitrato $(\mathrm{mg} / \mathrm{L})$ & 0,26 & 0,30 & 0,33 & 0,40 & 0,322 \\
Fosfato $(\mathrm{mg} / \mathrm{L})$ & 0,14 & 0,15 & 0,15 & 0,60 & 0,26 \\
\hline
\end{tabular}


Tabela 5-9: Erros-padrão obtidos para as demais variáveis de qualidade da água pela calibração das cianobactérias.

\begin{tabular}{|c|c|c|c|c|c|}
\hline Variáveis de & \multicolumn{5}{|c|}{ RMSE } \\
\hline $\begin{array}{c}\text { qualidade da } \\
\text { água }\end{array}$ & $1 \mathrm{~m}$ & $10 \mathrm{~m}$ & $15 \mathrm{~m}$ & $20 \mathrm{~m}$ & $\begin{array}{l}\text { Média nas } \\
\text { profundidades }\end{array}$ \\
\hline Temperatura $\left({ }^{\circ} \mathrm{C}\right)$ & 2,05 & 1,718 & 1,37 & 0,99 & 1,532 \\
\hline $\mathrm{OD}(\mathrm{mg} / \mathrm{L})$ & 2,8 & 3,4 & 2,8 & 1,92 & 2,73 \\
\hline Amônia (mg/L) & 0,29 & 0,27 & 0,29 & 0,36 & 0,302 \\
\hline Nitrato (mg/L) & 0,37 & 0,41 & 0,30 & 0,18 & 0,315 \\
\hline Fosfato (mg/L) & 0,07 & 0,08 & 0,08 & 0,69 & 0,23 \\
\hline
\end{tabular}

Na calibração voltada para o ajuste da biomassa das clorofíceas (Tabela 5-8), o nitrato apresentou melhores resultados em comparação com os dados observados pelo monitoramento da CAESB gerando um RMSE médio de 0,32 $\mathrm{mg} / \mathrm{L}$ nas 4 profundidades. Contudo, foi a calibração da biomassa de cianobactérias que gerou melhores resultados para as demais variáveis de qualidade da água (Tabela 5-9).

Na Tabela 5-9, as variáveis de concentração de temperatura da água, OD e nitrato apresentaram menores erros nas maiores profundidades, principalmente, a 20 metros da superfície. Já as concentrações de amônia e fosfato foram melhor simuladas nas profundidades de 10m e 1m da superfície, respectivamente. Encontrou-se RMSE médio de $1,53^{\circ} \mathrm{C}$ para o perfil de temperatura da água e em relação a OD e nitrato os RMSEs obtidos foram de, respectivamente, $2,73 \mathrm{mg} / \mathrm{L} \mathrm{e} 0,315 \mathrm{mg} / \mathrm{L}$.

Rigosi (2015), utilizando o GLM-FABM-AED, encontrou RMSEs de $1,52^{\circ} \mathrm{C}$ para a temperatura superfícial e $1,36^{\circ} \mathrm{C}$ para o perfil completo de temperatura. Já para OD, ela encontrou um RMSE de 2,19 mg/L no perfil ao longo da coluna d'água e para nitrato 0,17 $\mathrm{mg} / \mathrm{L}$ na superfície. Comparando os desempenhos obtidos pelo modelo para o lago Paranoá com os de Rigosi (2015), observa-se que o ajuste alcançado foi semelhante para OD na simulação das cianobactérias. Contudo, o melhor resultado alcançado para nitrato foi $0,315 \mathrm{mg} / \mathrm{L}$, que corresponde a quase o dobro do obtido pela pesquisadora.

No lago Paranoá, a média das concentrações de OD, ao longo da coluna d'água, e de nitrato, na superfície, no ponto $\mathrm{C}$, para o período simulado, correspondia a $5,2 \mathrm{mg} / \mathrm{L}$ e 
0,57 mg/L. Como observado na Tabela 5-9, o erro encontrado em relação ao OD correspondeu a quase metade do valor médio registrado. Em relação ao nitrato, o erro apresentou-se significativo quando comparado à concentração média do composto na profundidade mais superficial.

Todavia, ao comparar os RMSEs encontrados com os valores médios das mesmas variáveis no lago Paranoá, observados entre 1976 a 2010 (Tabela 5-10), infere-se que os erros associados às concentrações de OD nas maiores profundidades foram significativos, quando comparados com os valores médios de longo período. Assemelhando-se a esse comportamento e corroborando a comparação antes realizada com as médias do período simulado (2007-2009), os RMSEs das concentrações de nitrato em todas as quatro profundidades conseguiram superar os valores médios do composto para o Lago, o que evidencia erros significativos nas simulações do modelo para essa variável. Em contrapartida, os erros relacionados à temperatura da água e concentrações de amônia e fosfato não foram tão significativos, quando comparados as respectivas médias ao longo de mais de 30 anos de monitoramento.

Os gráficos das séries temporais de concentrações de OD, amônia, nitrato e fosfato do monitoramento das quatro profundidades do ponto $\mathrm{C}$ do Lago são dados no Apêndice C.

Tabela 5-10: Média dos valores registrados para temperatura, OD, amônia, nitrato e fosfato, pela CAESB, entre 1976 a 2010.

\begin{tabular}{cccccc}
\hline Profundidade & $\begin{array}{c}\text { Temperatura } \\
\left({ }^{\mathbf{o}} \mathbf{C}\right)\end{array}$ & $\begin{array}{c}\text { OD } \\
(\mathbf{m g} / \mathbf{L})\end{array}$ & $\begin{array}{c}\text { Amônia } \\
(\mathbf{m g} / \mathbf{L})\end{array}$ & $\begin{array}{c}\text { Nitrato } \\
(\mathbf{m g} / \mathbf{L})\end{array}$ & $\begin{array}{c}\text { Fosfato } \\
(\mathbf{m g} / \mathbf{L})\end{array}$ \\
\hline $\mathbf{1 m}$ & 23,9 & 6,72 & 0,45 & 0,123 & 0,0057 \\
$\mathbf{1 0 m}$ & 23,1 & 4,09 & 0,75 & 0,118 & 0,0055 \\
$\mathbf{1 5 m}$ & 22,4 & 2,41 & 0,99 & 0,147 & 0,0042 \\
$\mathbf{2 0 m}$ & 21,9 & 1,75 & 1,45 & 0,153 & 0,0057 \\
\hline
\end{tabular}

Trolle et al. (2008b) calibraram o modelo DYRESM-CAEDYM para o lago Ravn, localizado na Dinamarca, por um período de 7 anos. Os autores encontraram RMSEs médios de $1,44^{\circ} \mathrm{C}$ para a temperatura do epilímnio e $0,87^{\circ} \mathrm{C}$ para o hipolímnio e, em relação à calibração de $\mathrm{OD}$, amônia e nitrato, obtiveram RMSEs médio, em mg/L, de 1,67 e 2,64, 0,068 e 0,482, 0,42 e 0,92, para o epilímnio e hipolímnio, respectivamente. 
O modelo DYRESM-CAEDYM já foi citado anteriormente como semelhante e referência para a criação do GLM-FABM-AED. Dessa maneira, os resultados alcançados no estudo de Trolle et al. (2008b) evidenciam melhor desempenho nas simulações das variáveis de qualidade da água. Contudo, os autores calibraram todos os parâmetros sensíveis relacionados a essas variáveis.

\subsection{SIMULAÇÃO DO CENÁRIO DE EUTROFIZAÇÃo}

Para o lago Paranoá, o cenário proposto foi de condição de eutrofização, a mesma observada para o ano de 1978, tido como o momento com maior grau de trofia para o Lago. A simulação do cenário foi para um período de 1 ano que representaria uma mudança brusca na qualidade da água do Lago mantendo as mesmas condições climáticas e hidrológicas do ambiente. O período escolhido para fornecer as características meteorológicas, hidrológicas e batimétricas atuais foi de janeiro a dezembro de 2008, por apresentar os dados com períodos contínuos.

Pelos dados fornecidos pela CAESB para o ano de 1978, foi registrado, no lago Paranoá, uma média de oxigênio dissolvido de 7,71 mg/L a 1 metro, 3,36 mg/L a 10 metros e, $1,56 \mathrm{mg} / \mathrm{L}$ e $0,56 \mathrm{mg} / \mathrm{L}$, para as profundidades de 15 e 20 metros, respectivamente, considerando todo o ano. Esses valores caracterizam a anoxia da coluna d'água provocada pelo processo de eutrofização.

Nem todas as variáveis de qualidade da água responderam no cenário proposto, como exemplo da temperatura simulada, que não apresentou resposta. Como essa variável é bastante dependente das condições climatológicas do ambiente, ela não mostrou alteração no cenário pela razão de os dados meteorológicos de entrada terem valores semelhantes ao período utilizado para análise de sensibilidade e calibração do GLMAED. Dessa maneira, o modelo interpretou que a temperatura da água permaneceu a mesma.

Em relação aos nutrientes, especificamente nitrato e amônia, esses não apresentaram variação na simulação do cenário. Pode-se inferir que, assim como na calibração do fitoplâncton para 2007 a 2009, eles não conseguiram obter bom ajuste devido à falta de 
uma calibração específica nos parâmetros biogeoquímicos. No cenário proposto, também não houve respostas desses nutrientes à mudança na qualidade da água.

Todavia, para o nutriente fosfato, a simulação conseguiu responder bem à mudança na qualidade da água. A Figura 5-26 apresenta os resultados de concentração de fosfato observado e calibrado para 2007-2009 e na simulação do cenário proposto.
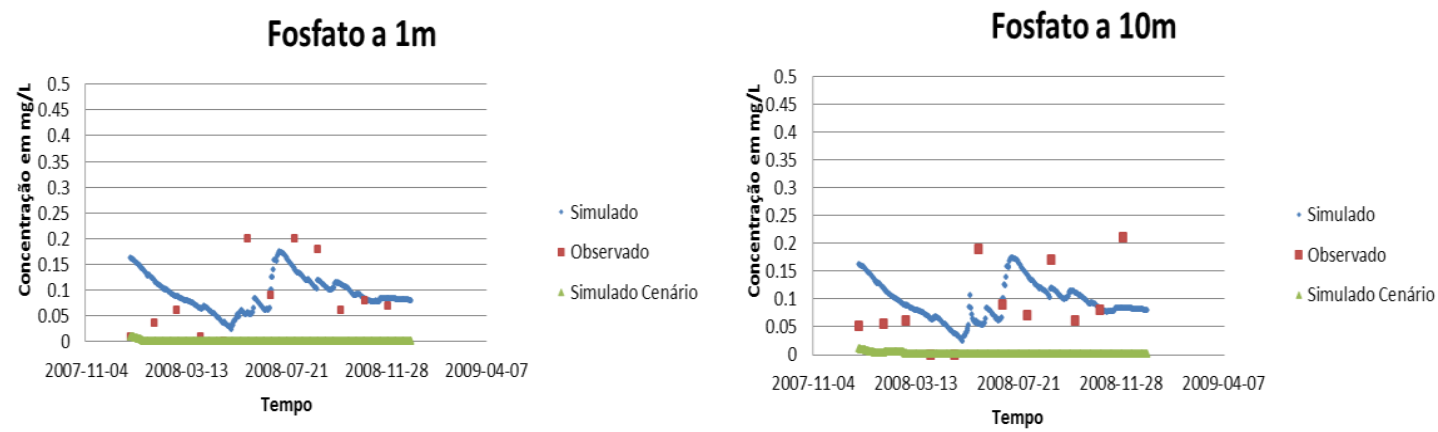

Fosfato a $15 \mathrm{~m}$

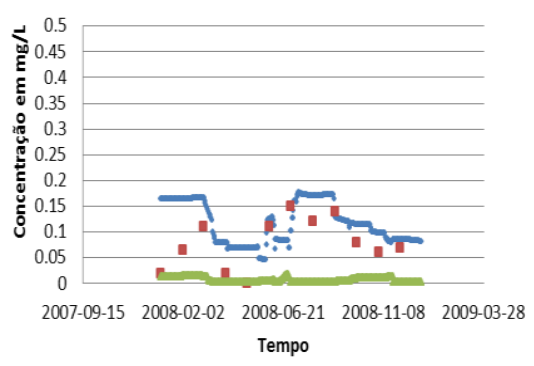

Fosfato a $20 \mathrm{~m}$

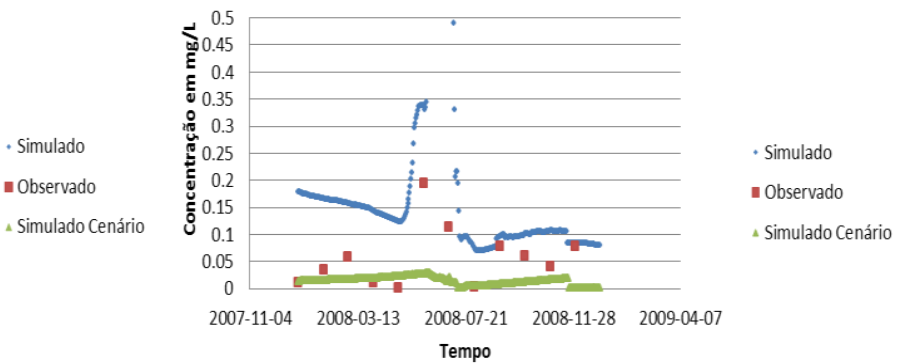

Figura 5-26: Gráficos de fosfato simulado e observado no período de 2007-2009 e simulado no cenário.

Na Figura 5-26, observa-se que, no cenário, o fosfato apresentou médias muito abaixo da média para os demais anos. As médias registradas pela CAESB para o referido ano foram de $0,01 \mathrm{mg} / \mathrm{L}$ de fosfato a $1 \mathrm{~m}$ e $10 \mathrm{~m}$ da superfície. Na profundidade de $15 \mathrm{~m}$ não há registro e, a $20 \mathrm{~m}$ da superfície, mediu-se uma concentração de 0,005 mg/L. As concentrações de fosfato ficaram semelhantes as registradas para o ano de 1978, pois apresentaram média de aproximadamente $0,03 \mathrm{mg} / \mathrm{L}$. Esse comportamento pode ser atribuído ao aumento da biomassa de cianobactérias, que aumentam sua biomassa em um episódio de florações e acabam por consumir a maior parte do ortofosfato presente na água. 
Em relação à biomassa de clorofíceas e cianobactérias, as Figuras 5-27 e 5-28 apresentam os resultados advindos da simulação do cenário em comparação aos resultados gerados na calibração do AED - módulo de fitoplâncton e biomassa observada no monitoramento da CAESB.
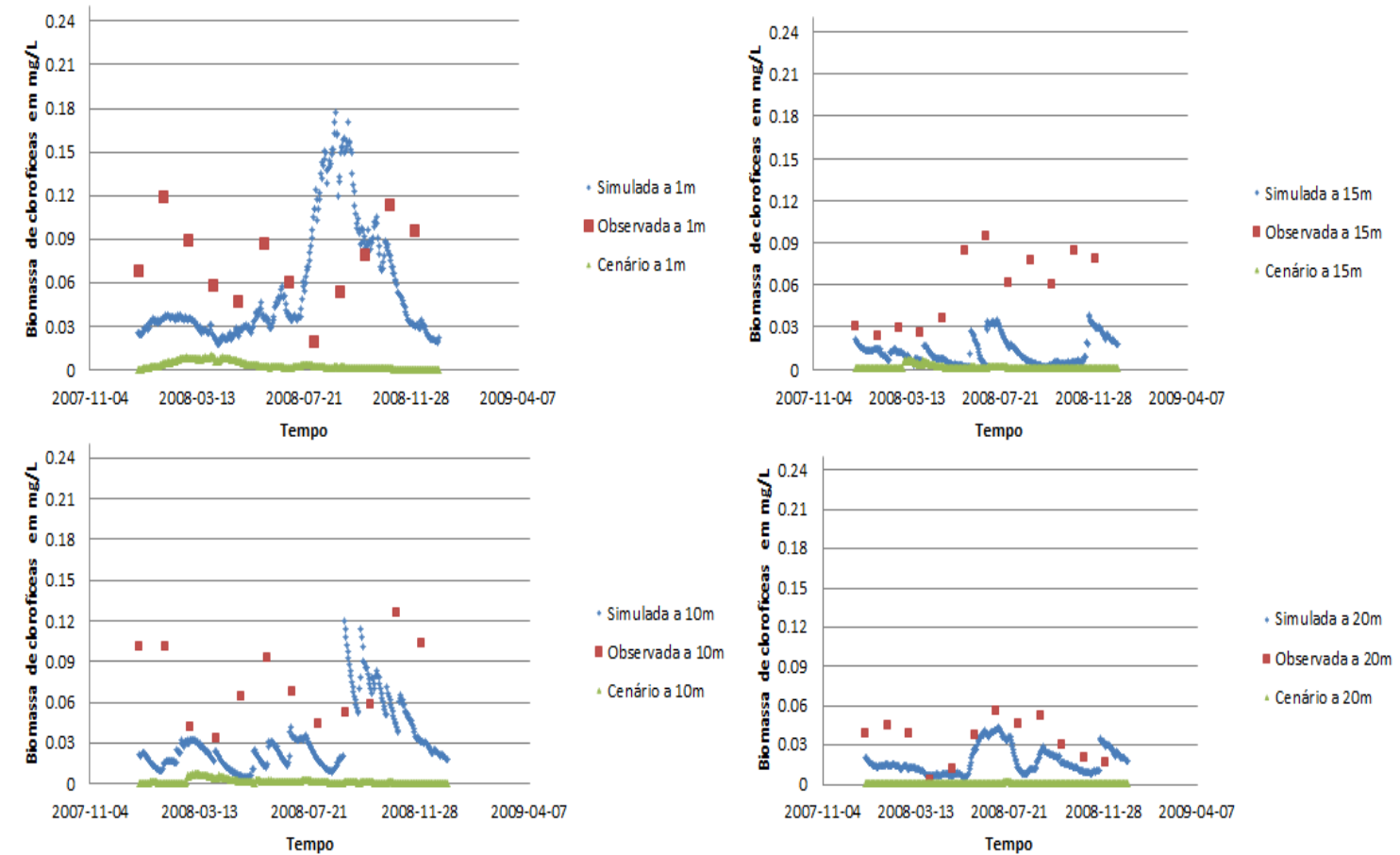

Figura 5-27: Biomassa de clorofíceas simuladas e observadas no período de 2007-2009 e simuladas no cenário.

No ano de 1978, as clorofíceas não apresentaram registros nas medições realizadas pela CAESB. Em relação às cianobactérias, para o referido ano, o grupo apresentou uma média de 0,125 mg/L para a profundidade de 1 metro e $0,05 \mathrm{mg} / \mathrm{L}, 0,025 \mathrm{mg} / \mathrm{L}$ e 0,012 $\mathrm{mg} / \mathrm{L}$ para as demais, respectivamente a $10 \mathrm{~m}, 15 \mathrm{~m}$ e $20 \mathrm{~m}$ da superfície.

Na Figura 5-27, nota-se que, para a biomassa de clorofíceas no cenário, o modelo conseguiu obter êxito ao demonstrar o não-aparecimento do referido grupo em uma situação de eutrofização e floração de cianobactérias. Esse comportamento pode ser atribuído à abundância do grupo das cianobactérias no meio por sua capacidade de migração na coluna d'água, tolerância à baixa luminosidade, afinidade com fósforo e amônia, capacidade de fixar nitrogênio atmosférico e resistência à herbivoria do zooplâncton (Nogueira, 1996). 
Os dois gêneros de cianobactérias que apresentaram maior presença identificada no monitoramento da CAESB no lago Paranoá, para o ano de 1978, foram Cylindrospermopsis e Microcystis. O segundo gênero foi o dominante no episódio de floração ocorrido no Lago no ano crítico.
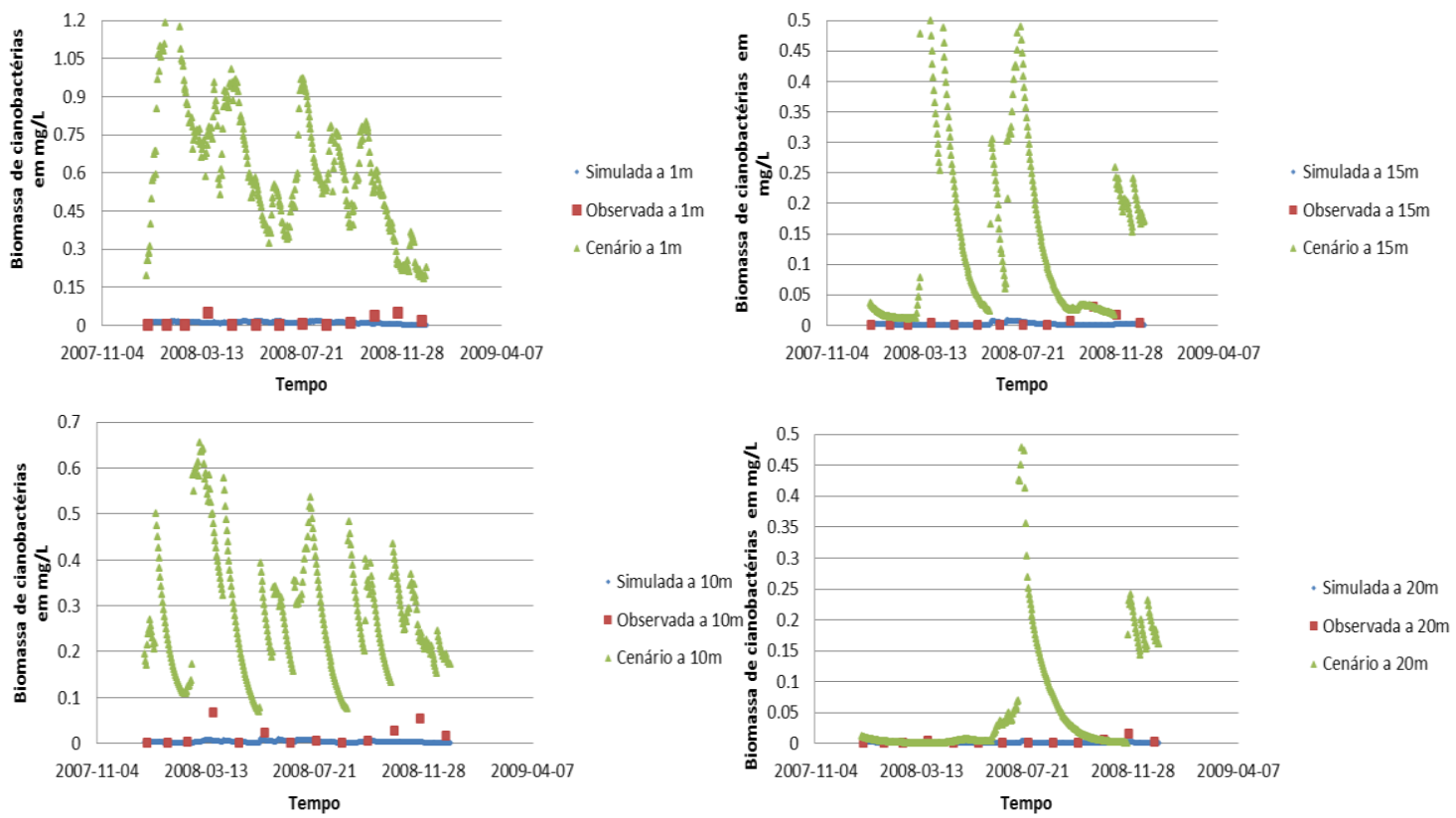

Figura 5-28: Biomassa de cianobactérias simuladas e observadas no período de 20072009 e simuladas no cenário.

Na Figura 5-28, nota-se que a simulação do cenário superestimou a biomassa de cianobactérias, pois alcançou valores de $1,2 \mathrm{mg} / \mathrm{L}$ a 1 metro e $0,67 \mathrm{mg} / \mathrm{L}$ a 10 metros da superfície. O valor máximo de biomassa do grupo encontrado em condição de eutrofização em 1978 foi de 0,37 mg/L a 1m da superfície. Contudo, o modelo GLMAED conseguiu prever o aumento e floração das cianobactérias em um nível trófico mais elevado e consequente degradação da qualidade da água.

Liporoni (2012) propôs cenários futuros de alteração das cargas das variáveis de qualidade da água do lago Paranoá com base na alteração das concentrações e das vazões para o ano de 2040. O autor utilizou o modelo CE-QUAL-W2 para executar as simulações. Os resultados não mostraram alterações significativas nas concentrações das variáveis de qualidade da água para as condições apresentadas. Porém, as mudanças nas concentrações de fósforo mostraram um aumento médio de $10 \%$, que podem 
acarretar alteração do estado trófico para eutrófico e, assim, causar problemas nos diversos usos múltiplos do Lago.

O modelo GLM-AED conseguiu apresentar alterações nas variáveis: fosfato, biomassa de clorofíceas e cianobactérias no cenário de piora de qualidade da água proposto. As concentrações de fosfato foram irrelevantes, bem como a biomassa de clorofíceas. Já a biomassa de cianobactérias mostrou-se muito alta, que pode evidenciar aumento do grau de trofia do meio e possibilidade de floração de cianobactérias no Lago. As demais variáveis de qualidade da água não apresentaram alterações importantes no cenário proposto.

A simulação do cenário permitiu observar o aumento de cianobactérias em uma condição de eutrofização do Lago e possível floração, assim como demais consequências desse estado, em que o grupo em questão inibe o grupo das clorofíceas até o desaparecimento dessas e as concentrações de fosfato que praticamente se esgotam, pelo consumo do grupo prevalecente.

Pode-se dizer que o modelo respondeu melhor a um reservatório com maior grau de trofia, no caso do cenário, do que no período de calibração do GLM-AED, correspondente a 2007-2009, no qual o lago Paranoá estava caracterizado como mesotrófico. 


\section{CONCLUSÕES}

O presente trabalho teve como objetivo utilizar-se da modelagem ecológica por meio do estudo da dinâmica da comunidade fitoplanctônica para avaliar a qualidade da água do lago Paranoá. O modelo hidrodinâmico-ecológico selecionado foi o GLM-AED e o período selecionado para análise de sensibilidade e calibração foi de 762 dias (01/03/2007 a 31/03/2009).

O modelo hidrodinâmico mostrou-se satisfatório ao simular o perfil de temperatura ao longo da coluna d'água, alcançando um erro padrão (RMSE) de $1,47^{\circ} \mathrm{C}$. Nas profundidades de $1,10,15$ e $20 \mathrm{~m}$ da superfície o erro também não passou de $2^{\circ} \mathrm{C}$. Contudo, o modelo alcançou melhores resultados nas maiores profundidades, a 15 e 20 metros da superfície, podendo ser atribuído ao fato de o modelo hidrodinâmico simular melhor a temperatura da água nas altas profundidades, pela baixa ação dos ventos e da radiação solar incidente.

A simulação hidrodinâmica inicial foi importante para regular alguns fatores ambientais que também influenciam na modelagem ecológica e dinâmica do fitoplâncton, como a vazão no Lago, temperatura da água e condições hidrometeorológicas que podem favorecer ou não os processos de fotossíntese e respiração do fitoplâncton.

A simulação ecológica demonstrou-se adequada ao representar o comportamento dos dois grupos do fitoplâncton (clorofíceas e cianobactérias), todavia os erros associados ainda foram significativos, mesmo após a análise de sensibilidade e calibração do módulo de fitoplâncton.

Como os módulos ecológicos AED são interligados e existem parâmetros específicos para cada, a análise de sensibilidade e calibração ecológica dos dois grupos de fitoplâncton tornou-se desafiadora pela falta de maiores informações acerca dos parâmetros do fitoplâncton e um processo iterativo que também contemplasse os demais parâmetros biogeoquímicos. 
A simulação ecológica das demais variáveis de qualidade da água não foi satisfatória, fato esse que pode ser atribuído, também, à falta de calibração dos módulos biogeoquímicos correspondentes ao período simulado, que foi de apenas 762 dias, e à própria base de dados formada, que contemplava dados de diversos órgãos, com diferentes períodos de monitoramento e, muitas vezes, com erros de medição embutidos.

A simulação ecológica de lagos e reservatórios demanda grande quantidade e tipos de dados distintos (hidrológicos, meteorológicos, limnológicos, morfométricos e de qualidade da água). Dessa maneira, torna-se um desafio em bacias com falta de monitoramento. No caso do lago Paranoá, há grande quantidade de dados de monitoramento, porém existem lacunas entre esses que não permitem considerar períodos contínuos com disponibilidade de registros.

A simulação do cenário de eutrofização proposto conseguiu simular o aumento da biomassa de cianobactérias e consequente diminuição da biomassa de clorofíceas e concentração de fosfato ao longo da coluna d'água. Todavia, não conseguiu resposta das demais variáveis de qualidade da água, como temperatura, $\mathrm{OD}$, amônia e nitrato.

A simulação do cenário, apesar de ser somente prospectiva, mostrou que o modelo GLM-AED responde adequadamente as alterações nos dados de entrada para a simulação. O modelo conseguiu responder melhor nas simulações do cenário, onde o ambiente se caracterizou com um maior nível de trofia. 


\section{RECOMENDAÇÕES}

Apesar do monitoramento de qualidade da água no lago Paranoá ser realizado há mais de 30 anos e, dessa forma, possuir um extenso banco de dados a ser utilizado em aplicação de modelos, existem lacunas entre esses dados que impossibilitaram a utilização de um período mais longo nas simulações. Por esta razão, recomendam-se estudos mais específicos que visem o preenchimento dessas lacunas nos diversos dados requeridos para a modelagem.

Visto, também, que o monitoramento de qualidade da água nos braços do Lago é realizado apenas em uma profundidade, sugere-se que esse contemple mais pontos de profundidade, para facilitar a compreensão do comportamento dessas variáveis ao longo da coluna d'água e dar maiores subsídios à aplicação da modelagem ecológica.

Em relação aos dados de entrada, recomendam-se análises de inconsistências também para os dados brutos de vazão e de qualidade da água, para melhor averiguação de possíveis erros associados, os quais exercem influência nos resultados das simulações.

Devido à indisponibilidade dos registros de algumas variáveis de qualidade da água, principalmente, temperatura dos efluentes das duas ETEs afluentes ao lago Paranoá, recomenda-se que esses dados sejam utilizados como entrada nos próximos estudos que aplicarem o modelo GLM-AED nesse ambiente.

Os dados disponíveis da batimetria do Lago eram provenientes do Plano de Gestão e Preservação do lago Paranoá: Relatório dos Levantamentos Batimétricos e Sedimentométricos do Lago Paranoá publicado pela CAESB em 2003, e, por esta razão, podem estar desatualizados ou incompatíveis com a atual realidade do ambiente. Por conta da dinâmica constante do Reservatório, essas cotas podem ter variado significativamente ao longo dos anos. Sendo assim, sugere-se que outras fontes de dados batimétricos sejam identificadas, ou ainda, novos estudos batimétricos sejam realizados no lago Paranoá. 
A Estação Meteorológica Brasília, onde foram retirados os registros dos dados meteorológicos advindos do INPE e INMET, encontra-se a uma distância de mais de 20 km do Plano Piloto de Brasília. Sabe-se que os dados de velocidade do vento exercem grande influência na modelagem hidrodinâmica de lagos e nos resultados de temperatura da água. Dessa forma, sugere-se que os próximos estudos que aplicarem esse tipo de modelo no lago Paranoá busquem dados de estações meteorológicas e anemométricas mais próximas, e/ou procedam à instalação experimental de equipamentos para esse tipo de monitoramento as margens do Lago.

Em relação à modelagem hidrodinâmica, recomenda-se que os próximos estudos utilizando o GLM para o lago Paranoá procedam à etapa de verificação para bem avaliar a calibração de temperatura da água aqui realizada. E que a referida etapa da simulação seja realizada, também, para a biblioteca de módulos ecológicos AED, observando o comportamento da biomassa fitoplanctônica em outro período de tempo.

Pelo presente estudo ter sido voltado às simulações do fitoplâncton no Lago e pela indisponibilidade de maiores informações sobre todos os parâmetros relativos aos módulos da biblioteca $\mathrm{AED}$, não se realizou a calibração dos demais módulos ecológicos/biogeoquímicos. Assim sendo, recomenda-se que os próximos estudos, utilizando esse modelo, efetuem a calibração de cada um dos parâmetros dos módulos ecológicos/biogeoquímicos da biblioteca AED. 


\section{REFERÊNCIAS BIBLIOGRÁFICAS}

Afshar, A.; Kazemi, H. e Saadatpour, M. (2011). "Particle Swarm Optimization for Automatic Calibration of Large Scale Water Quality Model (CE-QUAL-W2): Application to Karkheh Reservoir, Iran" Water Resources Management, 25, 2613-2632.

Agência Nacional das Águas - ANA. Disponível em: <http://pnqa.ana.gov.br/IndicadoresQA/IndiceQA.aspx>. Acesso em: 05 de abril de 2014.

Agência Reguladora de Águas e Saneamento do Distrito Federal - ADASA. Mapas. Disponível em: <http://www.adasa.df.gov.br/index.php?option=com_content $\& v i e w=\operatorname{article} \& i d=3$ 96\%3Asistema-de-recursos-hidricos-do-df-mapa-hidrografico-dof\&catid=79\&Itemid=303> . Acesso em: 20 de março de 2014.

Almeida, F.F. e Melo, S. (2009). "Considerações limnológicas sobre um lago da planície de inundação amazônica (lago Catalão - Estado do Amazonas, Brasil).” Acta Scientiarum: Biological Sciences, 31(4), 387-395.

Andrade, R.S. (2008). Dinâmica do fitoplâncton, qualidade de água e a percepção ambiental da comunidade de pescadores em açudes da bacia do rio Taperóa. Dissertação de Mestrado, Universidade Federal da Paraíba, Programa Regional de Pós-Graduação em Desenvolvimento e Meio Ambiente, João Pessoa, PB, 144p.

Andreoni-Batista, C. (2007). Estrutura da Comunidade Zooplanctônica e Qualidade da Água no Lago Paranoá, Brasília - DF. Dissertação de Mestrado, Universidade de Brasília, Departamento de Ecologia, Brasília, DF, 104p.

Baptista, G.M.M e Araújo Neto, M.D. (1999). O processo de eutrofização artificial no lago Paranoá, Brasília, DF. GEONOMOS, 2, 31-39.

Beck, M.W. e Hatch, L.K. (2009).“A review of research on the development of lake indices of biotic integrity."Environmental Reviews, 17, 21-44.

Beisner, B.E., Peres-Neto, P.R., Lindstrom, E.S., Barnett, A., Longhi, M.L. (2006). "The role of environmental and spatial processes in structuring lake communities from bacteria to fish." Ecology, 87, 2985-2991. 
Benndorf, J. e Recknagel, F. (1982). "Problems of application of the ecological model SALMO to lakes and reservoirs having various trophic states." Ecological Modelling, 17, 129-145.

Branco, C.W.C. e Senna, P.A.C. (1996). "Relations among heterotrophic bacteria, chlorophyll- $a$, total phytoplankton, total zooplankton and physical and chemical features in the Paranoá reservoir, Brasília, Brazil”. Hydrobiologia, 337, 171-181.

Brasil, J. e Huszar, V. L. M. (2011). "O papel dos traços funcionais na ecologia do fitoplâncton continental." Oecologia Australis, 15(4), 799-834.

Burnett, J.A.B.; Mattos, S.P. e Azzolin, N.M.P. (2001). "IX - Intervenções da companhia de saneamento." In: Fonseca, F. O. (org.). Olhares sobre o Lago Paranoá. Secretaria de Meio Ambiente e Recursos Hídricos, Brasília - DF.

Bruggeman, J. (2011). D2.14 Users guide and report for models in the MEECE library - Framework for Aquatic Biogeochemical Models (FABM). Relatório para "The EC FP7 MEECE Project 212085”. 57pp.

Chapra, S. (1997).Surface water-quality modeling.McGraw-Hill series in water resources and environmental engineering. Editora: McGraw-Hill.

Chow, V.T. (1964). Handbook of Applied Hydrology.MacGraw-Hill Book Co., Nova Iorque, EUA.

Companhia de Saneamento Ambiental do Distrito Federal - CAESB, (2003). Plano de Gestão e Preservação do lago Paranoá: Relatório dos Levantamentos Batimétricos e Sedimentométricos do Lago Paranoá. Brasília - DF, 17p.

Companhia de Saneamento Ambiental do Distrito Federal - CAESB, (2005). Projeto Básico para Ampliação do Sistema de Abastecimento de Água do Distrito Federal Utilizando como Manancial o Lago Paranoá - Volume I: Memorial Descritivo Parte 2. Brasília - DF, 27p.

Costa, M.E.L (2013). Monitoramento e modelagem das águas da drenagem urbana na bacia do lago Paranoá. Dissertação de Mestrado, Departamento de Engenharia Civil e Ambiental, Universidade de Brasília, Brasília, DF, 179p.

Dietzel, A.; Mieleitner, J.; Kardaetz, S e Reichert, P. (2013). "Effects of changes in the driving forces on water quality and plankton dynamics in three Swiss lakes long-term simulations with BELAMO.” Freshwater Biology, 58, 10-35.

Dooge, J.C.I. (1973). Linear Theory of Hydrologic Systems.Technical Bulletin n.1948, ARS, US Departamento of Agriculture, EUA 
Droop, M.R. (1974). "The nutrient status of algal cells in continuous culture."J. Mar. Biol. Assoc. UK, 54, 825-855.

Echeverria, R.M. (2007). Avaliação de impactos nos tributários do Lago Paranoá, Brasília - DF. Dissertação de Mestrado. Universidade de Brasília, Instituto de Geociências, Brasília, DF, 121p.

Elliott, J.A.; Persson, I.; Thackeray, S.J. e Blenckner, T. (2007).“Phytoplankton modelling of Lake Erken, Sweden by linking the models PROBE and PROTECH."Ecological Modelling, 202, 421-426.

Esteves, F. A., (2011). Fundamentos de Limnologia. $3^{\circ}$ edição, Interciência (Ed.), Rio de Janeiro - RJ, 826p.

Ferrante, J. E. T., Roncan, L., Netto, B. P. (2001). “III - Meio Físico” in Fonseca, F. O. (org.). Olhares sobre o Lago Paranoá. Secretaria de Meio Ambiente e Recursos Hídricos, Brasília - DF, 45-78

Fragoso Jr, C.R. (2008). "Modelagem de Reservatórios em Zonas Tropicais: Parâmetros Brasileiros". Anais do I Encontro Nacional de Hidroinformática, Vol. 1, Fortaleza: UNIFOR, Brasil.

Fragoso Jr, C.R. (2009). Modelagem Tridimensional da Estrutura Trófica em Ecossistemas Aquáticos Continentais Rasos. Tese de Doutorado, Universidade Federal do Rio Grande do Sul, Instituto de Pesquisas Hidráulicas, Porto Alegre, RS, 200p.

Fragoso Jr, C.R.; Ferreira, T.F.; Marques, D.M. (2009). Modelagem Ecológica em Ecossistemas Aquáticos. $1^{\circ}$ edição, Oficina de Textos, São Paulo - SP, 304p.

Fragoso Jr, C.R.; Motta Marques, D.M.L.; Collischonn, W.; Tucci, C.E.M. e van Nes, E.H. (2008). "Modelling spatial heterogeneity of phytoplankton in Lake Mangueira, a large shallow subtropical lake in South Brazil."Ecological Modelling, 219, 125-137.

Gal, G.; Hipsey, M.R.; Parparov, A.; Wagner, U.; Makler, V.; Zohary, T. (2009)."Implementation of ecological modeling as an effective management and investigation tool: Lake Kinneret as a case study." Ecological Modelling, 220, $1697-1718$.

Gal, G.; Imberger, J.; Zohary, T.; Antenucci, J.; Anis, A.e Rosenberg, T. (2003). "Simulating the thermal dynamics of Lake Kinneret" Ecological Modelling, 162, 69-86. 
Governo do Distrito Federal - GDF (2010). Zoneamento Ecológico Econômico do Distrito Federal - Volume II Diagnóstico: Relatório de Meio físico e biótico. Brasília - DF. 172p.

Governo do Distrito Federal - GDF (2012). Revisão e Atualização do Plano de Gerenciamento Integrado de Recursos Hídricos do Distrito Federal -Volume I Diagnóstico. Brasília - DF, 830.

Hamidian, A.H. e Hasanzadeh1, M. (2013). "Can the PAMOLARE 1-layer model predict eutrophication in hypertrophic lakes? A Case study: the Zaribar Lake, Iran" International Journal of Aquatic Biology, 1(3), 100-108.

Hamilton, D.P. e Schladow, S.G. (1997)."Water quality in lakes and reservoirs. Part I Model description”.Ecological Modelling,96, 91-110. DOI: 10.1016/S03043800(96)00062-2.

Hense, I. e Beckmann, A. (2006). "Towards a model of cyanobacteria life cycleeffects of growing and resting stages on bloom formation of N2-fixing species." Ecological Modelling, 195, 205-218.

Hipsey, M.R.; Bruce, L.C. e Hamilton, D.P. (2014). GLM - General Lake Model: Model Overview and User Information, v. $2.0 \beta$. The University of Western Australia Technical Manual, Perth, Australia. 42pp.

Hipsey, M.R.; Bruce, L.C. e Hamilton, D.P. (2013). AquaticEcodynamics (AED) Model Library: Science Manual. The University of Western Australia Perth, Australia. $34 \mathrm{pp}$

Hongping, P. e Jianyi, M. (2002). "Study on the algal dynamic model for West Lake, Hangzhou." Ecological Modelling, 148, 67-77.

Instituto Nacional de Meteorologia - INMET (2009). Normais Climatológicas do Brasil (1961-1990). Orgs: Ramos, A.M.; Santos, L.A.R.; Fortes, L.T.G. Brasília, DF. $465 \mathrm{p}$.

Janse, J.H.; Scheffer, M.; Lijklema, L.; Liere,L.V.; Sloot, J.S.; Mooij, W.M.(2010). "Estimating the critical phosphorus loading of shallow lakes with the ecosystem model PCLake: Sensitivity, calibration and uncertainty."Ecological Modelling, 221, 654-665.

Ji, Z. G. (2008). Hidrodynamics and water quality: modeling rivers, lakes and estuaries. John Wiley \& Sons Interscience, New Jersey, EUA, 676.

Jorgensen, S.E. (1997). “Ecological Modelling by 'Ecological Modelling'."Ecological Modelling, 100, 5-10. 
Jorgensen, S.E. (2010). "A review of recent developments in lake modelling."Ecological Modelling, 221, 689-692.

Jorgensen, S.E. e Bendoricchio, G. (2001). Fundamentals of Ecological Modelling. $3^{\circ}$ edição, Elsevier: Amsterdam, 523p.

Jorgensen, S.E.; Chon, T.S. e Recknagel, F. (2009). Handbook of Ecological Modelling and Informatics.Southampton: WIT Press, $431 \mathrm{p}$.

Karr, J. R. e Chu, E.W. (2000). “Sustaining living rivers.”Hydrobiologia, 422, 1-14.

Kingsland, S.E. (1985). Modeling Nature.Ed. Chicago. EUA, 267p.

Koide, S. - Coordenador (2010). "Avaliação do impacto do uso da terra sobre os sistemas aquáticos das Bacias Hidrográficas do Descoberto e do Paranoá para determinação de indicadores de integridade ambiental". Projeto de rede de pesquisa, edital MCT/CNPq/FNDCT/FAPs/MEC/CAPES/PRO-CENTROOESTE N ${ }^{\circ} 031 / 2010$.

Kratz, T.K.; Arzberger, P.; Benson, B.J.; Chiu, C.Y.; Chiu, K.; Ding, L.; Fountain, T.; Hamilton, D.; Hanson, P.C.; Hu, Y.H.; Lin, F.P.; McMullen, D.F.; Tilak, S. e Wu, C. (2006). “Toward a global lake ecological observatory network”.Publications of the Karelian Institute, 145, 51-63.

Larocque, G.R.; Mailly, D.; Yue, T-X.; Anand,M.; Peng, C.; Kazanci, C.; Etterson, M.; Goethals, P.; Jorgensen, S.E.; Schramski, E.J.B. McIntire, E.J.B.; Marceau, D.J.; Chen, B.; Chen, G.Q.; Yang, Z.F.; Novotna, B.; Luckai, N.; Bhatti, J.S.; Liu, J.; Munson, A.; Gordon, A.M.; Ascough II, J.C. (2011). "Common challenges for ecological modelling: Synthesis of facilitated discussions held at the symposia organized for the 2009 conference of the International Society for Ecological Modelling in Quebec City, Canada, (October 6-9, 2009).” Ecological Modelling, 222, 2456- 2468 .

Liporoni, L. M. (2012). Estudo preliminar da qualidade da água do Lago Paranoá, Brasília - DF, utilizando um modelo de qualidade de água bidimensional. Dissertação de Mestrado em Tecnologia Ambiental e Recursos Hídricos, Departamento de Engenharia Civil e Ambiental, Universidade de Brasília, Brasília, DF, 188p.

Loucks, D.P. e Van Beek, E. (2005).Water Resources Systems Planning and Management.UNESCO.680p.104p. 
Malek, S.; Ahmad, S. M. S.; Singh, S. K. K.; Milow, P. e Salleh, A. (2011). "Assessment of predictive models for chlorophyll-a concentration of a tropical lake”. Bioinformatics, 12, 104-109.

Markfort, C. D.; Perez, A. L. S.; Thill, J. W.; Jaster, D. A.; Porté-Agel, F. e Stefan, H. G. (2010). "Wind sheltering of a lake by a tree canopy or bluff topography". Water Resources Research, 46. DOI:10.1029/2009WR007759

Martin, J.L. e McCutcheon, S.C. (1999).Hidrodynamics and transport for water quality modeling. Lewis Publishers, EUA, 794p.

Mooij, W. M.; Trolle, D.; Jeppesen, E.; Arhonditsis, G.; Belolipetsky, P. V.; Chitamwebwa, D. B. R.; Degermendzhy, A. G.; DeAngelis, D. L.; Senerpont Domis, L. N. D; Downing, A. S.; Elliott, J. A.; Gaedke, U.; Genova, S. N.; Gulati, R. D.; Håkanson, L., Hamilton, D. P., Hipsey, M. R., Hoen, J., Hulsmann, S., Los, F. H, Makler-Pick, V., Petzoldt, T., Prokopkin, I. G., Rinke, K., Schep, S. A., Tominaga, K., Dam, A. A., Nes, E. H., Wells, S. A., Janse, J. H., Fragoso, C. R. (2010). "Challenges and opportunities for integrating lake ecosystem modelling approaches". Aquatic Ecology, 44(3), 633 - 667.

Moriasi, D. N.; Arnold, J. G.; Van Liew, M. W.;. Bingner, R. L; Harmel, R. D.; Veith, T. L. (2007)." Model evaluation guidelines for systematic quantification of accuracy in watershed simulations." American Society of Agricultural and Biological Engineers, 50(3), 885-900.

Moss, B. (2012). "Cogs in the endless machine: Lakes, climate change and nutrient cycles: A review." Science of the Total Environment,434, 130-142.

Muhid, P.; Davis, T.W.; Bunn, S.E.e Burford.M.A. (2013)."Effects of inorganic nutrients in recycled water on freshwater phytoplankton biomass and composition". Water Research, 47, 384-394.

Nash, J. E. e Sutcliffe, J. V. (1970). "River flow forecasting through conceptual models: Part 1. A discussion of principles.” J. Hydrology 10(3): 282-290.

Padisák, J.; Borics, G.; Grigorszky, I. e Soróczki-Pintér, E. (2006). "Use of phytoplankton assemblages for monitoring ecological status of lakes within the Water Framework Directive: the assemblage index." Hydrobiologia, 553, 1-14.

Philomeno, M.G. (2007). A Comunidade Fitoplanctônica e a Restauração do Lago Paranoá, Brasília - DF. Tese de Doutorado, Universidade de Brasília, Departamento de Ecologia, Brasília, DF, 223p. 
Pinto-Coelho, R.; Pinel-Alloul, B.; Méthot, G. e Havens, K.E. (2005). "Crustacean zooplankton in lakes and reservoirs of temperate and tropical regions: variation with trophic status". Can. J. Fish. Aquat. Sci.,62, 348-361.

Pires, V.A.C. (2004). Metodologia para apoio à gestão estratégica de reservatórios de usos múltiplos: o caso do lago Paranoá, no Distrito Federal. Dissertação de Mestrado. Universidade de Brasília, Departamento de Engenharia Civil e Ambiental, Brasília, DF, 203p.

Piveli, R. P., Kato, M. T. (2006). Qualidade das águas e poluição: aspectos físicoquímicos. ABES, São Paulo, Brasil, 285p.

Pujoni, D.G.F. (2015). Padrões Espaço-Temporais da comunidade planctônica do complexo lacustre do Médio Rio Doce. Tese de Doutorado, Universidade Federal de Minas Gerais, Instituto de Ciências Biológicas, Belo Horizonte, MG, 158p.

R Development Core Team. (2015). “The R language definition. R Foundation for Statistical Computing". <http://cran.r-project.org/doc/manuals/R-lang.html>.

Rangel-Peraza, J. G.; Obregon, O.; Nelson, J.; Williams, G. P.; Anda, J.; GonzálezFarías, F. e Miller, J. (2012). "Modelling approach for characterizing thermal stratification and assessing water quality for a large tropical reservoir." Lakes \& Reservoirs: Research and Management, 17, 119-129.

Read, J.S., Hanson, P.C., Dugan, H., Snortheim, C. e Winslow, L.A. (2014a). "Lake modeling workshop". http://github.gleon.io/pres/inspire

Read, J.S., Winslow, L.A., Hansen, G.J.A., Van Den Hoek, J., Hanson, P.C., Bruce, L.C., Markfort, C.D. (2014b). "Simulating 2368 temperate lakes reveals weak coherence in stratification phenology." Ecological Modelling, 291, 142-150.

Recknagel, F., Taliba, A. e van der Molen, D. (2006). Phytoplankton community dynamics of two adjacent Dutch lakes in response to seasons and eutrophication control unravelled by non-supervised artificial neural networks. Ecological Informatics, 1, 277-285.

Recknagel, F.; van Ginkel, C.; Cao, H.; Cetin, L. e Zhang, B. (2008). "Generic limnological models on the touchstone: Testing the lake simulation library SALMO-OO and the rule-based Microcystis agent for warm-monomictic hypertrophic lakes in South Africa.” Ecological Modelling, 215, 144-158.

Reynolds, C. S. (1999). Phytoplankton assemblages in reservoirs. In: Tundisi, J. G. and Straškraba, M. (eds), Theoretical Reservoir Ecology and its Applications. Backhuys, Leiden, 439-456. 
Reynolds, C.S.; Huszar, V; Kruk, C; Naselli-Flores, L e Melo, S. (2002). "Towards a functional classification of the freshwater phytoplankton."Journal of Plankton Research, 24(5), 417-428.

Rigosi, A.; Marcé, R.; Escot, C.; Rueda, F.J. (2011). “A calibration strategy for dynamic succession models including several phytoplankton groups". Environmental Modelling \& Software, 26, 697-710.

Rigosi, A. e Rueda, F.J. (2012a). "Hydraulic control of short-term successional changes in the phytoplankton assemblage in stratified reservoirs." Ecological Engineering, 44, 216-226.

Rigosi, A. e Rueda, F.J. (2012b). "Propagation of uncertainty in ecological models of reservoirs: From physical to population dynamic predictions." Ecological Modelling, 247, 199- 209.

Rigosi, A; Carey, C.C.; Ibelings, B.W. e Brookes, J.D. (2014). "The interaction between climate warming and eutrophication to promote cyanobacteria is dependent on trophic state and varies among taxa." Limnology and Oceanography, 59, 99-114.

Rigosi, A. (2015). Aquatic Ecosystem MOdelling Network (AEMON) discussion fórum.<https://groups.google.com/forum/?utm_source=digest\&utm_medium=em ail/\#!topic/aquaticmodelling/ZPX4cSWObyE>. Acesso em: 26/04/2015.

Salas, H.J. (1983). Resumo do Segundo Encontro do Projeto Regional "Desenvolvimento de Metodologias Simplificadas para a Avaliação de Eutrofização em Lagos Quentes”, coordenado pelo Cepis. Brasília, Brasil, 33p.

Schladow, S.G. e Hamilton, D.P. (1997). "Prediction of water quality in lakes and reservoirs. Part II. Model calibration, sensitivity analysis and application." Ecological Modelling, 96, 111-123.

Singh, V.P. (1995). Computer models of watershed hydrology. Water Resources Publications, Universidade de Michigan, EUA, 1130p.

Søndergaard, M.; Jeppesen, E.; Jensen, J.P. e Amsinck, S.L. (2005). Water Framework Directive: ecological classification of Danish lakes. J. Appl. Ecol.,42, 616-629.

Souza, A.P. (2013). Avaliação da utilização de índices de integridade biótica do fitoplâncton como ferramenta para estimativa de qualidade da água nos lagos Paranoá e Descoberto, no Distrito Federal. Dissertação de Mestrado, Universidade de Brasília, Departamento de Engenharia Civil e Ambiental, Brasília, DF, 174p. 
Souza, F.P. (2014). Monitoramento e modelagem hidrológica da sub-bacia do Lago Paranoá - Brasília/DF - e avaliação de bacias de detenção. Dissertação de Mestrado, Universidade de Brasília, Departamento de Engenharia Civil e Ambiental, Brasília, DF, 139p.

Togoro, E.S. (2006). Qualidade da Água e Integridade Biótica: Estudo de Caso num Trecho Fluminense do Rio Paraíba do Sul. Dissertação de Mestrado, Universidade do Estado do Rio de Janeiro, Departamento de Engenharia Sanitária e do Meio Ambiente, Rio de Janeiro, RJ, 159p.

Trolle, D.; Skovgaard, H. e Jeppesen, E. (2008a). "The Water Framework Directive: Setting the phosphorus loading target for a deep lake in Denmark using the 1D lake ecosystem model DYRESM-CAEDYM”. Ecological Modelling, 219, 138152.

Trolle, D.; Jørgensen, T.B.; Jeppesen, E. (2008b). "Predicting the effects of reduced external nitrogen loading on the nitrogen dynamics and ecological state of deep Lake Ravn, Denmark, using the DYRESM-CAEDYM model”. Limnologica, 38, $220-232$.

Trolle, D.; Hamilton, D.P.; Hipsey, M.R.; Bolding, K.; Bruggeman, J.; Mooij, W.M.; Janse, J.H.; Nielsen, A. Jeppesen, E. Elliott, J.A. Makler-Pick, V. Petzoldt, T. Rinke, K. Flindt, M.R. Arhonditsis, G.B. Gal, G. Bjerring, R. Tominaga, K. Hoen, J. Downing, A.S. Marques, D.M. Fragoso Jr, C.R. Sondergaard, M. Hanson, P.C. (2012). “A community-based framework for aquatic ecosystem models."Hydrobiologia, 683, 25-34.

Tucci, C. M. (org).(2009). Hidrologia: ciência e aplicação. $4^{\circ}$ edição. Editora da Universidade Federal do Rio Grande do Sul, Porto Alegre - RS, 943p.

Tucci, C. M., (2005). Modelos hidrológicos. $2^{\mathrm{a}}$ edição, Editora da Universidade Federal do Rio Grande do Sul, Porto Alegre - RS, 678p.

Tundisi, J.G.; Matsumura-Tundisi, T.; Henry, R.; Rocha, O. e Hino, K. (1988). "Comparação do estado trófico de 23 reservatórios do Estado de São Paulo: Eutrofização e manejo". In: Tundisi, J.G. (ed.). Limnologia e manejo de represas. Série Monografias em Limnologia/USP. Vol 1, 165-204.

Tundisi, J.G.; Matsumura Tundisi, T. (2008). Limnologia. 1ed, Oficina de Textos, São Paulo. 
Van Nes, E.H. e Scheffer, M. (2005). "A strategy to improve the contribution of complex simulation models to ecological theory." Ecological Modelling, 185, $153-164$.

von Sperling, M. (1994). Critérios e dados para uma seleção preliminar de sistemas de tratamento de esgotos. Bio Engenharia Sanitária e Ambiental. Encarte Técnico, Ano III, vol. 1, 7-21.

von Sperling, M. (2005). Princípios do tratamento biológico de águas residuárias. Vol. 1. Introdução à qualidade das águas e ao tratamento de esgotos. Departamento de Engenharia Sanitária e Ambiental - UFMG. $3^{\circ}$ ed. 452p.

Walter, M.; Recknagel, F.; Carpenter, C. e Bormans, M. (2001). "Predicting eutrophication effects in the Burrinjuck Reservoir (Australia) by means of the deterministic model SALMO and the recurrent neural network model ANNA." Ecological Modelling, 146, 97-113.

Whigham, P. e Recknagel, F. (1999). "Predictive modelling of plankton dynamics in freshwater lakes using genetic programming".Anais do Congresso Internacional de Modelagem e Simulação,vol. 3, 679-684, Hamilton, Nova Zelândia.

Whitfield, A.K. e Elliott, M. (2002). "Fishes as indicators of environmental and ecological changes within estuaries: a review of progress and some suggestions for the future." Journal of Fish Biology, 61(A), 229-250.

Winslow, L.A. e Read, J. S. (2014). GLMr/glmtools. Disponível em: <//github.com/USGS-R/glmtools>. Acesso em: 20 de maio de 2015.

Wrobel, L.C.; Eiger. S.; Rosman, P.C.; Tucci, C.E.M., Cirilo, J.A. e Cabral, J.P. (1989).Métodos Numéricos em Recursos Hídricos. ABRH - Associação Brasileira de Recursos Hídricos, Rio de Janeiro,

Yao, H.;Samal, N. R.; Joehnk, K. D.; Fang, X.; Bruce, L. C.; Pierson, D. C.; Rusak, J. A. e James, A. (2014). "Comparing ice and temperature simulations by four dynamic lake models in Harp Lake: past performance and future predictions".Hydrological Processes, Publicado online em Wiley Online Library <wileyonlinelibrary.com> DOI: 10.1002/hyp.10180.

Zhang, H.; Culver, D.A. e Boegman, L. (2008). "A two-dimensional ecological model of Lake Erie: Application to estimate dreissenid impacts on large lake plankton populations." Ecological Modelling, 214, 219-241. 
Zhang, J.; Gurkan, Z. e Jorgensen, S.E. (2010).“Application of ecoexergy for assessment of ecosystem health and development of structurally dynamic models."Ecological Modelling, 221, 693-702.

Zhang, W.; Watson, S.B.; Rao, Y.R. e Kling, H.J. (2013). “A linked hydrodynamic, water quality and algal biomass model for alarge, multi-basin lake: A working management tool." Ecological Modelling, 269, 37-50. 


\section{APÊNDICE A}

Tabela A-1: Equações de fluxo superficial, mistura vertical e fluxos de afluentes e efluentes para o modelo GLM. Adaptado de Hipsey et al.(2014).

\begin{tabular}{|c|c|c|}
\hline Função & Equação & Componentes da equação \\
\hline Momento & $\tilde{\imath}=\rho_{a} C_{D} U_{x}^{2}$ & $\begin{array}{c}\rho_{\mathrm{a}}-\text { densidade do } \mathrm{ar}(\mathrm{kg} \\
\left.\mathrm{m}^{-3}\right) \\
C_{D}-1.3 \times 10^{-3} \\
U_{x}-\text { velocidade do vento }\left(\mathrm{m} \mathrm{s}^{-1}\right) \text { a } \mathrm{x} \mathrm{m} \text { acima da } \\
\text { superfície da água }\end{array}$ \\
\hline Calor sensível & $\phi H=-\rho_{a} c_{p} C_{H} U_{x}\left(T_{a}-T_{s}\right)$ & $\begin{array}{c}C_{H}-1.3 \times 10^{-3} ; T_{a}-\text { temperatura do ar }\left({ }^{\circ} \mathrm{C}\right) \\
T_{S} \text { - temperatura na superfície da camada }\left({ }^{\circ} \mathrm{C}\right) .\end{array}$ \\
\hline Calor latente & $\phi E=-\rho_{a} C_{E} U_{x}\left(e_{a}\left[T_{a}\right]-e_{s}\left[T_{s}\right]\right)$ & $\begin{array}{c}e_{a}-\text { pressão de vapor; } e_{s}-\text { pressão de saturação do } \\
\text { vapor na temperatura da camada superficial }\end{array}$ \\
\hline $\begin{array}{l}\text { Radiação de ondas } \\
\text { curtas }\end{array}$ & $\phi_{S W}(z)=\left(1-\alpha_{S W)} \phi_{S W} \exp \left[-K_{D} z\right]\right.$ & $\begin{array}{c}\alpha_{S W} \text { - albedo para o hemisfério Sul: } \\
0.08-0.02 \sin \left[\frac{2 \Pi}{365} d-\frac{\Pi}{2}\right]\end{array}$ \\
\hline $\begin{array}{l}\text { Radiação de ondas } \\
\text { longas }\end{array}$ & $\phi_{L W n e t}=\phi_{L W i n}-\phi_{L W o u t}$ & \\
\hline $\begin{array}{l}\text { Fluxo superficial } \\
\text { de energia }\end{array}$ & $\frac{d h_{S}}{d t}=\lambda \phi_{E}+\mathrm{P}+\mathrm{S}$ & $\begin{array}{c}h_{S}-\text { altura da camada superficial; } \\
\mathrm{t}-\text { passo de tempo }(\mathrm{s}) ; \lambda-\text { calor latente de } \\
\text { evaporação; } \\
\mathrm{P}-\text { chuva }\left(\mathrm{m} \mathrm{dia}^{-1} ; \mathrm{S}-\text { neve }\left(\mathrm{dia}^{-1}\right)\right.\end{array}$ \\
\hline Energia disponível & $\begin{array}{l}E_{T K E}=\left(0.5 C_{K}\left(W_{s}^{2}+\psi^{3} \mu_{s}^{3}\right) \Delta \mathrm{t}+\right. \\
0.5 C_{S}\left[\mu_{b}^{2}+\frac{\mu_{b}^{2}}{6} \frac{d \xi}{d h}+\frac{\mu_{b} \xi}{3} \frac{d \mu_{b}}{d h}\right] h_{S-1}\end{array}$ & $\begin{array}{c}\mathrm{u}^{*} \mathrm{e} \mathrm{w}^{*} \text { - escalas de velocidade na horizontal e } \\
\text { vertical, respectivamente. }\end{array}$ \\
\hline Energia requerida & $\begin{array}{l}E_{P E}=\left[\left(0.5 C_{T}\left(W_{s}^{3}+\psi^{3} \mu_{s}^{3}\right)^{2 / 3}+\right.\right. \\
\left.\frac{\Delta \rho g h_{m i x}}{\rho o}+\frac{g \xi^{2}}{24 \rho o} \frac{d(\Delta \rho)}{d h}+\frac{g \xi \Delta \rho}{12 \rho o} \frac{d \xi}{d h}\right] h_{s-1}\end{array}$ & \\
\hline $\begin{array}{l}\text { Espessura da } \\
\text { camada dos } \\
\text { afluentes }\end{array}$ & $\mathrm{h}_{\mathrm{i}}=1.2 \mathrm{Edx}+h_{i-1}$ & $\begin{array}{l}\text { E - taxa de arrastamento; dx - distância percorrida } \\
\text { pela água afluente. }\end{array}$ \\
\hline $\begin{array}{l}\text { Número de } \\
\text { Grashof: }\end{array}$ & $\mathrm{G}_{r}=\frac{\mathrm{N}^{2} \mathrm{Ai}^{2}}{v^{2}}$ & $\begin{array}{c}\mathrm{G}_{r} \text { - Contabilização de fluxos de saída pela da } \\
\text { remoção de água da camada na profundidade } \\
\text { definida no ponto de saída. }\end{array}$ \\
\hline
\end{tabular}




\section{APÊNDICE B}

1. Séries temporais dos dados de qualidade da água e biomassa fitoplanctônica nos pontos de monitoramento da CAESB, no lago Paranoá-DF, no período simulado.

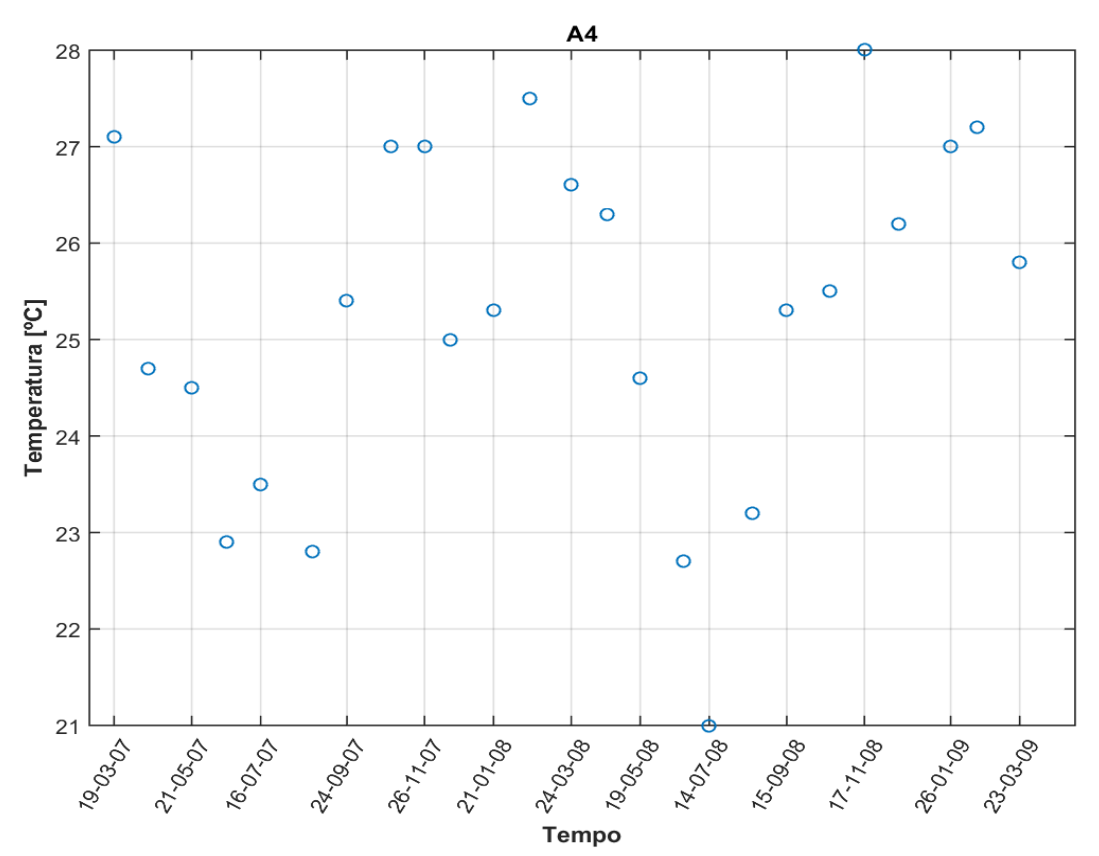

Figura B-1: Série temporal de concentração de temperatura da água registrada pela CAESB no ponto A4 entre 03/2007 e 03/2009.

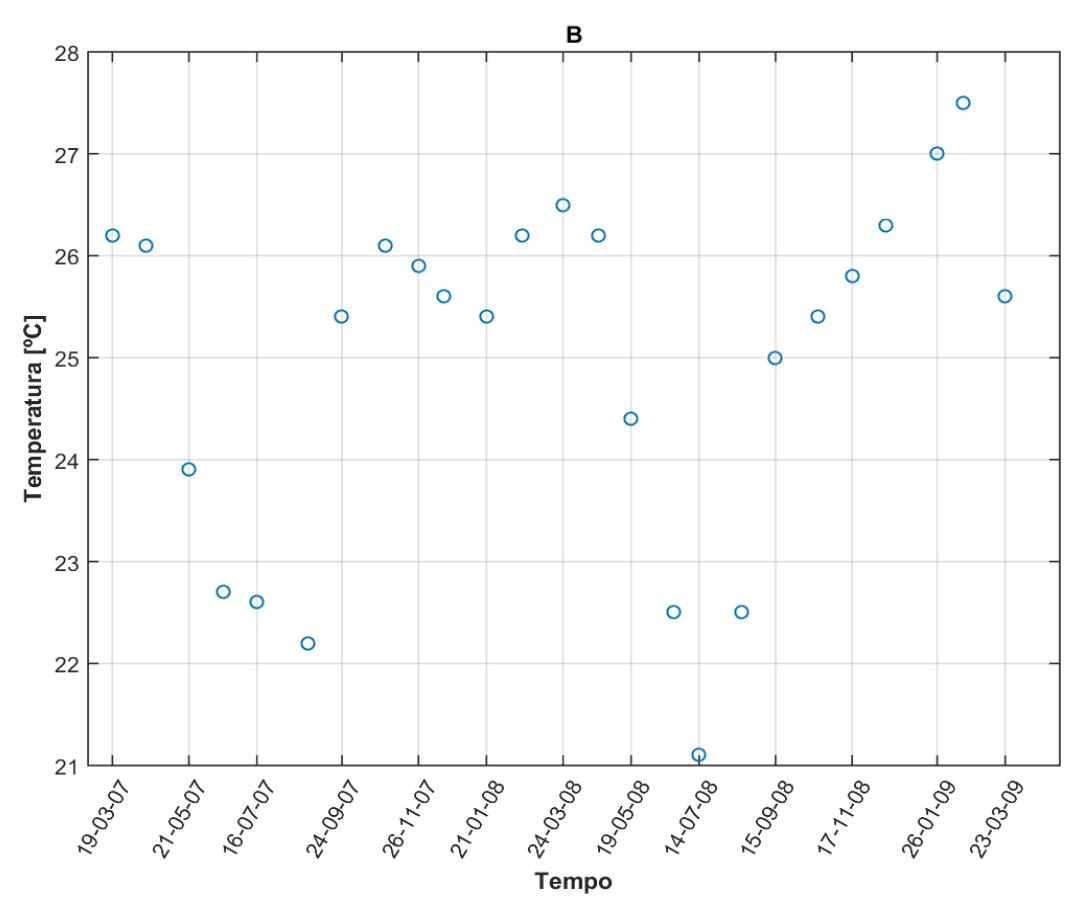

Figura B-2: Série temporal de concentração de temperatura da água registrada pela CAESB no ponto B entre 03/2007 e 03/2009. 


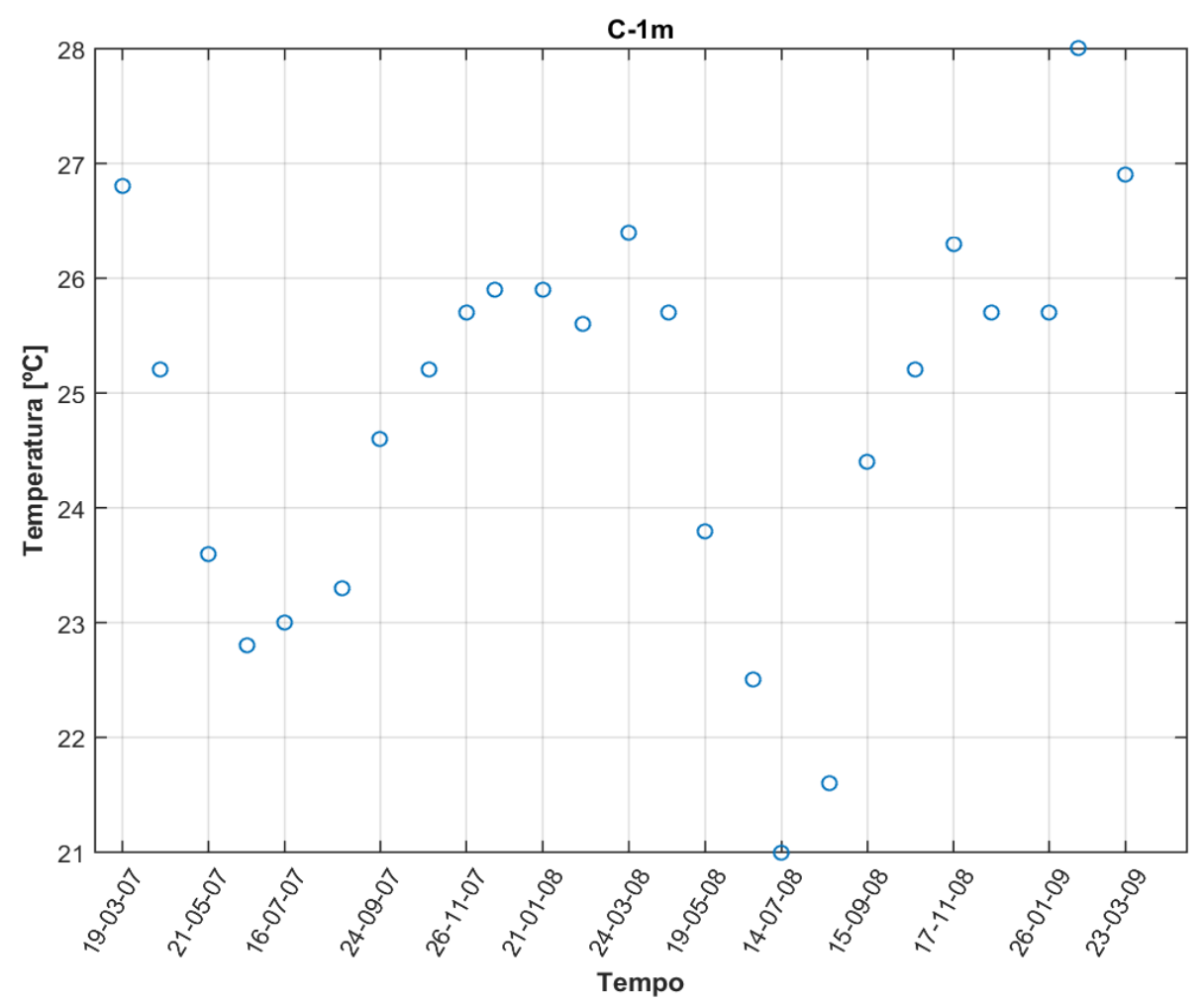

Figura B-3: Série temporal de concentração de temperatura da água registrada pela CAESB no ponto C a $1 \mathrm{~m}$ entre 03/2007 e 03/2009.

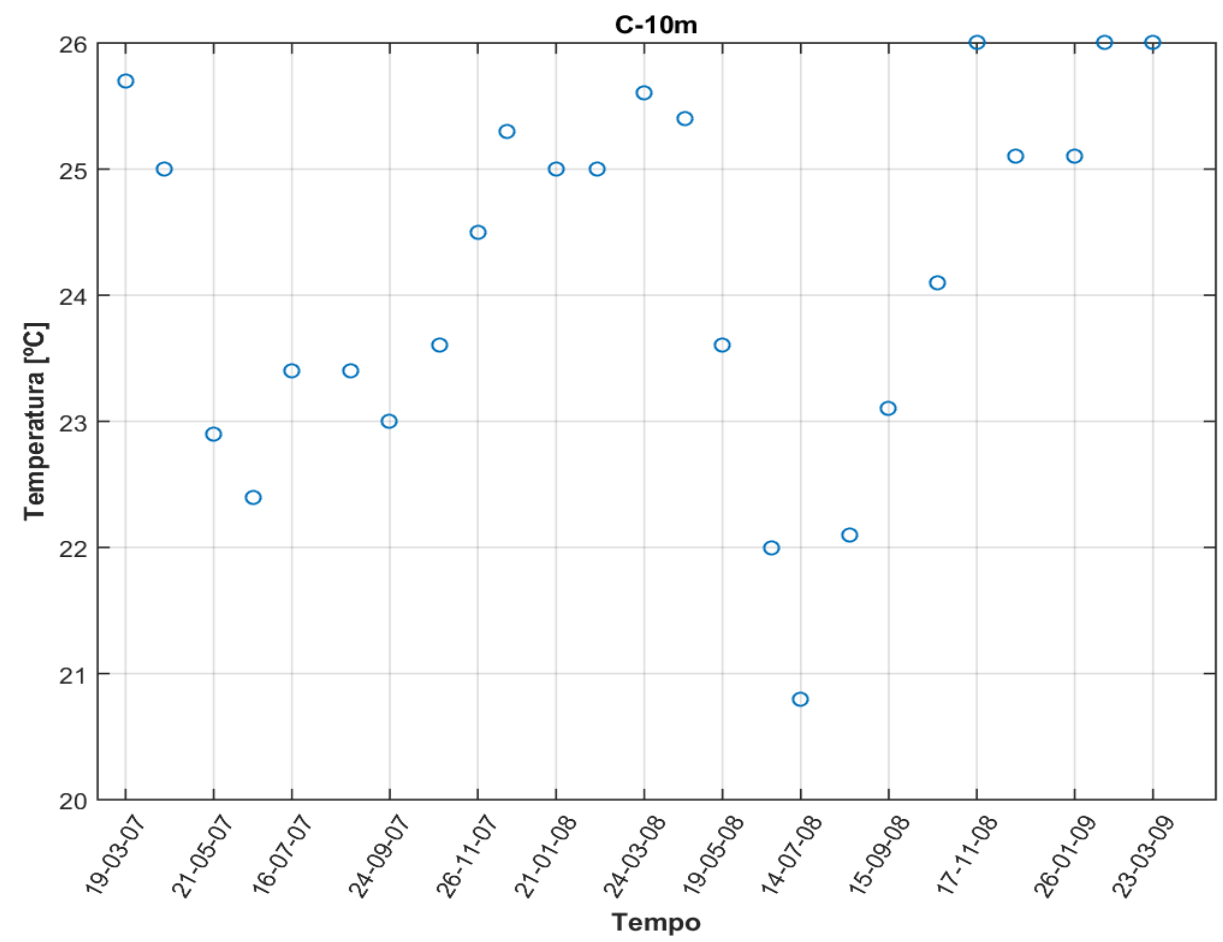

Figura B-4: Série temporal de concentração de temperatura da água registrada pela CAESB no ponto C a 10m entre 03/2007 e 03/2009. 


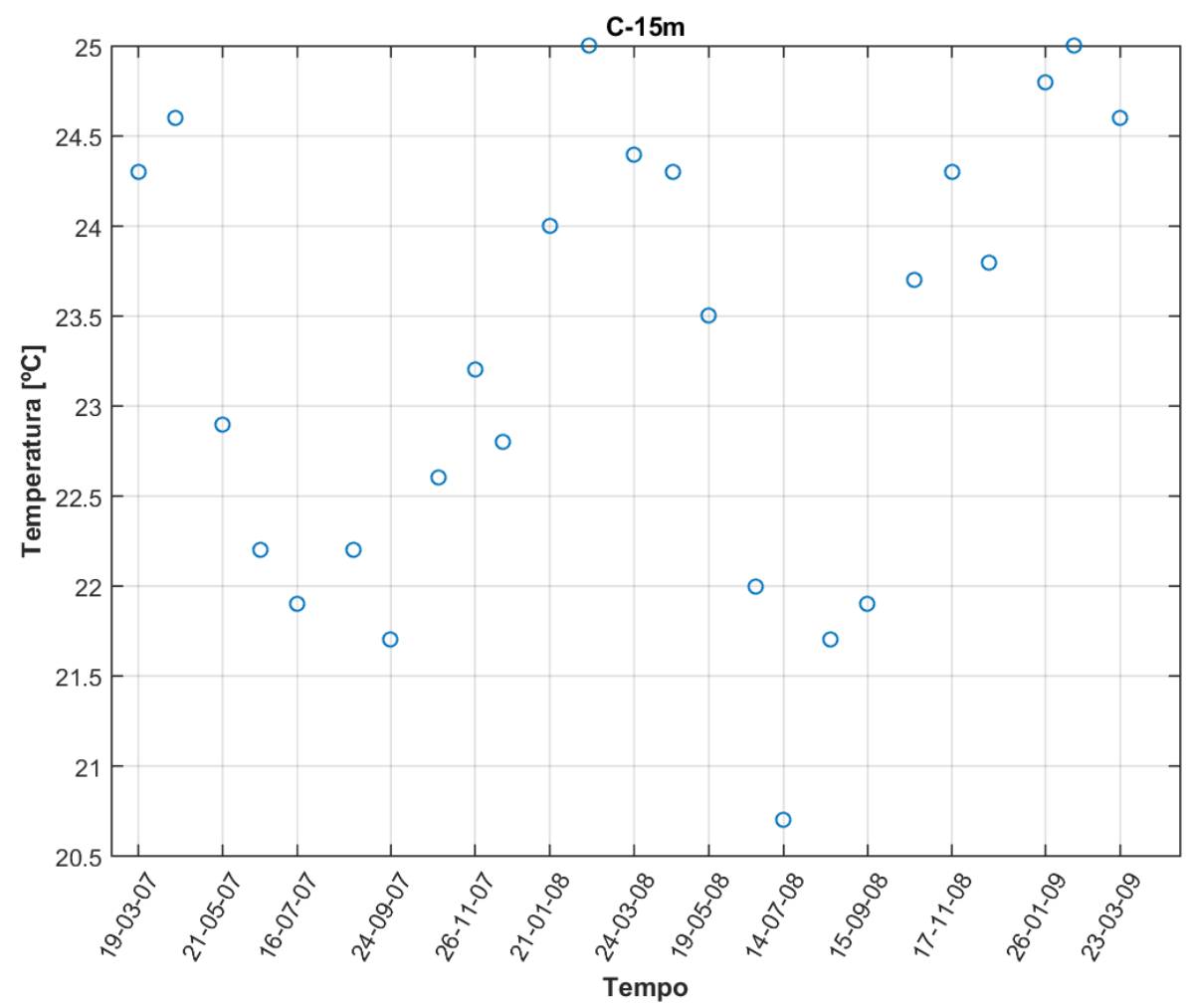

Figura B-5: Série temporal de concentração de temperatura da água registrada pela CAESB no ponto C a $15 \mathrm{~m}$ entre 03/2007 e 03/2009.

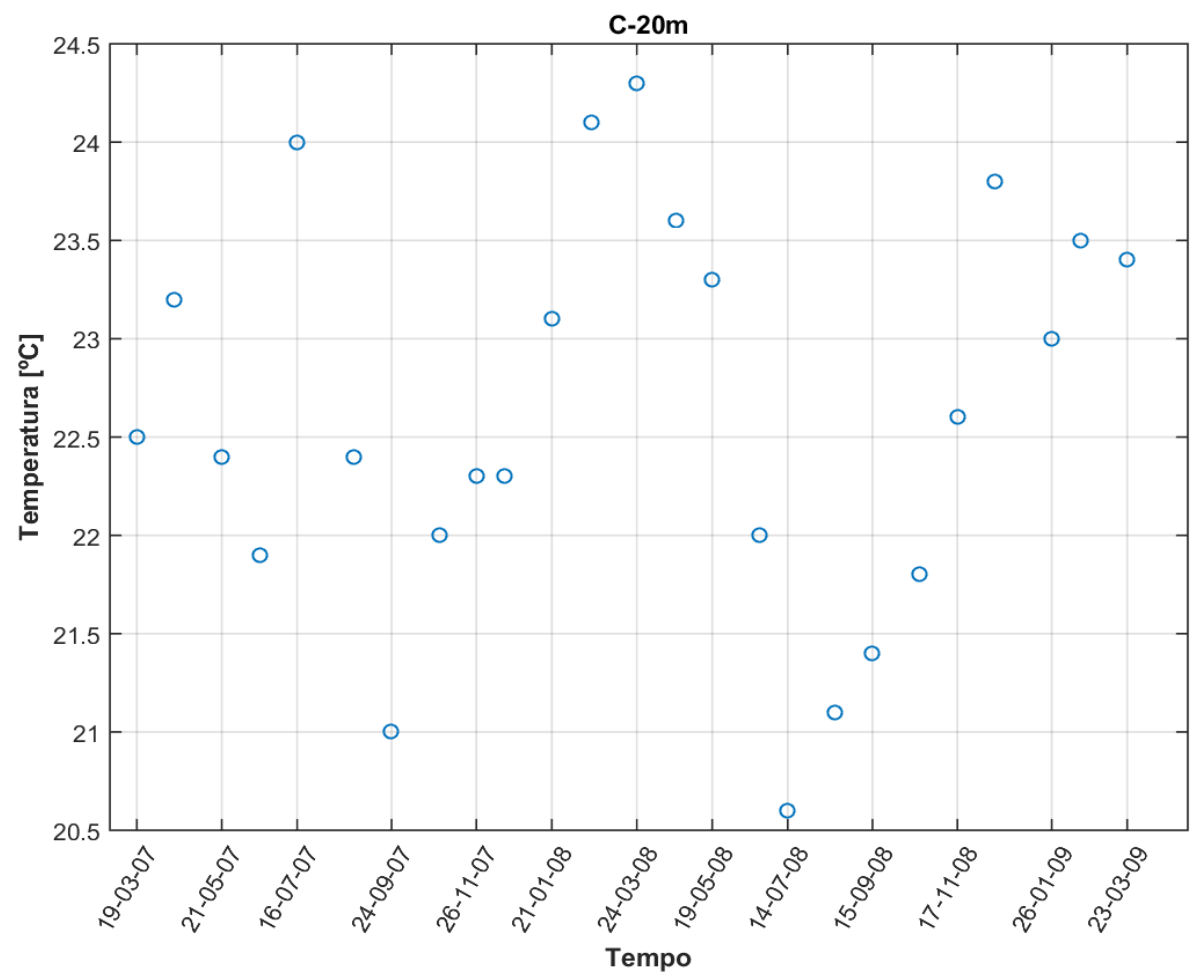

Figura B-6: Série temporal de concentração de temperatura da água registrada pela CAESB no ponto $\mathrm{C}$ a $20 \mathrm{~m}$ entre 03/2007 e 03/2009. 


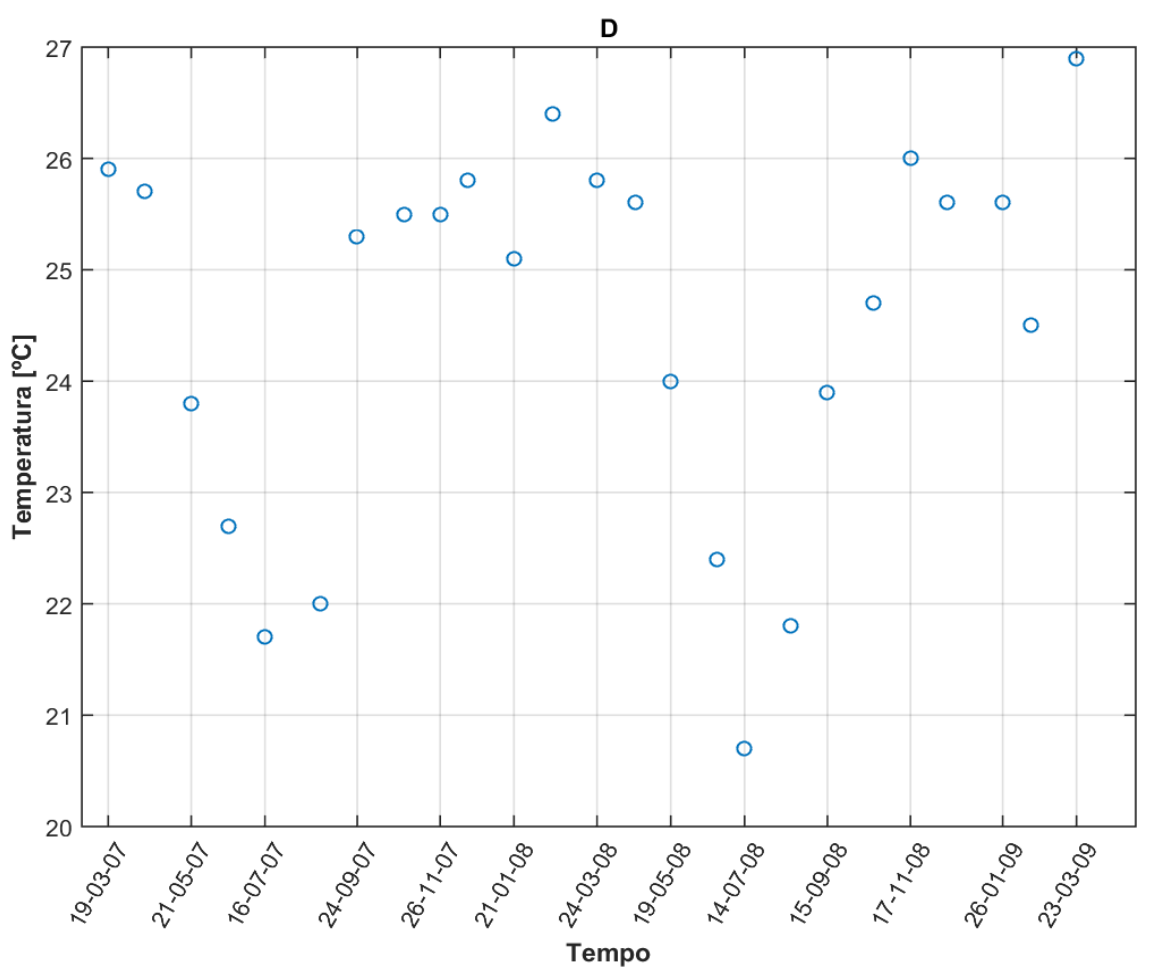

Figura B-7: Série temporal de concentração de temperatura da água registrada pela CAESB no ponto D entre 03/2007 e 03/2009.

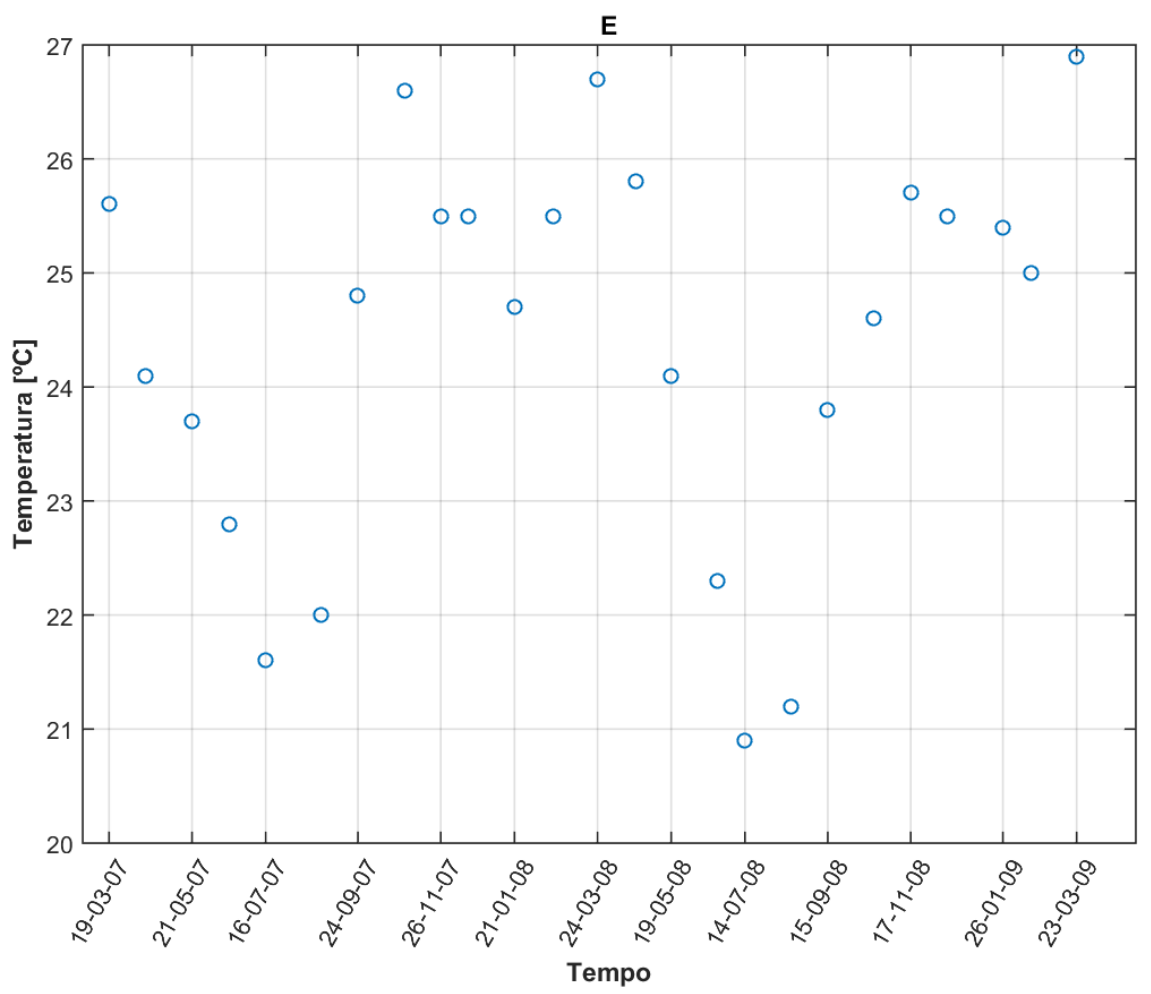

Figura B-8: Série temporal de concentração de temperatura da água registrada pela CAESB no ponto E entre 03/2007 e 03/2009. 


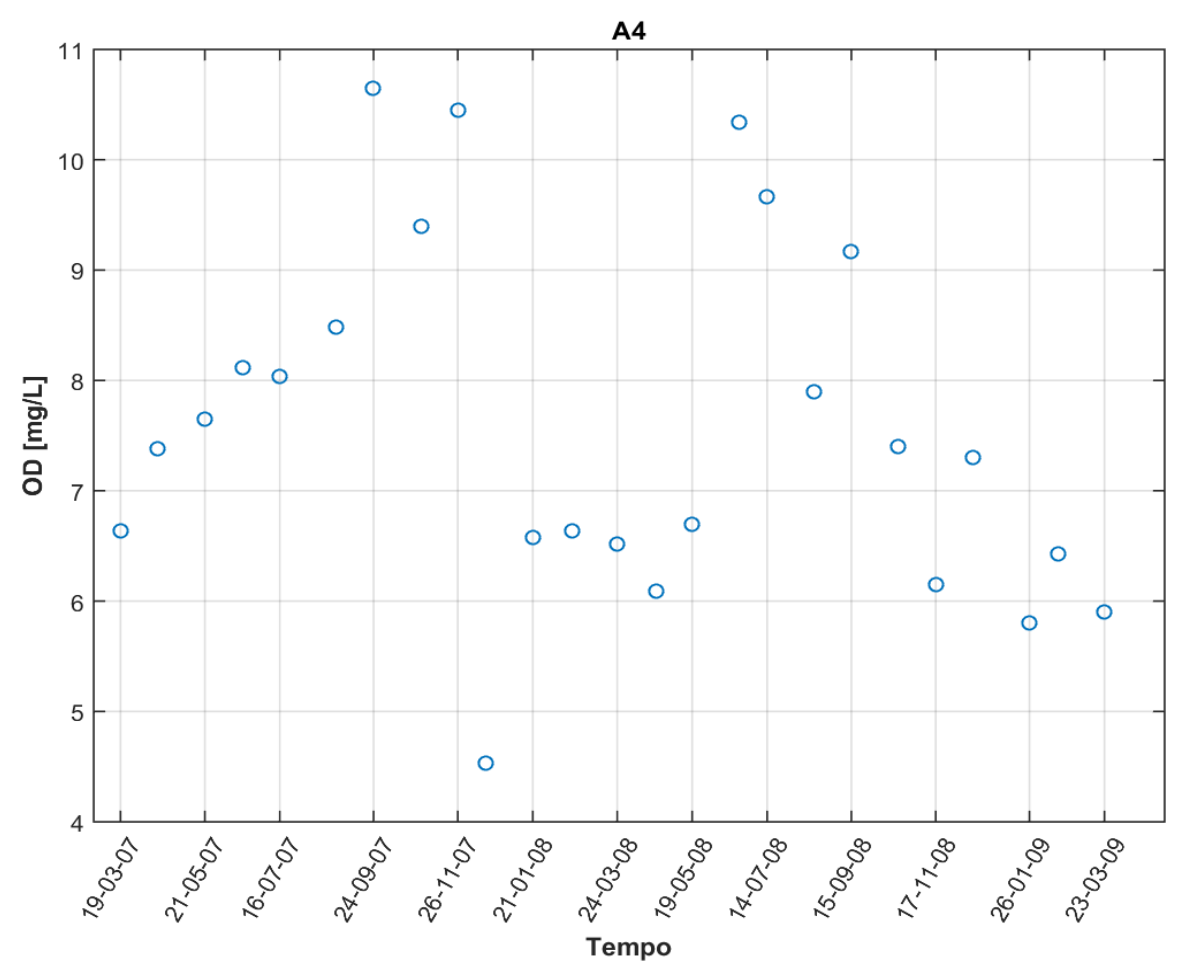

Figura B-9: Série temporal de concentração de OD registrado pela CAESB no ponto A4 entre 03/2007 e 03/2009.

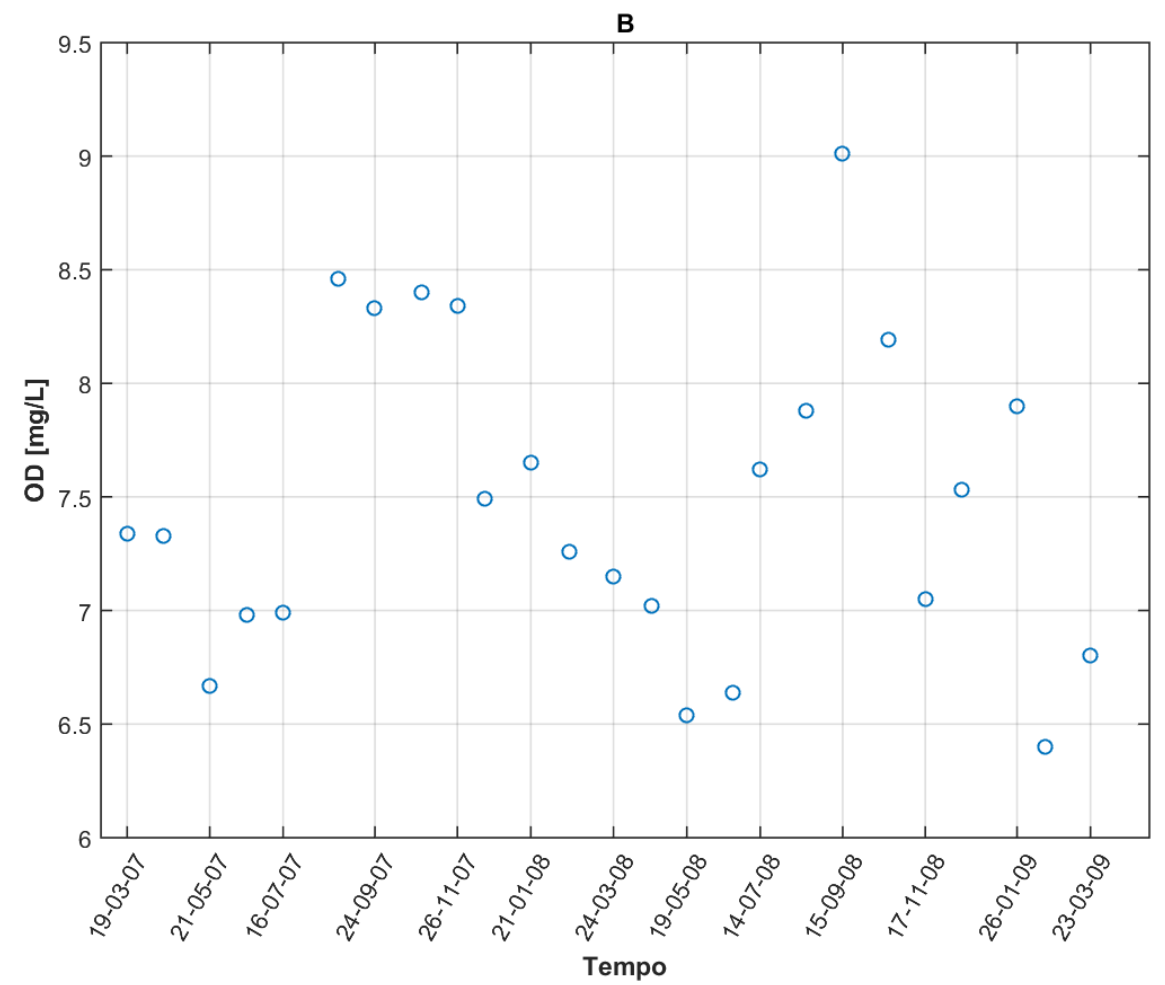

Figura B-10: Série temporal de concentração de OD registrado pela CAESB no ponto B entre 03/2007 e 03/2009. 


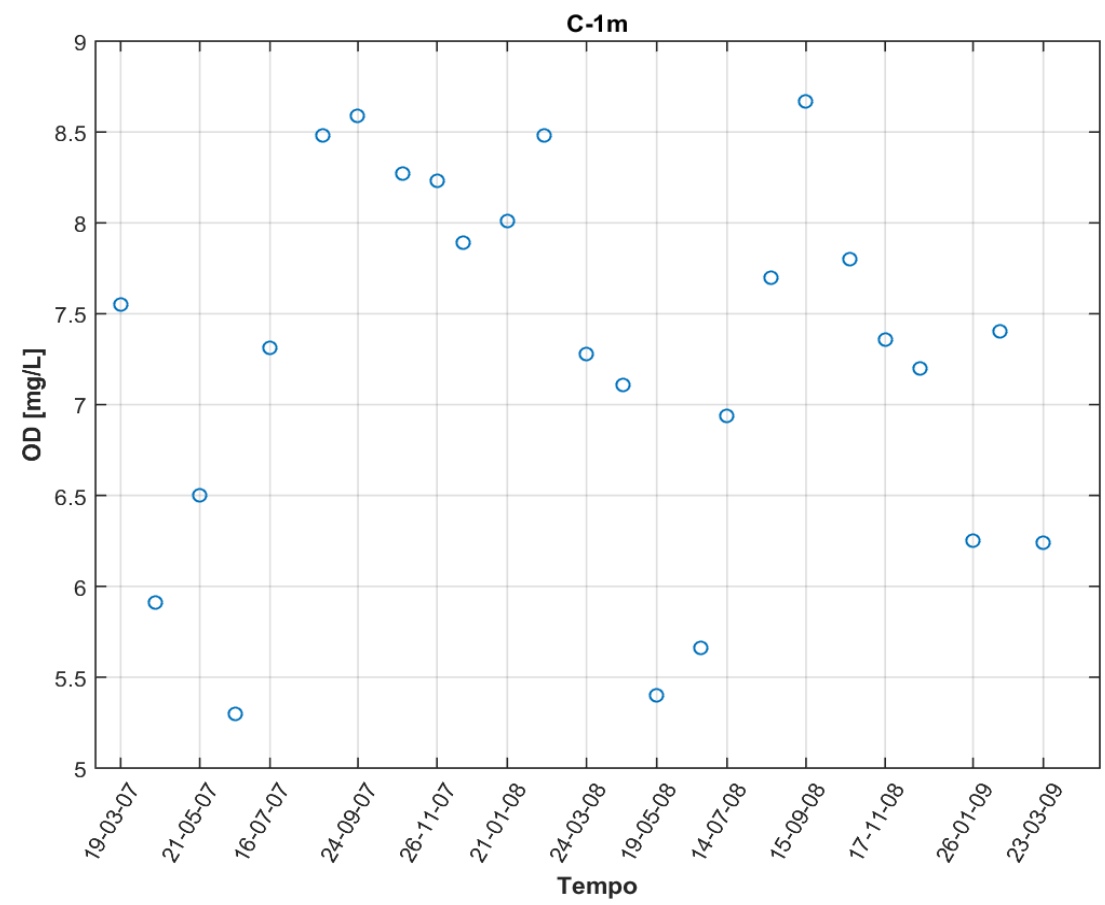

Figura B-11: Série temporal de concentração de OD registrado pela CAESB no ponto C a $1 \mathrm{~m}$ entre 03/2007 e 03/2009.

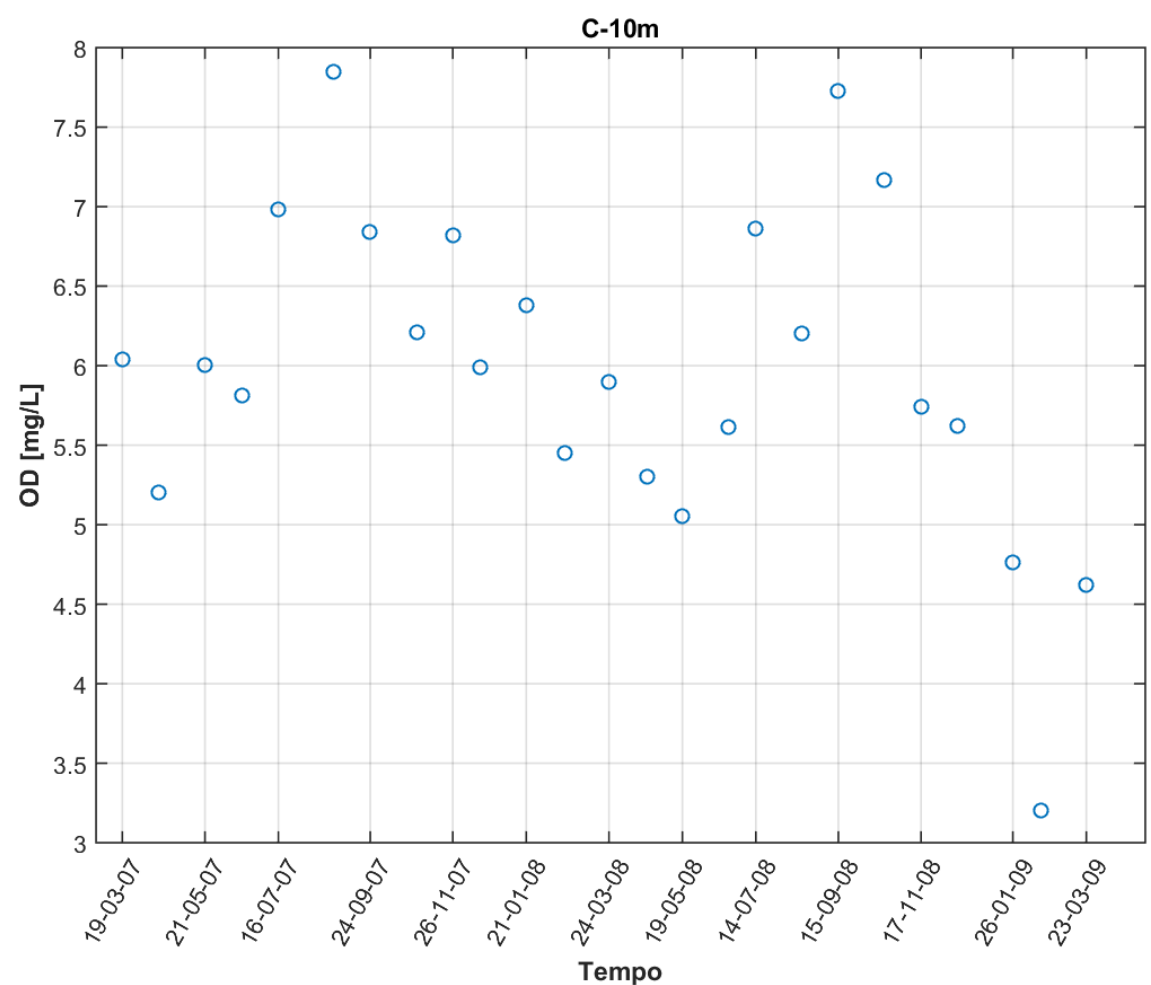

Figura B-12: Série temporal de concentração de OD registrado pela CAESB no ponto C a $10 \mathrm{~m}$ entre 03/2007 e 03/2009. 


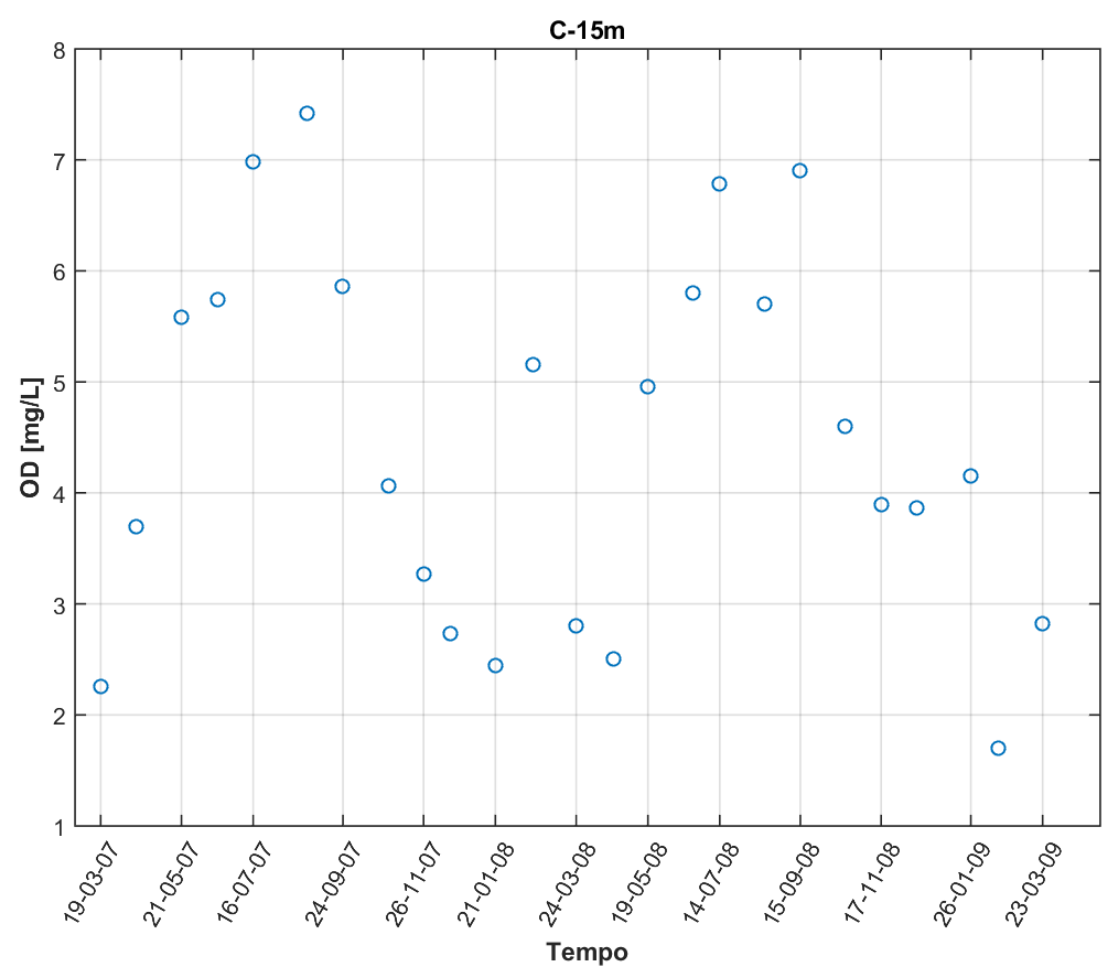

Figura B-13: Série temporal de concentração de OD registrado pela CAESB no ponto C a $15 \mathrm{~m}$ entre 03/2007 e 03/2009.

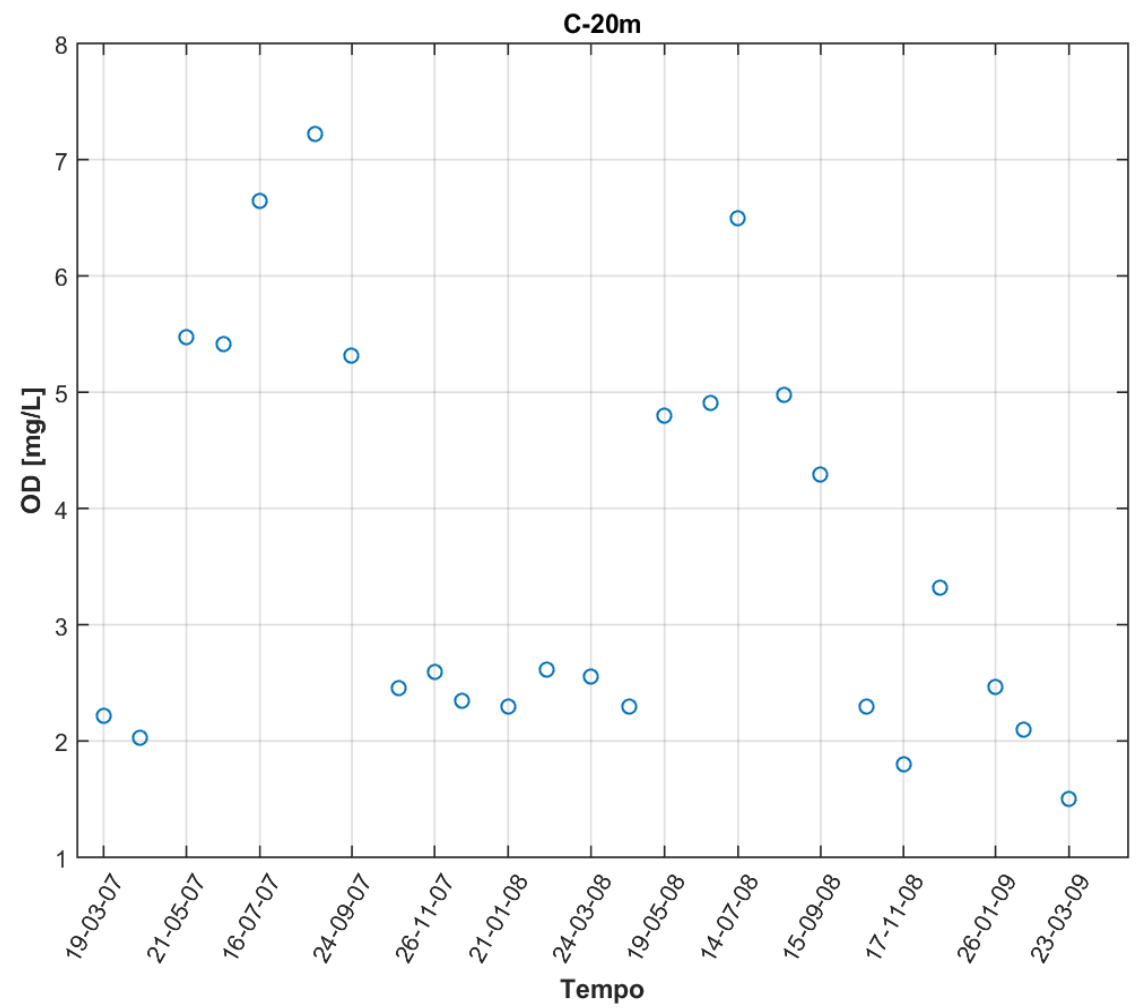

Figura B-14: Série temporal de concentração de OD registrado pela CAESB no ponto C a 20m entre 03/2007 e 03/2009. 


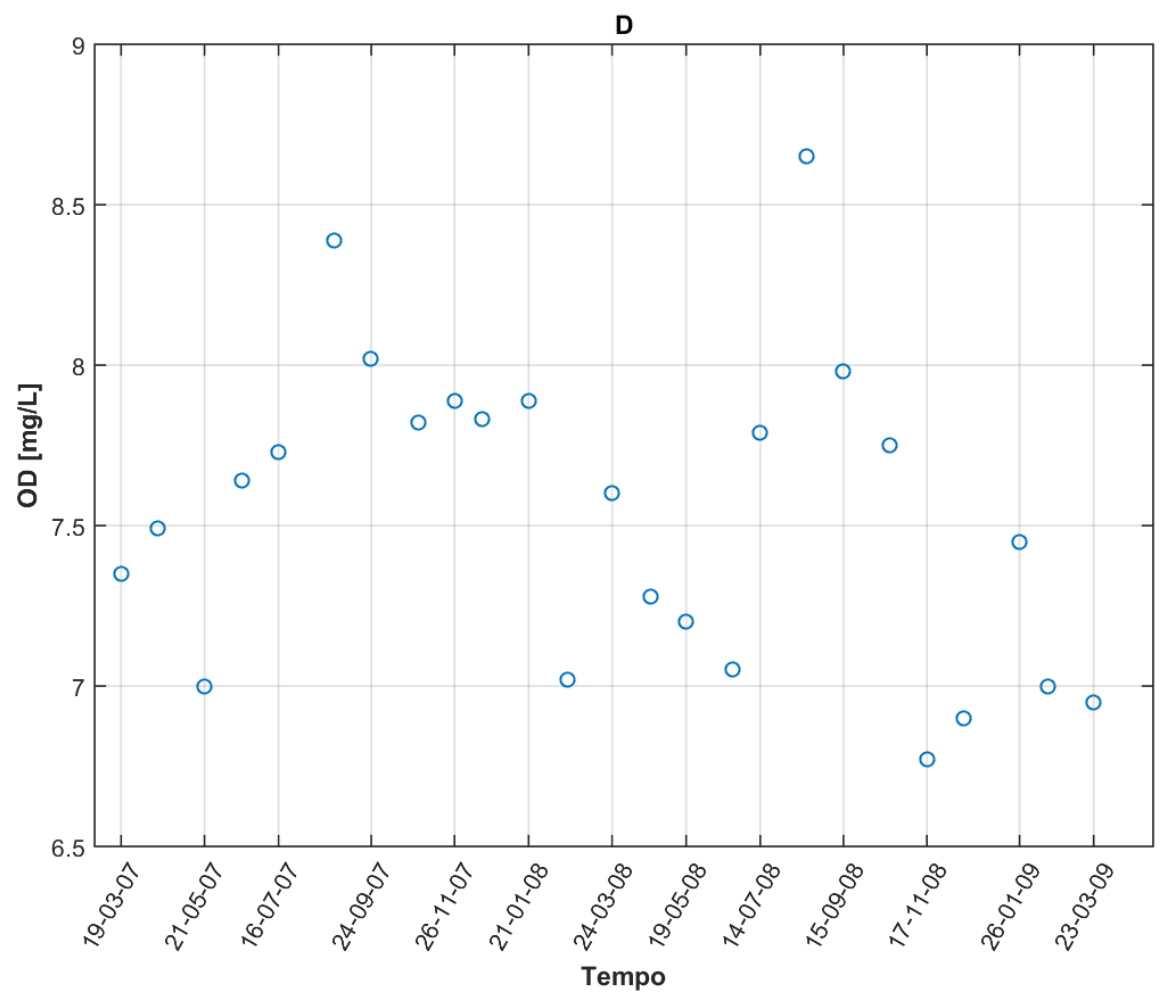

Figura B-15: Série temporal de concentração de OD registrado pela CAESB no ponto D entre 03/2007 e 03/2009.

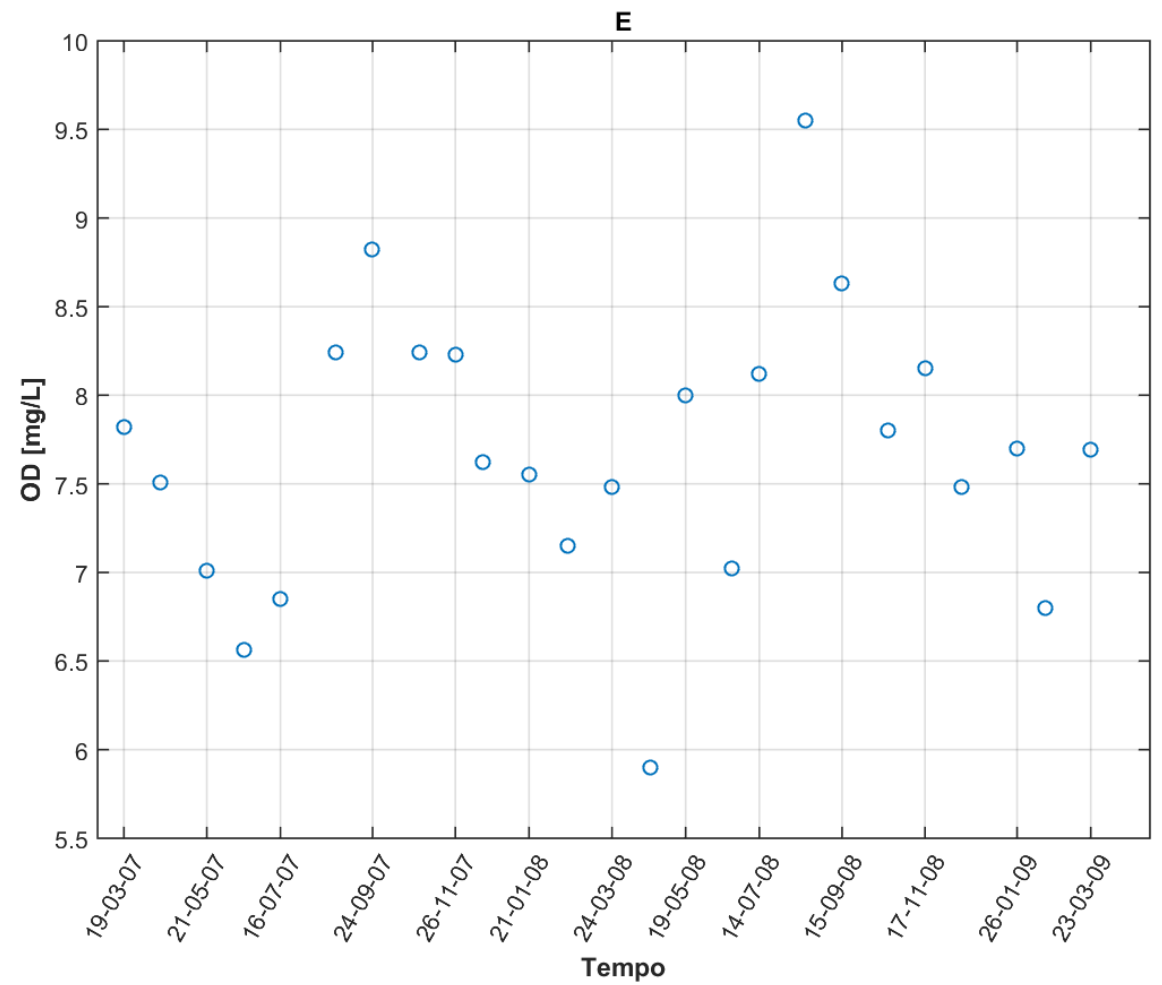

Figura B-16: Série temporal de concentração de OD registrado pela CAESB no ponto E entre 03/2007 e 03/2009. 


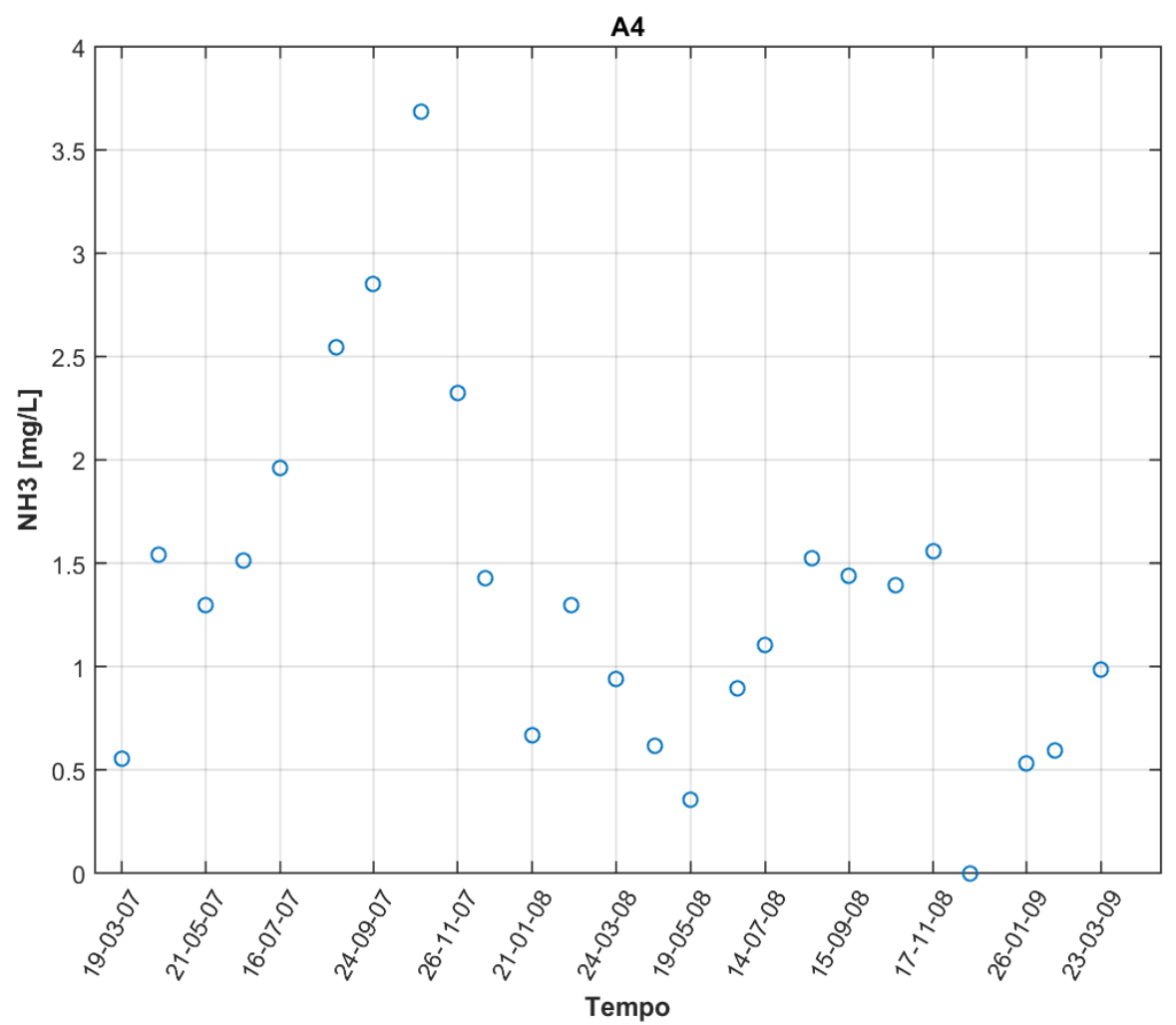

Figura B-17: Série temporal de concentração de amônia registrado pela CAESB no ponto A4 entre 03/2007 e 03/2009.

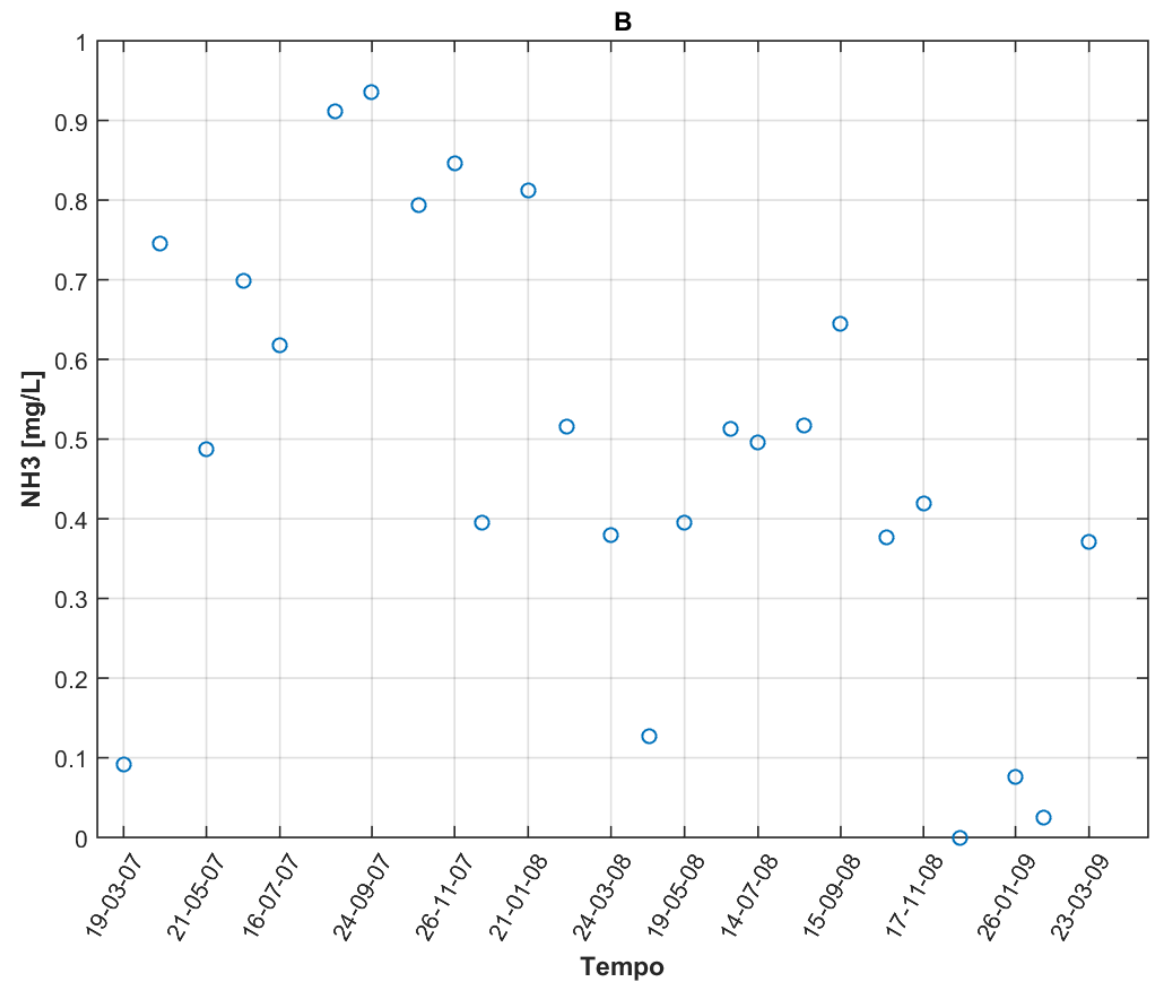

Figura B-18: Série temporal de concentração de amônia registrado pela CAESB no ponto B entre 03/2007 e 03/2009. 


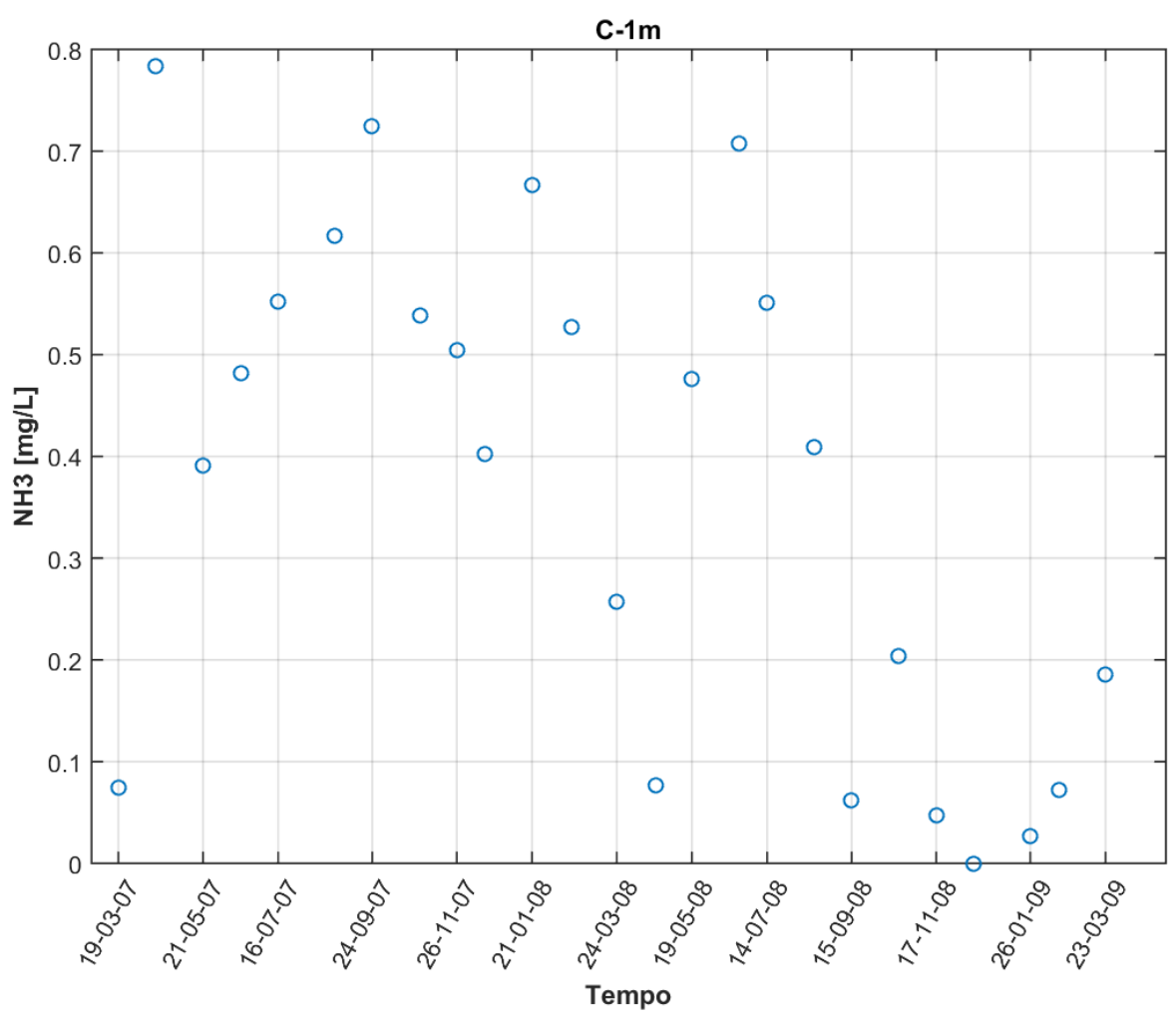

Figura B-19: Série temporal de concentração de amônia registrado pela CAESB no ponto $\mathrm{C}$ a $1 \mathrm{~m}$ entre $03 / 2007$ e 03/2009.

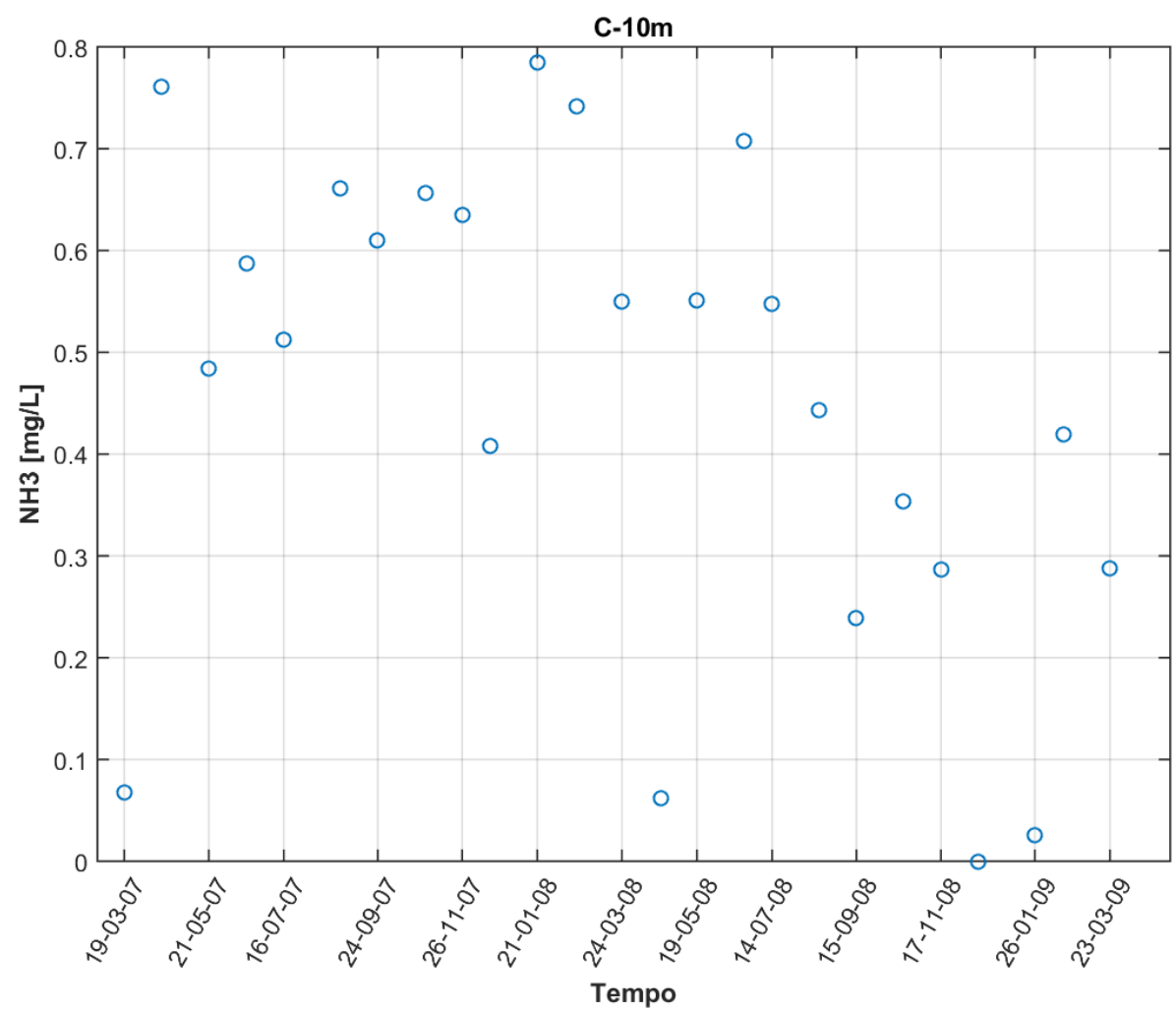

Figura B-20: Série temporal de concentração de amônia registrado pela CAESB no ponto C a $10 \mathrm{~m}$ entre 03/2007 e 03/2009. 


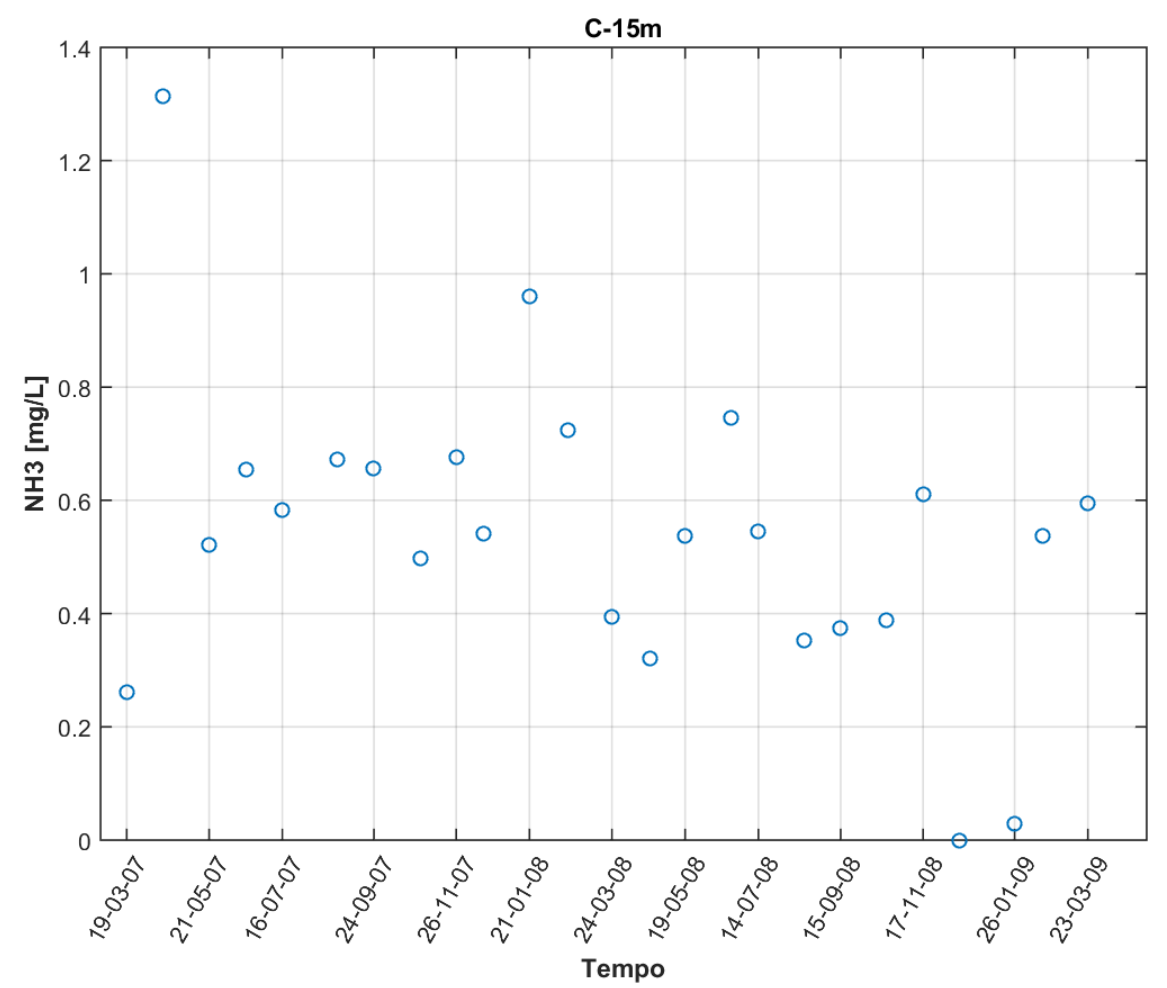

Figura B-21: Série temporal de concentração de amônia registrado pela CAESB no ponto $\mathrm{C}$ a $15 \mathrm{~m}$ entre $03 / 2007$ e $03 / 2009$.

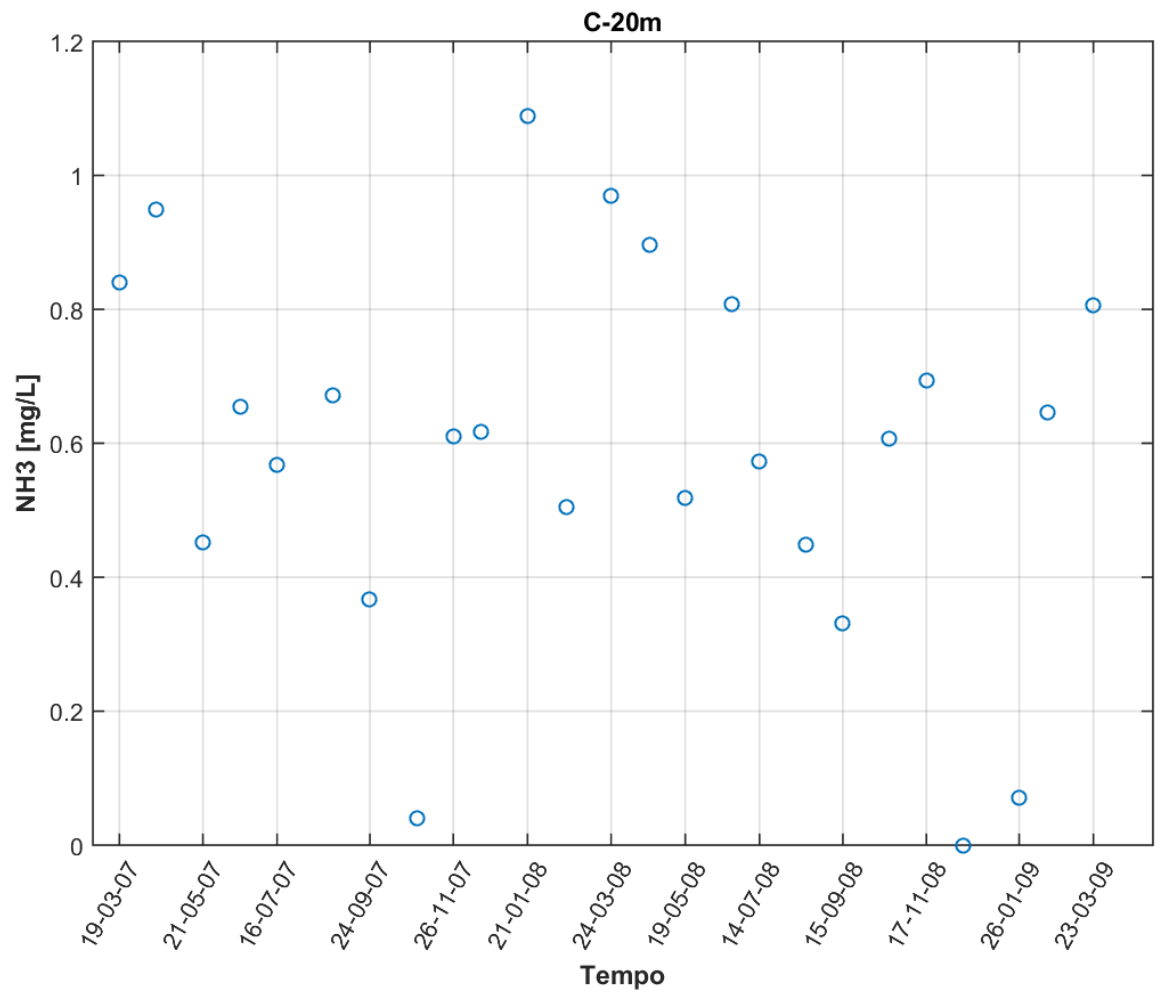

Figura B-22: Série temporal de concentração de amônia registrado pela CAESB no ponto $\mathrm{C}$ a $20 \mathrm{~m}$ entre $03 / 2007$ e $03 / 2009$. 


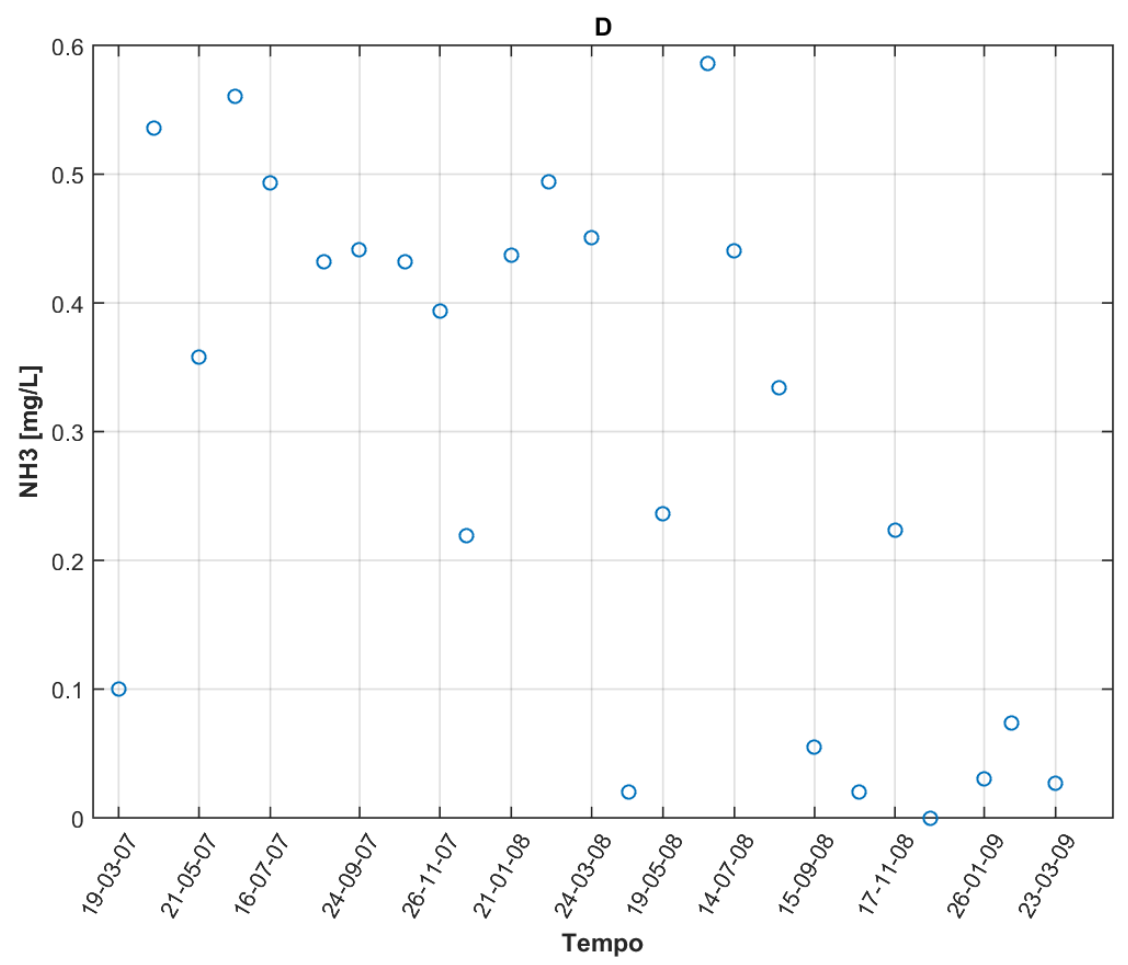

Figura B-23: Série temporal de concentração de amônia registrado pela CAESB no ponto D entre 03/2007 e 03/2009.

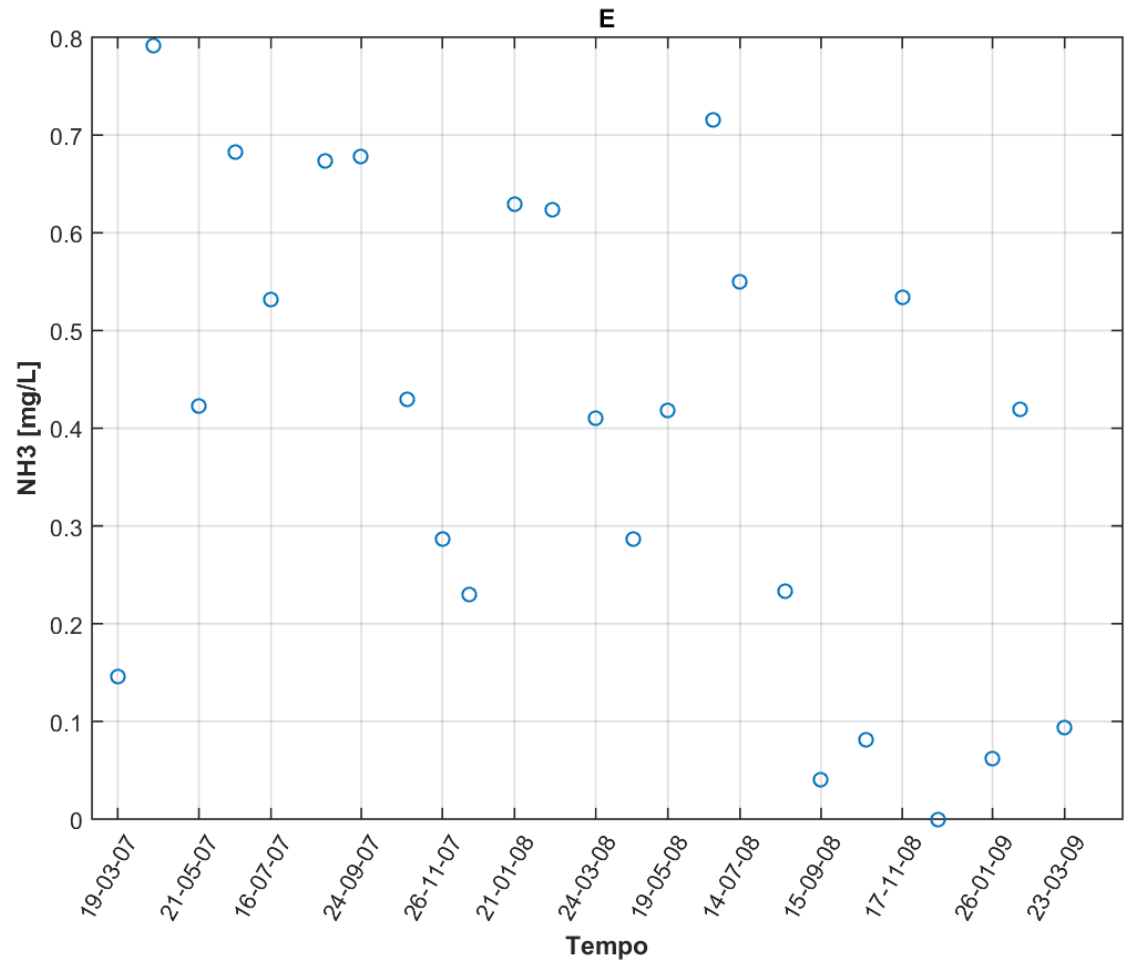

Figura B-24: Série temporal de concentração de amônia registrado pela CAESB no ponto E entre 03/2007 e 03/2009. 


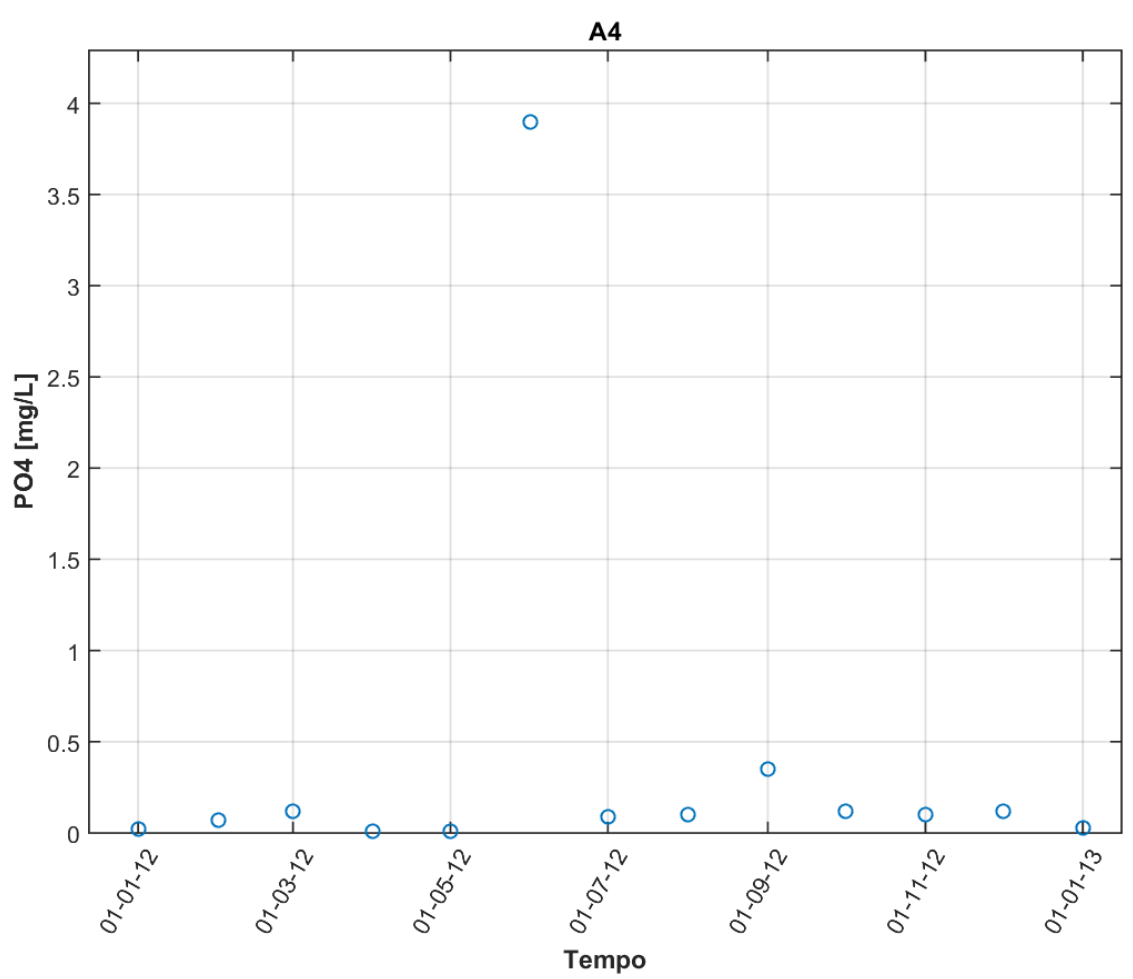

Figura B-25: Série temporal de concentração de fosfato registrado pela CAESB no ponto A4 entre 01/2012 e 01/2013.

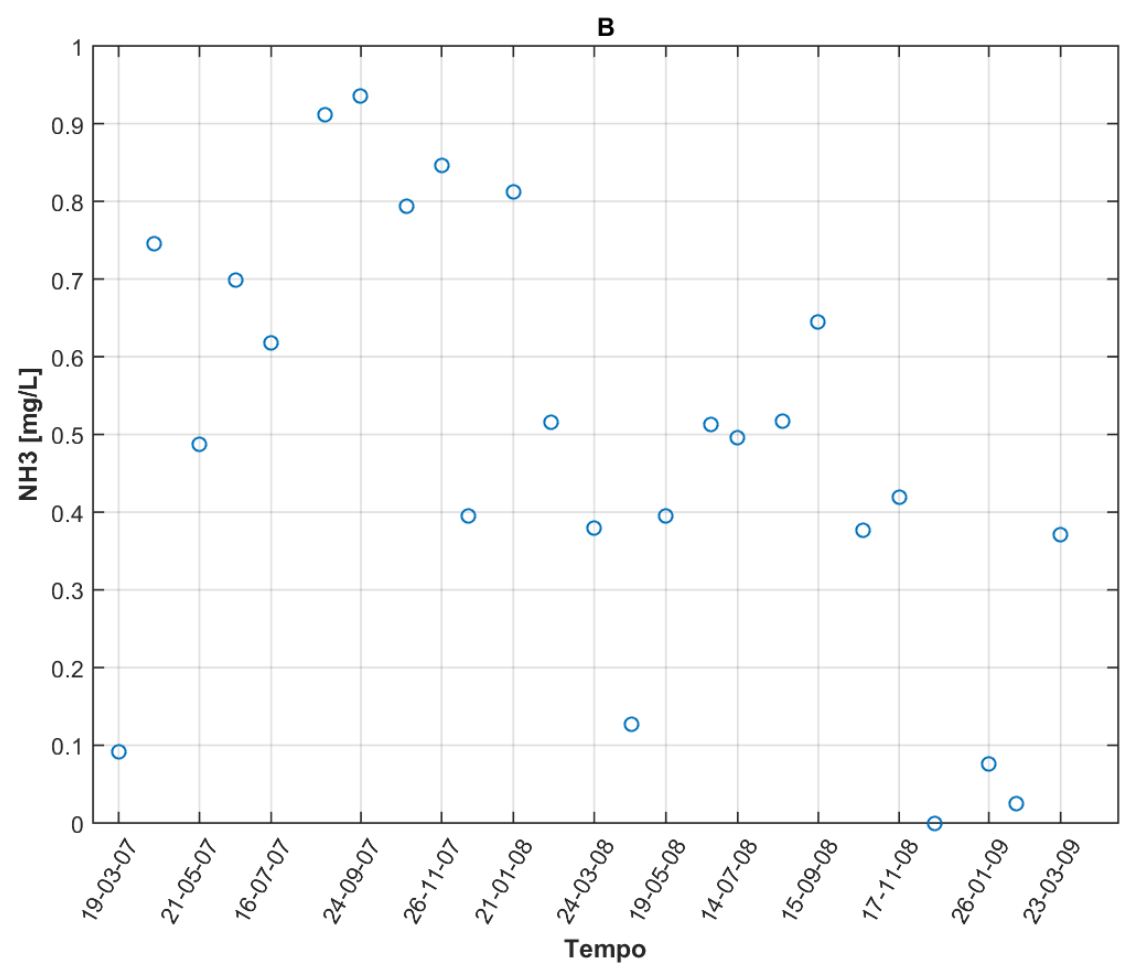

Figura B-26: Série temporal de concentração de fosfato registrado pela CAESB no ponto B entre 01/2012 e 01/2013. 


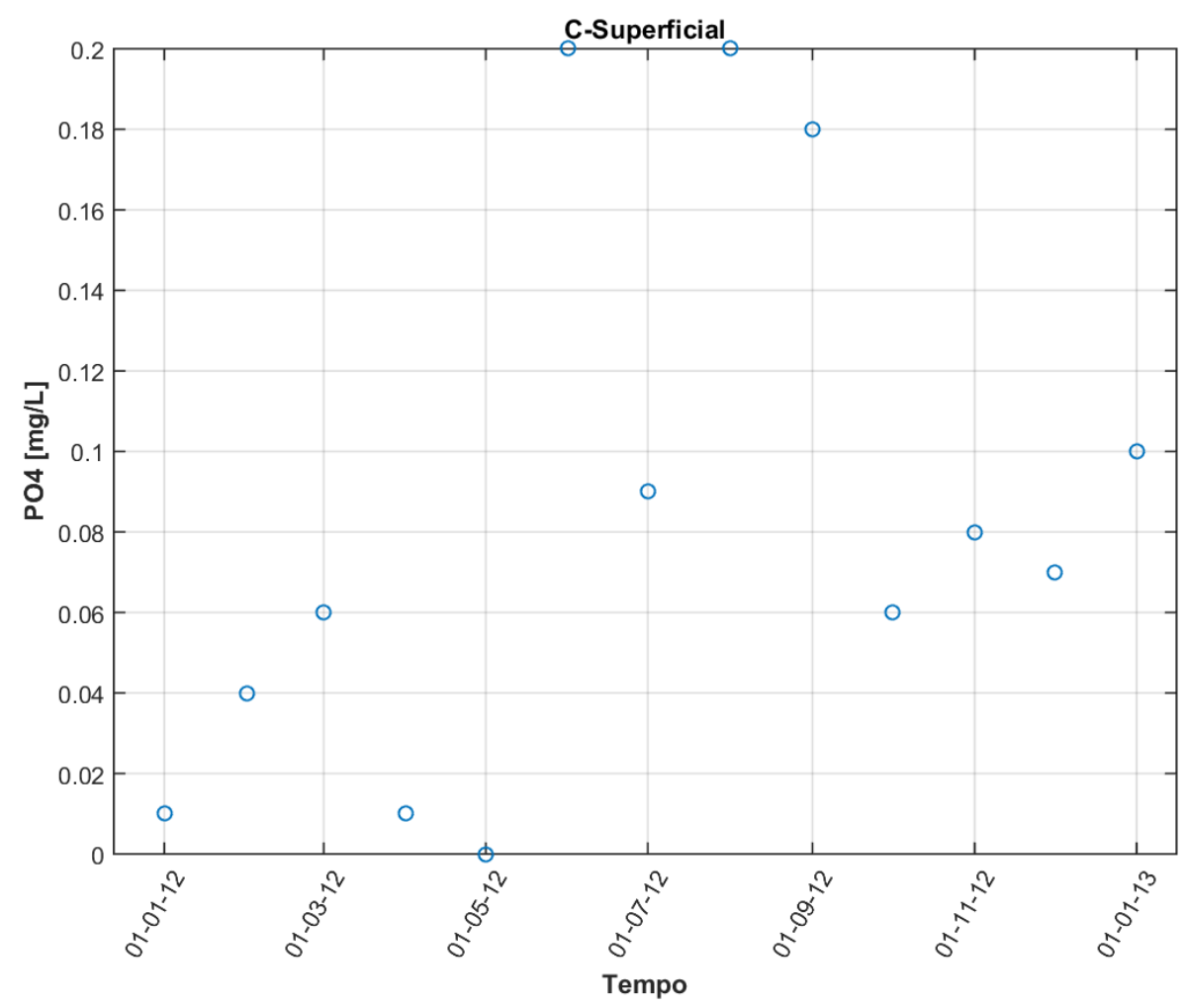

Figura B-27: Série temporal de concentração de fosfato registrado pela CAESB no ponto C a superfície entre 01/2012 e 01/2013.

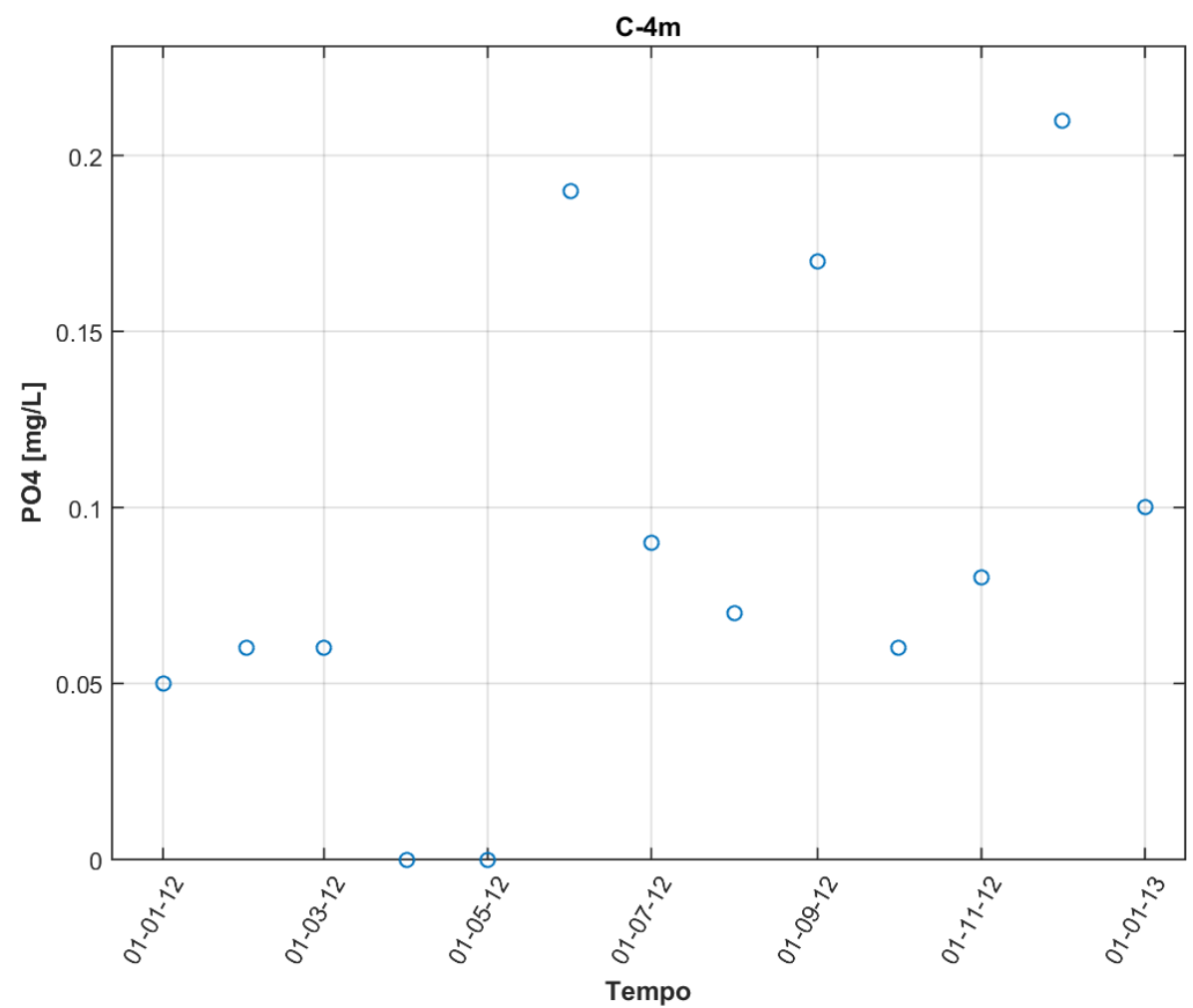

Figura B-28: Série temporal de concentração de fosfato registrado pela CAESB no ponto $\mathrm{C}$ a $4 \mathrm{~m}$ entre 01/2012 e 01/2013. 


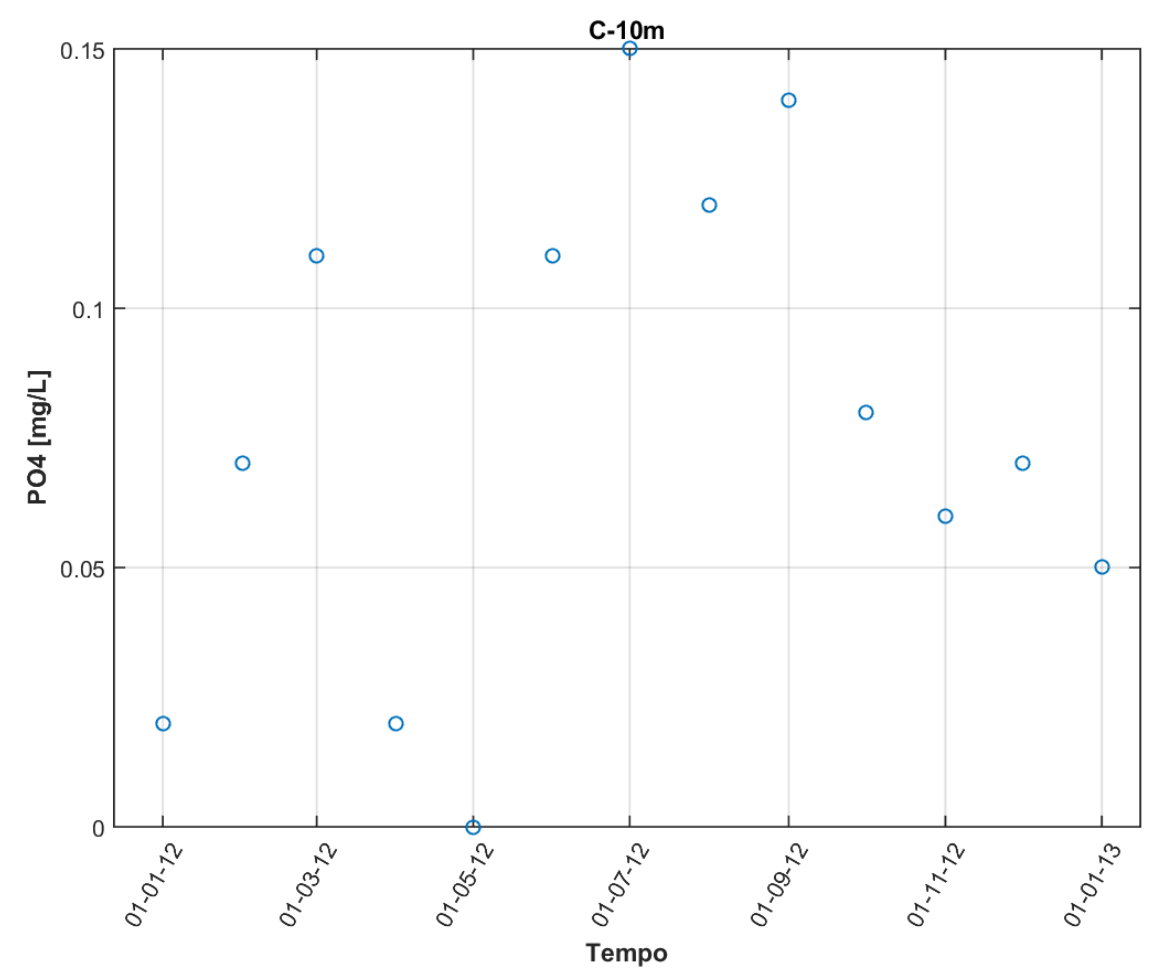

Figura B-29: Série temporal de concentração de fosfato registrado pela CAESB no ponto C a $10 \mathrm{~m}$ entre 01/2012 e 01/2013.

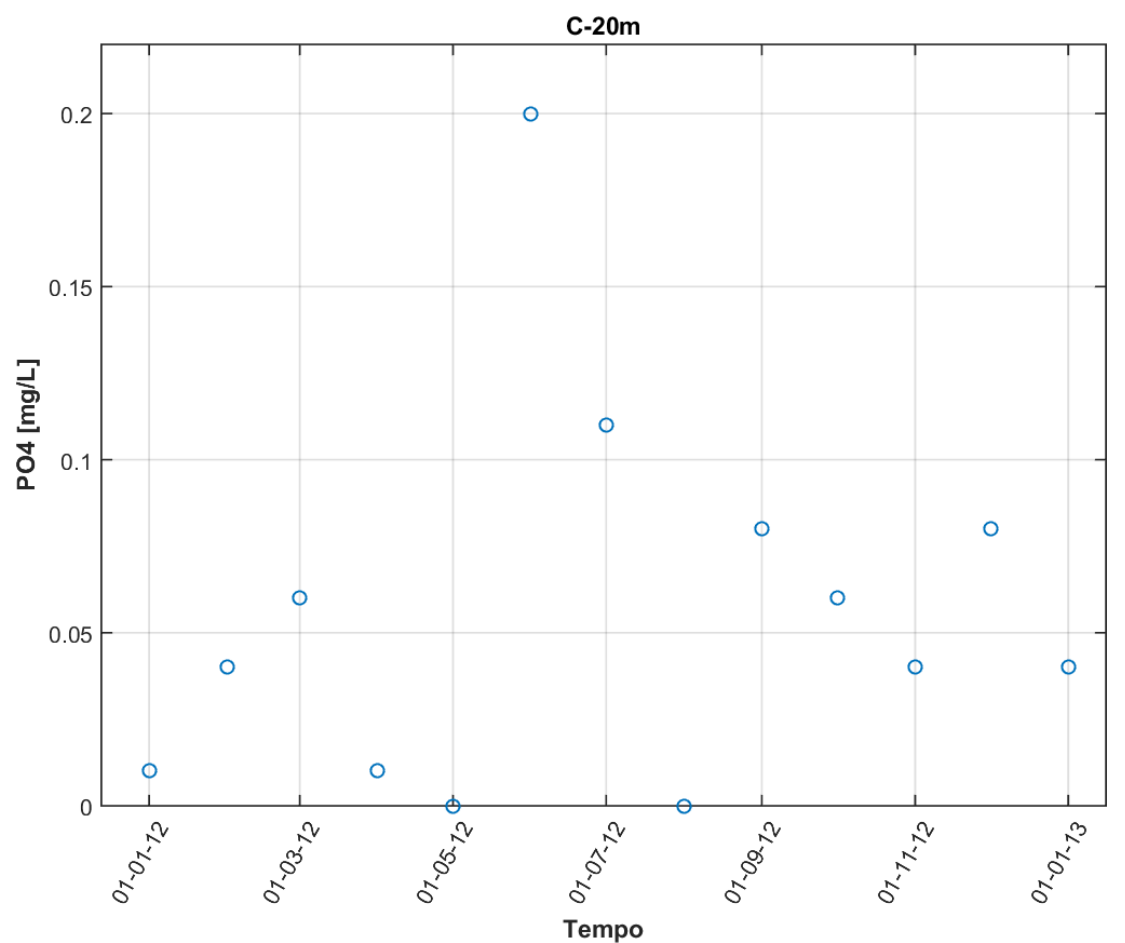

Figura B-30: Série temporal de concentração de fosfato registrado pela CAESB no ponto C a 20m entre 01/2012 e 01/2013. 


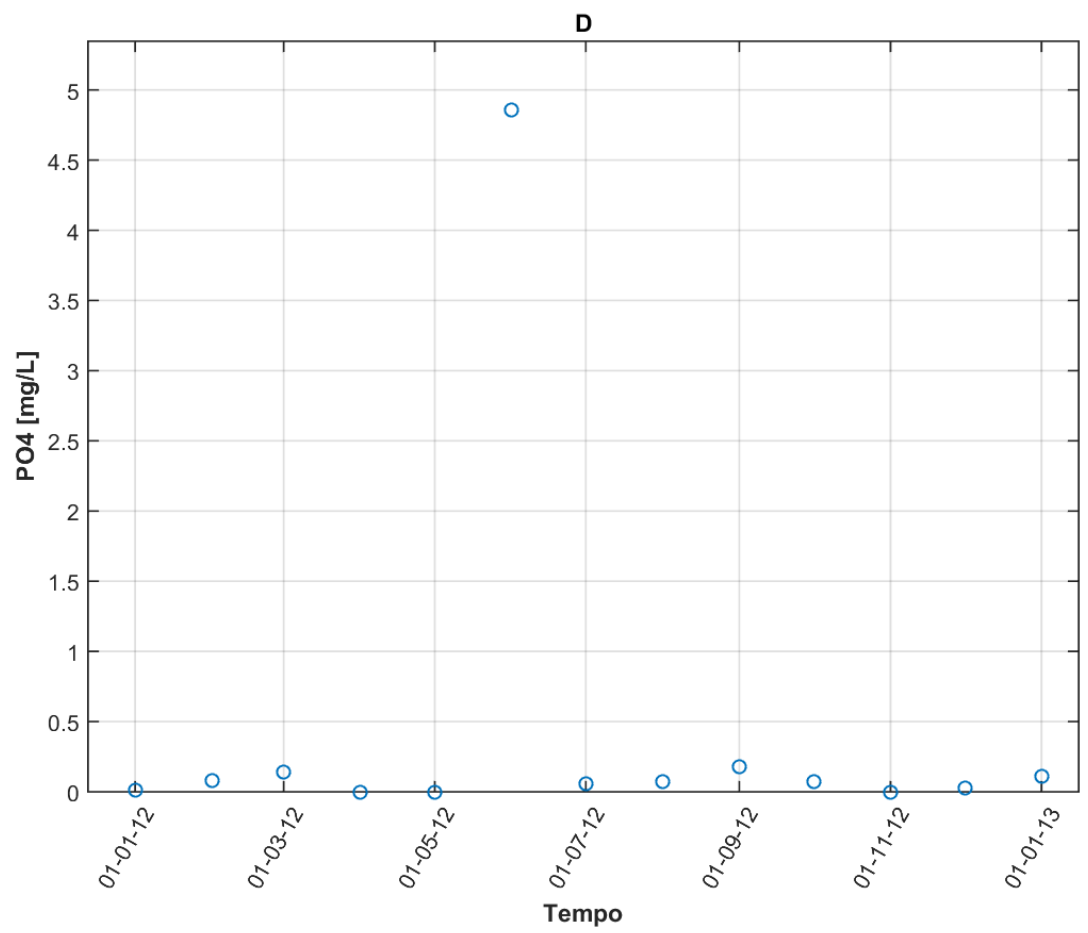

Figura B-31: Série temporal de concentração de fosfato registrado pela CAESB no ponto D entre 01/2012 e 01/2013.

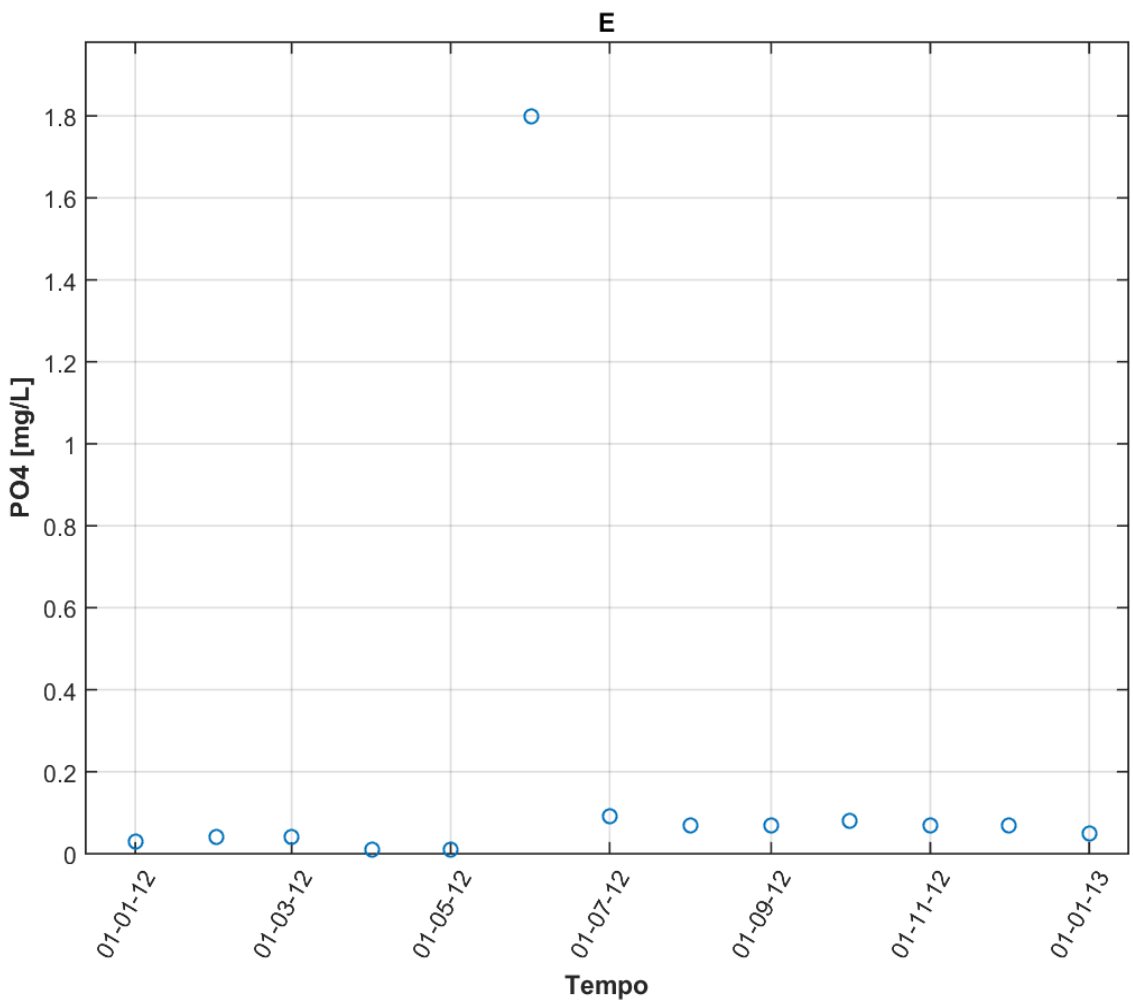

Figura B-32: Série temporal de concentração de fosfato registrado pela CAESB no ponto E entre 01/2012 e 01/2013. 


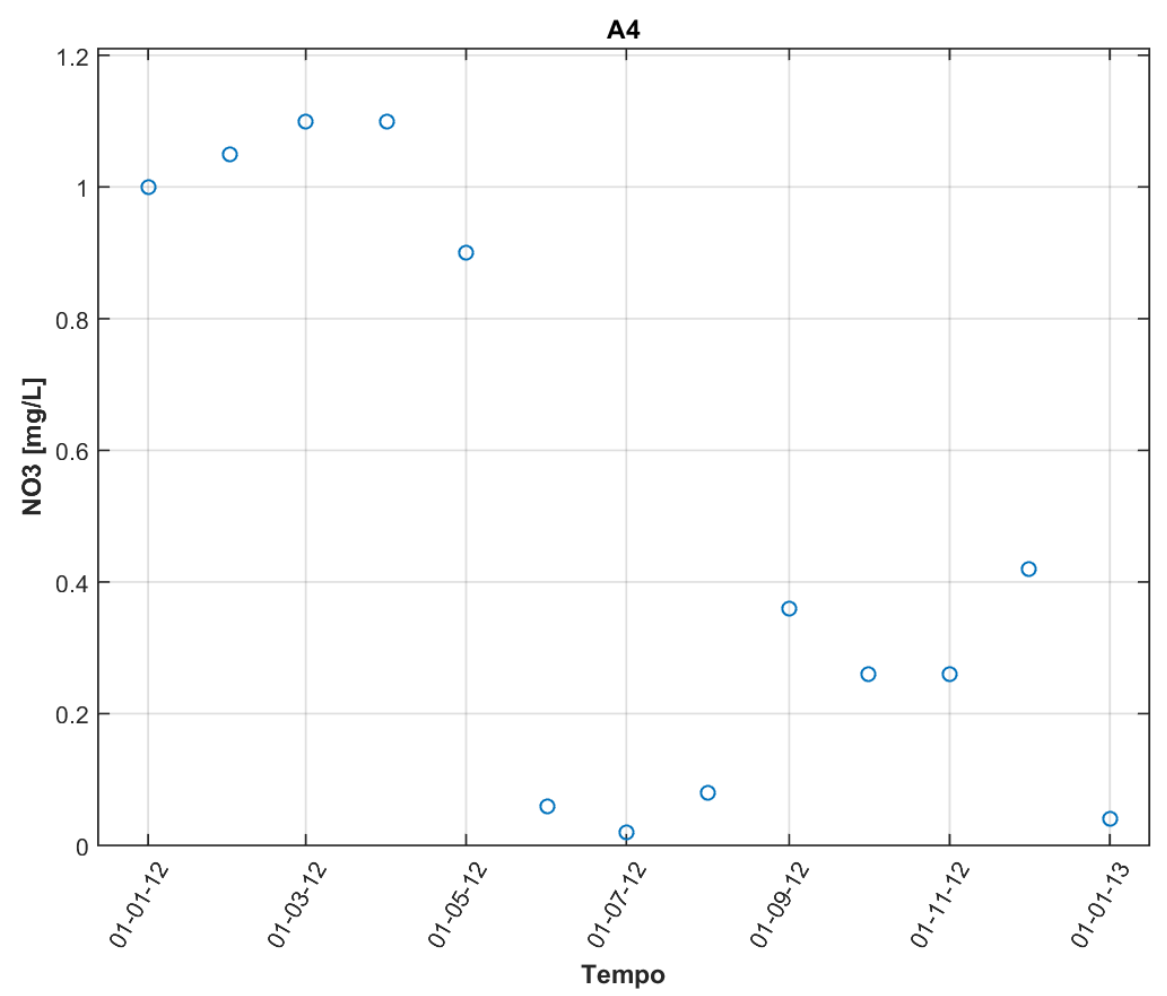

Figura B-33: Série temporal de concentração de nitrato registrado pela CAESB no ponto A4 entre 01/2012 e 01/2013.

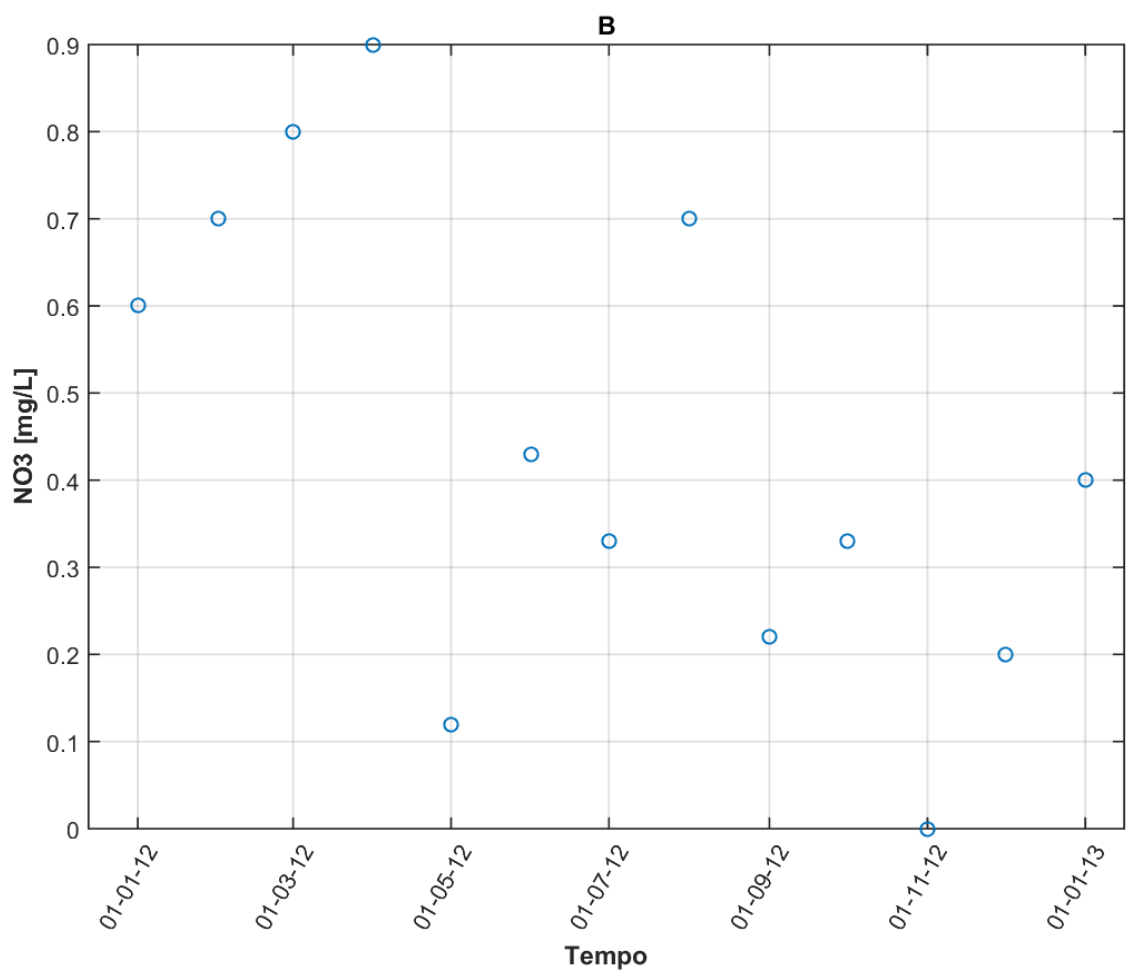

Figura B-34: Série temporal de concentração de nitrato registrado pela CAESB no ponto B entre 01/2012 e 01/2013. 


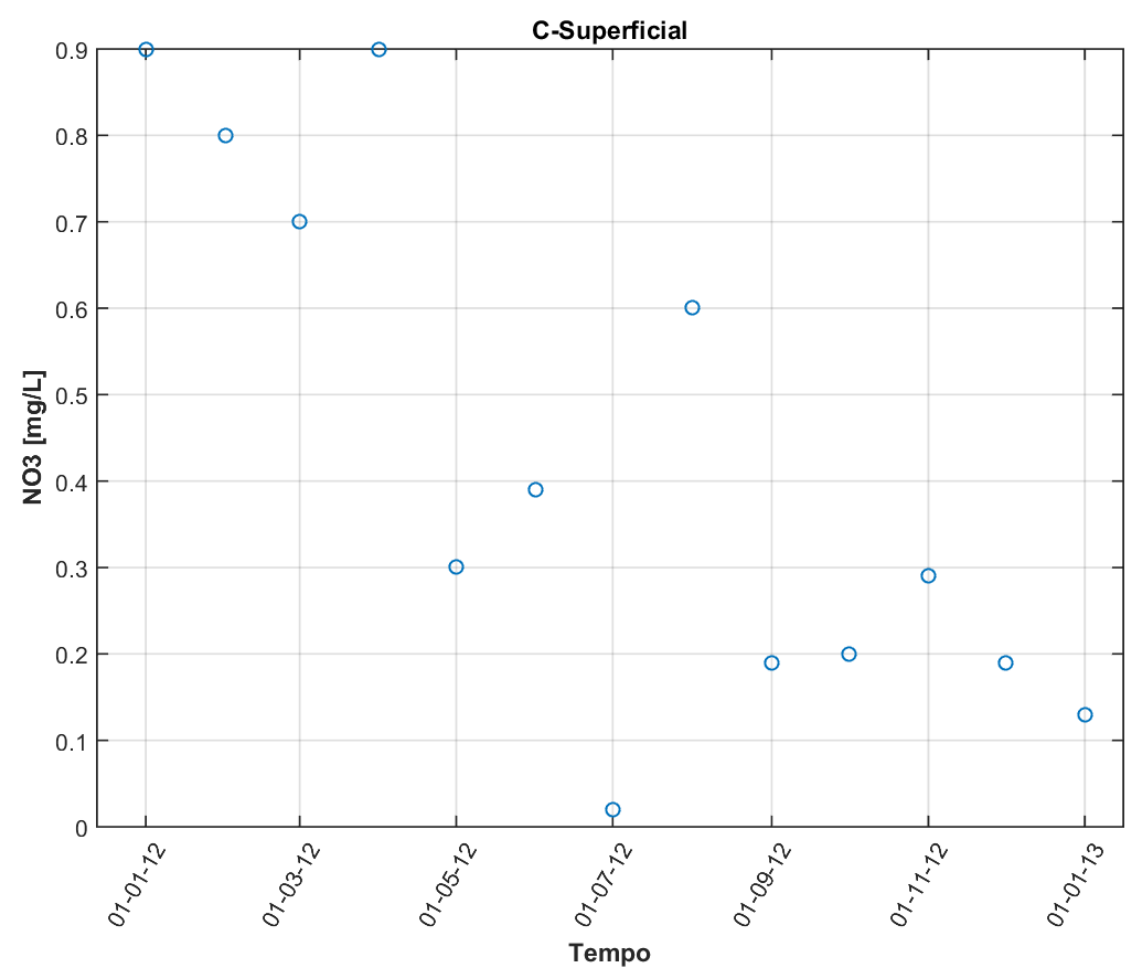

Figura B-35: Série temporal de concentração de nitrato registrado pela CAESB no ponto C a superfície entre 01/2012 e 01/2013.

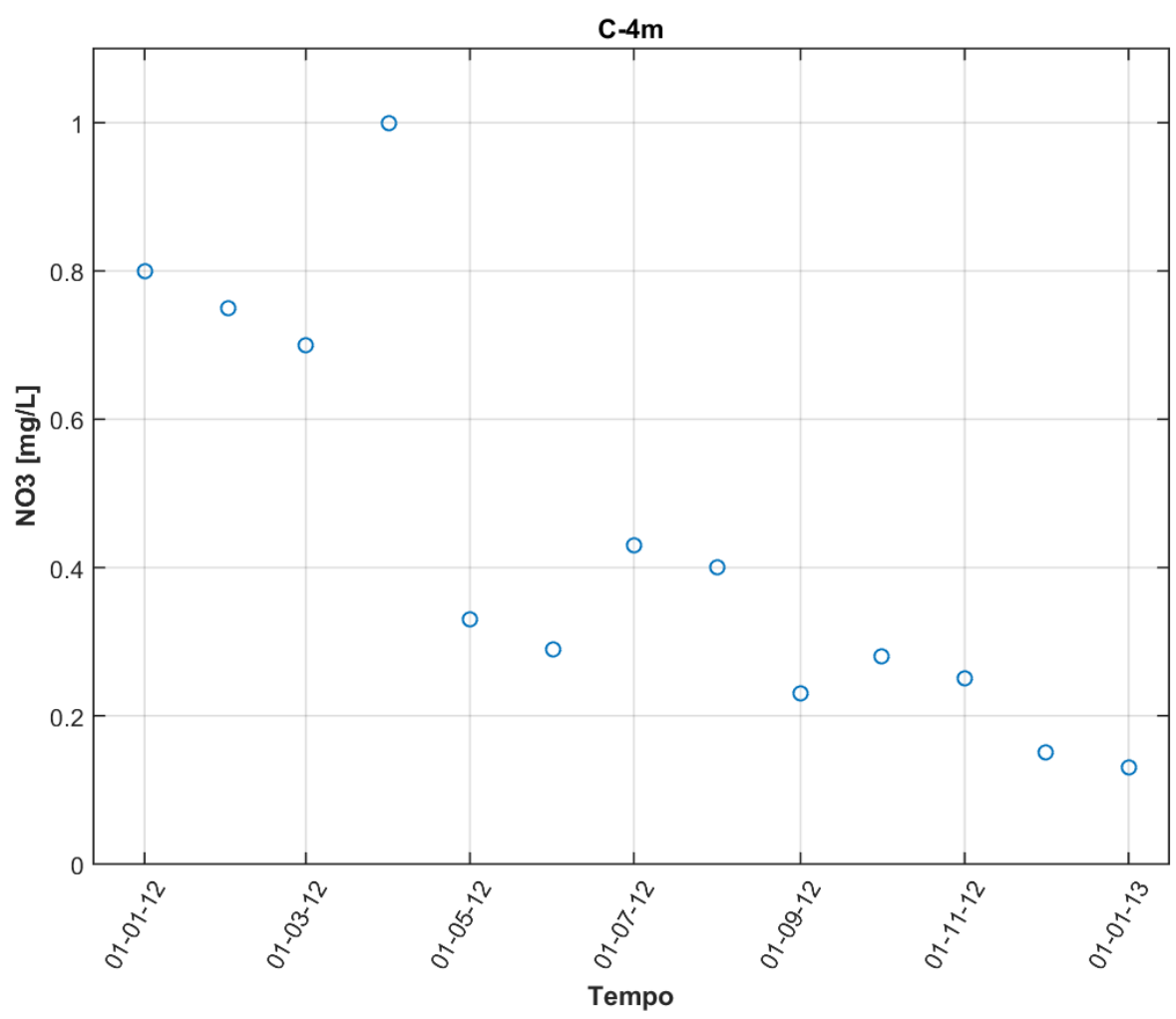

Figura B-36: Série temporal de concentração de nitrato registrado pela CAESB no ponto $\mathrm{C}$ a $4 \mathrm{~m}$ entre 01/2012 e 01/2013. 


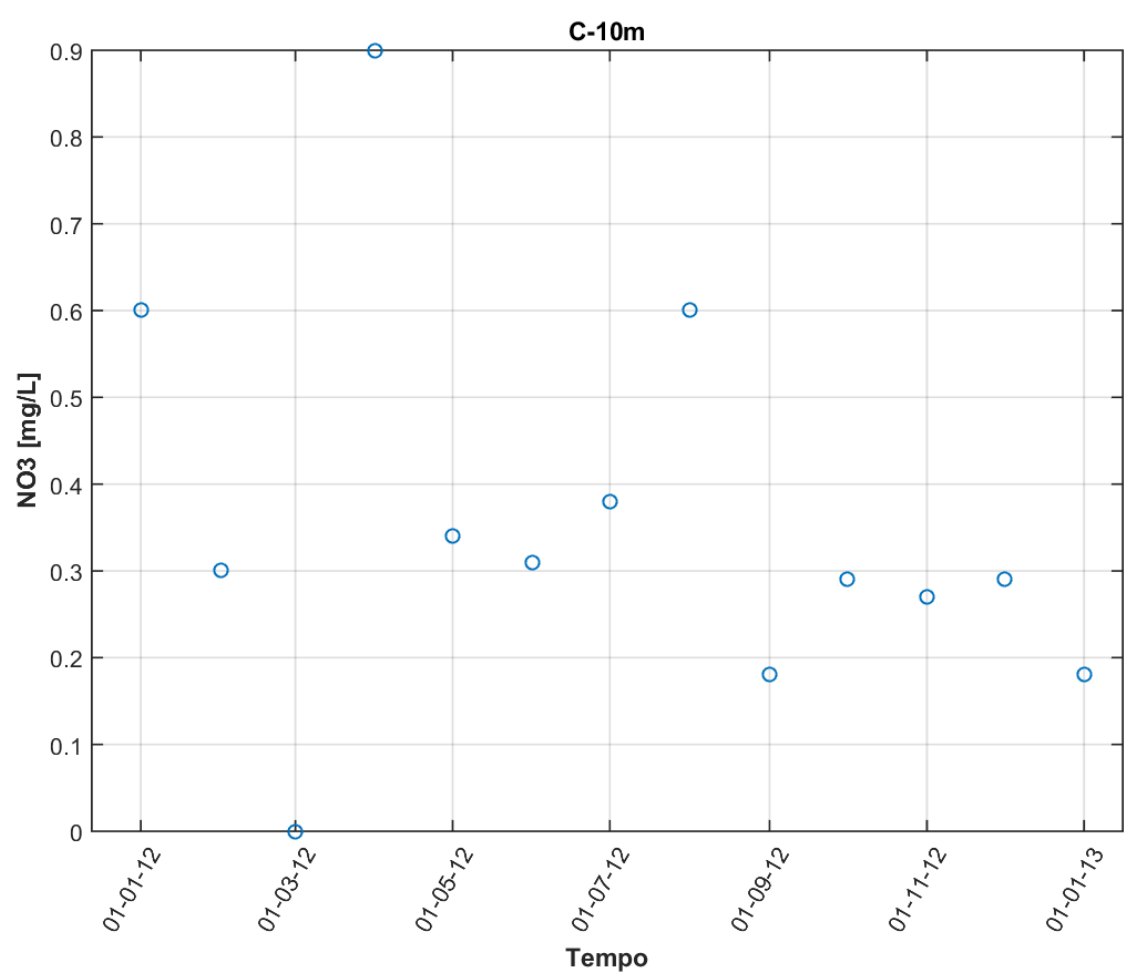

Figura B-37: Série temporal de concentração de nitrato registrado pela CAESB no ponto C a $10 \mathrm{~m}$ entre $01 / 2012$ e $01 / 2013$.

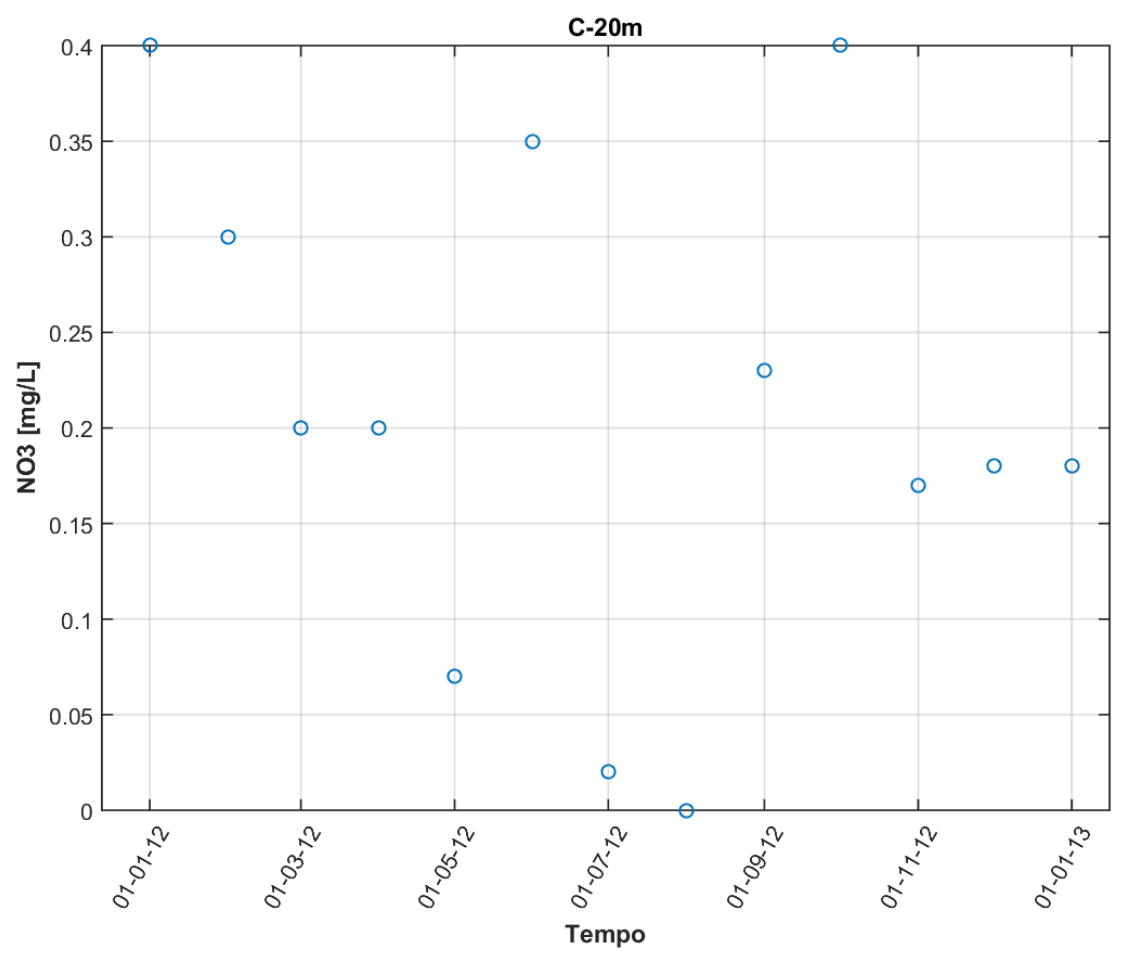

Figura B-38: Série temporal de concentração de nitrato registrado pela CAESB no ponto $\mathrm{C}$ a $20 \mathrm{~m}$ entre $01 / 2012$ e 01/2013. 


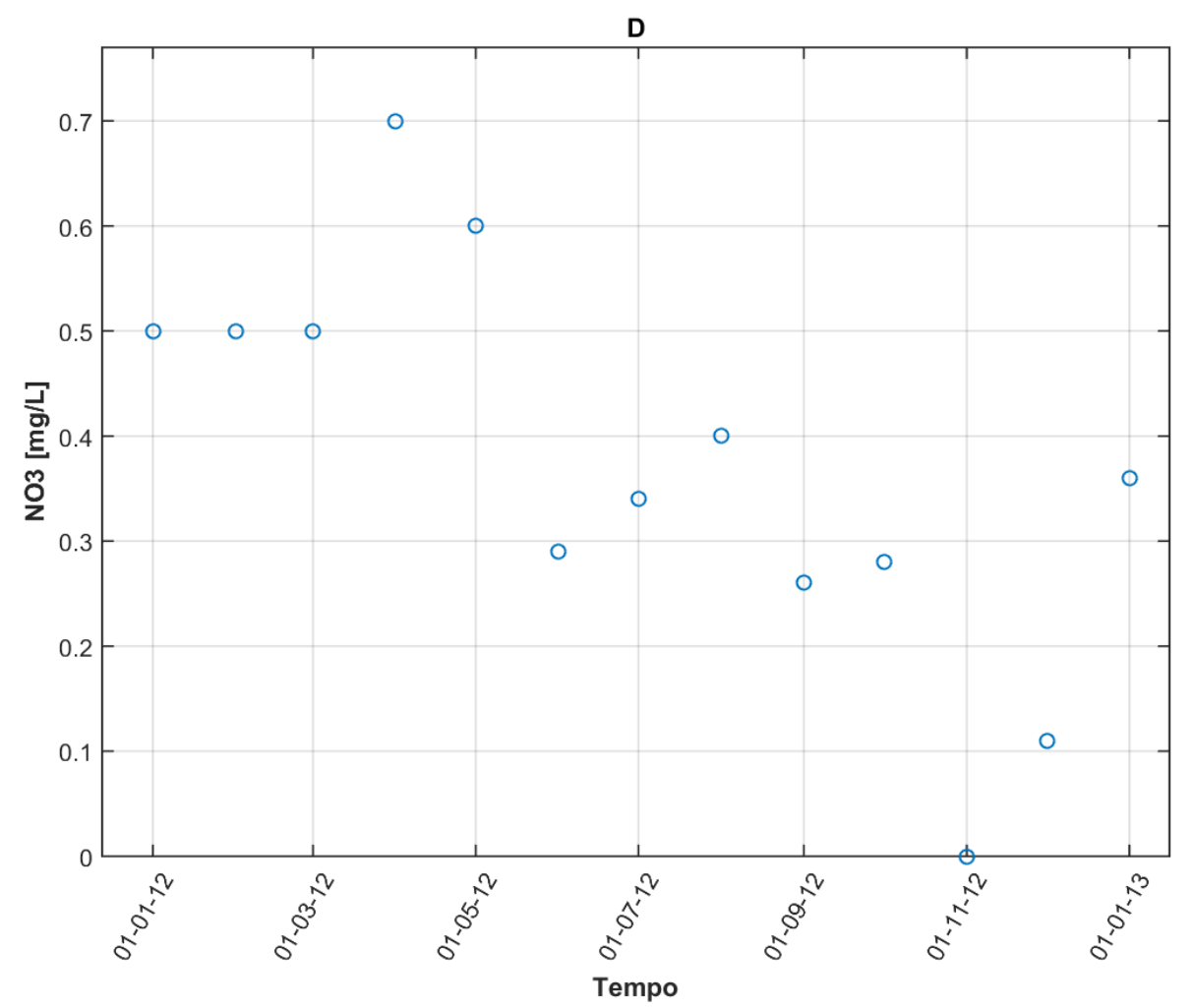

Figura B-39: Série temporal de concentração de nitrato registrado pela CAESB no ponto D entre 01/2012 e 01/2013.

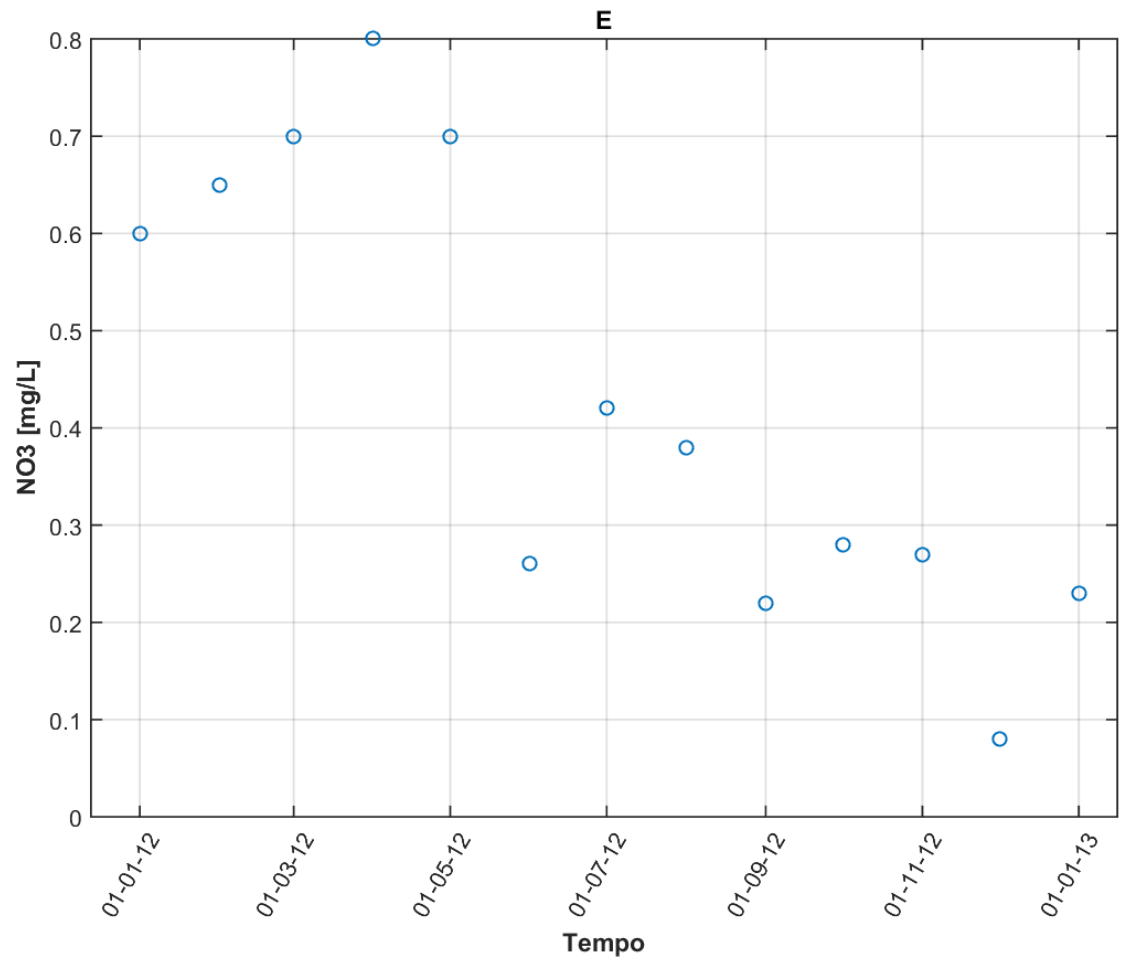

Figura B-40: Série temporal de concentração de nitrato registrado pela CAESB no ponto E entre 01/2012 e 01/2013. 


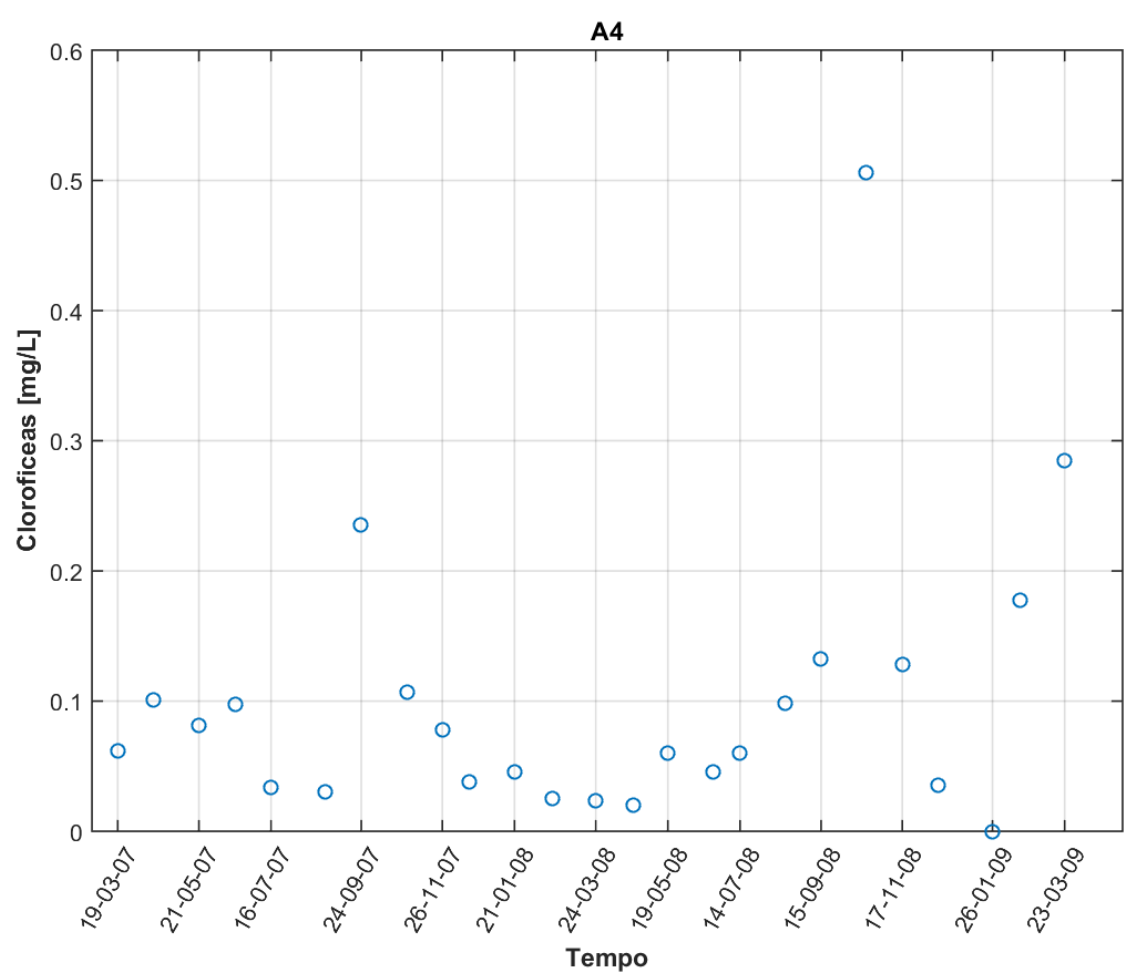

Figura B-41: Série temporal de biomassa de clorofíceas registrado pela CAESB no ponto A4 entre 03/2007 e 03/2009.

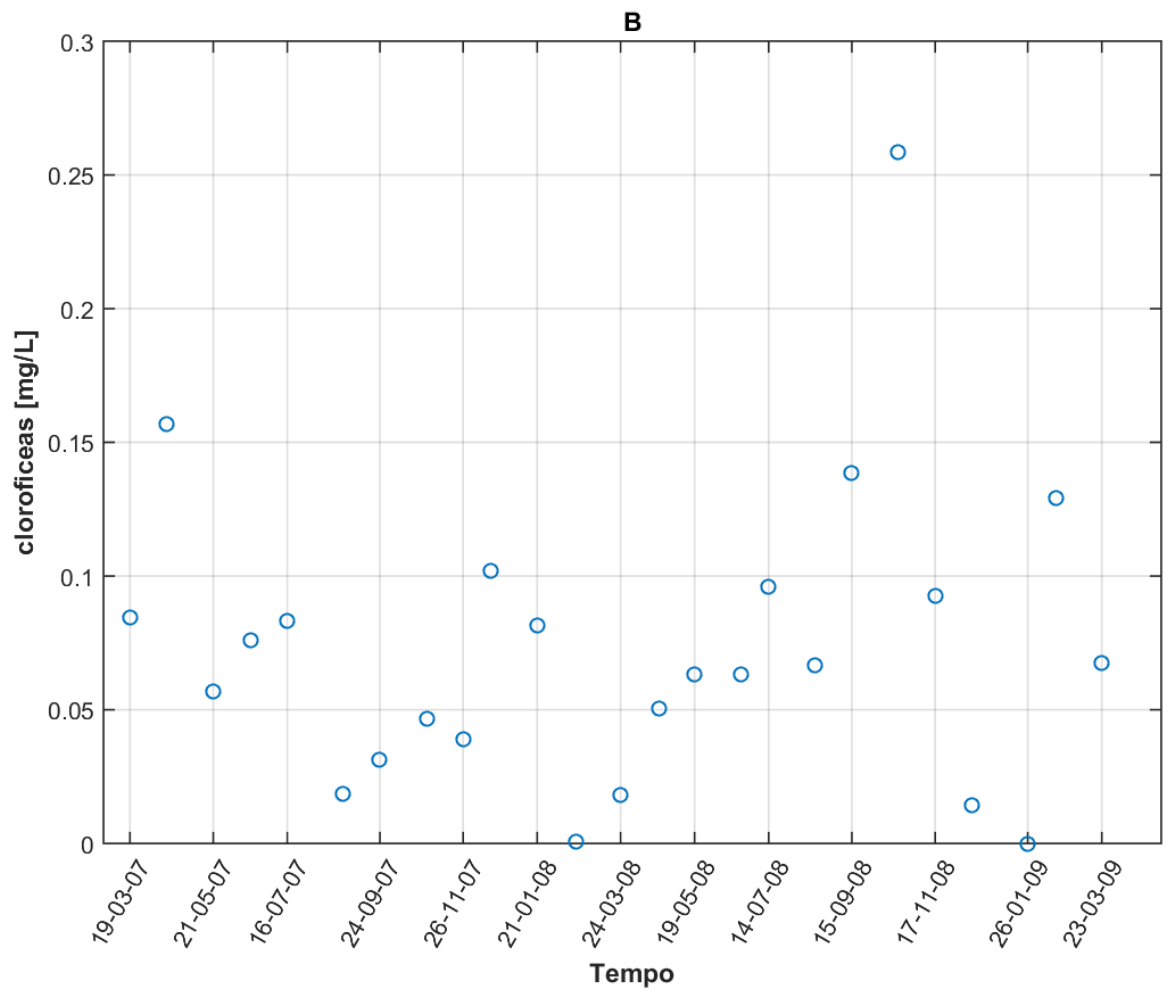

Figura B-42: Série temporal de biomassa de clorofíceas registrado pela CAESB no ponto B entre 03/2007 e 03/2009. 


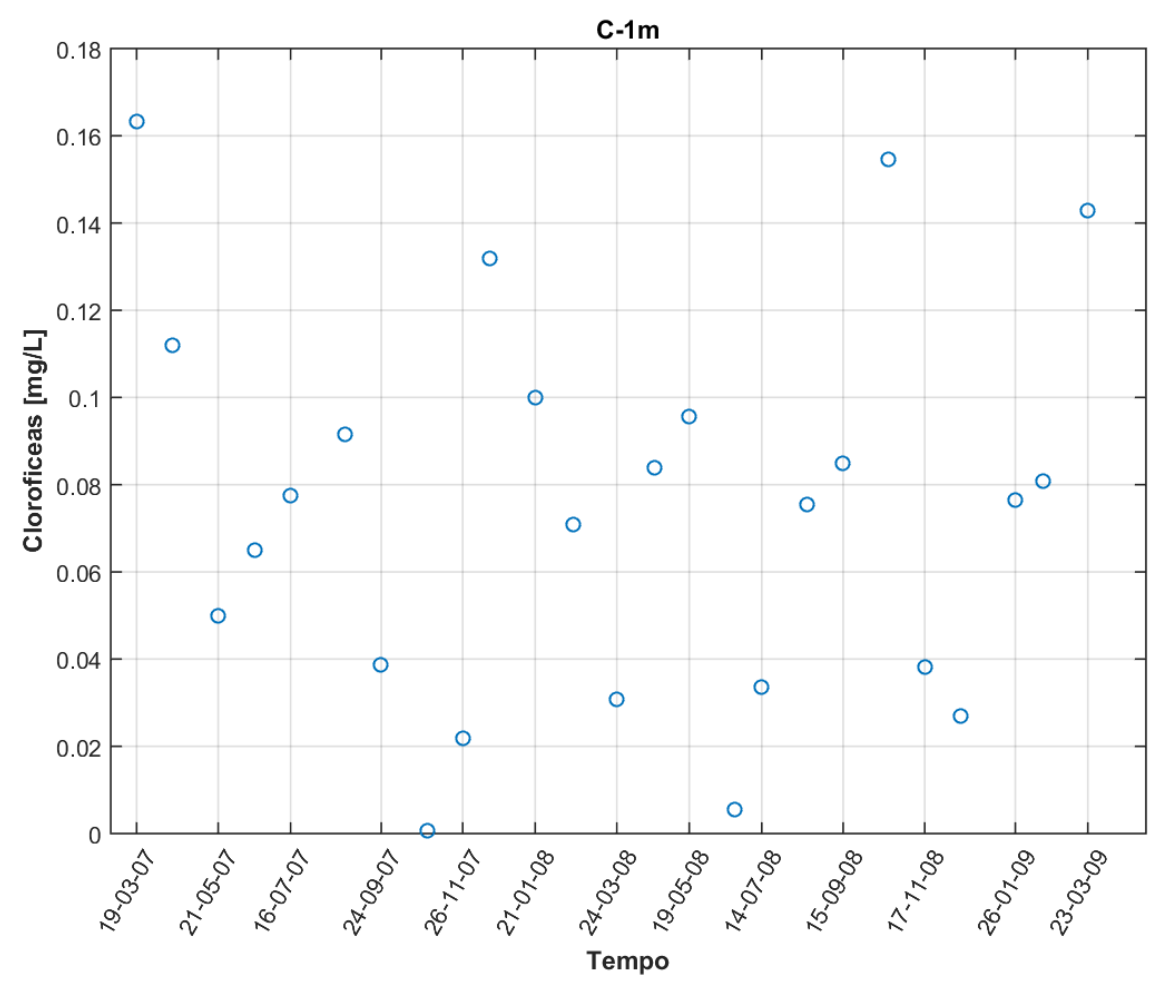

Figura B-43: Série temporal de biomassa de clorofíceas registrado pela CAESB no ponto C a $1 \mathrm{~m}$ entre 03/2007 e 03/2009.

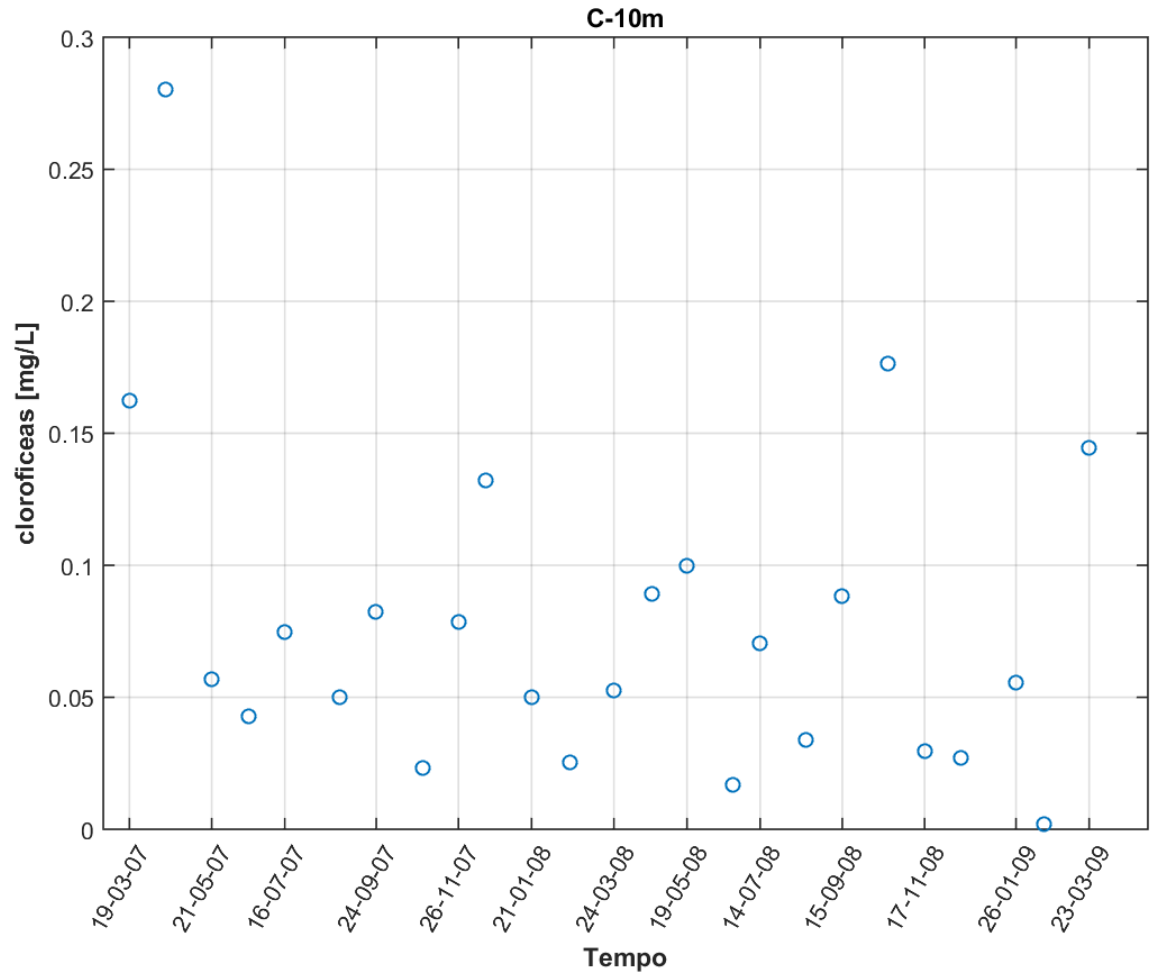

Figura B-44: Série temporal de biomassa de clorofíceas registrado pela CAESB no ponto C a $10 \mathrm{~m}$ entre 03/2007 e 03/2009. 


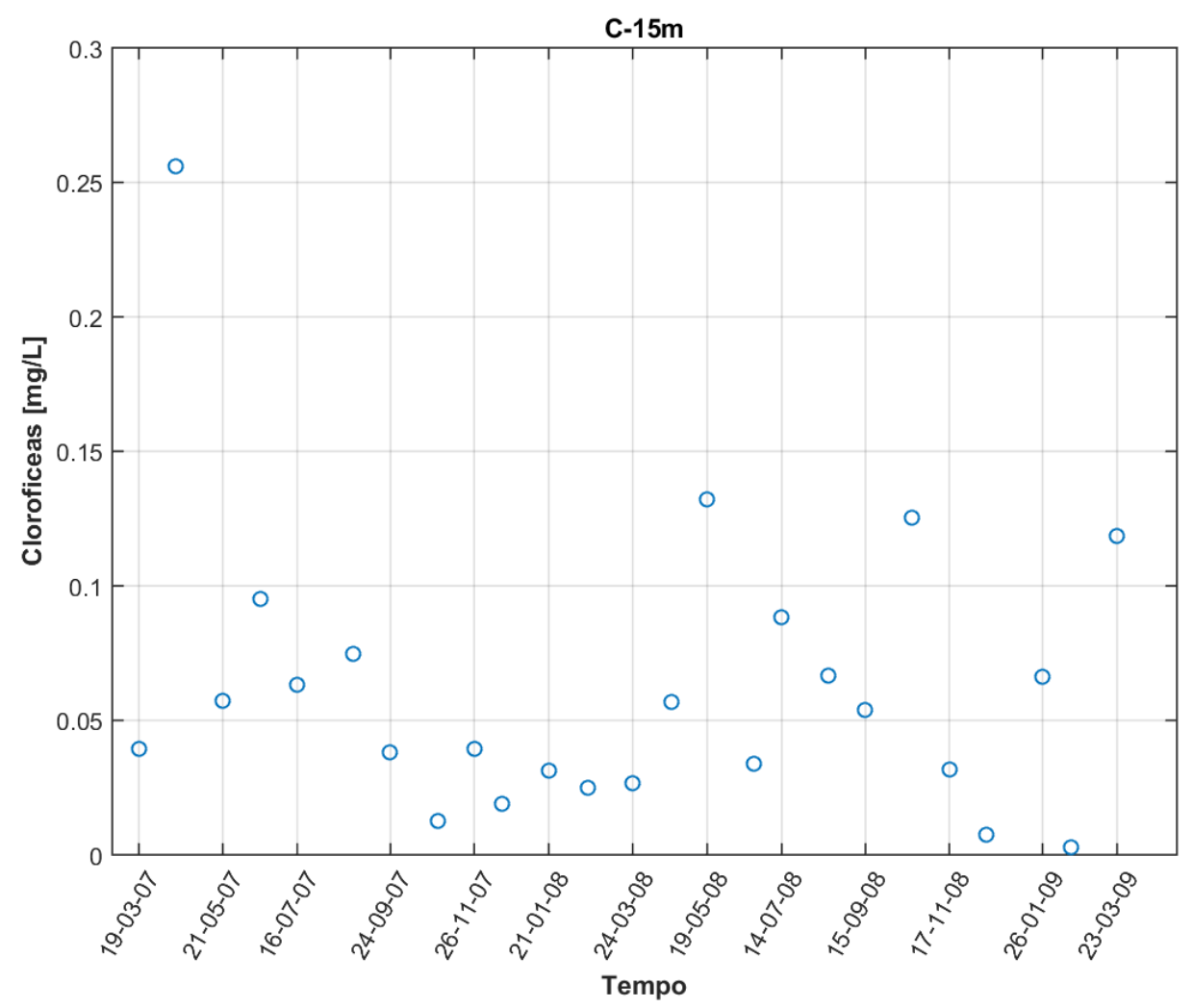

Figura B-45: Série temporal de biomassa de clorofíceas registrado pela CAESB no ponto $\mathrm{C}$ a $15 \mathrm{~m}$ entre $03 / 2007$ e $03 / 2009$.

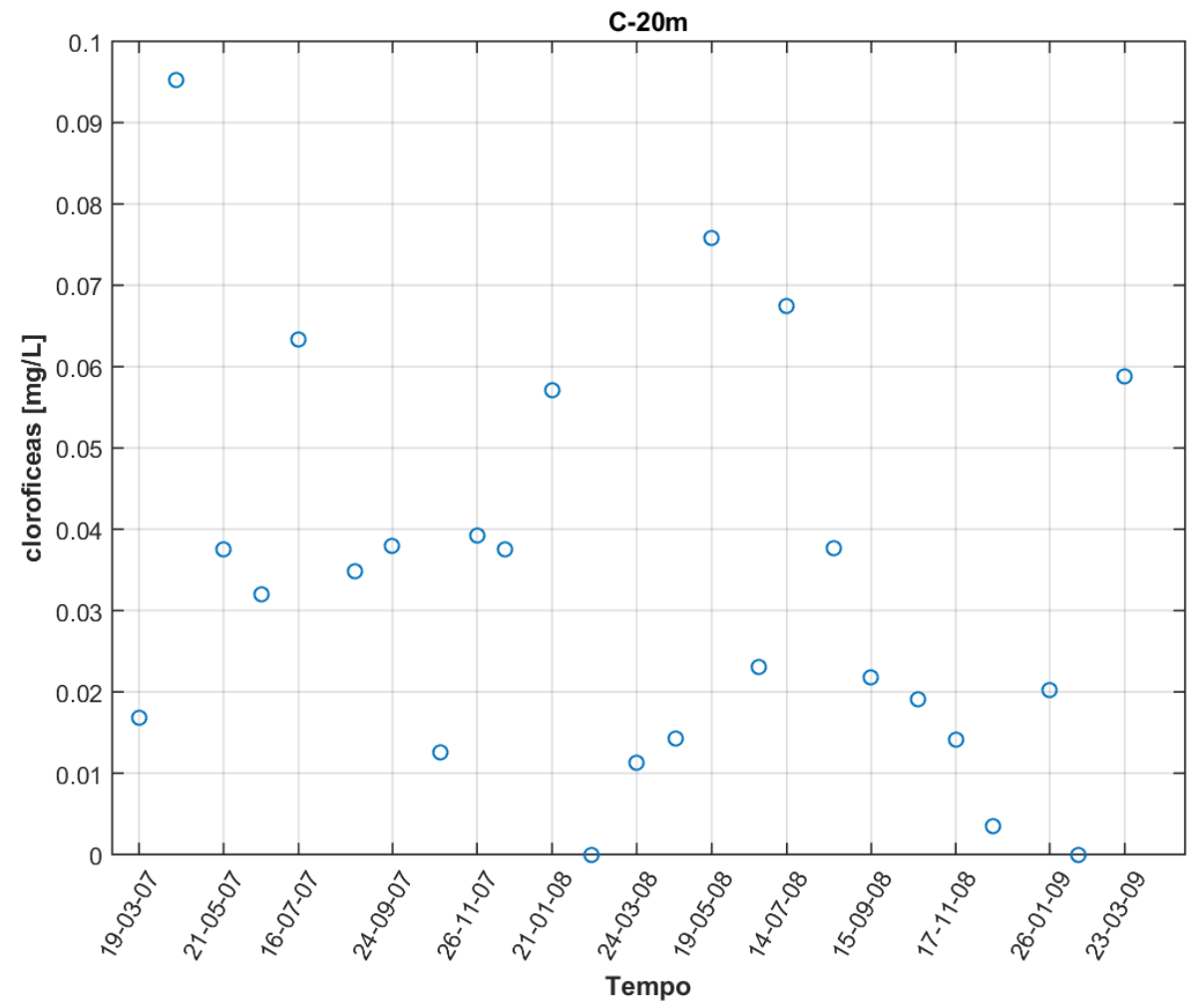

Figura B-46: Série temporal de biomassa de clorofíceas registrado pela CAESB no ponto C a $20 \mathrm{~m}$ entre 03/2007 e 03/2009. 


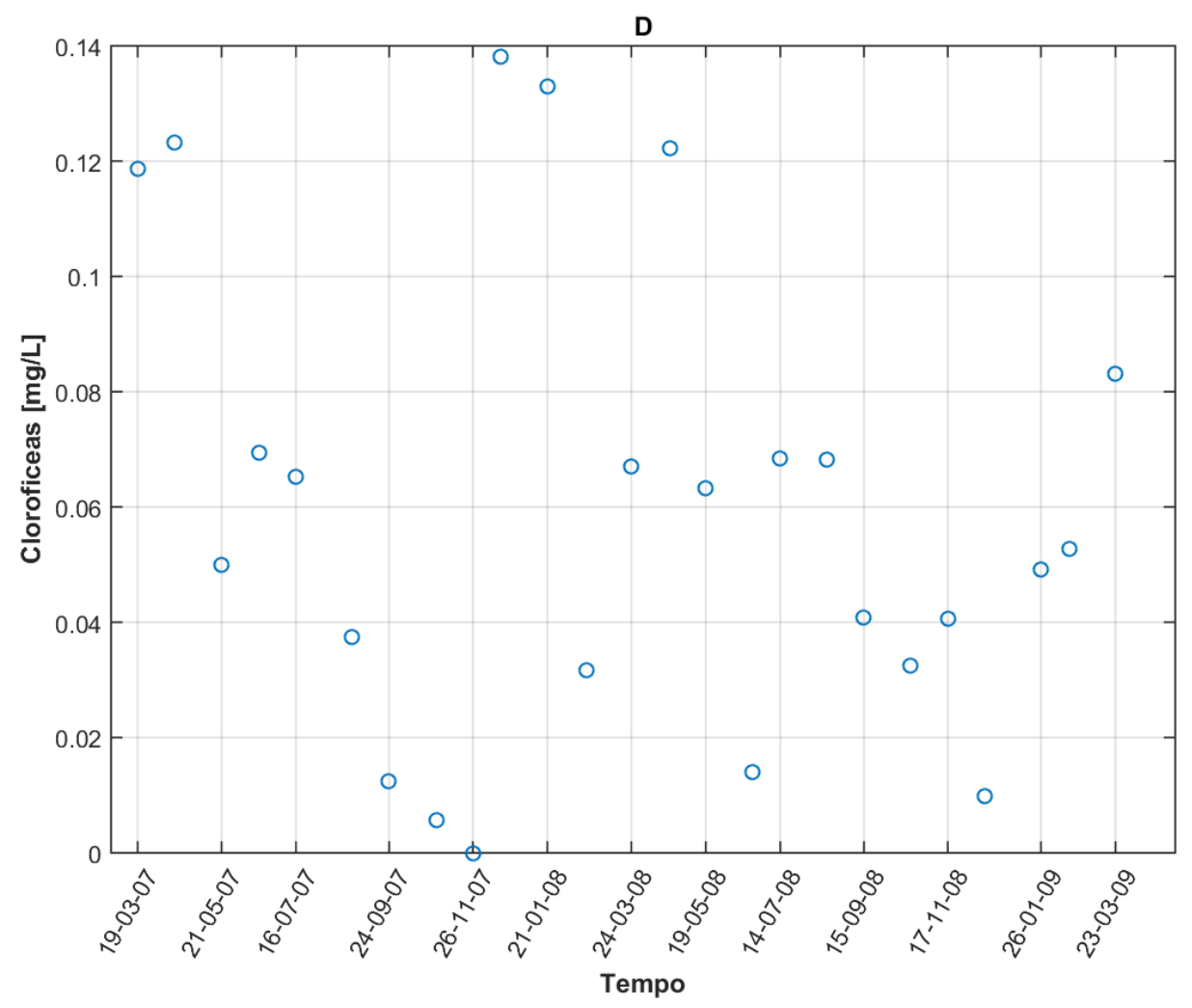

Figura B-47: Série temporal de biomassa de clorofíceas registrado pela CAESB no ponto D entre 03/2007 e 03/2009.

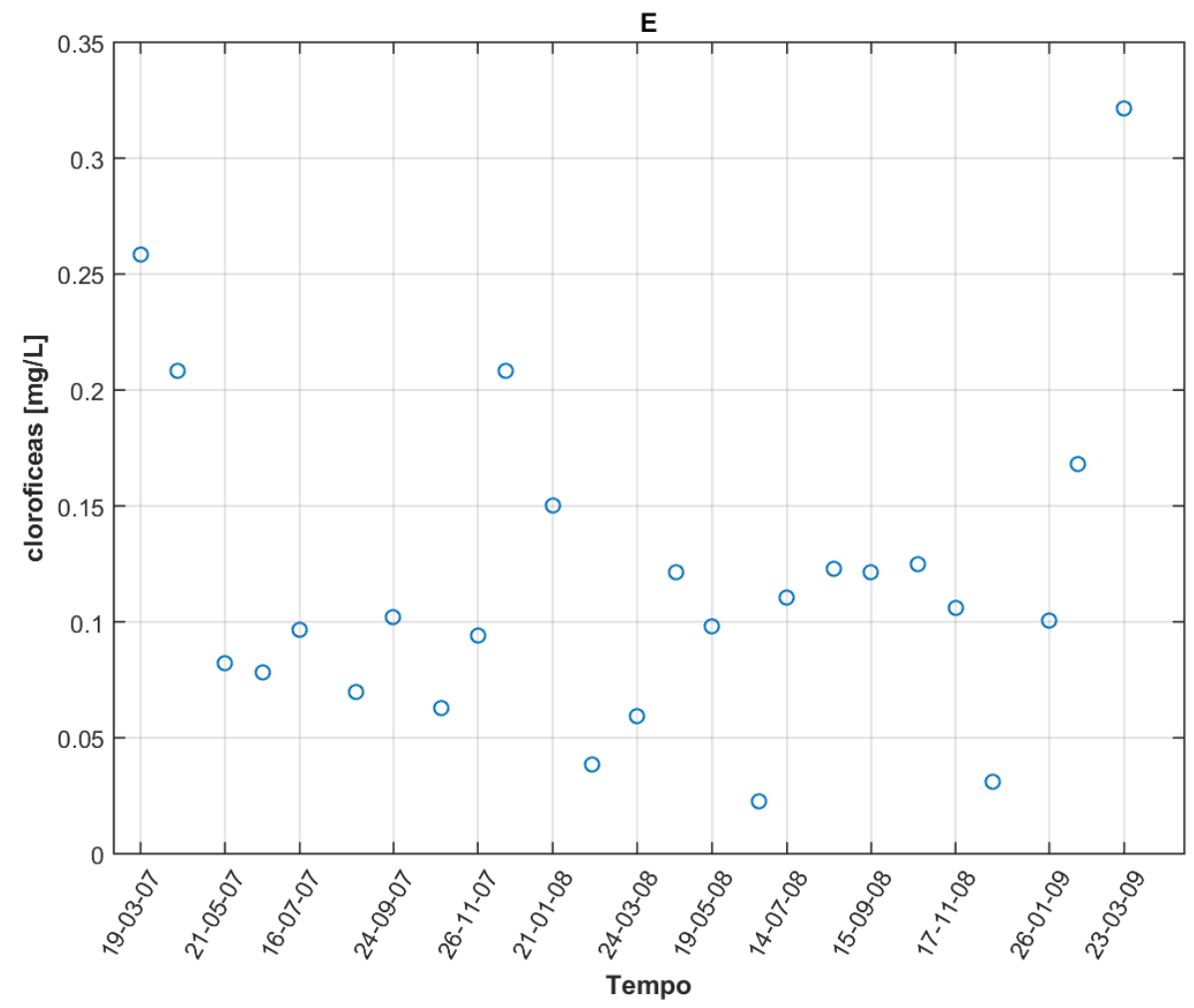

Figura B-48: Série temporal de biomassa de clorofíceas registrado pela CAESB no ponto E entre 03/2007 e 03/2009. 


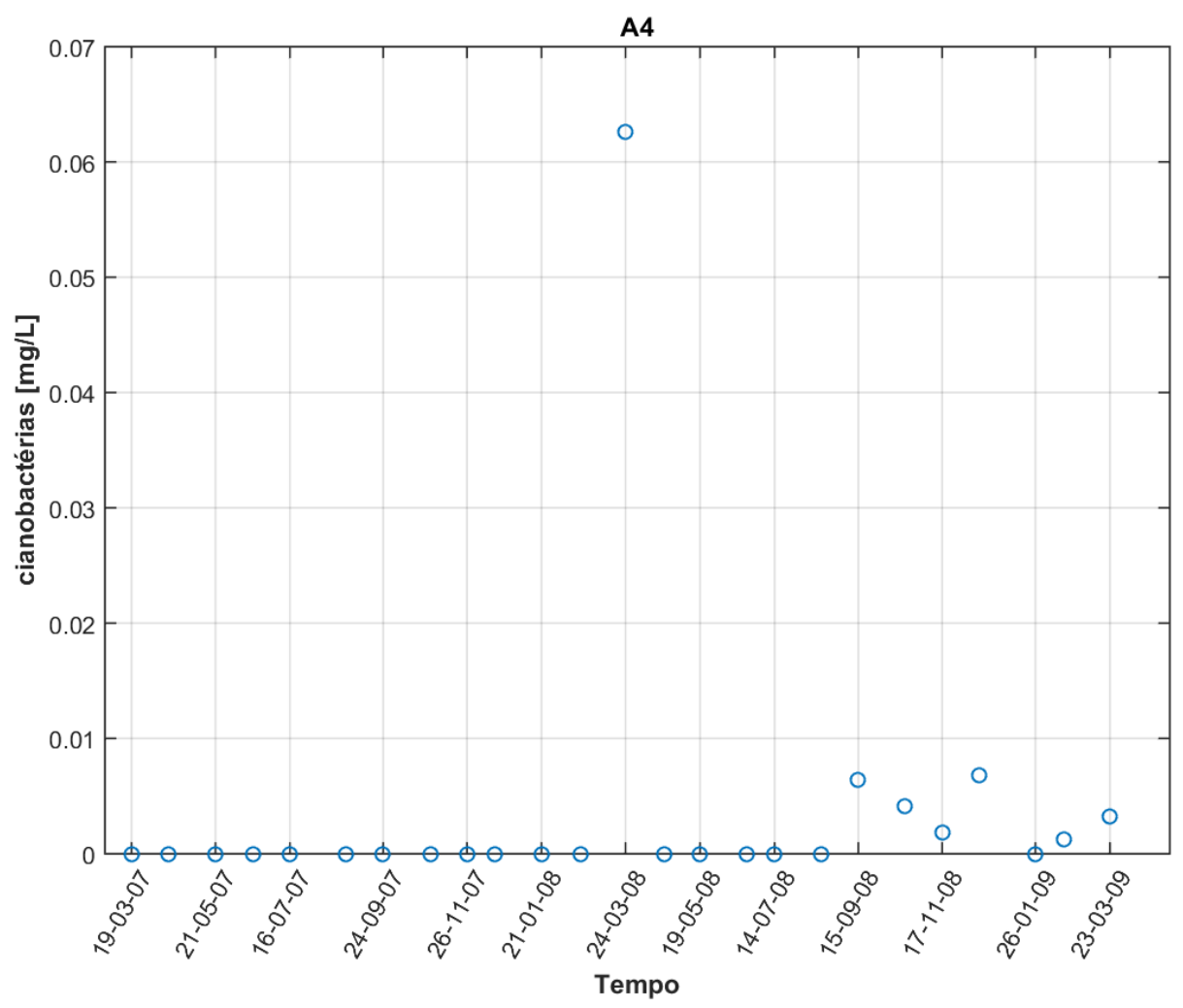

Figura B-49: Série temporal de biomassa de cianobactérias registrado pela CAESB no ponto A4 entre 03/2007 e 03/2009.

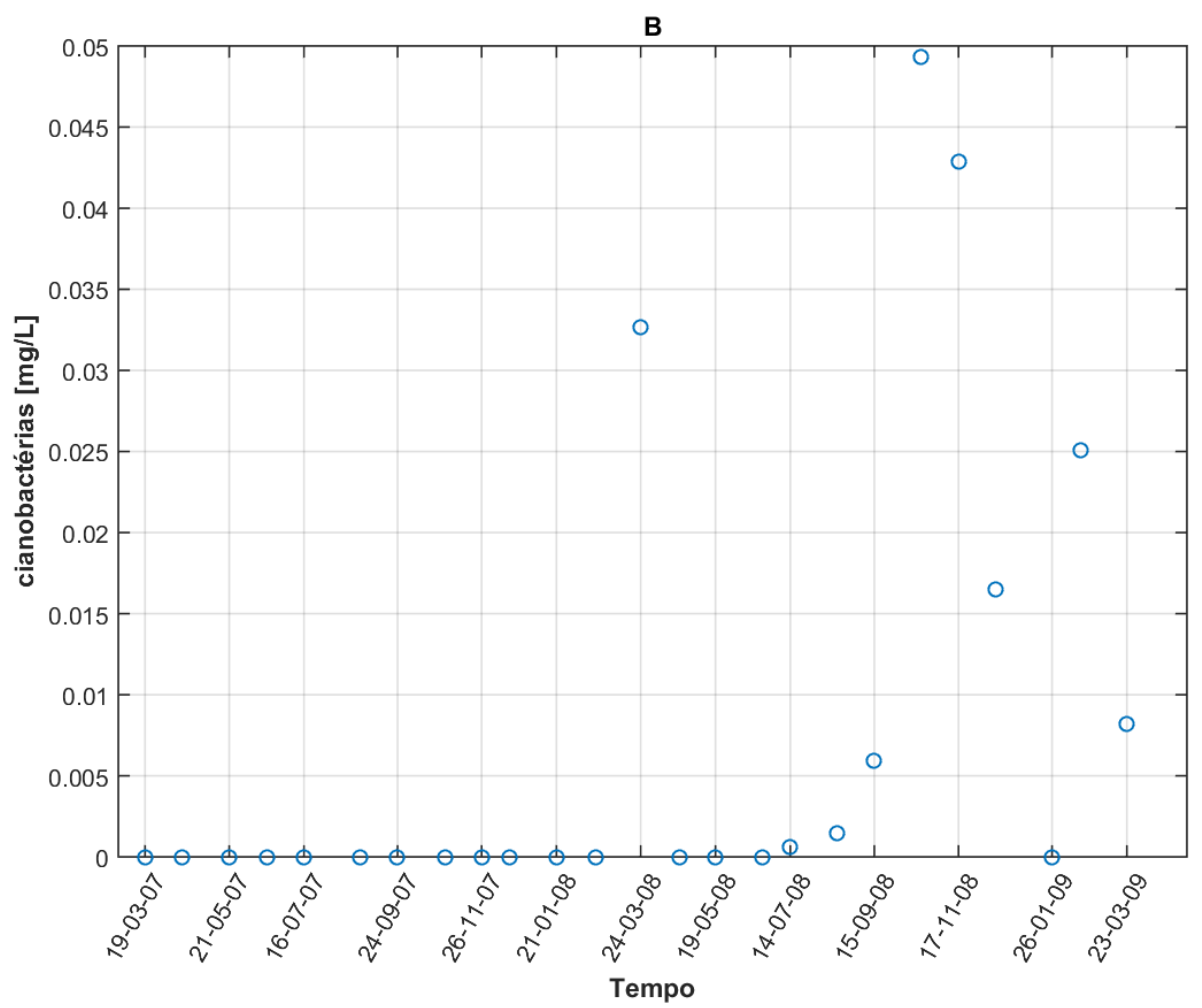

Figura B-50: Série temporal de biomassa de cianobactérias registrado pela CAESB no ponto B entre 03/2007 e 03/2009. 


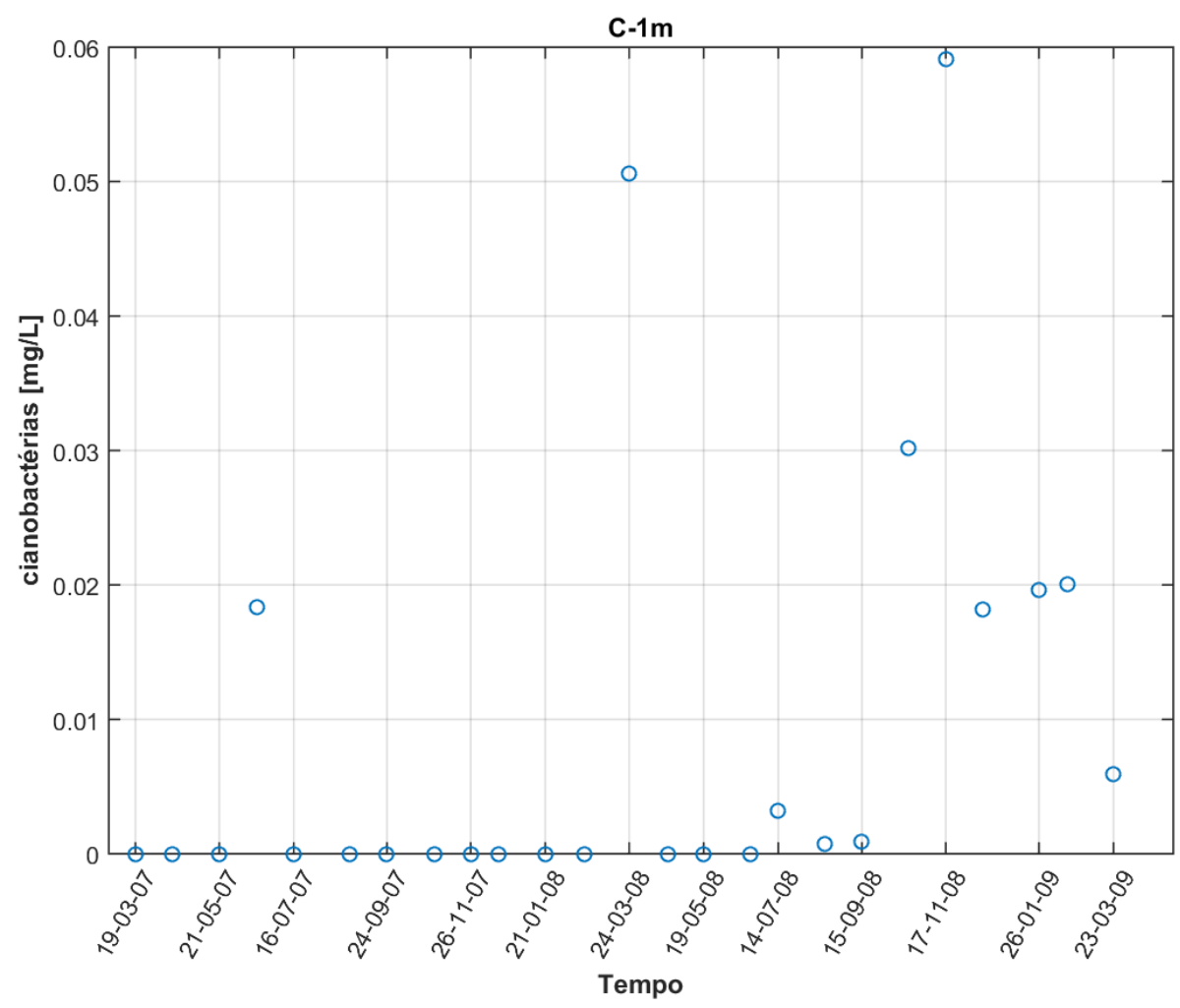

Figura B-51: Série temporal de biomassa de cianobactérias registrado pela CAESB no ponto $\mathrm{C}$ a $1 \mathrm{~m}$ entre 03/2007 e 03/2009.

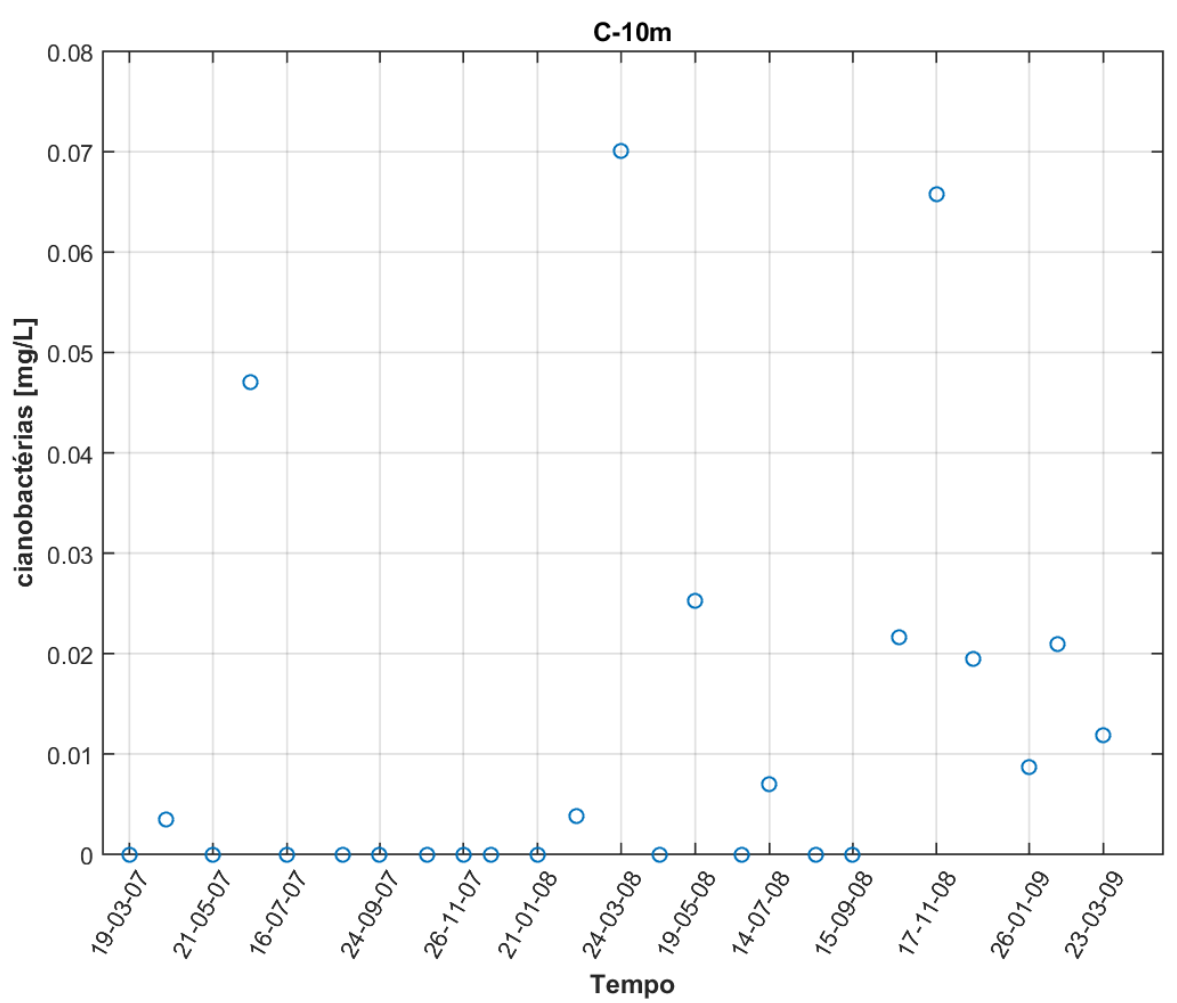

Figura B-52: Série temporal de biomassa de cianobactérias registrado pela CAESB no ponto C a $10 \mathrm{~m}$ entre $03 / 2007$ e $03 / 2009$. 


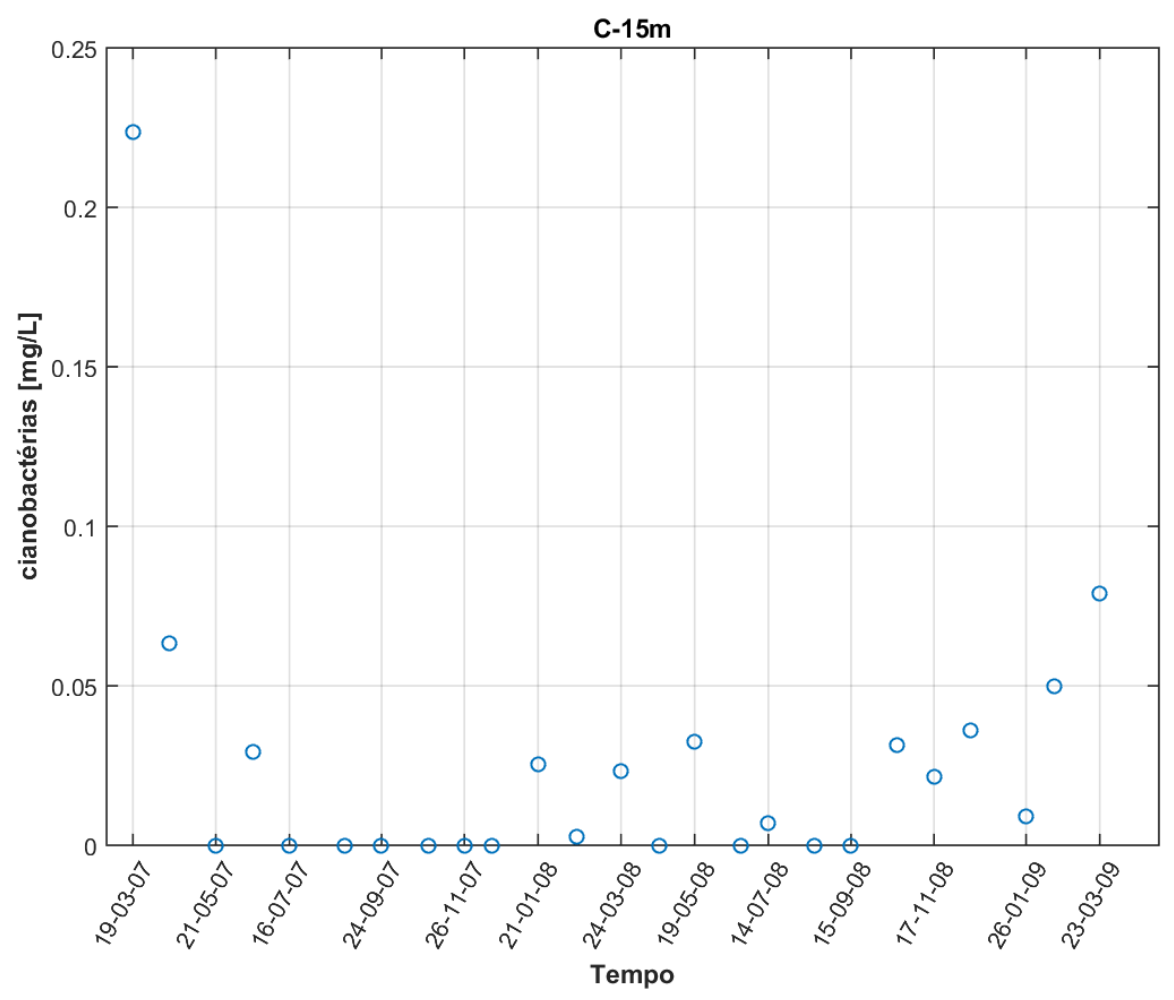

Figura B-53: Série temporal de biomassa de cianobactérias registrado pela CAESB no ponto $\mathrm{C}$ a $15 \mathrm{~m}$ entre $03 / 2007$ e $03 / 2009$.

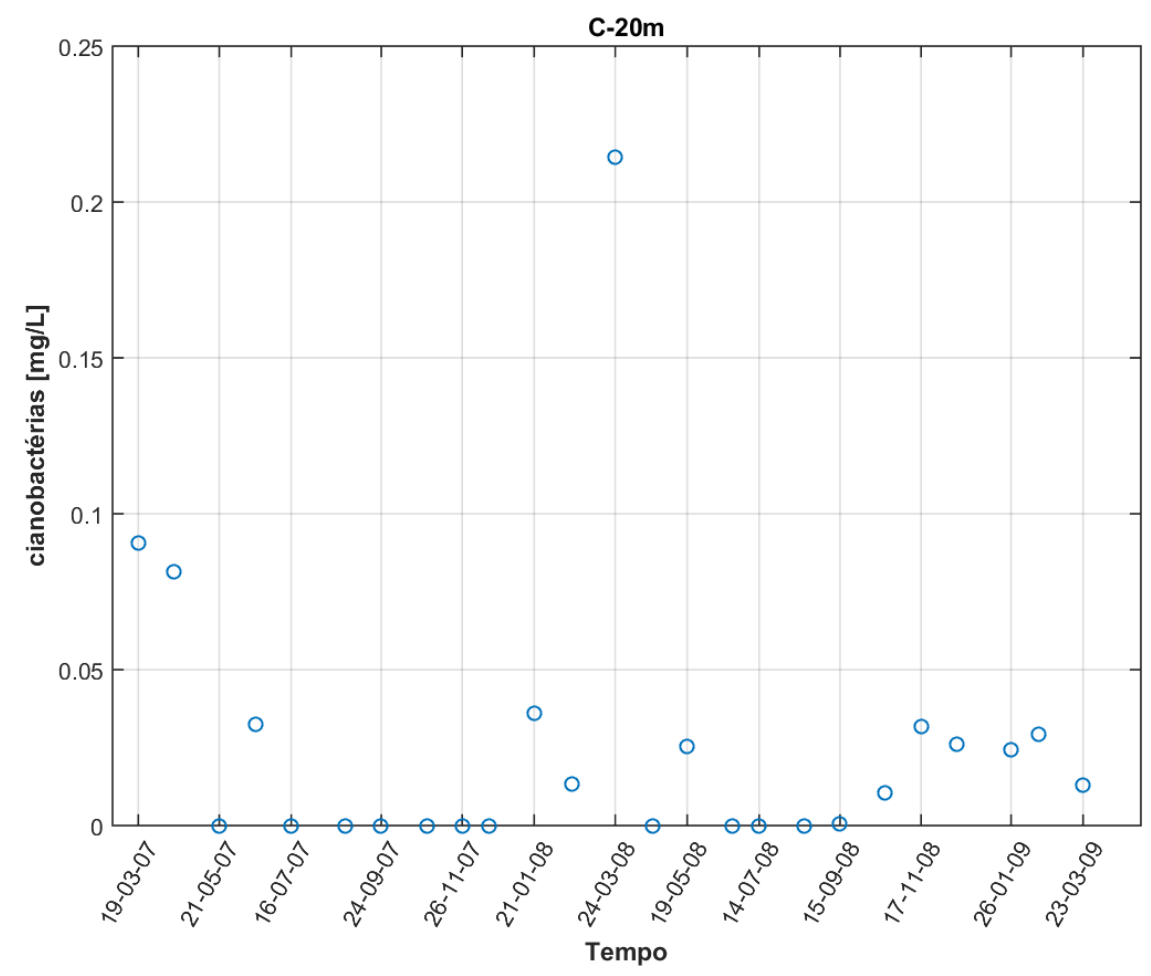

Figura B-54: Série temporal de biomassa de cianobactérias registrado pela CAESB no ponto $\mathrm{C}$ a $20 \mathrm{~m}$ entre $03 / 2007$ e $03 / 2009$. 


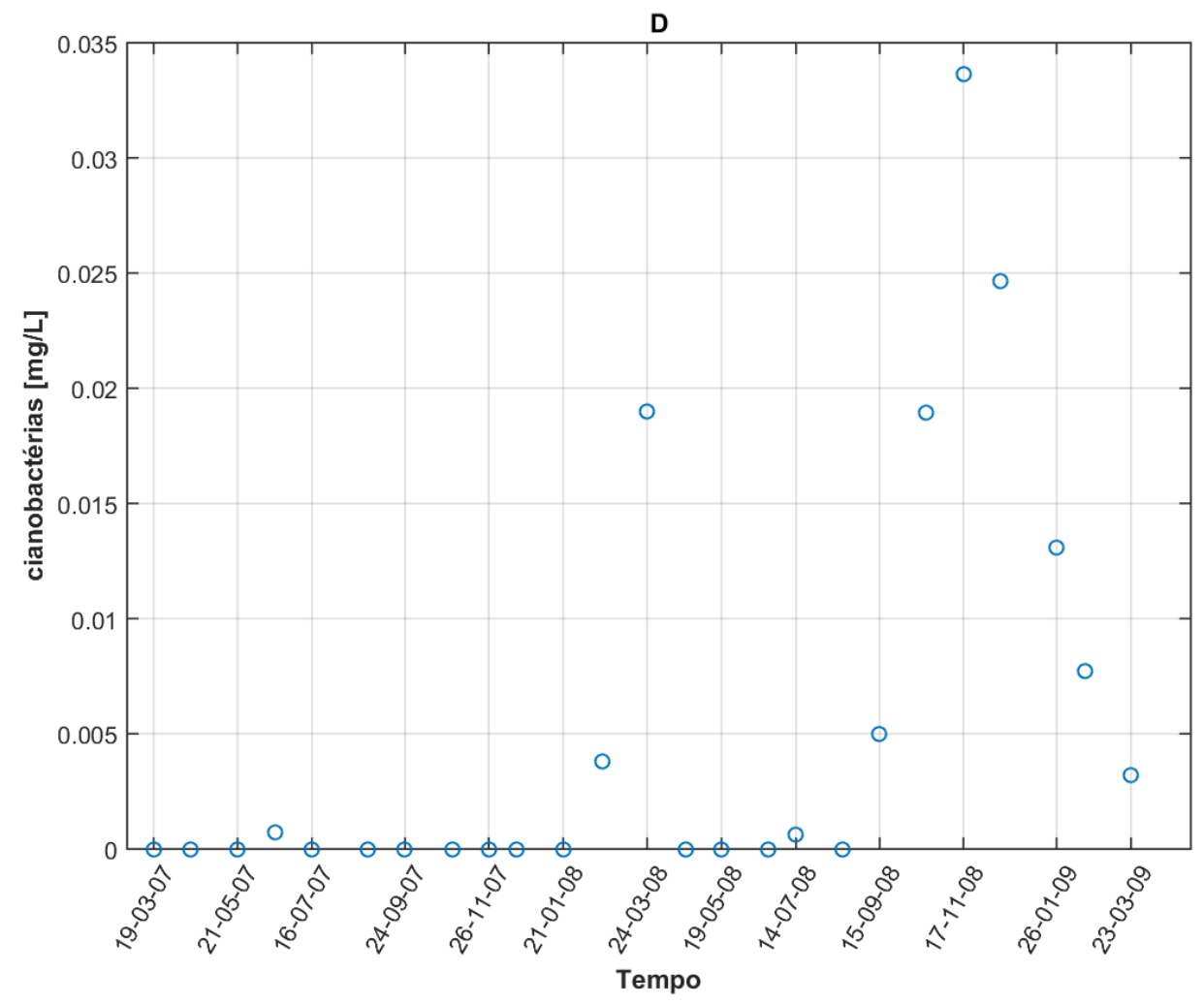

Figura B-55: Série temporal de biomassa de cianobactérias registrado pela CAESB no ponto D entre 03/2007 e 03/2009.

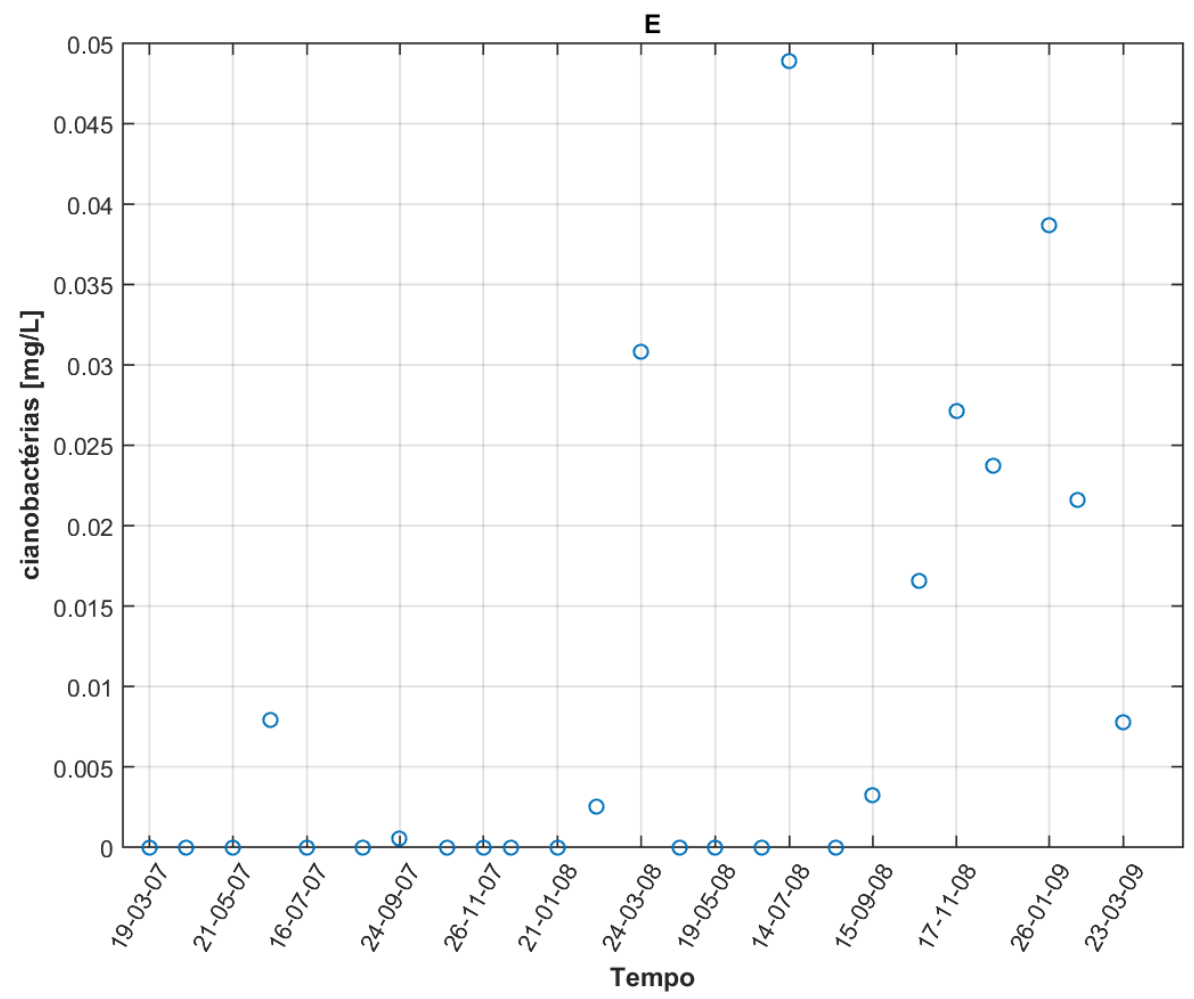

Figura B-56: Série temporal de biomassa de cianobactérias registrado pela CAESB no ponto E entre 03/2007 e 03/2009. 


\section{APÊNDICE C}

1. Séries de longo período para as concentrações de OD, amônia, nitrato e fosfato no ponto de monitoramento $\mathrm{C}$ do lago Paranoá, nas profundidades de $1 \mathrm{~m}, 10 \mathrm{~m}$, 15m e 20m, entre 1976 a 2010, registradas pela CAESB.
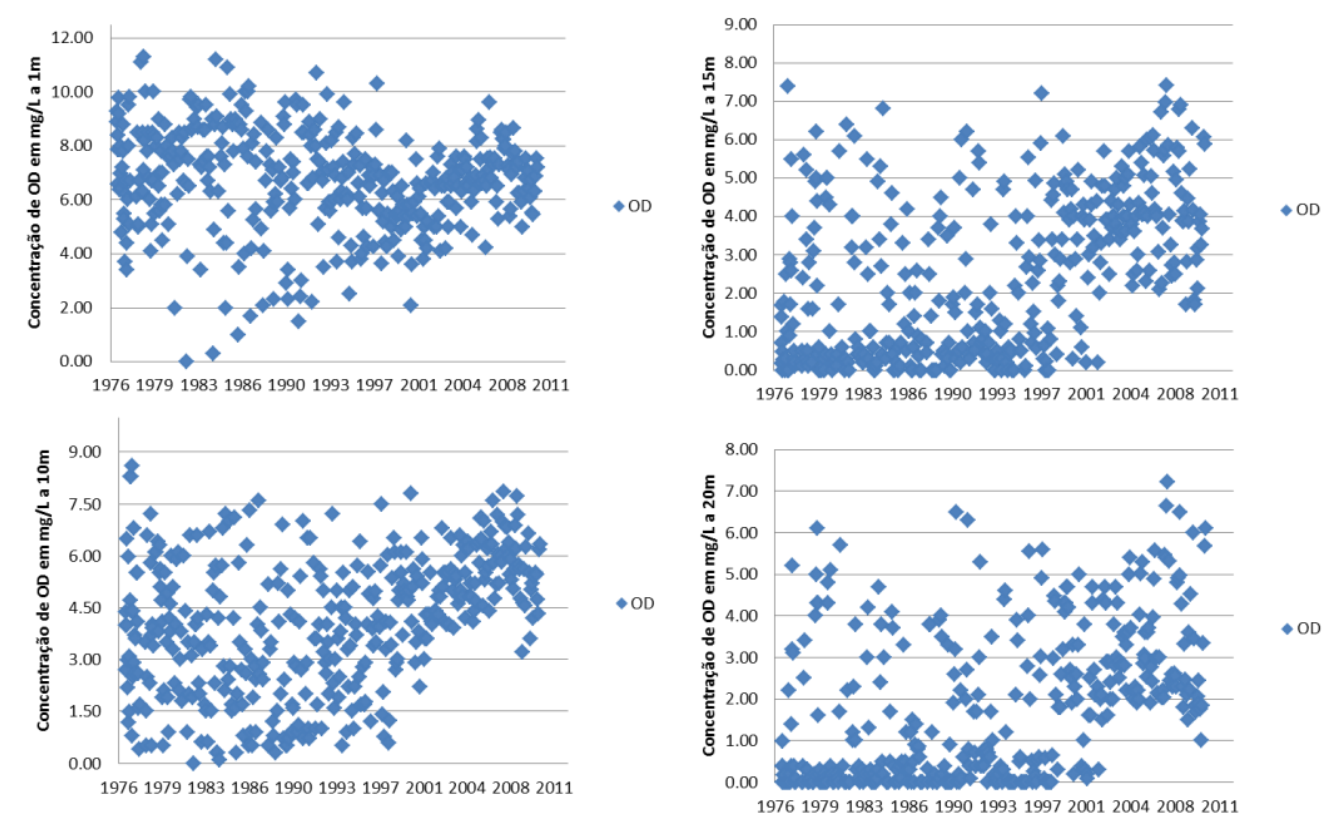

Figura C-1: Série temporal de concentração de OD registrada pela CAESB no ponto C entre 1976 e 2010.
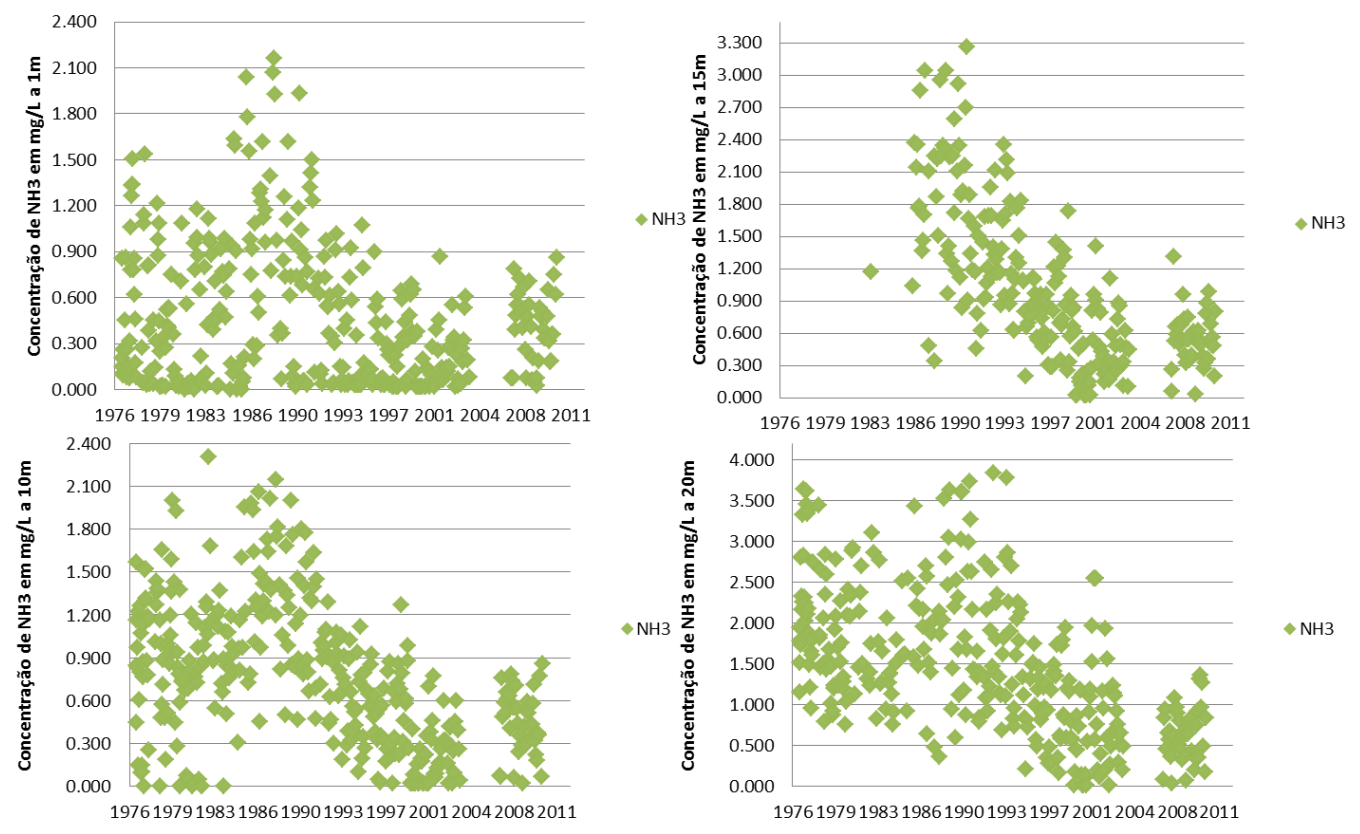

Figura C-2: Série temporal de concentração de NH3 registrada pela CAESB no ponto C entre 1976 e 2010. 

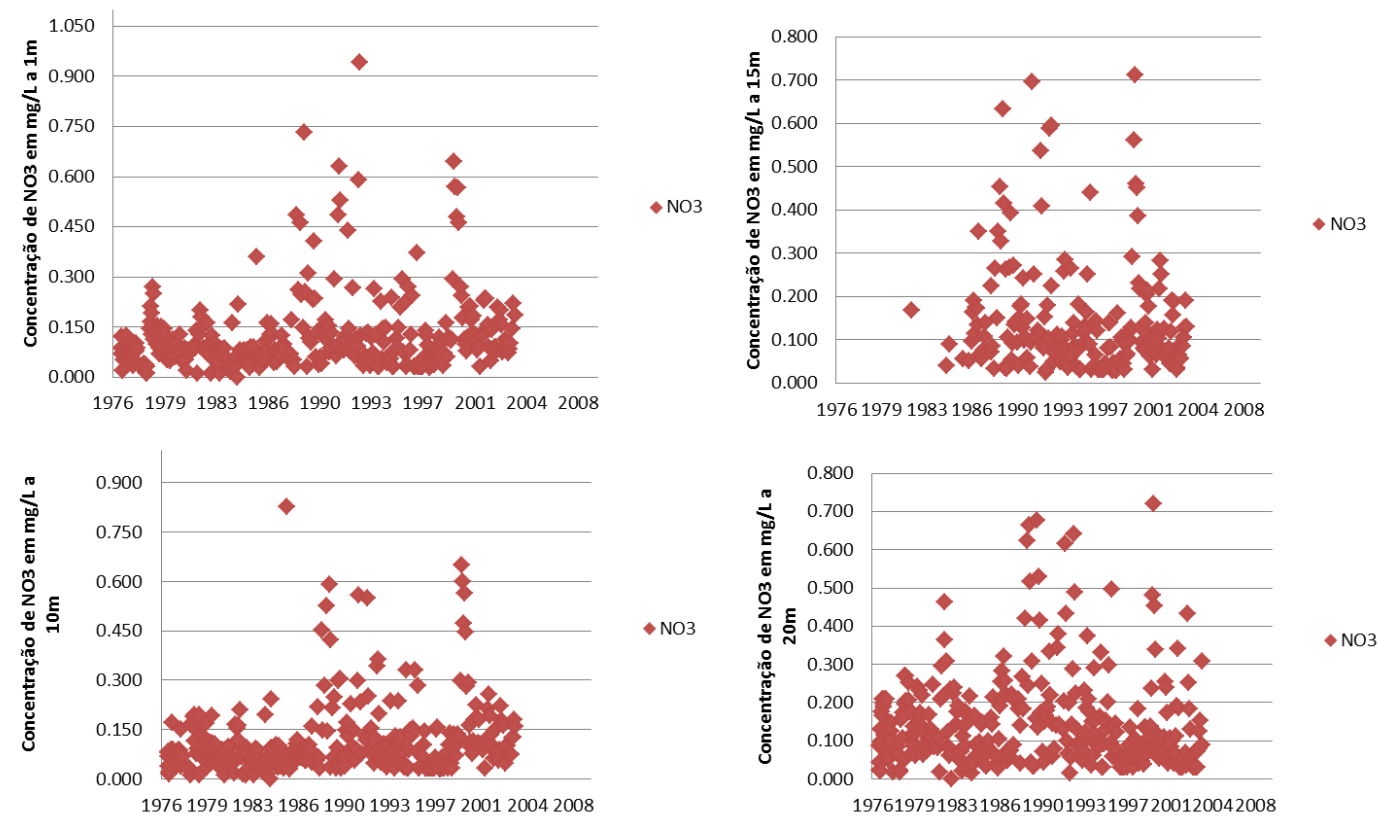

Figura C-3: Série temporal de concentração de NO3 registrada pela CAESB no ponto C entre 1976 e 2010.
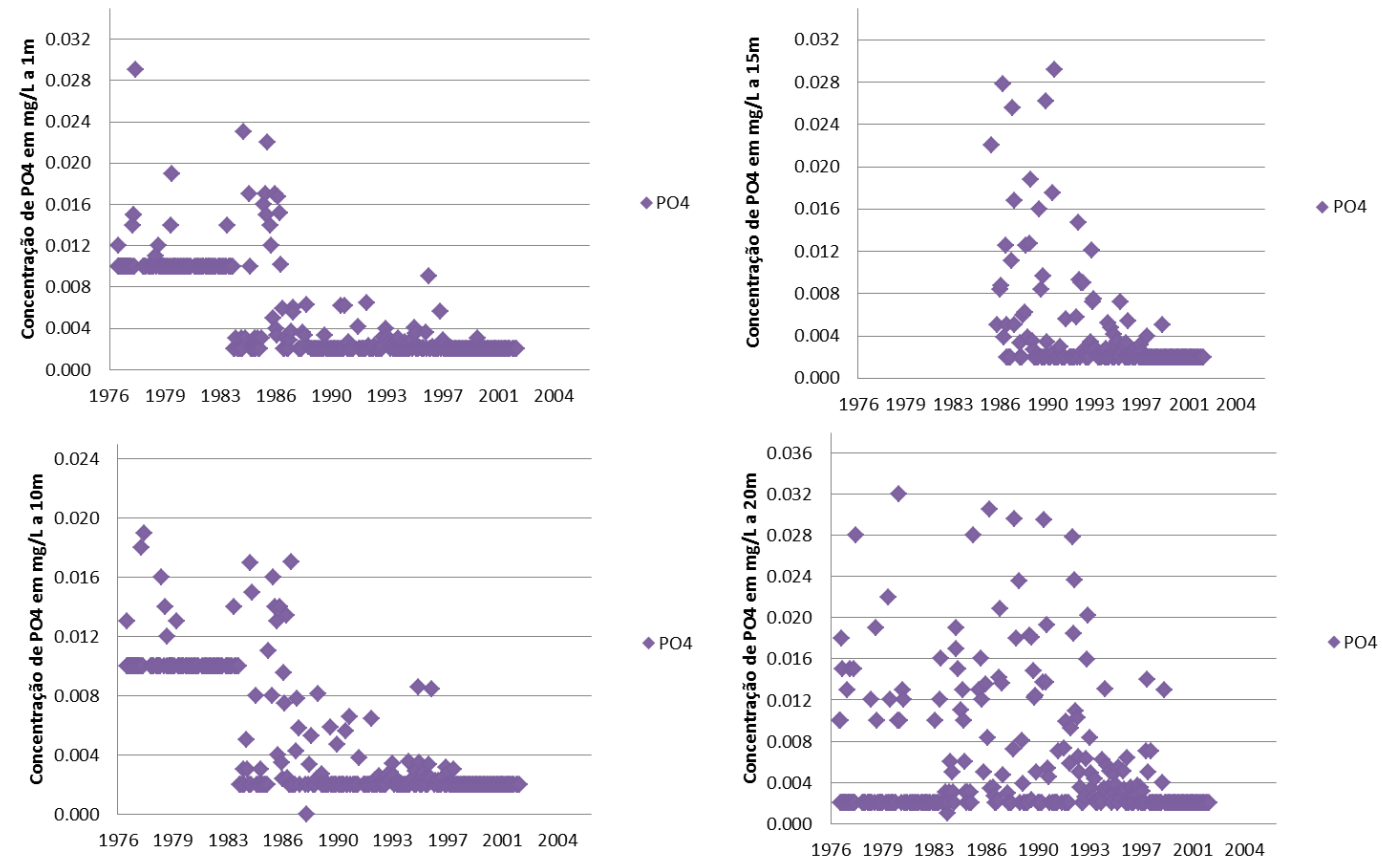

Figura C-4: Série temporal de concentração de PO4 registrada pela CAESB no ponto C entre 1976 e 2010. 